\title{
Teacher decision making and the implementation of an integrated arts curriculum
}

\author{
Mary K. Devono \\ West Virginia University
}

Follow this and additional works at: https://researchrepository.wvu.edu/etd

\section{Recommended Citation}

Devono, Mary K., "Teacher decision making and the implementation of an integrated arts curriculum" (2009). Graduate Theses, Dissertations, and Problem Reports. 2920.

https://researchrepository.wvu.edu/etd/2920

This Dissertation is protected by copyright and/or related rights. It has been brought to you by the The Research Repository @ WVU with permission from the rights-holder(s). You are free to use this Dissertation in any way that is permitted by the copyright and related rights legislation that applies to your use. For other uses you must obtain permission from the rights-holder(s) directly, unless additional rights are indicated by a Creative Commons license in the record and/ or on the work itself. This Dissertation has been accepted for inclusion in WVU Graduate Theses, Dissertations, and Problem Reports collection by an authorized administrator of The Research Repository @ WVU.

For more information, please contact researchrepository@mail.wvu.edu. 


\title{
Teacher Decision Making and the Implementation of an Integrated Arts Curriculum
}

\author{
Mary K. Devono \\ Dissertation submitted to the \\ College of Human Resources \& Education \\ at West Virginia University \\ in partial fulfillment of the requirements \\ for the degree of \\ Doctor of Education \\ in \\ Curriculum and Instruction
}

Department of Human Resources and Education

Joy Faini-Saab, Ed.D., Chair

Christina Lavorata, Ed.D.

Patricia Obenauf, Ed.D.

Perry Phillips, Ed.D.

Jacqueline Webb-Dempsey, Ed.D.

Morgantown, West Virginia

2009

Keywords: Curriculum and Instruction; Decision Making; Integrated Arts Instruction

Copyright 2009 Mary K. Devono 


\section{Abstract \\ Teacher Decision Making and the Implementation of an Integrated Arts Curriculum}

\section{Mary K. Devono}

This study examines the impact of teacher decision making upon implementing an integrated arts curriculum. Qualitative research methods, including interviews, lesson plan document analysis, and teacher discussion of student artwork comprise the research data from eight elementary classroom teachers. This study is designed to add to the descriptive data on teacher perceptions, especially with regard to their professional autonomy, and ultimately, the decisions within their sphere of influence-the classroom arts curriculum. The implications of this study reveal insight into teacher decision making. The research provides knowledge that contributes to professional development initiatives, acquisition of instructional and curricular resources, and student achievement. Ultimately, this knowledge will assist policy makers, administrators, the public, and teachers themselves, in understanding the enigma surrounding how and why teachers decide on their students' instructional course. Every stakeholder in the educational community benefits from a deeper understanding of a teacher's role in curricular design and implementation. What commands teachers' attention when making their instructional decisions? 


\section{Acknowledgements}

Paramount to the completion of an extensive research report is the assistance and cooperation of many contributors. Such a standard applies to this dissertation. The author wishes to express appreciation to the various contributors whose assistance with this research insured its success.

Grateful thanks to Dr. Joy Faini-Saab, West Virginia University, chairperson of the doctoral committee, for her dedication to my research pursuit. Thank you for your invaluable assistance in orchestrating my research, and for believing in the value of my research topic. To my esteemed committee members, Drs. Christina Lavorata, Patricia Obenauf, Perry Phillips, and Jacqueline Webb-Dempsey, I would like to express my deepest gratitude for contributing your gifts of time, expertise, and guidance to this research.

I express sincere acknowledgement to each of the public school practitioners, teachers, school administrators, and district superintendent who participated in the research. The unique blend of collaborative efforts, generous contribution of practical knowledge, and accessibility to field study has enriched the scope of this qualitative research.

To my husband, Frank, and my children, Frank Jr., Rachael, and Gabriel Paul, I express deep gratitude for encouraging me and for listening enthusiastically to the revelations made during my research analysis. Thank you for holding me to this accomplishment, this life-long goal, this capstone of my professional career. 


\section{Table of Contents}

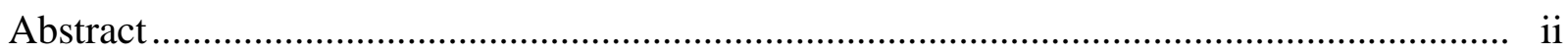

Acknowledgments............................................................................................................... iii

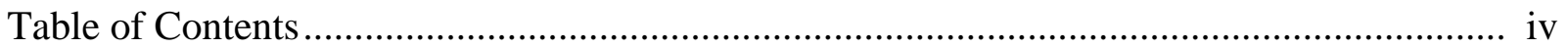

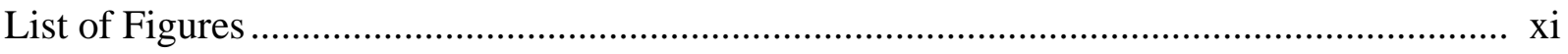

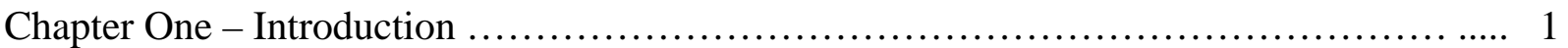

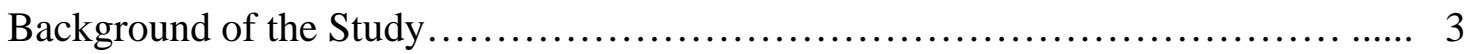

Problem Statement ....................................................................... 5

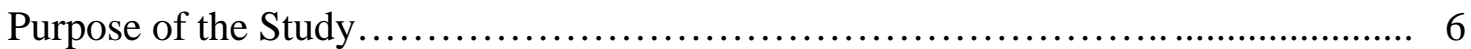

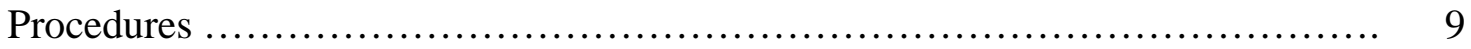

Professional Significance of the problem...................................... 10

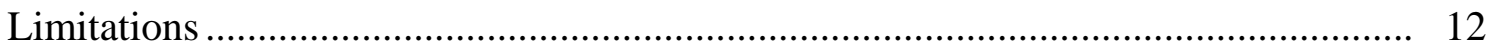

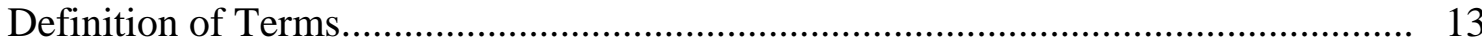

Organization of Future Chapters............................................................................ 15

Chapter Two - Literature Review..................................................................................... 17

Historical and Evolutionary Role of Autonomy and Decision Making....................... 18

Teacher Development and Support for Making Changes and Decisions ..................... 20

Community Support and Decision Making ................................................................. 23

The Student Influences on Decision Making............................................................ 24

Accountability and Decision Making ........................................................................ 25

Summary and Rationale for the Study ................................................................ 25

Current State of Research................................................. 27

Summary of Rationale and Purpose.................................................... 29 
Chapter Three - Methods and Procedures.................................................. 32

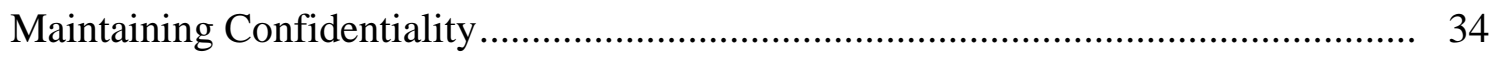

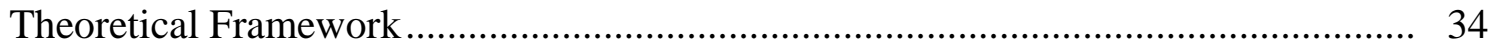

Selection of School Sites ........................................................................... 34

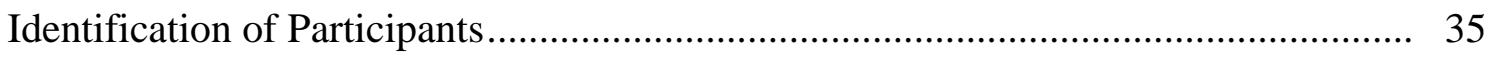

Data Collection and Analysis...................................................................... 35

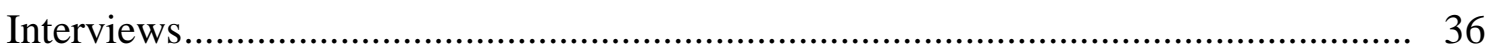

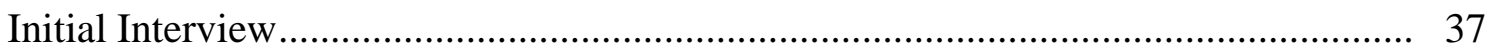

Open Discussion and Photographs of Student Work Samples... ............................. 37

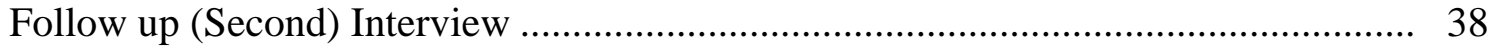

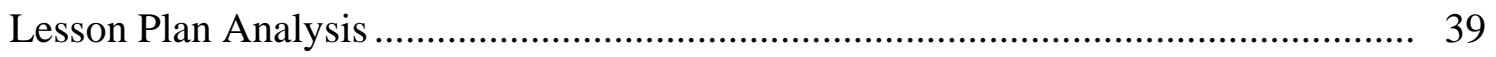

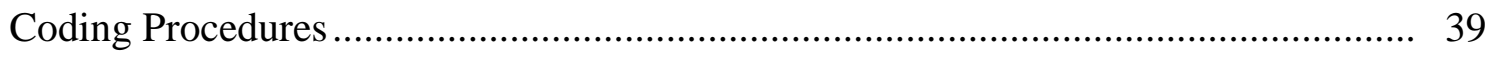

Data Findings and Graphical Representation .................................................. 40

Insuring Trustworthiness and Research Study Credibility .................................. 40

Chapter Four - Data Narratives........................................................... 43

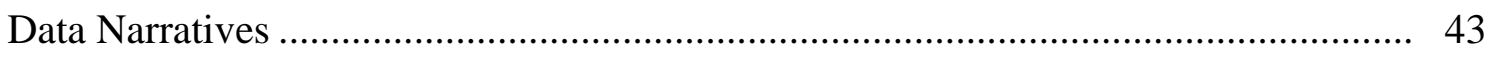

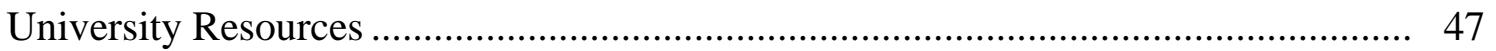

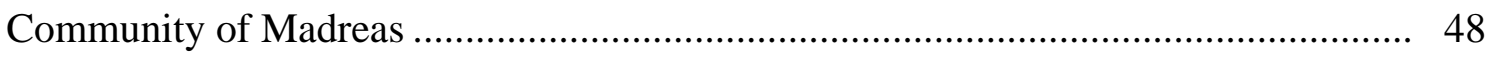

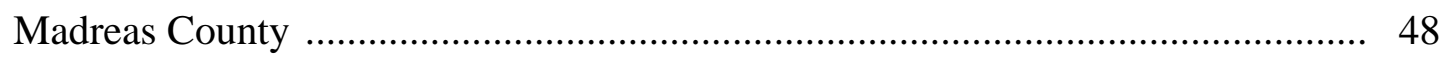

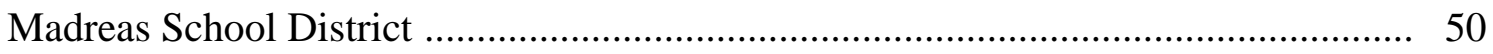

Madreas County School System Demographics ............................................ 50

Long Range Strategic Planning for Madreas School District............................. 51 
Madreas County School System Mission .............................................................. 51

Madreas County School System Belief Statements............................................ 52

Bickle Creek Elementary School Demographics.................................................. 53

School Culture ..................................................................................... 54

Antonella of Bickle Creek Elementary ............................................................... 55

Portrait of a Kindergarten Teacher ................................................................. 55

Interview Question \#1: Curriculum ............................................................ 56

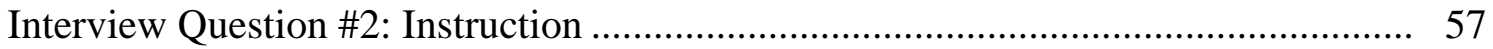

Interview Question \#3: Decision Making ....................................................... 58

Interview Question \#4: Reflection Community ................................................. 59

Antonella’s Comments on Student Artwork.......................................................... 63

Connections to Four Over Arching Questions........................................................ 64

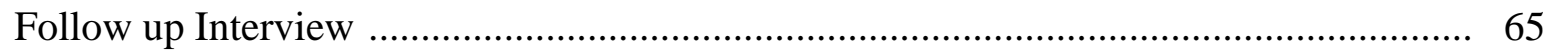

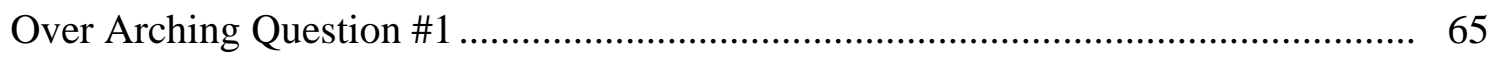

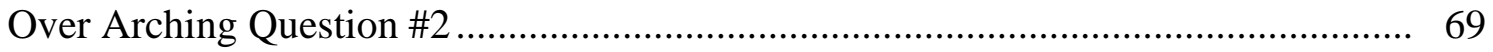

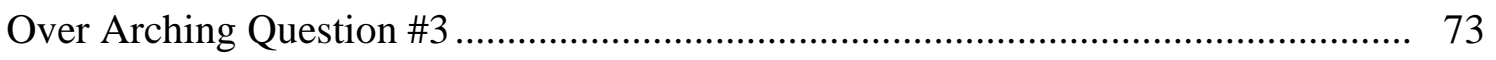

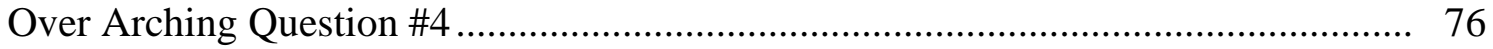

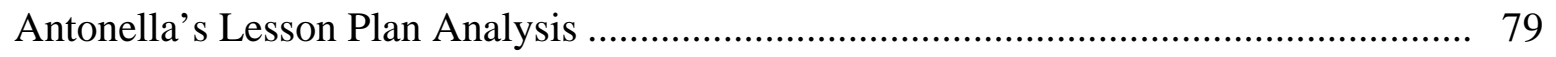

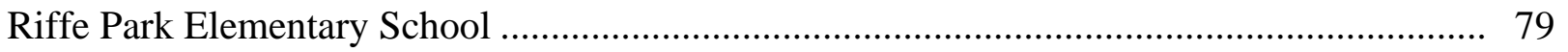

Celine and Veronica of Riffe Park Elementary ................................................... 81

Interview Question \#1: Curriculum ........................................................ 82

Interview Question \#2: Instruction .............................................................. 86 
Interview Question \#3: Decision Making ................................................................. 89

Interview Question \#4: Reflection Community .................................................. 91

Veronica’s Comments on Student Artwork.............................................................. 94

Celine’s Comments on Student Artwork .................................................................. 98

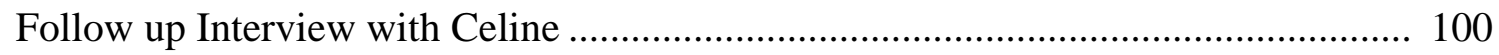

Over Arching Question \#1 ....................................................................... 100

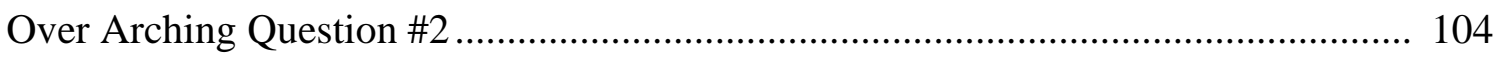

Over Arching Question \#3 .............................................................................. 108

Over Arching Question \#4 ............................................................................. 111

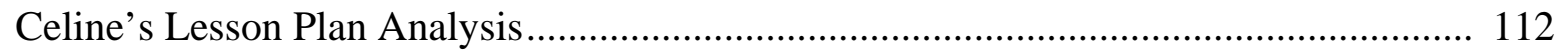

Follow up Interview with Veronica ................................................................. 112

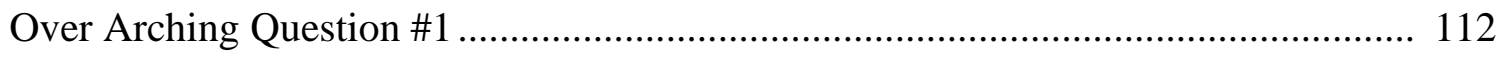

Over Arching Question \#2 …....................................................................... 115

Over Arching Question \#3 ........................................................................... 116

Over Arching Question \#4 ............................................................................ 119

Veronica’s Lesson Plan Analysis....................................................................... 122

Selena M. Day Primary School................................................................................ 123

Kara of Selena M. Day Primary School................................................................ 127

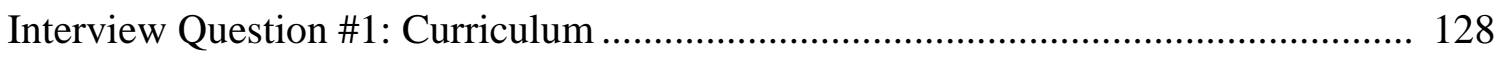

Interview Question \#2: Instruction ............................................................... 130

Interview Question \#3: Decision Making ........................................................... 131

Interview Question \#4: Reflection Community ................................................. 132 
Kara’s Comments on Student Artwork.................................................................. 133

Follow up Interview with Kara ........................................................................ 137

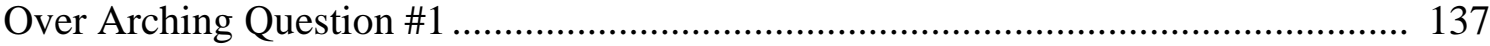

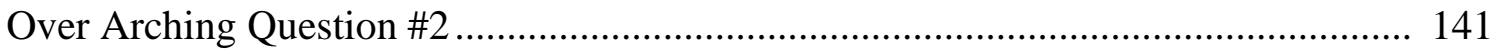

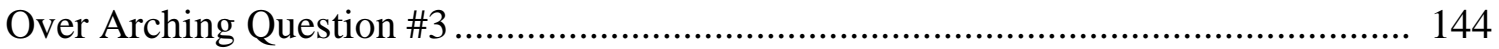

Over Arching Question \#4 .......................................................................... 149

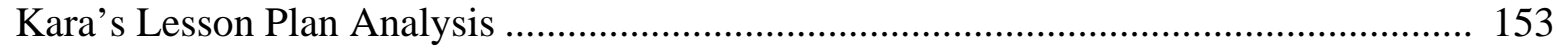

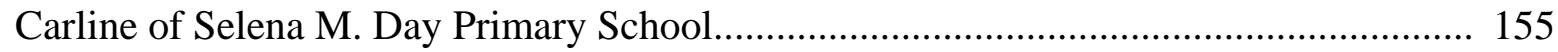

Interview Question \#1: Curriculum .............................................................. 156

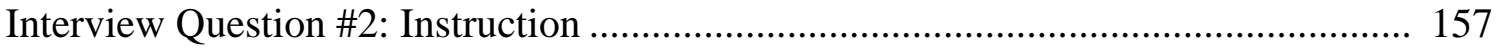

Interview Question \#3: Decision Making.......................................................... 157

Interview Question \#4: Reflection Community ................................................ 159

Carline's comments on Student Artwork............................................................. 160

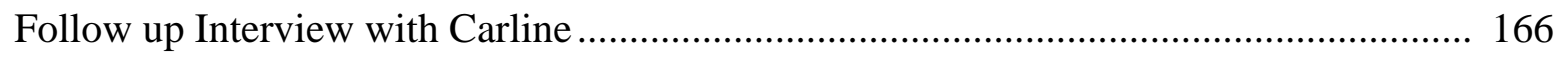

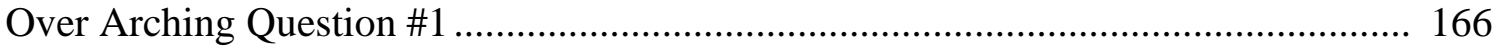

Over Arching Question \#2 …..................................................................... 170

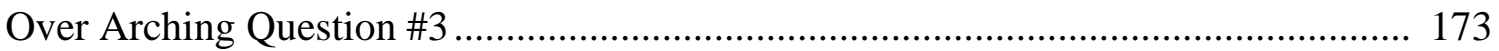

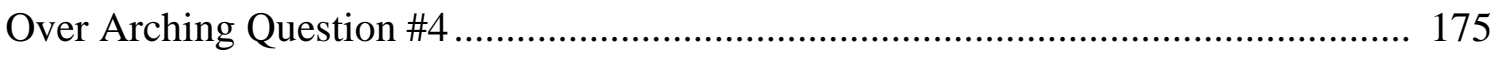

Carline’s Lesson Plan Analysis ..................................................................... 176

Janice, Kate, and Ida of Selena M. Day Primary School .......................................... 180

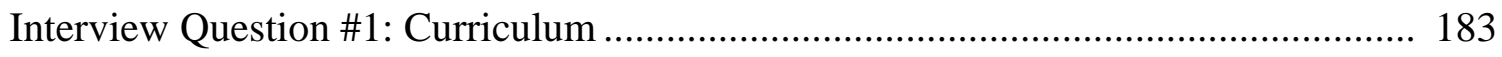

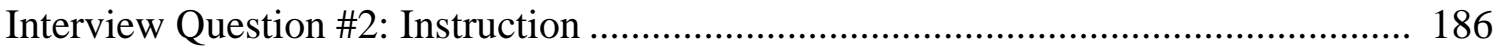


Interview Question \#3: Decision Making............................................................. 188

Interview Question \#4: Reflection Community ................................................. 190

Janice, Kate, and Ida’s Comments on Student Artwork ........................................... 192

Follow up Interview with Janice, Kate, and Ida ................................................... 200

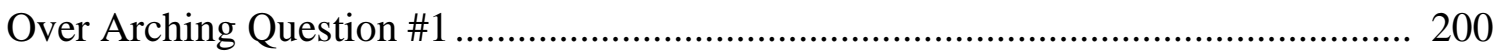

Over Arching Question \#2 ......................................................................... 206

Over Arching Question \#3 .............................................................................. 211

Over Arching Question \#4 ............................................................................ 215

Lesson Plan Analysis ................................................................................ 218

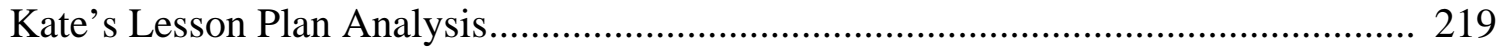

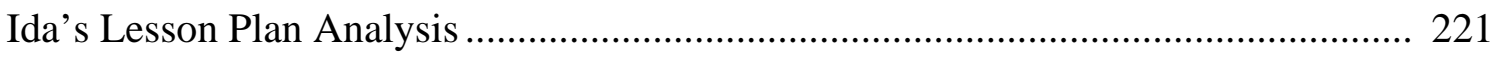

Joyce’s and Ida’s Lesson Plan Analysis ......................................................... 224

Chapter Five - Results ....................................................................................... 230

Summary of Literature Review.................................................................... 232

Leading to the Research Questions ................................................................... 235

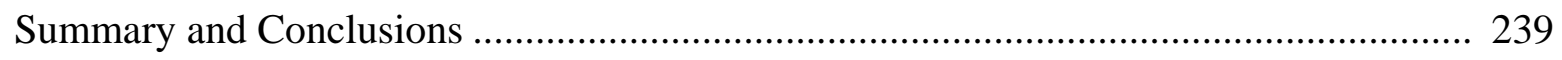

Antonella as an Arts Integration Decision Maker..................................................... 239

Celine as an Arts Integration Decision Maker .................................................... 247

Veronica as an Arts Integration Decision Maker................................................... 254

Kara as an Arts Integration Decision Maker......................................................... 259

Carline as an Arts Integration Decision Maker...................................................... 265

Janice as an Arts Integration Decision Maker ..................................................... 273 
Kate as an Arts Integration Decision Maker................................................................. 279

Ida as an Arts Integration Decision Maker ........................................................... 284

Implications for the Future of Arts Integration........................................................... 291

Implications for Curriculum ......................................................................... 292

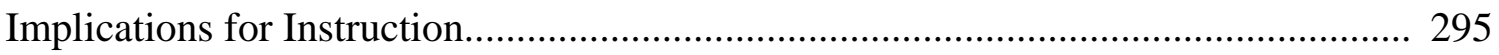

Implications for Reflection and Professional Development ................................... 297

Implications for Community and Future Policy .................................................. 300

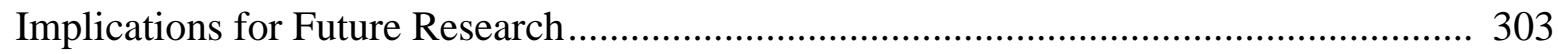

Teacher - Learner Exchange Principle .............................................................. 306

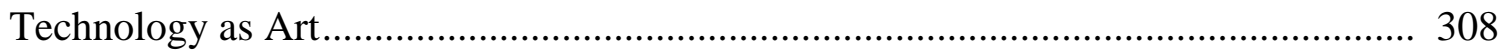

Over Arching Four Question Framework ............................................................ 308

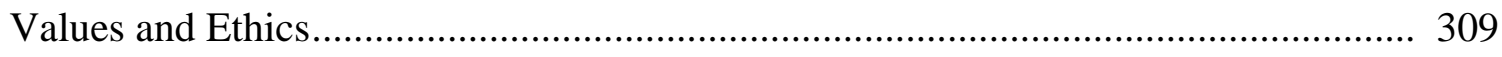

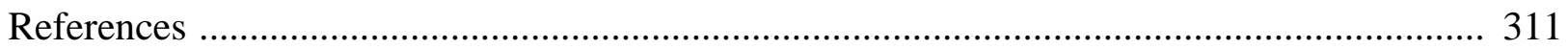

Appendix A - Historical Overview of Literature Review ............................................... 320

Appendix B - Initial Interview Questions for Teachers .............................................. 321

Appendix C - Follow up Interview Questions ........................................................... 322

Appendix D - Student Work Sample Checklist .............................................................. 325

Appendix E - Integrated Arts Course Syllabus .......................................................... 326

Appendix F - Demographic Matrix …................................................................. 342

Appendix G - Artwork Connections to Teacher Decision Making...................................... 343

Appendix H - Implications with Supporting Narratives ............................................. 345

Appendix I - Data Findings by Question Frameworks .............................................. 347 


\section{List of Figures}

Figure 1. Arts Integrated Science Lesson Diorama ………..................................................... 64

Figure 2. Arts Integrated Group Poster Project ..................................................................... 97

Figure 3. Puppet Characters from Book Reports .................................................................... 99

Figure 4. Sea Life Science Torn Paper Art ........................................................................ 134

Figure 5. Pizza Pie Health Lesson ................................................................................ 136

Figure 6. Hieroglyphics Journal Entry ............................................................................. 162

Figure 7. Four Seasons Weather Drawing ......................................................................... 165

Figure 8. Bandy Snatcher Sketch....................................................................................... 193

Figure 9. Student Masks ............................................................................................. 195

Figure 10. Impressionist Water Color Style ……………................................................ 197

Figure 11. Divergent Thinking Sketching Activity ................................................................ 199

Figure 12. Reflective Teacher Flow Chart ………………................................................. 298

Figure 13. Teacher Learner Exchange Principle...................................................................... 306 


\section{Chapter 1}

\section{Introduction}

As far back as $5^{\text {th }}$ century B.C. Athenian culture became an intellectual marketplace with roots in drama, music, poetry, sculpture, architecture, philosophy, statecraft, and literature.

The ancients believed that music, for example, had educative power and was used in dramatic performances of the great Greek tragedies. Pythagoras' discovery that musical intervals can be expressed through numerical ratios combined mathematics and the science of sound to express consonant and dissonant intervals in music.

Plato discovered the mathematical basis of music and maintained that music could ennoble the soul and provide proper training for future leaders. Integration of the arts in antiquity can be seen in the structure of the educational systems of the Middle Ages.

Seven liberal arts were divided into two curricular subdivisions, the trivium (verbal arts) and the quadrivium (mathematical arts). A strong emphasis upon the arts curriculum of antiquity has had a significant impact upon Western civilization and can be evidenced in present day American education.

Yudkin 1989

Tracing the development of arts education and curricula provided a research foundation upon which to layer teacher professional development and instructional decision making. Writing from a musician's perspective permitted me to blend my musical arts experience with instructional decision making by sharing how my own career development and that of eight other teachers have evolved. My career is woven into the research through the lens of my professional development, teaching perspectives, and decision making strategies. The following is a historical view of arts curricula that will provide a background for teacher awareness of arts curriculum and a definition of arts integration. 
Yudkin traces the Middle Ages arts beginning in 9th and 10th century Europe where schools flourished in the politically charged, centralized governments of the day. Evidence of arts in the Middle Ages can be seen in the flying buttress of cathedral architecture, visual arts, morality plays and sung dramas, and literary and poetic works.

After the Crusades, there was controversy surrounding what should control the university: the papacy or the empire? These were intellectually stimulating times, and regardless of the political strife, students were present in the audience. Thirteenth century universities trumped the papal vs. empire issue by forming guilds. Self-governance was their method. Intellectual independence won out, returning control to universities. Masters and their students established a semester system and an autumn school start-up with liberal arts and humanities at the core of curriculum. A sense of autonomy was present from the beginning of institutional learning. For example, Paris was a strong intellectual center with the first university in medieval Europe that was governed by a bishop tied closely to Rome. Splinter groups from the University of Paris formed Oxford; splinter groups from Oxford founded Cambridge. Both universities attracted students who became steeped in liberal arts education, away from the stronghold of ruling bishops (Yudkin, 1989). Teacher autonomy and decision making were alive and well, even in ancient times.

Fourteenth century paintings are touted as outstanding works of the Middle Ages, and music was essential to the lyrics of secular songs and sacred chants. Boethius (c.475-525), a Roman statesman, authored The Principles of Music (De Institutione Musica), which became the textbook in European schools for nearly a thousand years (Yudkin, 1989). His definition of a musician has survived its Greek roots and upheld modern day standards that characterize a musician as: “...not the performer or the composer, but the educated and rational thinker who 
can judge performances and compositions” (Yudkin, 1989). This dissertation research on teacher decision making and integrated arts curriculum is grounded in Boethius' definition of a musician, and it strives to illuminate teacher decisions to use an integrated arts curriculum.

As a learner, I had a rich background of musical experiences in the decade of 1950, both at home and in school, that shaped my attitudes and perspectives on the importance of integrating the arts into my classroom teaching. Piano lessons at age five, anticipating our traveling music teacher's visits to the elementary school with a piano in every room, finger paints and easels, hand-renderings of maps, square-dancing, finger plays and rhymes are just a sampling of the arts in my early childhood learning. Classroom teachers and the traveling specialists in elementary schools offered rich, hands-on, arts-integrated opportunities. At the time, I did not realize the influence that my own teachers' arts offerings would have upon my professional attitudes and the development of my teaching career. With decades of personal perspective upon the changes that have occurred in arts integration since the 1950s, along with current research studies from the turn of the century, there is ample opportunity for study and conversation around change in arts integration and teacher decision making.

\section{Background of the Study}

A historical context for arts integration begins with an understanding of how arts instruction is embodied in the curricular movements or trends in schools. Outlined in the Chapter Two literature review of Arts Integration Frameworks, Research and Practice is a compilation of writings between 1995 and 2007 assembled by Burnaford, Brown, Doherty and McLaughlin. These research practices, issues, and trends are clear reminders that curricular movements are shaped by the conversations around the issues and trends facing teachers, students, administrators, and policy makers. 
Throughout the course of curriculum development, a variety of influences have made an impact on instructional decision making. The literature examines change over time in teacher development, socialization, bureaucratization, autonomy, professional preparation, continuous education, and the depth of teachers' professional knowledge in the areas of research, high stakes testing, and accountability. For decades, researchers have used countless approaches to delve into the educator-psyche to pinpoint what causes teachers to implement or not to implement curricular program decisions.

My previous teachers’ educational arts experiences impacted my teaching decisions. For example, throughout high school, I recognize that my choral director's decision to offer musical theatre productions gave me an opportunity to develop audition skills, memory and public speaking, vocal expression, confidence in body awareness and movement, character interpretation, stage presence. Recalling these rewards with arts integration impacted my instructional planning priorities for my students. As a reading specialist working with third graders, I addressed the struggles of a small group of remedial readers by bringing a story to life through dramatic interpretation. Students worked together to create scenery, costumes, and props; they even memorized their characters' lines. My decision to integrate the arts during reading instruction gave students hope and strategies for learning a difficult subject.

Elliot Eisner, scholar, prolific writer and publisher, educational reformer, sage on curriculum development, and well-known recipient of awards and honorary degrees, has helped to shape teacher education and school reform (Uhrmacher and Matthews, 2005). Eisner’s dissertation on creativity, written at the University of Chicago, argued for new thinking that creativity might be viewed as various behaviors rather than one single behavior. Using the visual arts, his study categorized creative behaviors into boundary pushing, inventing, 
boundary breaking, and aesthetic organizing (Eisner, 1962). On the curriculum scene of the 1960s, the objectives movement captured the attention of educators. Eisner's thoughts on objectives included both pro and con, purporting that objectives help teachers select and organize content. Consequently, he pointed out that if teachers are not using objectives, then it may be no fault with teachers, but with the theory (Eisner, 1967/1985).

Stevenson and Deasy's Third Space, 2005, challenged schools with the question of how to create effective learning environments that are not singly focused upon increasing test scores. Their concept of "third space" is that powerful place between and among teachers, learners, and works of art. Arts education competes with increased attention to and emphasis upon legislation to insure mastery performance in reading and mathematics. Arts education stands in line to seek adequate funding to promote and sustain rich, sound arts curricula. Hence, the conscious commitment to arts instruction is not exempt from challenge to thrive.

\section{Problem Statement}

What is it that commands teachers' attention when making instructional decisions? Exploring this problem from the perspective of general teacher decision making and more specifically, from the perspective of arts integration can inform the profession from a deeper perspective. Every educational stakeholder must provide teachers with the necessary support, resources, and professional development training to strengthen their work. Knowledge of what influences teacher decision making can guide stakeholders in providing effective supports. This data can provide important information to curriculum developers, administrative planners, and grant funding agencies. Teachers' awareness of their own capacity and responsibility for instructional decisions can become a tool for instructional focus and a pathway to sound, consistent teaching and learning. 
Teachers constantly make decisions that impact classroom instruction and student achievement. From the early days of education in the Middle Ages, the teacher commanded the curriculum. Although today curriculum committees, experts, and professional associations establish procedures and labor over content standards and curriculum mapping, it is the teacher who determines, organizes, and delivers the daily instructional plan. Students, parents, and community are all subject to teacher decisions for student learning. When achievement fails to occur, educators look everywhere to find solutions through interventions, resources, toolkits, and any variety of remedies for the problem—often at great expense to school systems, taxpayers, and parents. The teacher is a powerful factor in student learning and achievement. Finding answers to understand why students fail to achieve may depend upon determining specific and reliable evidence about teacher decision making. If research helps define influential factors of teacher decision making, then teachers will have knowledge to assist them in making sound decisions in curriculum and instruction.

\section{Purpose of the Study}

This dissertation researched teacher decision making as a factor in the implementation of a curricular design —an integrated arts curriculum. Current educational trends place strong emphasis upon analyzing student achievement data, teaching to curricular standards, using a core instructional program, responding to intervention plans with explicit instruction, and using high-stakes accountability testing. Eisner continues to contribute to current curriculum development by sharing his knowledge of the human learner. His concept of expressive outcome is the result of "curriculum activities that are intentionally planned to provide a fertile field for personal purposing and experience” (Eisner, 1994). Uhrmacher and Matthews wrote a biographical sketch of Elliot Eisner's curricular contributions included in the Intricate Palette. 
The authors trace his curricular contributions through the 1960s to the present day, an era that is "obsessed with issues of conformity and standardization," and show how Eisner embraces the work of Sir Herbert Read. Eisner believes that "education should foster productive idiosyncrasy among students, rather than mold all to standard uniformity” (Uhrmacher and Matthews, 2005).

I believe that I have experienced Stevenson and Deasy’s “third space” numerous times as a teacher of elementary and middle school students and with my own teaching colleagues. Realizing the importance of building capacity in my teaching career, I have pursued additional endorsements such as reading specialist, elementary education, early childhood generalist (National Board for Professional Teaching Standards) and administrative leadership. Fortunately, as a teacher I have had opportunity to work with students from pre-kindergarten through college and with my own teaching colleagues as a supervisor of instruction. Personal examples from my career include directing a county elementary children’s choir, participating in a county teachers' chorus, presenting a faculty holiday play to our elementary students, and encouraging special needs students to produce a holiday songs audio tape with writing samples to send to President Reagan—one that received a presidential response. The metaphor of "third space” is a powerful reality. Lessons of enduring human energy and expression are made possible through carefully orchestrated instructional decisions. These contributions to the community of leaders and learners cannot be measured in standard ways, but will find themselves repeated over and over again, as teachers and students exchange the magic of teaching and learning in that "third space."

We live in an era where knowledge of the research lends credibility to academic policy and decision making. Collaborations between public and private sectors signify a strong 
commitment to sustaining the arts in education. Two major collaborative documents referenced below are gaining significance as vehicles for change. These compendiums of research examine arts education programs using multiple methodologies to demonstrate the impact of the arts upon learning. Research of this nature depends upon teachers who consciously decide that their curricula will support and sustain integrated arts instruction.

The first compendium published by The Arts Education Partnership (AEP) is entitled Third Space: When Learning Matters (2005). It is a three-year study examining the impact of an arts-centered curriculum upon economically disadvantaged students in rural and urban regions of the country. The second is Champions of Change, in which seven research teams examine the impact of the arts on learning. These collaborative documents include research from inner city and urban schools, studies of students performing opera and Shakespeare, methods and practices, and theoretical frameworks, presenting evidence of how an educational arts experience changes the lives of young students. Publications and studies through AEP seek answers to important questions from the teachers themselves, because teachers are primary agents in consciously implementing arts curricula in their classrooms. Critical Evidence: How the Arts Benefit Student Achievement (2005) is another collaborative publication of the National Assembly of State Arts Agencies and AEP. In this brochure, teachers provided insight and answers to important questions such as, "How do we know that the study of arts contributes to student achievement?” and "What does the research say about how integration of the arts can lead to better schools?”

This dissertation functioned under the framework of four overarching themes. Questions of an open-ended nature provided a forum for the hermeneutic study in which eight research participants pictured themselves as decision makers for integrating arts into classroom 
curriculum. Their stories were written from the perspective of how I saw that picture and how the research participants saw it. I interspersed my story within the findings. The initial interview question themes were as follows:

- Curriculum-How do you decide what to teach?

- Instruction-How do you decide how to teach?

- Decision Making-What professional development do you seek?

- Reflection-What does the community say?

\section{Procedures}

Increased knowledge of teachers' instructional and planning decisions has critical importance to teacher professional preparation and continuous educational development. This qualitative study researched three sources of triangulated data from eight West Virginia elementary classroom teachers who have implemented an integrated arts curriculum. Data sources included two separate teacher interviews, an analysis of teacher lesson plans, and a discussion with teachers about particular arts integrated student products that they have used in their work.

This study examined how teacher experiences and perceptions impact teacher decision making upon implementing an integrated arts curriculum. Four major emphases comprised the design structure within this research, and four questions were explored during interviews with each of the eight teachers. The four-question set is outlined in detail below and includes subcategories for a follow up, semi-structured interview setting.

1. What professional attributes characterize an arts rich teacher? Specifically, this would include professional description, experience with the arts, professional development, reflective practice, and classroom teaching context. 
2. What impact do teacher beliefs and attitudes have upon implementation of an integrated arts curriculum? These beliefs include, but are not limited to, teacher commitment to arts integration in classroom instruction, teacher satisfaction, teacher autonomy over curricular decisions, and factors influencing change.

3. How do you integrate the arts? Areas to be considered include awareness and examples of student motivation, choices in lesson planning and curriculum pacing, teaching adjustments for struggling and successful students, and teaching accommodations for students with special needs.

4. How do you use arts beyond classroom community to affect decisions to integrate arts in the curriculum? Considerations include parental involvement, community involvement in the arts, and interaction within and among district schools.

\section{Professional Significance of the Problem}

Researched practices and curricular programs make it possible to promote academic excellence and school reform. Textbooks are designed to provide teachers with guidance in both curriculum and pedagogy. In a 2007 Education Week article by Nancy Ginsburg Gill, “Goodbye, Mr. \& Mrs. Chips,” a warning was issued about using instructional design and programs that are scripted in nature. Ginsburg, a teacher, education writer, and consultant from Los Altos, California, wrote, "If higher test scores are achieved by mandating that teachers follow a script and eschew spontaneity and passion, we will find few great teachers left in the classroom.” Gill argued that teachers can inspire students to learn beyond what is covered on grade level tests. She challenged the research that adhering to scripts will pay off in higher test scores for students. Even though teachers enter their profession for a variety of reasons including affinity for subject matter, a desire to make a difference, and a quest for professional 
study or travel, their interest in working with students is a deciding factor in becoming a teacher.

Professional development training is a costly expenditure to schools, districts, and the individual teacher. Too often, purchasing curricular programs and professional development workshops does not produce a firm commitment to implementation of the instructional design within the classroom. Typically, purchased trainings and materials are provided and all too often quality researched programs and methods languish in their implementations or fail to maintain their sustainability. Not until there is an increased knowledge of factors that inhibit researched reform practices will a conscious and consistent use of these methodologies and reforms be understood. The teaching profession needs answers to enlighten and insure effective results in student learning, excellence in instruction, and concrete evidence that the educational system is working to produce results. Identifying the barriers to implementation will assist all educational stakeholders in recognizing what works best. A constant pursuit to reveal specific reasons why teachers make the decision whether or not to implement instructional methods must be carefully and fully considered to inform educators.

An analysis of teacher beliefs and attitudes sheds light upon the impact of teacher development and the decision about implementing an arts integrated curriculum or not. A cross-case analysis design is a valuable methodology for ascertaining knowledge (Elba, 1981). Eight teachers (two retired) from three different schools were the focus of this research. They agreed to participate with the researcher in interviews, analysis of lesson plans, and an open discussion of particular arts integrated student products used in their instructional work. The research was designed to determine what commands teachers' attention when making decisions to implement integrated arts instruction. Each school's demographic information, and data on 
overall school data and academic performance data were included to provide insight into student performance and teacher instructional focus. Review of lesson plans documented a connection between student academic performance and teacher instructional and planning decisions. Data from four major research questions comprised the analysis of how teachers integrate the arts. Emerging themes unfolded into an organizational tool for collecting and reporting data and for expediting research conclusions.

\section{Limitations of the Study}

1. The researcher holds strong views regarding arts in the curriculum based upon a lifetime of arts instruction and two music master's degrees-in music education, ME, and organ performance, MFA. I have experience in both elementary and secondary general music and choral instruction. Additionally, I am elementary classroom certified and have instructed students in art, music, and physical education to cover teacher planning periods. I am also a reading specialist and National Board Certified Early Childhood Generalist. My continued pursuit of professional development has strengthened my knowledge of curriculum and given me confidence to make instructional decisions for the students I teach. I participate in community music events both secular and sacred, such as community recitals, weddings, fairs and festivals, and holiday worship services.

2. Because of the complex and rich nature of narrative description used in hermeneutic methodology, eight teachers participated in this study. All participants were female, and all were certified elementary teachers who received professional development in integrating arts into the classroom curriculum.

3. Unique demographic data—gender, age, educational background and arts influence are items that each educator brought to life in the classroom. 
To contain researcher bias, the interview questions met the rigors of a standardized structure and an organizational framework designed to analyze lesson plans. Responses were collected and patterns established to generate conclusions. The goal of this research was to model what Lincoln and Guba (1985) espouse: "By providing a rich, thick description, the researcher establishes a base of information appropriate to the judgment of anyone interested in transferability.” (pp. 124-125). Guba’s quote presumes that the researcher uses responses to develop an instrument that will be used to collect data from a large group.

\section{Definition of Terms}

For a more thorough understanding of terms used in this study, a list of definitions is provided:

1. Classroom Autonomy - freedom of operation a teacher perceives as necessary to carry out teaching performances. Operational definition is determined by three factors: how much the teacher participates in establishing goals for teaching; freedom to make choices during teaching in order to accomplish the goal outcome; level of involvement in setting the standard for determining successful attainment of goals (Callison, 1970).

2. Instructional decision making-deciding what to teach within the broad range of instructional topics (Rollins, 2003).

3. Accountability — holding teachers responsible for individual student's performance results or for providing good instruction (Willis, 1999).

4. Planned curriculum — written state or district-prescribed curriculum to guide instructional planning, pacing, and presentation (Rollins, 2003).

5. Taught curriculum—choice of instructional content (Rollins, 2003).

6. Sustainability — ability to implement and maintain an instructional method, program, or curriculum over a period of time. 
7. Variability—individual differences among pupils that require teachers to make continual adjustments in teaching performance (Callison, 1970).

8. Warranted practice — using the research as a way to promote teacher change (Richardson, 1990).

9. Fidelity — the degree of accuracy with which an intervention, program, or curriculum is implemented according to research findings and/or its developers' specifications (Buffam, Mattos, Weber, 2009).

10. Sanctions—-formal and informal rewards or punishments. Formal sanctions are rewards or punishments based upon the legal authority given to officials in the school (Callison, 1970).

11. Reflective practice- teacher self-monitoring activity to think about what they do and why, and what's valuable to teach, and the best way to teach it (Green, 1986).

12. Collaboration—a systematic process in which people work together, interdependently, to analyze and impact professional practice in order to improve individual and collective results (DuFour, DuFour, Eaker, 2008)

13. Professional development—a lifelong, collaborative learning process that nourishes the growth of individuals, teams, and the school through a daily job-embedded, learnercentered, focused approach (National Staff Development Council, 2001).

14. Arts integration—learning through and with the arts; arts integration as a curricular connections process, and arts integration as collaborative engagement (Burnaford, Brown, Doherty and McLaughlin 2007, pp. 11-14).

15. Arts Education Partnership—private, nonprofit coalition of more than 100 national education, arts, business, philanthropic and government organizations; committed to 
advancing the role of arts education so that all children can succeed in school, life, and work.

16. CAPE network—Chicago Arts Partnership in Education, a network of nine neighborhood-based partnerships, 33 arts organizations, and 11 community-based organizations; pioneer in finding novel ways to integrate the arts with learning across the curriculum.

17. Champions of Change—a body of research findings compiled by seven teams of researchers. Teams studied a variety of arts education programs using diverse methodologies.

18. LITA study—-Learning in and Through the Arts"—a dynamic model where learning in one domain supports and stimulates learning in a complex web of influence. LITA's compelling evidence of student achievement supports high quality arts program coupled with a culture of active and productive learning.

\section{Organization of Future Chapters}

Chapter Two is a literature review with introductions to teacher development and autonomy that trace the research of historical influences upon teacher decision making, teacher accountability, and change forces. Included in the literature review are the most current research findings on integrated arts instruction and constructivist learning. Chapter Two concludes with a summary, rationale, and purpose for the research study.

Chapter Three articulates research methodology and procedures used in the dissertation. The research problem and four questions serve as an over-arching structure for this qualitative research design and are followed by procedures for selecting school sites and teacher participants to be included in this study. 
Chapter Four presents data collection and illuminates for the reader what individual teachers say through their interviews, their lesson plans, and their open discussions of student integrated artwork and the resulting impact upon the work of a teacher. Chapter Four presents teacher narratives from three schools. Organizational structure of the narrative data is through each teacher's association at her school. The three school sections open with a demographic picture. Following is the narrative story of each teacher from that school. Their conversations with me include a discussion of the big four thematic structures of curriculum, instruction, reflection, and community. Teachers discuss their student assignments and some offer a preview of their lesson plans. Each school section is divided into subsections that represent their teacher data.

Chapter Five begins with a summary of the research literature as relevant to the data gathered, followed by a re-statement of the research questions. The remainder of the chapter collects and presents the data by each individual teacher and by the research questions, reconnecting to the big four over arching questions surrounding curriculum, instruction, reflection, and community. The dissertation ends with research conclusions, implications for practice, policy, and the future. 


\section{Chapter 2}

\section{Literature Review}

This study researched experiences and connections as factors in deciding to implement curricular instructional designs. The goal of this study was to define the impact of what commands teacher attention when deciding to integrate the arts curriculum into classroom instruction.

Teacher-as-decision-maker is a concept that has intrigued researchers for decades. Historically, teaching has evolved as a profession in which its members and members of society have diligently striven to comprehend the intrigue surrounding teacher autonomy.

According to an educational analysis by Raymond E. Callahan, the early 1900s was a time when business and industrial values were applied to education. Efficiency in management was the administrator's goal, and workers were to do as they were told. For teachers, this did little to encourage teacher decision making.

Other studies explore teaching as a profession and attempt to show the connections between a worker's profession and the decisions to do the work. The concept of professionalism in Myron Liberman’s 1956 book, Education as a Profession, contributes to the study of autonomy by asking pertinent questions regarding teachers as decision makers. Consequently, Lieberman presents teaching as a profession that must allow for professional judgment on what to teach: "If there is no scope for independent judgment, there is no autonomy and no profession.” Teacher autonomy, in its early stages, grew to be associated with the professional status of the job. Over time and due to research, teacher autonomy has emerged through various dimensions that have changed the face of the teaching profession. This change can be corroborated by teachers who determine their course content and pacing, 
and by teachers who admit to knowing the research findings, yet choose not to follow a prescribed curriculum, a content strategy, or an intervention strategy.

Recent research on arts instruction indicates that school climate and administrative support can influence the richness of an arts integrated curriculum. Burton, Horowitz, and Abeles' (1999) Learning In and Through the Arts: Curriculum Implications was a significant study finding that administrators who supported a strong arts program evoked in their teachers a confidence to learn new skills, to take risks, and to expand the depth and breadth of their curriculum. Benefits of such encouragement are stronger teacher-pupil relationships; a keener teacher interest and commitment to professional development, change, experimentation and innovation; and strong collegial working relationships. Instruction in high-arts settings tends to result in an open and flexible curriculum with fewer adherences to formalization or centralization.

\section{Historical and Evolutionary Role of Autonomy and Decision Making}

Before public recognition of teaching as a profession, two significant articles by early researchers of the autonomy concept offered insight. Sloan R. Wayland's 1964 Structural Features of American Education as Basic Factors in Innovation, and Henry M. Brickell’s 1964 State Organization for Educational Change: A Case Study and a Proposal, Innovation in Education both capture the influence of teaching as a profession upon teacher decision making. Both writers concur that neither do teachers have professional status, nor have they sought this power. Much of the decision making associated with teaching is determined by others within the educational system. Brickell believes that teachers are a functionary piece of the bureaucratic system — and replaceable. Wayland admits, however, that a teacher’s work involves continuous decision making about student instruction (Samuels, 1966). 
In studies of larger organizational systems where rules, routines, guidelines, hierarchical stratifications, and performance evaluations are in place, member autonomy is subject to organizational controls. James C. Worthy’s (1950) Organizational Structure and Employee Morale determined that members subject to constant control have little autonomy. Supervision and evaluation procedures can shift focus to work procedures rather than to the impact of performance results. Time, research, and the educators themselves have helped to reconcile the schism between teacher-professional image and the power associated with autonomy and decision making. In the face of consolidation efforts, larger schools and districts face the challenges of meeting the needs of individual teachers.

Turbulence in the 1960s and 1970s involved teachers in strikes and collective bargaining. Teacher associations and federations took on a more active role in legislative activities, and associations used their dues and funds to centrally organize teachers (Myers, 2007). Since the 1990s, top-down leadership has shifted to a more collaborative role (Wiles, Bondi, 2000). Emergence of teacher professional organizations has resulted in strong advocacy, employee unity, and leadership for teachers, thereby returning decision-making power to the teachers. Old habits of telling teachers what to teach and how to teach are yielding to teacher collaboration and reflection. In a study by Simmons (1985), teachers were becoming classroom researchers and informing their own practice through action research. This study suggested a stronger connection to self-selected professional development and knowledge of research.

Research interest in refining the nature of teacher autonomy has helped educators understand the variety of influences upon them and has proved valuable in enhancing the teaching profession. An important outcome of teacher development training is the confidence 
gained in strategies, content, and pedagogy. Although administrators and curriculum supervisors do not make all of the educational decisions, they do benefit from having an awareness of teacher perceptions and attitudes, bureaucratic decisions, and social influences that impact the course of curricular design in the classroom and the school system. Supervisors are an influential factor in fostering a culture of instructional creativity for teachers. Those who do so lead their schools, teachers, and students to learning excellence. One way to accomplish such a culture is to encourage teachers to try new ideas and techniques in classroom instruction and to reassure teachers that "lessons learned" from an unsuccessful outcome will benefit the entire teaching and learning community. Constructive experimentation with instructional approaches can improve teaching (Wiles, Bondi, 2000).

Meyers (2007) characterizes teachers as having the self-perception of professionals while Etzioni (1969) says sociologists argue for a more semiprofessional classification like that of nurses and social workers. For the public to make professional decisions for teacher autonomy is as ludicrous as deciding how lawyers or doctors will conduct their professions. Public interference in a group’s professional decision-making only serves to limit a worker's expectation of teaching autonomy.

\section{Teacher Development and Support for Making Changes and Decisions}

Dichele (1994) clarifies why teachers make changes or choose not to make changes in their classroom instruction. Her study explores when and why teachers make changes and how instructional theory evolves into classroom practice. This research presents insight into teacher beliefs as they impact instructional behaviors and how these beliefs change. An underlying belief surrounding educational improvement hinges on "an attempt to more seriously empower teachers - to help them make more informal judgments and get them thinking and being more 
reflective about what they do and why and what's valuable to teach, and what's the best way to teach it” (Greene 1986, p. 428). Teachers are essential in deciding what is taught in the classroom. They must be afforded a teaching culture where collegial discussions on methodologies and research-based practices, as well as reflective practice, offer rich opportunities to discuss and plan instruction.

Dichele’s consideration of the powerful influence of curriculum is supported by research on mandates versus reflective practice. Ashton (1988) and Wellington (1991) suggest that teachers whose curricula are designed and specific are subject to a stilted instructional delivery. When considering the power of an arts-integrated curriculum, Burton, Horowitz, and Abeles (1999) stress the need for well-educated teachers-teachers who have experience in the arts, and teachers who are complex, reflective thinkers and practitioners. Collaboration and willingness to explore content beyond their own disciplines is necessary for arts teachers committed to offer arts learning along with other disciplines.

The act of decision-making is also an important aspect of the research. Because decision-making is comprised of deciding upon the job content, how to do a job is ultimately left to the discretion of the person doing it. An employee is expected to make choices and judgments that will best accomplish the tasks he or she was hired to do. Teachers are able to make these decisions when their work is not pre-designed or prescribed (Elliott, 1956).

Opportunities for collaboration and risk-taking empower teachers to think, research, create, and decide. Teachers who are focused upon student achievement, accountability to standards, and a set of planned objectives to accomplish learning are able to see the connections between what they are teaching and why. 
The Chicago Arts Partnerships in Education (CAPE) is a 1992 initiative of the Chicago Public Schools. Foundation and corporate support sought to revive partnerships between local artists and teachers. CAPE's premise was that teachers and artists would accept the responsibility of integrating arts instruction into all aspects of the curriculum. The expectation was that educators would not only make decisions that support specific academic goals, but also administer appropriate assessments to determine the instructional impact of arts on other academic subjects such as reading or science. In a focused six-year study, James S. Catterall, principal investigator, and Lynn Waldorf, field researcher, co-authored a summary evaluation of the 37 participating schools, representing 57 professional arts organizations and 27 community organizations. North Central Regional Laboratory (NCREL) and CAPE produced several reports that tracked the impact of integrated arts upon teachers and the artists. The study was successful in identifying student growth in various skills and in identifying characteristics that support high quality arts-integrated instruction. Lesson plans from artists and teachers contained a connection between goals and objectives along with assessments. By asking the question, “What does it take to create high quality arts-integrated instruction?” the study was able to illuminate specific supports that teachers need when making decisions on a curricular/instructional program. For those who were successful at arts-integration instruction, the following factors were identified: supportive principals, risk-taking, defined learning objectives, matching assessment plans, and sharing with colleagues. 


\section{Community Support and Decision Making}

Callison (1970) suggests that a classroom teacher's autonomy is influenced by three factors: (1) his ability to set goals for teaching; (2) the freedom to teach in the manner that he feels will accomplish the goals; and (3) setting his own standards for judging the successful accomplishment of goals. Callison's concept of permeability suggests that external factors outside school structure offer formal and informal sanctions that influence teachers and their school activities. His study compares data from smaller, less hierarchical schools to highly regulated urban schools to determine the degree of permeability. This determination is accomplished by comparing the influence of outsiders upon teachers' choices in content, materials, and teaching approaches. Community members and parents are outside-the-school influences; the principal and teacher colleagues represent inside-the-school constituencies.

Communities and arts organizations that team with teachers and administrators within the school are considered an influential force on instruction. When communities support arts integration, teacher instructional decisions have greater impact, as seen when mechanisms for funding through community grants are available and when involvement and collaboration from local artists are more accessible. The arts, unlike other school subjects, present a public face to learning (Burton, Horowitz, Abeles, 1999).

CAPE received results from North Central Regional Educational Laboratory’s (NCREL) survey of teachers and artists in 1997-98, in which several variables were considered supportive. School principals and arts organizations were considered highly supportive. Local school councils were ranked as supportive; while the non-arts community was ranked as somewhat supportive. Lowest in support were teachers who were non-CAPE, evidence that not all teachers decided to embrace the arts integrated curriculum (Caterall, Waldorf, 1999). 


\section{Student Influences on Decision Making}

Variability requires teachers to make decisions when it is apparent that students' backgrounds require performance adjustments. Teachers who understand their students’ performance also know how to make changes that will account for student learning variance. Selecting materials and instructional approaches other than those determined by the school district enriches student learning and shows a teacher's willingness to make instructional adjustments. When students have not experienced rich exposure to the arts, teachers have the power through their instructional decisions to influence change for students. Burton, Horowitz, and Abeles (1999) compared experiences in high-arts and low-arts groups, based on the inschool arts instruction received. In areas such as creative thinking, originality, and elaboration, low-arts students paled in comparison to the high-arts group. How teachers decide to plan and deliver instruction can be influenced by teacher perceptions and responses to student variability.

NCREL (Caterall, Waldorf, 1999) conducted interviews and surveys from teachers, artists, and principals who reported a list of activities in which important life skills were observed in both arts and non arts-integrated lessons. Observation rating scales ranged from non, low, and medium to high. In the observations of integrated arts lessons, teachers and principals rated student motivation to learn as high. Change in teacher-student relationship was rated as medium to high. Artists and teachers also rated student growth in various skills. Teachers and artists rated student responsibility as very high and self-management as medium to high. In the observations of non-integrated arts lessons, student responsibility was rated as medium, while in integrated lessons student responsibility was rated medium to high. Informational data on student responses and growth in various skills provided valuable 
feedback to teachers who were deciding whether to continue with or participate in an integrated arts curriculum.

\section{Accountability and Decision Making}

Greater knowledge of educational procedures such as standards-based instruction, formative and summative assessment, scientifically based instructional practices, and teacher accountability has influenced educational law, regulations, and policies in states' educational programs and practices. There is growing interest in teachers’ perceptions of state accountability programs and attitudes and responses to such mandates. Rollins’ (2003) study suggests that North Carolina's ABCs of Public Education is an accountability system that influences teachers but does not control their instructional decisions and practices. Teachers admit concern that their ability to make instructional choices and decisions has been reduced, although approximately 50\% believe that student learning and behavior are impacted. Rollins says that although before high-stakes testing teachers decided what to teach, now the test determines what to teach.

The Common Sense Foundation (1999) data report that North Carolina’s accountability program's emphasis on a state-mandated curriculum is promoting a greater instructional focus. Many factors contribute to successful school programs. Test scores in isolation do not provide teachers and students a full measure of feedback. Indicators such as drop out rates, student safety and welfare, and teacher and administrator quality are among the factors that determine school success or failure (Rollins, 2003).

\section{Summary and Rationale for the Study}

Over the years, research on autonomy and teacher decision-making shows a vacillating pattern between administrative control and teacher autonomy. The profession has evolved 
from early days of industrial values where the administrator told teachers what and how to teach, through the days of teacher empowerment and collaboration where creativity and decision-making were negotiated or left entirely to the teachers, and then to the current day with standards accountability and high-stakes assessment of teaching mandates and program initiatives.

Donald Allen Myers’ 2007 article “Teacher Power—Revisited” considers the evolution of teacher power to govern instruction. He asserts that others impose instructional decisions upon the classroom: principals, district offices, local board members, and state departments of education. In the 1970s, there was an outcry by teachers to have control in and over their own classrooms. Teacher unions and professional organizations fought for teacher rights to gain control over curricular issues. “A Nation at Risk” (1983) exposed failing schools and stirred public debate surrounding alternative structures such as charter schools and vouchers. The U. S. Department of Education's Public Law 107-110, No Child Left Behind (NCLB), gave rise to the standards movement, only to be named for sabotaging teacher autonomy with a standardized curriculum for all students. Meyers contends that this emphasis on standards has forced a shift from progressivism and constructivism to perennialism and essentialism. Teachers are required to forego many courses such as music, art, and creative writing, and are focused on teaching and mastering learning standards and objectives. There is a perception that teachers no longer have command over curricular decisions and instructional implementations, signifying a step backward for the profession and for professional decision-making.

Torres-Guzman and Hunt (2006) researched teacher collaborative groups and found that creative and effective teaching has power to overcome the uniformity and conformity brought forth by a standards-bearing curriculum. These learning groups sought a structure to recoup 
their teaching freedom. As they worked collaboratively, teachers used problem-solving and inquiry methods, brainstormed effective teaching strategies, sustained and encouraged novice teachers, established study groups, and supported each other in constructing new learning. They reinvented a professional development model with ownership of their own insights, leading to greater teaching freedom in the midst of standardization.

\section{Current State of Research}

The current state of research in the teaching profession offers databanks of research reviews such as the United States Department of Education's 2002 What Works Clearinghouse, and assistance to support teacher lesson planning such as ERIC (Education Resources Information Center), instructional resources, and an understanding and interpretation of student academic achievement. Publishers are collaborating with professional education associations' memberships such as the International Reading Association with an eagerness to offer their researched learning solutions. Richard DuFour and Robert Eaker's research publications on professional learning communities (PLC’s) support teachers and administrators in mastering the art of collaboration and team work for the benefit of student achievement.

Teachers are participating in professional development initiatives such as National Board Certification whose tenets promote reflective practice and continuous learning. A June 11, 2008, press release from the National Board for Professional Teaching Standard's (NBPTS) website at http://www.nbpts.org/about_us/news_media/press_releases?ID=422 affirms the National Board Certification’s positive impact on student achievement and learning. The National Research Council (NRC) of the National Academies affirms that NBPTS teachers raise student achievement and commit to improving their schools, according to Joseph A. 
Aguerrebere, NBPTS president and CEO. The Teacher is a powerful factor in student learning and achievement. How do teachers make instructional decisions?

In the September 2008 RAND report, Cultivating Demand for the Arts: Arts Learning, Arts Engagement, and State Arts Policy, authors Laura Zakaras and Julia Lowell report that nearly every state mandates standards-based arts education. For the past fifteen years, national reform movements in general education have promoted accountability testing that focuses largely upon language and mathematics and increased demand for accountability in core curricular areas. Responsibility for delivery of arts instruction has been relegated to local district and school control. Therefore, when funding is limited, cuts in program support for the arts are rationalized by the perception that arts are peripheral to the main curriculum.

Thousands of arts programs and their instructional specialists fell victim to the budget cuts of the 1970s and 1980s (Caterall and Brizendine, 1984: Jackson, 2007).

Building upon the ancient historical knowledge of arts curriculum, many modern-day zealots, champions of the arts, and visionaries are playing a critical role in keeping the arts alive in America’s classrooms. State Arts Associations (SAAs), private foundations, and community-based arts programs partner with school systems by providing grant structures that help schools keep their arts programs going (Bubgarner 1994a,b).

The President’s Committee was created in 1982 by Ronald Reagan’s Presidential Executive Order to encourage private sector support. This influential committee includes executives from federal cultural programs such as the National Endowments for the Arts and the Humanities, the U.S. Department of Education, the John F. Kennedy Center for the Performing Arts, and the National Gallery of Art. These organizations are renowned for raising the level of arts awareness and increasing the value of the arts and humanities through credible 
cultural programs, meetings, and publications. The committee encourages collaboration between leading citizens from the private sector and heads of agencies previously mentioned.

The 2006 brochure, “Making a Case for the Arts: How and Why the Arts are Critical to Student Achievement and Better Schools,” is a publication available to arts advocates which presents benefits of arts instruction in a question and answer format. The 1995 Arts Education Partnership publication espouses a strong commitment from the private, nonprofit coalition dedicated to promoting the essential role of arts education for American students. The goal is for all students to thrive in school, life, and work. The partnership, a powerful private, nonprofit coalition of over 100 national education, arts, business, philanthropic and government organizations, is hard at work advocating for a sustained and rigorous arts curriculum for all students.

\section{Summary of Rationale and Purpose}

The rationale and purpose for this study were to get to the core of teacher decisionmaking for providing an integrated arts curriculum. The aforementioned research on decisionmaking and autonomy indicates that teachers were subject to top-down decisions, administrative bureaucracy, and pressures of high-stakes testing. The research also documents how teacher content knowledge and the privileges of having such knowledge help teachers be recognized by the public as a professional group. Teacher unions and associations as well as legislation and policies have created a political tug-of-war between teachers, policy-makers, and the public. Is it any wonder, then, that researchers examine the mystique surrounding teachers’ classroom instructional decisions? Refer to Appendix A for a graphic representation of the historical overview of the literature. 
The research for this study consisted of two interviews and one open discussion with eight elementary teachers. Two comprehensive discussions with teacher participants sought out their stories on what commands their attention when deciding to implement an integrated arts instructional design in their classrooms. The open ended interview set the stage for gathering individual teacher demographic data and framed each teacher's classroom culture and design. In the subsequent semi-structured interview, four over-arching questions became the framework in gathering research data and information. Some of these included successful academic achievement, motivation, and unique learning needs. Specific teacher demographic influences that were unique to each case facilitated a deeper understanding of how teachers make and commit to their instructional decisions. Interviews gave insight into teacher commitment and to arts integration by illuminating their decision making strategies.

For each of the eight cases, the researcher and teacher participated in an open discussion over particular arts integrated student products used in their work. One or two samples of student artwork from each of the eight teachers, along with teachers’ comments and insights, were analyzed and presented in a categorical representation. A matrix checklist (see Appendix D for the work sample checklist) of elements representing features of the curriculum and student development provided a starting point for the discussion. Elements were gleaned from an April 2007 literature review “Arts Integration Frameworks, Research \& Practice” by Burnaford, Brown, Doherty, and McLaughlin.

Where provided, a review of teacher lesson plans completed the cross-case analysis. Emerging themes, practices, instructional strategies, resources, and assessments are among the many considerations that teachers have. Gathering data around the characteristics of teacher lesson planning can contribute to the important research of understanding teacher decision 
making. A rich triangulation of data from interviews, student artwork, lesson planning, and discussions was coupled with other studies, such as the aforementioned Lieberman 1956 research study on professionalism in education. Research methods and document analysis of this dissertation explored teaching as a profession and attempted to show the connections between a worker's professional teaching decisions and their impact upon student and classroom learning. 


\section{Chapter 3}

\section{Methods and Procedures}

What is it that commands teachers' attention when making instructional decisions to implement an integrated arts curriculum? Exploring this problem from the perspective of general teacher decision making as related to arts integration has strong potential to inform the

profession from a deeper perspective. Knowledge of what commands teacher decision making can guide stakeholders in providing effective supports. Teacher awareness of the capacity and responsibility for instructional decisions can become a tool for instructional focus and a pathway to sound, consistent teaching and learning.

Teachers constantly make decisions that impact classroom instruction and student achievement. When achievement fails to occur, educators look everywhere to find solutions through interventions, resources, toolkits, and any variety of compresses to remedy the problem—often at great expense to school systems, taxpayers, and parents. Teacher is a powerful factor in student learning and achievement. Answers to this problem depend upon determining specific and reliable evidence about teacher decision making. With such knowledge rests the assurance of influencing the teaching profession by building a conscious capacity to make sound curricular and instructional decisions.

Understanding the nature of teacher decision-making is a topic that continues to be of keen interest to researchers. As the pendulum of education swings, influences will impact teacher development and the consequences of their instructional decisions. This study was designed to add to the descriptive data on teacher perceptions, especially with regard to their professional autonomy, and ultimately, the decisions within their sphere of influence: the classroom. Knowledge of teacher perspectives will assist policy makers, administrators, the 
public, and teachers themselves in understanding the enigma surrounding what, how, and why teachers decide on their instructional course for students. Who better to provide that knowledge than the teachers, and what better way to secure the information than to provide an opportunity to hear their voices?

Hence, this study is a means to understanding and valuing teachers' insights into what commands their attention when they make instructional decisions. The abstract nature of this research problem was addressed by researching eight concrete examples (teachers) and comparing them to my own professional development, decisions, and insights. A thorough and complete data analysis provided concrete conclusions about teacher development and linked them to a significant factor in their decision to implement an integrated arts curriculum.

The straightforward design of this study was grounded in knowledge of research design and principles. It was conducted under natural and familiar conditions, minimizing the chance of investigator manipulation and insuring that there was no predetermined course set by and for the researcher (Patton, 2002). Three sources of documentation made up the methodology for this study and provided research data for a rich analysis. The first was in-depth, open-ended interviews during which eight teachers offered their insights during two separate interviews in which they identified their perceptions, influences, and understandings. An open discussion of student artifacts gave teachers a forum for discussing how they used particular arts integrated student products in their teaching. Document analysis was the third point of qualitative data collection. Teacher lesson plan documents provided insight into teacher decisions regarding instructional priorities and decisions. This chapter presents a detailed description of methodologies and procedures used to substantiate and implement the research study. 


\section{Maintaining Confidentiality}

Permission for this study was granted based upon assurance of confidentiality and upon the condition that participants' rights to confidentiality be protected. Therefore, the actual districts, school names, locations, and names of participants mentioned in this study are fictitious. Any similarities to actual names and locations are merely random, coincidental, and unintended.

\section{Theoretical Framework}

For the two interviews, four themes and overarching research questions provided the researcher with a clear case study focus. Themes were curriculum, instruction, reflection, and community. Overarching research questions were as follows:

- What professional attributes characterize an arts-rich teacher? (Reflection)

- What impacts do your beliefs and attitudes regarding commitment, satisfaction, autonomy, and change, have upon your implementation of an integrated arts curriculum? (Curriculum)

- $\quad$ Describe how you integrate the arts. (Instruction)

- How do you use the arts beyond your classroom community to affect your decisions to integrate arts into the curriculum? (Community)

\section{Selection of School Sites}

The study’s eight participants represent elementary schools in one school district.

District willingness to participate and those who integrate the arts were critical elements in selecting the schools and teachers. Schools were selected based upon their participation in and awareness of arts. Teacher and principal willingness to participate in the study, along with previous knowledge and professional development training in arts integration were influential in the selection to participate. 


\section{Identification of Participants}

Teachers identified to participate in this study were selected on the basis of the following criteria: willingness to participate, professional development training in integrating arts into the curriculum, and elementary certification. Schools represented in the study were from Madreas County Public Schools (research locations are fictitious names) Bickle Creek Elementary, Riffe Park Elementary, and Selena M. Day Primary School. All participants in the study were veteran teachers who met the above criteria.

Although there were not equal numbers of participants from each school, there was no intent to equally match teacher-to-teacher for this study; rather, each case was individually analyzed and each stood independently with equal importance in the data analysis.

\section{Data Collection and Analysis}

The purpose of this study was to examine teacher decision making as a factor in the implementation of a curricular design: an integrated arts curriculum. One of the best and most authentic ways to determine teacher perspective is to use a methodology that examines teacher decisions and practices. This dissertation employs the hermeneutic qualitative inquiry method. Teacher narratives are their voices which tell about their work and show the conditions in which they practice and, ultimately, decide upon curricular issues in their classrooms. Patton's guidance from the Qualitative Research and Evaluation Methods, asks the question: "What does this narrative or story reveal about the person and world from which it came? How can this narrative be interpreted so that it provides an understanding of and illuminates the life and culture that created it?” (Patton, 2002). Through the stories of eight participants and the researcher, data are gathered about our life experiences and our interaction with arts culture, 
our teaching, and the community. Through the lenses of our unique personal and professional experiences, the hermeneutical perspective's emphasis on interpretation has the power to interpret and inform narrative studies. Patton cites Bochner, 2001, “... 'the narrative turn’ in qualitative inquiry honors people's stories as data that can stand on their own as pure description of experience, worthy as narrative documentary.” An especially reliable methodology to study acquisition of knowledge of teacher practice is the cross-case analysis (Elbaz, 1981, 1983). Full descriptions of each teacher presented her evidence of knowledge, practice, and perspective. Conducting an analysis of each teacher was the primary data to ascertain individual uniqueness and teacher commonalities. We value the teachers' classroom stories and support them as contributing to the body of narrative studies.

\section{Interviews}

For the purposes of this study, eight participants' narratives formed the research core. Methodology included two interviews, one at the beginning of the study in which each teacher participated in a semi-structured interview (see Appendix B for initial interview questions) with pre-established questions that gathered demographic data about teacher development and the instructional culture of the classroom. Interviews were conducted in a 30-minute, face-to-face setting. A second interview (see Appendix C for follow-up interview questions) with the four over-arching questions established an opportunity for teachers to offer their points of view. Interviews were tape recorded, and teachers were identified by fictitious names. Responses were transcribed and coded to facilitate the data. Lofland (1971) says that open-ended responses give the participants a chance to respond in their own terms. Data gathered from individual's responses are a strong source of hermeneutics in which the researcher describes 
"how I see that picture, and how does the other person see it." Teacher quotes reveal how they are organizing their work, the influence of their experience, and the personal, unique thinking patterns surrounding their instructional practices and decisions.

\section{Initial Interview}

During the initial interview, interaction between teacher and researcher was guided by a set of semi-structured questions. Four open ended question themes focused on curriculum, instruction, reflection, and community. See Appendix B for semi-structured initial interview questions.

\section{Open Discussion and Photographs of Student Work Samples}

One way to illuminate teacher decision-making and its impact upon curriculum and instruction is to examine teaching outcomes: student work samples. This researcher participated in an open discussion with the teacher participants over particular arts integrated student products that they have used in their work. A tape recorded discussion was analyzed to provide insight into how the student influences teacher decision making. The categorical matrix found in Appendix D was used to frame teacher responses. One way to illuminate how teacher decision-making impacts curriculum and instruction is to illuminate ultimate teaching outcomes through a teacher discussion of student work samples. This study included a sampling of student artifacts, one or two selections from each of the eight participating teachers. Revelations of artistic expressions have the capability to add an aesthetic dimension to the cognitive nature of this research. After discussion with teachers, responses were categorized to illuminate teacher use of particular arts integrated student products.

Analysis of these discussions was organized into a table of elements that offer a framework for looking at student artwork. New elements were added to the matrix as 
phenomena emerged and categories were added and revised. The matrix was inspired by selected elements from the April 2007 literature review, "Arts Integration Frameworks, Research \& Practice” by Burnaford, Brown, Doherty, and McLaughlin. Organizational structure included four categories of student learning: curricular content, student response, language expression and development, and social skills awareness. For example, the table reflects student artwork that demonstrates evidence of curricular content; artwork reveals student self-motivation including confidence, engagement, esteem, efficacy, aspiration; artwork reveals reading and language development such as text interpretation, writing, character development; artwork demonstrates social skills-awareness such as tolerance, conflictresolution, community service, and social problem solving. The student work checklist of elements represents features of curriculum and student development.

\section{Second Follow up Interview}

Second follow up interviews completed the interview-discussion-interview cycle. Tape recorded, transcribed, and then coded, the second interview focused on four semi-structured questions. To facilitate each teacher's time investment in the study, the second recorded interview was conducted in person. The questions are as follows:

- What professional attributes characterize an arts rich teacher?

- What impact do your beliefs and attitudes regarding commitment, satisfaction, autonomy, and change, have upon your implementation of an integrated arts curriculum?

- Describe how you integrate the arts.

- How do you use the arts beyond your classroom community to affect your decisions to integrate arts into the curriculum?

At the conclusion of this cycle, the researcher had meaningful face-to-face interactions with the eight participants. Fieldwork for this portion of the study attempted to give insight 
into actual teacher cases through dialogue, descriptive observations, and interpretations of student and teacher documents and artifacts.

\section{Lesson Plan Analysis}

Lesson plan analysis provided the researcher with information that cannot be acquired during interviews and observations. Teacher decision-making and level of commitment to instructional programs and approaches can be implied in lesson plan design. Confidentiality of the documents was assured through a coding process, and when pertinent and relevant to the study, quotations from the lesson plans were anonymously included in the analysis. Gale Miller (1997) has defined institutional documents in places such as schools, hospitals, and governments as pervasive (in massive amounts of files and reports.) Miller contends that the texts of institutional documents help make sense through reconstruction, and that they help researchers challenge views of social reality. One challenge in analyzing lesson plans was in making connections to the interviews, open discussions, and student work samples. A sampling of thematic units and lesson plans was analyzed, using a template checklist designed to feature elements for analysis such as decision-making strategies, recurring instructional techniques, frequencies, omissions, attention to content standards, and evidence of constructivism. Lesson plan analysis was conducted to gain insight into planning trends that emerge over time.

\section{Coding Procedures}

Coding procedures for data analysis of teacher narrative stories included codes for the interview questions. Initial Interview was coded as II followed by teacher first initial, and the date of interview. For example, the coding for teacher narratives for the first interview might 
look like the following: (II-TA-4.23.09) This code would be interpreted in the following manner: The initial interview for teacher, Antonella, on April 23, 2009.

\section{Data Findings and Graphical Representation}

Data were examined for teacher insight into analysis of relationships, salient research points, and patterns. Any themes that emerged were in narrative story fashion throughout the study and were considered relevant in the hermeneutic research design. When data did not meet the parameters of case categories and sub-categories, the researcher returned to clarify the documentation of interview and discussion tapes, lesson plans, student assignment document analysis, and interview transcripts.

\section{Insuring Trustworthiness and Research Study Credibility}

Strength of this study was insured through triangulation of qualitative methods for collecting the data. Denzin (1978) identified four basic types of triangulation. This study used the data triangulation approach to analyze a variety of data sources: interviews, open discussion of student artwork, and lesson plan documents. Using multiple methods promoted assurances against the vulnerabilities associated with only one method (bias, untrue or incomplete responses) and provided validity checks. The multiple methods approach fortified the researcher and the study with "an arsenal of methods” to limit weaknesses and to compliment strengths (Brewer and Hunter 1989:17).

By writing each teacher's story in her own voice, the research participant’s story was re-told with accurate details and research integrity. Approval of the Institutional Review Board (IRB) was granted by the university, sought in advance by providing thorough and accurate details such as who would be interviewed and the specific questions to be asked. This qualitative study connotes the central activity of fieldwork. Interactions with people in their 
own environments provided the researcher and participants with an opportunity to develop a sense of shared experiences (Patton, 2002).

The initial open-ended interview served the purpose of setting the stage for trust. Teachers had the opportunity to respond in their own terms and from their own perspectives. The open discussion of student products connected researcher to teacher and students, and shed light upon teachers' use of student work in the arts integrated classroom. The methodology relied upon the teacher as “expert in the classroom.” Building upon Elliot Eisner’s mode of evaluation and research called “educational criticism and connoisseurship” allowed the research participants to offer their insights on what actually takes place in that "third space" of teaching and learning. They were able to express their insights through paintings, plays, and other forms of artistic representation (Uhrmacher and Matthews, 2005). The second, follow up interview, with four semi-structured questions, made no presumptions and gave teachers freedom to answer from their full range of knowledge and understanding. Teachers brought their classroom curriculum and instruction to life through the process of thoughtful lesson planning. Through this research, documents anchored a teacher to the instructional decisions made on behalf of students in a classroom setting.

\section{Summary}

Eight teachers from three schools in a public school district completed the cycle of multiple methodologies: open ended initial interview, open discussion of student artifacts, a follow up semi-structured interview, and lesson plan analysis. Lesson plan and discussion about particular arts integrated student products that these teachers used in their work was included in the triangulation of data. Teacher selection was based upon willingness to 
participate, affiliation with integrated arts instruction, and experience as elementary classroom teachers. The goal of this study was to examine teacher decision making upon the implementation of an integrated arts curriculum.

Results of the data for this study are presented in narrative fashion in Chapter Four. The first section includes data from one teacher at Bickle Creek Elementary, a large rural kindergarten through fifth grade elementary school. Data from two teachers at Riffe Park Elementary, a small rural kindergarten through fifth grade elementary school, comprise section two. Data from one teacher and four retired teachers from Selena M. Day Primary School, a small rural pre-kindergarten through third grade are presented in section three. Finally, section four consists of the prominent themes set forth in the four research questions and pertinent connections to teacher narratives on decision making that emerge from the hermeneutical study analysis.

Chapter Five presents the findings from this study in a discussion of the evidence of data analysis and emerging themes. Chapter Five concludes with a discussion of the implications for practice, policy, and future research. 


\section{Chapter 4}

\section{Data Narratives}

Hearing and reading teachers' professional classroom exchanges make for a rich hermeneutic methodological study. In this chapter, read the stories of eight elementary teachers as they trace their journeys of professional development through their teaching experiences. Take their offerings of understanding and clarity to gain insight into what commands their attention when they make decisions to integrate the arts in classroom instruction.

Experiences and professional developments that I have encountered throughout my teaching career are described in this dissertation as shared experiences that are important to the integrated arts perspective. My teaching narrative is interspersed with theirs as additional biographical narrative to expound upon how I see that picture and how the other person sees it. My personal and professional biography and reflections are written in Arial Narrow Bold font and correlate to the same question frameworks of the eight research participants. My involvement in the narrative adds a dimension of personal challenge to this dissertation research.

I work to strike a balance by connecting my voice and career involvement in arts instruction to the vested interest I have in the results of this research. This tension-resolution is metaphorically like a musical suspension. The new edition of the Oxford Dictionary of Music defines a music compositional device called suspension in which a note in a chord is held over, sounded slightly late, as a momentary discordant part of the combination that follows; then it falls a degree to a note that forms a part of the second chord. The dissonance resolves to the pleasing tones of the real second chord. To the listener, the dissonant notes of a music 
suspension create interest, tension, and desire for resolution. In a similar manner, the reader of this dissertation experiences eight teacher narratives connected to the researcher's voice. All voices will present connections and scenarios that may seem remarkably similar, despite divergent circumstances.

Triangulating the other data sources, student arts-integrated assignments and teacher lesson plans with the teacher interview narratives, adds breadth and depth to each biographical narrative. Throughout the eight teacher narratives, I describe both how I see the picture of arts integration and how the other person sees it; I do so by interspersing my story with theirs. Part of this chapter presents how I see the overarching picture of arts integration from my multiple perspectives as teacher, administrator, and curriculum supervisor, and how each of the eight teachers views arts integration as integral to her classroom instruction.

I answered the interview questions in order to gain understanding of the same struggles or insights that the participants experienced. Initially the interview experience felt contrived. Answering the questions, however, helped me to realize that my investment in these questions exceeded the purposes of this dissertation research.

Throughout my teaching and administrating career, I have invested in my students, my colleagues, and myself. The questions made me feel like an accomplished teacher and at the same time, a struggling teacher. For example, I struggled with answering the questions about student motivation and accommodating students with special needs. I am a reading specialist and making interventions for struggling readers is paramount to my work. Integrating the arts into reading was easy and fun because we created plays, illustrated stories and poetry, and performed the folk dances of cultures around the world. It is not easy for me, however, to identify how student motivation impacted my curriculum planning and instruction. Looking 
back through my teaching experiences, I believe that any responses I had to their motivation were unconscious teaching decisions made from solid lesson planning skills such as following the teacher manual and seeking outside resources such as websites and resource books. I wish I could say that I focused upon student motivation to help me with curriculum and instruction decisions, though I honestly can not.

Another aspect of the self interview experience that I struggled with was the "attributes that characterize an arts rich teacher” question. I was privileged to experience music and art as a young learner. This advantage pricks my conscience, especially now that I have interviewed the eight research participants. When Antonella said she did not have many arts experiences as a child, I felt guilty that I had so many opportunities, and I was sad that she did not. Then I realized that lack of experience with arts was probably the norm for most teachers and students. As an administrator who has opportunity to plan and design professional development for a school system, I have unfinished work.

There was a great deal of satisfaction in answering the questions about professional growth and development and methods of reflective practice. Investing time and monetary resources to extend my professional growth and development was always a priority. Answering these questions gave me a chance to retrace my professional pursuit to become a more knowledgeable educator. I remembered the days when it was a financial strain to pay tuition and to find time to study because being a young mother and a working professional was a balancing act. Answering the interview questions put me in touch with eight research participants, but more importantly the questions connected me to my past teaching experiences and to their present ones. 
Each teacher brings a unique set of skills to make arts come alive for his/her students. As you read all of the teachers' stories and their student assignments, look at their lesson design and planning strategies. Try to reconnect to your own educational past and classroom experiences. Consider the instructional setting and planning decisions that were specifically prepared for you and your classmates by your teachers. Think about those arts integrated lessons that most inspired you, thrilled you, and energized you. Decide for yourself if any experiences with arts integrated lessons changed your life or caused you to make a career choice, even led you to community involvement or still continue to influence you today in your recreational choices or your philanthropy.

In this reflective exercise, the research conclusions that are presented in Chapter Five may broaden the connections, understandings, and realities between you, the researcher, and the eight educators whose decision to integrate the arts has impacted student achievement.

The eight teacher narratives that follow are presented through a framework of two sets of questions that focus on teacher decision making in four over-arching areas characterized as the Big Four framework: curriculum, instruction, decision making, and reflection. In two semistructured interviews using one-on-one and focus group formats, teachers provided insights into their classrooms, discussed their arts integrated classroom assignments, and provided lesson plans that comprise the research data for this dissertation. As researcher, public school elementary and middle school teacher, reading specialist, musician, and curriculum administrator, I wove my own story of arts integration into the tapestry of rich biographical data of descriptive subjective experiences. The study seeks to contribute to the research on “What commands teachers’ attention when making instructional decisions?” 
This chapter presents the data in a design flowing naturally from the eight teachers’ stories, available lesson plans, and student assignment samples. Although the question framework was created to guide the interviews and seek teacher perspectives, teachers launched from questions directly into descriptions of their classroom integrated arts assignments. Teachers’ own frameworks related to their discussions about their students' arts integration samples.

\section{University Resources}

The university’s support for public school professional development was a resource in which educators from both institutions actively benefited. Advantages of this participation for the public schools included availability to educational relationships with university experts; access to university facilities, libraries, and cultural centers; invitations to participate in action research; and specific coursework designed to promote the arts in the public schools and the community. This dissertation's research participants availed themselves of the university’s professional development opportunities through courses that promoted creative expression in their classrooms and in professional development collaborative cohorts through the College of Human Resources and Education. Each participant related her perspective of the benefits gained through opportunities and relationships with the university.

The power of a shared vision for schools and community emerged throughout this research. University experts viewed public school teachers and the school system as a valuable resource for preparing preservice teachers. Working together provided an opportunity to develop stronger lesson planning strategies, a more focused curriculum design, and a place where the arts could be integrated into core content with integrity and accountability. What 
developed were lasting relationships among teachers and learners, a chance for the arts to thrive in elementary classrooms, and students whose lives were enriched through their participation in arts related activities.

Largely responsible for the increased awareness of arts integration in elementary schools was university professor, Dr. S., who recognized the need and provided the opportunity for teachers of grades preschool through sixth grade to receive professional development coursework through the university. Dr. S.’s course maintained high standards for its participants that (as described in the syllabus) “included the use of creative arts in learning activities, curriculum development, and instructional strategies. Course experiences (see Course Syllabus Appendix E) included teaching with, through and about the arts.” This work was supported through funding through the Professional Development Schools network housed at this university. Teachers who participated in the course were guided by eight objectives for developing arts integrated classroom instruction. Some of the objectives included: Roles of the arts in pre-kindergarten through sixth grade education; integrating arts into content areas; using arts for aesthetic education; using arts to develop creativity; supporting diverse learning styles and multiple intelligences of students; involving children’s families and school communities. Research participants spoke with an unconscious awareness about those objectives that had become embedded in their set of teacher skills and strategies.

\section{Community of Madreas}

\section{Madreas County}

Madreas County has a special appeal to me because I received my master's degree at the major university in the heart of the county seat of Madreas County. Little did I know back in 1973, 
freshly graduated with my undergraduate teaching degree from my home town college and embarking on the next academic level, what the future would hold. Here I was, commuting to this big university town, studying in the creative arts center to earn my Master of Arts degree in music education, grades K-12. Unbeknownst to me, 30 years later I would find myself full circle in my career and returning to live in this university town.

Living in the community offered many cultural opportunities. I liked participating with the citizens of Madreas County in many of the community activities: skating along the rail trail path, enjoying the Army band's Fourth of July water front concert, walking in the parks; watching college students play guitars; attending public concerts, plays and arts exhibits at the creative arts center theatre. These experiences and more provided important schema for my collaboration with teachers and the school system. My experiences and life circumstances are woven into this research, and I write them from my personal lens as educator-musician. Time has passed quickly and kindly, and now I have the broader perspectives of my years in the teaching profession, the blessings of children and grandchildren, and an understanding of critical links among business community, schools, and parents.

Madreas County, population of 88,000 , is nestled in the north central region of a state located in the eastern United States. We are just 60 miles from a major metropolitan city and boast a superb small metro area for business and careers. This proud university community has a competitive sports program. The community has a general hospital, municipal airport, a public library system with four branches, a major research university with 28,000 students, a medical research center, and a creative arts center on the university campus.

Madreas County hosts a thriving arts association composed of artists, public and business officials, and community volunteers who work collaboratively to improve its community. The arts association is committed to providing local events that promote arts 
appreciation through dance, dramatic and performing arts, literary arts, music, and visual arts. The association hosts a website with a calendar of events and is completing a study on the economic impact of arts patron spending. Spending in 2005-2006 totaled \$4 billion and impacted 73 jobs for a total of $\$ 750,000$ in employee compensation. The arts are important to the schools and community in Madreas County, and the community is a pillar of the research for this dissertation.

\section{Madreas School District}

\section{Madreas County School System Demographics}

Madreas County is the state’s seventh largest county in student population, with 10,221 students, pre-kindergarten through twelfth grade. The district's 20 schools are comprised of 12 elementary schools, 4 middle schools, 3 high schools, and a career technical center.

Instructional staff boasts an average of 16.3 years of experience, and $33 \%$ of the teachers have master's degrees plus additional 45 hours. The teacher-pupil ratio is 1:15.

Madreas complies with state accountability standards for attendance (97\%) and graduation rate $(84.8 \%$.) The dropout rate is 3.9\%; there is a $38 \%$ low income rate. All of the schools in this study have met accountability standards, but only Selena M. Day, a primary school, has had a perfect record since 2005. Teachers in this study discuss test scores and accountability in relation to arts integration. Education is faced with high-stakes accountability testing, public attention, sanctions, and increased demands on teaching and assessment. Looming in teachers’ minds are justifications and rationalizations for instructional decisions, and this research centers on what commands teacher attention to integrate arts instruction. 


\section{Long range strategic planning for Madreas County School District.}

VISION: "The Vision of Madreas County Schools is to provide the community with an exemplary educational environment that promotes individual development, intellectual growth, and responsible citizenship."

Board Adopted: 10/13/98

The state mandates districts and schools to annually revise their long-range strategic plans. The school system’s Mission, Vision, Belief Statements, and Core Principles demonstrate a thoughtful and reflective position on teaching, learning, and community. At the heart of Madreas' strategic planning are commitments to students and community. For example, in the paraphrased Mission Statement, notice the italicized elements that are student and family centered. The public school system's mission expresses commitments to the intellectual, academic, and cultural aspects of community living. The over-arching framework includes arts integration. Teachers speak articulately about their involvement with parents and community in Madreas’ mission statement:

\section{Madreas County School System mission.}

To work cooperatively with families and the community to ...

- Help all students achieve; promote lifelong learning; accommodate individual differences

- Prepare students to assume roles as productive citizens

- Offer curricula to facilitate students' future employment

Board Adopted: 10/13/98

Amended: $3 / 9 / 02$

All community members and parents dream of having the best educational opportunities for their children. Parents expect only the best that schools have to offer, and many become personal advocates for assuring their children's success. A high expectation is placed upon teachers to provide for their students. Some teachers bend or even break under the weight of these expectations. We know that our students connect our schools to the future. Our learners 
lead us into a growing community, and when they receive strong, nurturing educations from the school system, there is a contribution in return to the community.

It behooves a school system to invest thoughtfully in developing the strategic pathways of its work with children. In doing so, a strong and important message is sent to all stakeholders: the work of all educators is work that is important enough to evoke critical thought. Planning begins with decision making. The work must be thoughtful, visionary, and with a mission or purpose as a torchlight. Madreas has constructed a set of eight inclusive belief statements to encompass the important work of education. The district models for its schools in strategic planning processes. Following are Madreas County belief statements as paraphrased and italicized with key words that articulate the district's stand on teaching and learning:

\section{Madreas County School System belief statements.}

- Educational programs provide equitable access to all stakeholders

- Learners will become life long, independent, and self-directed

- Students are prepared to assume role as responsible citizens

- Educators demonstrate a commitment to excellence, creativity, and high expectations

- Meaningful collaborations link partnerships with parents, business, industry, higher education, community at large in order to enhance the educational process

- Parents, students and school system share responsibility for student success

- Safe educational environment permits all stakeholders with a sense of belonging

Board Adopted: 10/13/98

Amended: 9/24/02

Data gathered for this study focus upon decision making as related to teaching for student achievement, learning academic content, building effective community, and purposeful reflection. In the research narratives, each teacher explains and defends her rationale for making content decisions while planning and teaching arts integrated lessons. With the district focus on specific elements including learning content and community involvement, the data 
analysis can focus upon identifying a planned or an incidental influence of Madreas district's mission and vision. How or in what ways will the district's strategic planning process influence each school's strategic planning? Will the school's mission, vision, and beliefs transfer an influence upon teacher decision making?

In the forthcoming discussion of the three elementary schools is a description of each school's long-range strategic planning vision, mission, and core beliefs. Knowledge of the school culture and insight into the vision for student achievement are key to a deeper understanding of the teacher narratives and the impact of planning and instructional decisions. District and school planning strategies are lessons that look at connections among and between district, schools, and teacher decision making.

\section{Bickle Creek Elementary School}

\section{Demographics}

Turn off exit 15 and take a leisurely drive 10 miles from the interstate highway. Meander along the well-traveled, winding country road that parallels little Bickle Creek. Just before coming to the volunteer fire department, make a sharp right turn and drive up the lane to Bickle Creek Elementary School. The spacious school complex opens out into a nice clearing where parents have ample parking to pick up their children, busses can line up without paralyzing community traffic patterns, and teachers have their choice of parking spaces. A sprawling field behind the school house is where children's recess seems like heaven, and you can chase your partner in a game of tag, climb on playground gyms, and kick the soccer ball in the fresh air and sunshine. 
Bickle Creek Elementary is a pre-K through 5th grade school with 463 students and three teachers per grade level. Teachers average 17.8 years of experience, and $35 \%$ have master's degrees plus an additional 45 post graduate hours. The average class size is 18.4 students. Bickel Creek has a 2.6 retention rate and $46 \%$ low income population. Special area teachers include four Title I reading specialists, four special educators, a Reading First mentor teacher, a library media specialist, a physical education instructor, a school nurse, an art, and music/band teacher. Bickel Creek accountability progress since 2003 and up to 2007 resulted in a “meets standards” designation. In 2008, the school did not meet AYP standards for the first time since the inception of No Child Left Behind legislation.

\section{School Culture}

Walk into the bright hallways of Bickel Creek Elementary, fully accessible, and you will see a clean, orderly and learning-focused environment. Student artwork lines the hallways. Students move purposefully along the corridors. On any occasion, a guest in the building is greeted by a staff member offering a visitor's pass and sign-in clipboard. A culture of courtesy, order, and learning permeates the building.

Bickel Creek offers website links that are just a click away, where web guests are treated to class and grade level dramatic productions. A school website features links to class plays and reader's theatre productions replete with back drops. Students don character masks and read narrations full of content about the ocean, jungle, desert, and mountains. A strong sense of community collaboration exists with relationships among six business partners including a local fast food restaurant, bank, health system, bowling lane, and the state public theatre production company. 


\section{Antonella of Bickle Creek Elementary}

A teacher's beliefs about students' chances of success in school influence the teacher's actions with students, which in turn influence students' achievement. If the teacher believes students can succeed, she tends to behave in ways that help them succeed. If the teacher believes that students cannot succeed, she unwittingly tends to behave in ways that subvert student success or at least do not facilitate student success. This is perhaps one of the most powerful hidden dynamics of teaching because it is typically an unconscious activity

Marzano, 2007

\section{Portrait of a Kindergarten Teacher}

Antonella’s kindergarten classroom is transformed into an academic playground with life-size ponds, clay sculptures of sea creatures, illustrated writing, finger paintings, and “creation stations” full of pieces and parts of craft materials and art supplies. There are no desks and rows in her classroom, only tables where children and the teacher collaborate on learning. An energy that is almost tangible flows amongst the students and their teacher. Antonella's sonorous voice becomes the musical background for teaching and learning in a bubbling room of five year olds. She maneuvers throughout the classroom with just the right grace and proximity to engage the students' attention. When one child asks a question, suddenly that student becomes the most important person in the world of her classroom. Anyone observing Antonella knows this because she leans forward, making eye contact and nodding at each word the child expresses.

Antonella's fourteen years in the classroom and her master's degree in early childhood education have shaped her command of academic content and her wisdom in early childhood growth and development. Antonella is certified to teach elementary and early childhood education, newborn to kindergarten, with teaching experience in grades pre-k, kindergarten, happy school, first, and second grades. She stayed in Madreas County to earn her education 
degrees at the research university. Antonella has kept professionally involved by participating in her district's teacher leadership cohort, her local professional teacher's association, and the school's commitment to professional development through the Reading First initiative. She was distinguished as the local news publication’s “October Teacher of the Month.” Antonella’s prior involvement in the arts was as a member in her middle and high school band where she played flute.

\section{Initial Interview Question \#1: Curriculum “How do you decide what to teach?”}

\section{Antonella’s curricular decisions.}

In trying to determine what commands a teacher's attention when making teaching decisions, there may be one major thing, or maybe many different things. Antonella offered her own perspective and gave a clue in the first few words she spoke: “First of all, it's the state content standards and objectives.” (CSOs). Her organizational scheme is to group the state standards in folders and correlate them to the teacher manuals. It is part of this school's culture for teachers to collaborate. Antonella values the times spent planning with her kindergarten team mates deciding how to deliver instruction from chapters in the core textbook. She said she usually teaches in order of sequence provided by the teacher manual. She explains, "So looking through the CSOs and at the art and music CSOs that are included on the website, from that I can tell what to teach, too, and even get some ideas for things to add to my own lessons." (II-TA-4.23.09) By staying grounded in the standards for curriculum and augmenting these lessons, Antonella has found a way to have ownership in her curricular decisions, while maintaining fidelity to state and district established procedures and policies for teaching standards. 
Bickle Creek is a participating Reading First school. Reading First program goals are established to increase reading instruction in the early grades, beginning with kindergarten. States receive funding through a grant writing process. Funds are to be used by states and districts. Participating in a national movement to improve reading for students in grades K-3 is an example of a curriculum-driven, school-wide initiative. Antonella’s thoughts were distinct and insightful, yet revealed some of the other externally imposed influences that teachers face in their curriculum decisions.

Also, Reading First I think has also been a big part of deciding what I have to teach because a lot of phonics awareness now has been placed upon it. No regrets, because I think it has been wonderful, but those are the things that have made me decide. That's how I decide what to teach. (II-TA-4.23.09)

\section{Initial Interview Question \#2: Instruction: “How do you decide how to teach?”}

\section{Antonella's instructional decisions: The art of provision.}

When posed with the question of deciding how to teach a concept or lesson, Antonella explained that a number of considerations are in her decision making skill set. These considerations came flowing forth naturally in her description of how she was going to teach a concept. She expressed herself in a checklist of instructional dynamics that included providing for student needs, group instructional needs, length of time per class period, subject matter to be taught, preparation for fun lessons, themes.

I want to make sure how I'm going to teach. It is the age level of the children and the interests that they have; the attention spans that they have. I have to look at whole group settings. I have to look at small groups. We have a whole group for almost forty-some minutes in the morning. We go to five stations 
every day. Those five stations are all different. They change daily, and I incorporate all five of the reading components that we need to have. So, not only am I trying to do it in whole group, but you try and make something that is not carbon copy at the stations as the kids go from one to the other.

I have an essential question of the week which relates to reading, and that also helps me decide how I am going to teach other things. And then in math I make sure that I have three centers in math. I need to make sure that I have stations ready for that. I want it to be fun. I want them to learn something. I want them to be able to do some problem-solving, whether it be individually or as a group. So, that's pretty much how I decide how to teach. I look at the overall theme of the week and go from there. (II-TA-4.23.09)

Initial Interview Question \#3 Decision Making: “What professional development do you seek and how do you use these skills?”

\section{Antonella's professional development decisions.}

Teachers have a challenge when trying to achieve content standards-based instruction and to provide instruction that is outlined in the core textbook program. It becomes a balancing act to fit the sciences and social studies, the writing and language arts into the taught curriculum. Antonella explained that her solution is an efficient one that is contrived from looking at thematic possibilities. Although well thought out, she admitted that integrating the arts into content is not a simple process, but rather one that takes commitment, creativity, and follow through. She used the textbook's organizational structure and pacing guide in a way that works for her arts integration planning. 
Our book is, you know, divided up into themes and it happened to be environment, so I just try and say, “What can I do with environment?” I pretty much just go with the theme and decide what I can pull to use in writing and science and math and reading. It's tough. It's tough to decide. We did put the pond in so we thought, well ... writing. So let's go ahead and use water color. Water color the pond, you know. So, we water colored. What did you see? We gave them the day to look at the pond and all that was in it. The next day we water colored. Then we kept the paintings and said, “OK, let’s write about that. What can we write about the painting that you made of the pond?” Then we decided to go ahead and just make the environment so that they were able to relate it all together to science. Tomorrow we are going to use microscopes and actually pull out some pond water to look at. (II-TA-4.23.09)

\section{Initial Interview Question \#4: Reflection: “What does the community say about your arts integrated teaching?”}

\section{Antonella's instructional decisions: Community.}

Antonella understands that immersion for her kindergartners is an important aspect in their developmental learning. When they study an alphabet letter, she looks in the dictionary to see what possible words are there. If studying "W" there's the waltz. Students have to be up moving, so it seems natural to teach them to make up a sort of kindergarten waltz, pulling in classical music. "W" also includes West Virginia, a heritage that is rich in clogging. Inviting community cloggers to dance for the class builds relations between students learning and adults teaching. Antonella admitted the importance of reaching out beyond her classroom when she says, "It's fun for us. It's fun for the teacher aide and me, and its fun for the kids. Who matters 
most in the community are the kids and what they take back, and when their parents come in.” (II-TA-4.23.09)

A sense of community rounds out Antonella's instructional approach to the curriculum and to her students. She acknowledges her purpose. She knows her clients. She commands her curriculum.

The kids are number one. I put that as my number one client! They are the kids. Parents ... I've received great compliments from parents about what goes on. A little different, though, when it comes to my colleagues. We're so stuck in this copy-paper ditto. "Got to do these worksheet things.” Sometimes colleagues come in and go, “Well, you really shouldn’t be doing that in reading.” Then it’s like, “No, it fits. If I can justify how it works, then let me show you what I have.” I still hear it. I still hear it, you know. I'm not really so sure that people even know what goes on sometimes. I mean, even from the upper. I don’t think it’s even taken into consideration. Come down and see what we're doing. Let me show you how this works. Yes, take a walk in my room, and let me tell you why we did this. Actually, let me ask the kids to tell you why we did this. (II-TA-4.23.09)

\section{Antonella's professional development decisions for incorporating}

\section{activities into instruction.}

Teachers seek to scaffold their learning and often using their resources including energy, time, and money. In a college town, opportunities are available to foster collaborative relationships among teachers, professors, and administrators. Antonella met a university

professor, Dr. S., and together they fostered a learning community bond that demonstrated 
positive and energetic relationships. Teachers learned about integrating the arts and were invited to be project participants. Teachers became learners. So committed were they to the work and to each other that they agreed to meet on Saturdays. Part of their learning community was sharing and modeling quality arts integrated lessons. Additional affiliations in learning communities included completing the requirements for professional development in Reading First through which colleagues participated in 100 hours of professional development. Some of the activities included reading professional articles, writing reflections, and having collegial conversations around book studies.

My Reflections

I have thought a great deal about that energy and have, over the course of my career, come to recognize it in my teaching and in my observations and stories of other teachers with their students. One such example is Erin Gruwell and her "Freedom Writers." In the year 2001, when I was working to attain my National Board for Professional Teaching Standards (NBPTS) certification, I had an awareness of this unmistakable energy between the students and me. It started with a Christmas holiday Appalachian social studies unit in which l'd invited a local musician to visit a class of second graders three weeks before Christmas. In the preparing of this Appalachian unit, I had to research local artists, history of Appalachian music, instruments crafted by local artisans, and more. At this point, I was the student navigating the wave of my own learning curve. I was striking out on a course to gather all of the basic and peripheral knowledge about the subject I wanted to teach. I experienced a self-motivated form of energy as I browsed websites, contacted local citizen-experts, and read history and local culture.

We planned a full day of interactions with the various musical instruments. Our guest musician demonstrated how to play fiddle, spoons, wood blocks, mouth harp, strummed and hammered dulcimer. I noticed a type of energy coming from the students. I could try to 
characterize it as excitement, attention, intrigue, or motivation, but that energy was present among performer, teacher, and students.

My quest for knowledge to share with my students was only the starting point, though. In order to transfer that knowledge to the students effectively, I had to rise to a level of blending skill and artistry. I had to plan and orchestrate the best design for utilizing the teaching and learning resources for my students. The work of teaching required me to consider how to introduce and pace the scope and sequence of the unit information. It took personal time to find ways to connect the community and instructional resources into the lesson plans. Plan and design were only a scratch upon the surface of the instructional unit. I had to facilitate student engagement, assess the effectiveness of the lessons and student learning. In all of these multiple roles, I expended personal resources, energy, time, and money. It was a time of giving forth, my choice to spend my resources.

In my reflections throughout the unit, I noticed that students received the energies of my efforts to plan and deliver an arts integrated lesson. As learners, they accepted instructional design as if it were a product of carefully designed content, activities, guest expert, and research products. Their inquisitiveness resulted in a desire to learn more and work together with a zeal for new learning. As the students processed my energy offerings through the stages of learning, they converted and transmitted that energy in their own form and sent it right back to the teacherlearner decision. Depending upon the dynamic of the lesson and depth of content, the exchange can become cyclical as teacher and learner continue to extend the teaching and learning throughout the classroom and into the school and local community. 


\section{Antonella’s Comments on Student Artwork}

Antonella and I both articulate that certain energy among a teacher and her students in our story narratives. We can describe how we begin by researching for deeper knowledge on content. Our lessons have the power to go beyond the four walls of the classroom and right into the community. We plan lessons that take commitments of time, energy, and resources. We do all of these things for our students' benefit. Learners take the preparations offered by their teachers and process them into a reciprocal type of energy in the form of interest, intrigue, motivation, enthusiasm. So in the initial interview, I asked Antonella to talk about her students' reactions to a unit she taught on the environment. Using a large plastic children's swimming pool, the teacher and her students set up a pond, center-stage, and right in the middle of the classroom. Not on the sides or in the back of the room, but right in the middle. They gathered stones, branches, goldfish and more. Students had created an ecosystem. The pond became a source of learning extensions:

Oh, they loved the pond! Anytime we can do any of that learning . . . Just yesterday someone said, "I really think it could use a waterfall." So then the secretary walked in and I said, “The kids need a waterfall.” Well, she brought that waterfall, which is behind that plant, but I'm not so sure I have electric to hook up that pump. But they just add to it. They just love it. They go home and share, then the parents will come in and say, "We heard there is a pond." The kids just love it, and I love it as much as they do because it's just so fun. It's fun for me to go home and plan, it really is. Though it's also tough, because to know you're going to come in and show them something that they’ve never been exposed to before. It's just a treat! You are excited to 
come to work. You really are, because you just can’t wait to tell them what we're going to do today. (II-TA-4.23.09)

Antonella used an integrated arts approach to extend her environment ecosystem lesson. Her students worked in cooperative learning groups to create dioramas using materials and supplies from the supply bins. Antonella calls it her creation station. "We put it within the reach of the students as they are designing or creating a project from which they can write or record some facts or an interesting story.” (II-TA-4.23.09)

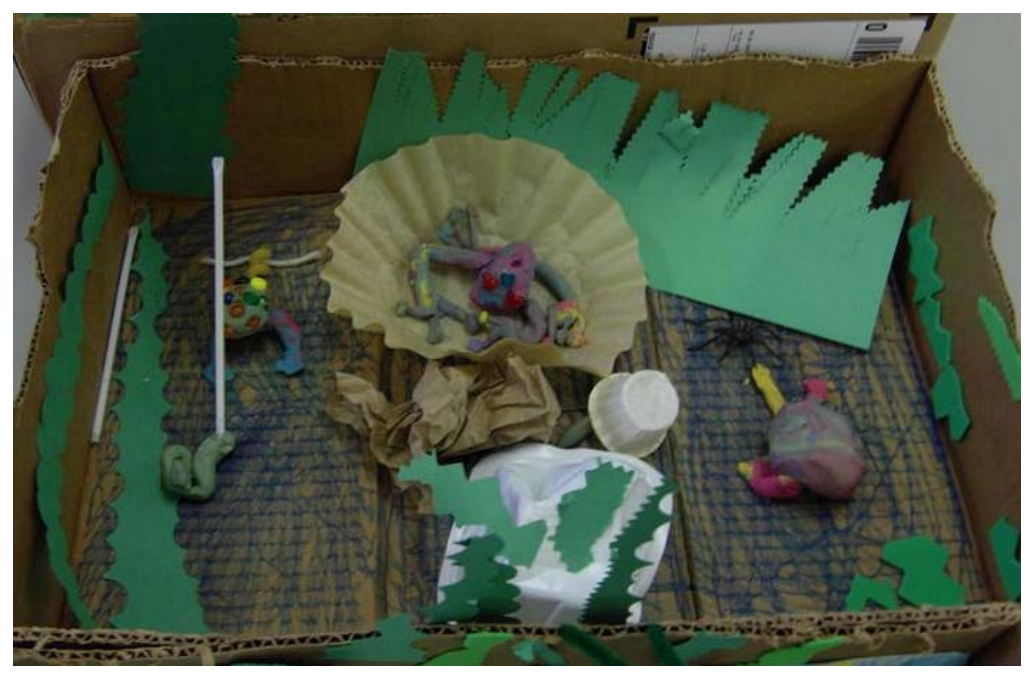

Figure 1. Arts Integrated Science Lesson Diorama. Students created a diorama using materials from their creation station. The science lesson was an extension of student learning on ecosystems.

\section{Artwork Connections to Four Over Arching Questions}

Using the four over arching interview questions of curriculum, instruction, reflection, and community, the matrix for discussing student artwork, teachers connect decision-making to student work samples. The following table takes the matrix checklist items and summarizes the categories of teacher instructional decisions that can be seen in student lesson samples. 


\begin{tabular}{|l|l|l|l|}
\hline \multicolumn{1}{|c|}{ Curriculum } & \multicolumn{1}{c|}{ Instruction } & \multicolumn{1}{c|}{ Reflection } & \multicolumn{1}{c|}{ Community } \\
\hline $\begin{array}{l}\text { Reading/Language Arts, } \\
\text { Science }\end{array}$ & Text interpretation & $\begin{array}{l}\text { Aspiration, confidence, } \\
\text { esteem }\end{array}$ & $\begin{array}{l}\text { Community service, } \\
\text { conflict resolution, } \\
\text { Social problem solving }\end{array}$ \\
\hline
\end{tabular}

Antonella determined that the curriculum would be core content areas of reading/language arts and science. Her core curriculum, content standards, and teacher’s manual as a resource grounded her decision to teach this lesson. Through the arts integrated assignment, a diorama, students conveyed an understanding of science by including the elements from the pond environment. Kindergarten students have taken the knowledge gained from teacher instruction, trade books supporting the topic, pictures, and discussion to interpret content knowledge through their artwork. Integrating the arts provides an opportunity for students to express knowledge gained through instruction in a manner that builds confidence and esteem. Their aspiration to replicate a model of the pond environment studied in the classroom comes forth in their diorama. The implications for community come through teacher guided discussions about how to care for ponds, to observe what is happening with the plant and animal life in the pond environment. Student groups worked together to build the diorama and were able to problem solve and arrive at conflict resolution.

\section{Follow up Interview Over Arching Question \#1: Demographic setting and professional} attributes of an arts rich teacher.

\section{Antonella's self-characterization of professional educator.}

The portrait of a teacher is blended from the palate of rich experience and unique personal attributes. These attributes have the potential to shape a teacher's views and thereby her decisions. During the follow up interview, the first over-arching question asked the teacher to describe herself as a professional educator. 
Antonella conveyed how she felt about flexibility and change. "You've got to be open and willing to change. We can't get stuck in that rut.” She characterized herself as a teacher who likes to let the children express themselves in all ways.

I like to let the children express themselves in all ways. That, to me, is one of the most important things, and by doing that, they learn so much. You don’t realize how much they're learning when they are actively involved in a lesson or dancing or moving to music around their paintings. It's surprising to me sometimes when I go back and have to do assessment testing on them and see how quickly they are able to master the content. You know, you think you know how to do a lesson. No, you can always add so much more. The manipulative and the tactile part of learning is just incredible and what a difference it made this year. (IF-TA-5.12.09)

\section{Antonella's personal experience with the arts.}

Antonella's own personal experiences from childhood are reflected in her integrated arts classroom. Many educators think that a teacher must be an art or music teacher, or have experience in dance or theatre in order to provide students with arts learning experiences. Antonella talked openly about her own arts background from childhood up to being a parent: I love the arts. I played flute when I was in high school and was part of the band. I love music ... all kinds of music ... do a lot of concerts. My own daughter was real big into theatre, so I've attended practically every production she's done. She will graduate with her degree in puppetry, so if that's a tale of anything. I have gained insight into the arts by going to her theatre events. (IF-TA-5.12.09) 


\section{Antonella's professional growth and development.}

Teachers gathering together in professional learning communities thrive on their conversations about work. Many times they become inspired to retrain and retain their skills as a result of working and collaborating as a staff, independently, or with courses in higher

education. Antonella's affiliation with Dr. S. and the integrated arts class work is another way she had demonstrated her willingness and initiative for professional development.

I have done some conferences with Dr. Jean who does a lot of music. I went to a conference out of state which covered a lot of topics on differentiated instruction. Using the arts in that, you are really being able to meet the different levels that these kids have. As for the required 100 professional development hours required for teachers in a Reading First school, it will be nice not to be dictated, you have to do it. But I can foresee still, you're still going to look for ways, especially when you get little people. You're confused about what they need. (II-TA-5.12.09)

Dr. Jean Feldman is a nationally renowned educator whose 35 years of expertise in working with early childhood teachers and children has earned teachers' respect. She is a well known author and consultant.

\section{Antonella's reflective practice.}

Teachers often want to be aware of the most current updates and changes in education. The process of personally assessing what areas of development would foster professional expertise is part of a teacher's ability to exercise personal reflection. Antonella had the following to say about her own reflective practice: 
That is something I'm not real great about doing. When we were in college we had to reflect on lessons. I kind of miss that because I don't take the time to reflect on either a lesson or the whole unit. Now there are things I'll " $x-$ out” because I knew it didn’t work. Or, I'll look at my kindergarten aide and go, "Well, that's something we're not going to do anymore.” Other than that . .. that's an area I'm weak in—actually reflecting on things. The best ideas come from talking with each other. Tried and true. Share an idea. (IF-TA$5.12 .09)$

\section{Antonella's classroom teaching context.}

Antonella's kindergarten classroom is a spacious teaching and learning environment with lots of windows to lend brightness. There are no desks and rows, but tables and chairs are arranged in station locations throughout the classroom. The central classroom area is surrounded by learning materials and books. Children hang their coats and book bags in the back vestibule that opens out onto a concrete patio in the back of the building. Her classroom maximizes space. Learning stations are clearly defined, and she discusses her choices about the room setup:

Lots of space, I do like that. I don't like clutter. A lot of places I might be called a little too organized, but I do like for them to be able to move around a lot. I don’t want to bump into things. I try and put my centers where they work. The reading center where it's quieter is away from the busy middle center. Then over here when we cook and things are next to the kitchen. And I change every year. Sit down and rearrange. My student groups are determined randomly. I try and look at levels and mix my students in to the groups, changing throughout 
the year as students get to know each other more. My schedule includes five learning stations in the morning that make up the reading components. For math, we are more relaxed ... pick and choose ... one potato, two potato, then off to our stations. (IF-TA-5.12.09)

\section{Follow up Interview Over Arching Question \#2: Arts integration and the influence of job satisfaction, commitment, autonomy, and change.}

\section{Antonella's commitment to arts integration.}

Teachers' beliefs and attitudes are important to the profession. These beliefs and attitudes define the knowledge and experience that portray the teacher as a capable decision maker. In this research, it is the teacher's voice that becomes solid data. Teachers make choices based upon what they believe about their teaching situation. Antonella was clear and specific on her views about her commitment to arts integration for her kindergarten students.

I would have to say that my commitment is pretty great. Because after just watching this year, the last couple of years, how they learn from that has really astonished me. I mean, there's that worksheet end and then there's this. Just allowing them to create those stories that are in the hallway. Create these little critters and then write about them. It means so much more to them. And I feel that their writing has become so much more expressive. I've had students move this year more than I've ever had them move. On the assessment, their progress has advanced from intensive need right up to benchmark. I think their progress has a lot to do with arts integration. It really does. (IF-TA5.12.09) 


\section{Antonella's teaching satisfaction.}

Antonella described her job satisfaction as an emotional connection to her work. She provided specific examples of student learning that endear her to the students, their activities, and the ways her students respond to learning. Her wisdom emerged when it came to describing how she should be conducting her classroom, and she cited specific examples of that energy between teacher and learner. Antonella expressed her satisfaction with high energy and emotion. She spoke from her knowledge as a teacher and as a parent whose own child is motivated by his teacher to learn:

I love my job! I'm very satisfied with teaching. I'd like to see the arts integrated into all classrooms, from pre-kindergarten to grade twelve. I mean, if that's what we're dealing with ... we're dealing with the creative arts end of it. It just needs to be everywhere. My own son will come home from high school with a project in English that's just totally so different than what you are used to, writing responses and such. And he is so excited to get started to do it. Well, of course! And like they've said before, if the teacher's doing the work, it's too much. It's the kids that need to do the work. You're just the overseer of everything and just to sit with them and watch them work is priceless, really. (IF-TA-5.12.09)

She continued to illustrate her love for teaching through scenarios of students who have mastered their reading skills of blending sounds and science concepts of buoyancy. "They just take everything in. They're just sponges. They want all that information. And if they can do the lessons with hands-on, then they can remember the concepts.” (IF-TA-5.12.09) 
Antonella identified through her stories and illustrations what master teachers know and understand about meeting student needs. Well prepared and enthusiastically delivered instruction is a gift to students of all diversities.

\section{Antonella's control over curriculum and instruction.}

Antonella spoke of the life experiences that teachers provide for students, such as the opportunity to experience concepts through hands-on lessons. She asked students to combine grape juice with a plop of ice cream. The goal for this experience was to study the blended letters "gl” and "pl” for the concoction of "glop" and for the "plop” of ice cream dropped into the grape juice. When one student came back from a weekend of camping where he had fallen off the dock into the water, he said, "I plopped down and then came right back up in the water." Antonella then decided what activities would best help the students and what scope and sequence she would use to introduce the concepts of blending sounds and sinking/floating.

I feel like I have quite a bit of control over my lesson presentation, my station activities. I do follow the content standards (CSOs) and I use the phonemic awareness book. I use what I've been instructed to use, but I'm able to extend that, and I think my lesson presentation is the whole thing. As for student motivation, oh please! I know when it is time to switch gears and change the activities that will get us up and get us down. I can decide what we do in circle time. I really do feel like I have control over all of that. You take those CSOs that you have to cover and then a plan is devised from there. (IF-TA- 
Antonella on making and sustaining change in teaching.

I spoke with Antonella about creating and sustaining change and the various influences upon teacher decision making. Teachers have both external and internal forces at work in the change factors facing teaching and learning. It is critical to the profession to learn what helps promote and sustain change. She told me that you know when something is working, and you continue to use it the next day. Change can be as subtle as adding a different dimension to an already existing practice or behavior. She summed up change by reflecting on a very important question that asks, “Does it work? There have been times when I've found that things just don’t work . . . and then you just nix those. (IF-TA-5.12.09) My Reflection

In my current job as district professional developer for teachers, I think that the hardest aspect of my work is introducing new changes, getting buy-in, supporting staff through the struggles and growth prompted by change. All of this is for naught, however, if change goes by the wayside. I've seen individual teachers and entire staffs of teachers go through rigorous staff development, for example National Board Certification or year-long embedded professional development with a consultant. There is a certain "honeymoon" period where the information and resources are still novel, and the commitment is fresh. At this point, efforts to provide the professional development, both money and planning time, are enthusiastically received. However, when the rigor increases and the reality of change becomes an expectation, behaviors like avoidance, resistance, or retreat replace the enthusiasm and commitment behaviors. Perhaps the novelty wears off; newly established practices become tiresome and boring or too difficult; changing practice seems stifling or scripted. Whatever other characterizations or excuses we admit, we just fall away from change. Even though the expected change is research-based and proven to work with students, and can be quantified through student progress and assessment 
data, I have seen many instances where change in practice meets resistance and rejection. The main question I have is, "How do you make that change happen in you, and then how do you sustain it?"

\section{Follow up Interview Over Arching Question \#3: Student learning and how you integrate} the arts.

Teachers and students have an interactive dynamic that is unique to the classroom during instruction. When teachers plan instruction, a variety of decisions come into play. I asked Antonella what her ideas were on the role her students play in her teaching and about the role students' learning plays in her teaching. Her examples of student motivation become important evidence to the profession as she shares knowledge of and examples of her students’ motivation and what she does with that motivation.

\section{Antonella's awareness of student motivation.}

Oh gosh! Student motivation is the big one! That's what I deal with constantly because if they're not motivated, they're going to be doing something else because they're five years old. That's just all there is to it. I make note of restlessness happening and then I just stop. Even if we are in the middle of a concept, I stop. We buddy up, do “mirror,” put on some music and pantomime or anything. Anything it takes to get them back. Today we put on boogie shoes and swam as different fish through the ocean. It is kind of like a magic act. We have a container of hats that we put on to act out our ideas or role play a character. You can just feel it if they're with you or not. (IF-TA-5.12.09) 
My Reflection

When I was teaching 5th grade students in an early morning extended-day program, one of the lesson goals was to produce a play. We had to study the process of production, beginning with selecting a script, through auditioning, rehearsing lines, blocking and staging, props, costumes, publicity, and performance. The students selected to participate were at-risk children who were either academically or behaviorally struggling in school. In order to participate in the morning program, parents and students signed a participation commitment. In the early stages before moving to the auditorium, our classes involved workshop style classes. We poured over various scripts, set the calendar for our timelines and goals, and identified our production challenges. Then we talked about the parts each student wanted to play.

This group of students became so committed to the production that on many mornings someone would come in with a new idea, a prop, or an approach we had not thought about. Many were thinking and talking about the play at home with their parents. I knew without a doubt that student motivation could be identified through their conversations with parents or their independent research of an idea on the internet. One student came through the door on a Monday morning and handed me a souvenir tack pin she had purchased over the weekend. Her parents had taken her to see "Phantom of the Opera" in Pittsburgh. I used this event as an opportunity to have students look over the playbill and use it as a model to design the program for our play. I also encouraged students to search for plays that we could plan for a culminating field trip. Then, when I went to see "Ragtime" in Pittsburgh, I brought back a souvenir tack pin and the playbill to trade! 


\section{Antonella's teaching design for successful and struggling students with special}

needs.

Teachers work with a broad spectrum of students. I asked Antonella to talk about her instructional design for students who succeed and the adjustments for those who struggle and have special needs. Oftentimes those struggling students are not necessarily identified as special needs students. In the teaching profession, there is little tolerance for teachers who do not find ways to adjust their instructional methods and materials to provide equitable learning solutions to all students. Richard DuFour, in his book On common ground: The power of professional learning communities, puts the onus on teachers to stop using cliché and get to the business of identifying a commitment to all learners. He says, "Don’t tell me you believe all kids can learn ... tell me what you're doing about the kids who aren't learning.” (DuFour, 2005).

Antonella shared these thoughts about modifications she made for struggling students:

That's the most difficult one because you want to feel like you're giving enough to those children that have already done a lesson before. I like to buddy them up with someone who’s not as advanced, for example using letters. I've asked them to pantomime to each other, and then they try to guess which one starts with that letter. They take turns being the leader because they feel terrific. My students are doing all right. Having pre-kindergarten . . . what a blessing that has been. Get those kids in here and let them be introduced to all this learning. (IF-TA-5.12.09)

Richard DuFour, in his foreword to Pyramid Response to Intervention RTI, Professional Learning Communities, and How to Respond When Kids Don't Learn, highlights the challenge 
facing educators as they gain greater understanding of the legislation that expects learning interventions for students who are academically failing (Buffum, Mattos, Weber, 2009).

Follow up Over Arching Question \#4: Use of the arts beyond the classroom Antonella's involvement with parents and colleagues integrating arts. Though Antonella understands the busy lives parents live, she also knows that it is wonderful when parents visit the classroom and see their children thriving as learners. At the very beginning of the year, I like to encourage parents to come in and help. I welcome parents to join us if they have free time. When they can come, I put them at a station, and even though I don't get a lot of volunteers, I do encourage it. I send home a weekly newsletter. It is important to keep them on top of things. I also call when someone's having a tough time. I send their little story books home to read together after I’ve listened to them read here. (IF-TA-5.12.09)

I asked Antonella about collaborations with community business partners or civic groups. In my teaching experience, our civic groups would make cloth desk organizers or read aloud to children. Antonella does not have these affiliations in her setting. On a school-wide basis, students made cards at holiday time to send to the local hospital. The local newspaper visited the school in the fall to present Antonella with an award. Her Teacher of the Month distinction was publicized in the news media. A colleague participating in this research shared the same teaching distinction awarded by the newspaper. Antonella praised her colleague from another building for her work in puppetry with students.

We perform for other classrooms. At the end of the year, we usually do something for parents like a puppet show. I think the realization of this 21st 
Century Learning is the biggest thing right now. We have got to be able to meet what the community needs are. There is no longer this teach-regurgitate-kind of thing anymore. Students must be able to problem solve and work as a team. That's been the biggest thing I've noticed as a change. I did the Teacher Leadership Institute for the first year cohort and we received professional development on what we need to be doing as educators, and what we are not doing. I am also working with a representative from the university on integrated arts curriculum. (IF-TA-5.12.09)

\section{My Reflection}

One of my additional administrative responsibilities is as principal of an alternative learning, on-grounds secondary school. Our small teaching staff determined to set a high standard for using technology by increasing student time in the computer lab and providing them with access to current technologies. Students showed a keener interest and motivation to learn when working on their projects in the computer lab. They were more interactive and communicative with each other and the teachers, and also demonstrated more excitement at the task of illustrating their poetry samples and researching information to create their Power Point presentations. The use of technology as an arts enhancement gave students a form of expression in their core subjects.

Antonella and I had the opportunity to discuss technology and its place with arts integration. National and state technology standards for teachers and for students are clearly defined, and an emphasis on tools for teaching and learning is a conversation waiting to happen. One of the questions facing us as educators is, "How will we be incorporating technology into the arts?” Our statewide Global 21 or 21st Century Learning includes a strong 
push for using technology. Should we be having conversations with our art, drama, music, and dance teachers about the use of technology? Is it possible that classroom teachers and specialists can enhance their students’ learning by a more skillful or artistic approach to current technologies? For musicians, the use of software for composition has a powerful potential for inspiring students to research historical styles of music and for creating their own unique compositions as a demonstration of their command of content. Art teachers have the entire world of graphic arts at their fingertips. Writing teachers can encourage students to illustrate their poetry and short stories, and/or create Power Point presentations to feature their creative works. In considering the use of technology in integrating the arts, we are limited only by our own inability to think outside the box. I asked Antonella about her use of technology for expressing the arts:

No, not this year. I haven't tried that. I was fortunate to be named as the October Distinguished Teacher Award this year. The children and I received a photo in the newspaper along with some goodies for the room. I had to show how I use the newspaper in the kindergarten classroom . . . so I pulled out the detective hats, magnifying glasses, and the newspapers and we got to work looking for letters (at the beginning of the year) and words that we knew. We cut them out and glued them onto a large letter or word. Though we had done some fun things, not individual kinds of things, but just some things on the white board. But I'm not using technology. No. No. It would be hard, but it would be exciting. I mean, I would have to be learning at the same time as the students. These kids can do it. It is just breaking out of that fear that we're going to do 
something wrong or tear up that computer. We know that they are not. We

have to have a goal over our heads. (IF-TA-5.12.09)

\section{Antonella's Lesson Plan Analysis}

We discussed lesson planning and the procedures used. Antonella is firmly grounded in her content standards and the use of her core curriculum. The school's participation as a Reading First project insures that all teachers are using a core curriculum for reading instruction. In our conversations, her references to lesson planning were in response to the question on curriculum design and pacing. She stated, "Sometimes, let me tell you, you just keep some old standbys up there by the learning circle. You know, where I like to stand a lot. I keep things because I can't get it all in my lesson plans because sometimes there are things that just pop up.” (IF-TA-5.12.09) There is no lesson plan analysis for Antonella. The participant did not include lesson plans for analysis of arts integration.

\section{Riffe Park Elementary School}

Riffe Park Elementary is a classic neighborhood school. The schoolhouse is nestled in a rural country setting just seven miles from downtown Madreas and stands between a church and a patch of wooded property. Riffe Park is just yards away from busy State Route 119 and one mile from Interstate 79. Across the street is a locally owned florist and greenhouse.

Otherwise, this school is in a residential neighborhood surrounded by homes. A little playground is tucked strategically in the grassy nook that makes up the corner of an L-shaped, red brick, one story schoolhouse. 
Riffe Park is a pre-kindergarten through fifth grade school with 32 teachers, whose mission focus is developing each child. With $37 \%$ poverty, Riffe is not among its district's schools that qualify for Title I federal assistance. In kindergarten through third grade, there are three teachers per grade level, and two teachers per grade level in grades four and five. Resource educators include counselor, psychologist, nurse, speech, and interventionist. Supporting the arts are band, strings, music, and art teachers. Riffe Park business partners include a local lawn care company, a community bank, an ice cream parlor, and an engineering systems establishment.

School Report Card touts a 15:6 pupil-teacher ratio, with average years of experience at 18 years. The average class size is 21 students, and there is a $100 \%$ attendance rate. Performance on state accountability tests rate $74 \%$ on reading and $72 \%$ proficiency in math.

Riffe's school website is a curriculum resource for the educational community. The website offers curriculum mapping documents, tutorials for technology whiteboard instruction, and a page of parent links. Website links for K-2 include links to things for families and students to do, art museums and galleries, and Dance Mat Typing. There are evening events scheduled for the community, including their combined arts program for band, choir, and strings.

\section{School Culture}

When guests arrive at the main entrance, they walk into a children's art museum. At the time of my visit to Riffe Park Elementary, everyone was bustling about preparing for the school's annual spring "Festival of the Arts.” This school's unified commitment to an arts experience was evident on walls, halls, and classrooms. In one wing of the schoolhouse, a bulletin board displayed Shel Silverstein's art and illustrations. Environmentally conscious, the 
school has a go green bulletin board of artwork. Art history takes on a new Rock ' $\mathrm{n}$ Roll twist thanks to fifth graders who study Rock Artist styles and use Power Point presentations to debate their favorite artists—DaVinci, O’Keefe, and others.

\section{Celine and Veronica of Riffe Park Elementary}

The ultimate guardians of excellence are not external forces, but internal professional responsibilities.

$\sim \sim$ Paul Ramsden (1992, p. 221)

Learning to Teach in Higher Education

Two teachers from Riffe Park Elementary are participants in this research study. Veronica teaches fifth grade, and Celine teaches fourth grade. Hearing their teaching stories from the small, rural classrooms was an opportunity to explore the works of two arts integration teachers among a staff of committed arts-integration instructors. Our first interview was conducted as a mini-forum. The second interview was a one-to-one conversation exploring the questions more in-depth.

Celine, Veronica, and I sat around a library table early in the morning before school opening. This interview was our first encounter, and I was aware of my anticipation. I was hoping for a kindred connection among us as we began sharing our arts and teaching stories. A collection of puppets made by Celine's fourth grade classroom was keeping vigil over the library book stacks. After introductions, we talked in cliché fashion about our school year and how fast time was passing, our families and parenting experiences, and even the weather and our excitement for summer vacation.

Celine is a 22-year veteran in the teaching profession, with a master's degree in learning disabilities and inclusion. She is certified in elementary education and in special education. 
Also, she has a science specialization and experience teaching intermediate grades fourth through sixth. Celine is a member of American Federation of Teachers (AFT) and serves on her school’s Local School Improvement Council (LSIC). Her prior training in the arts includes arts classes taken to earn her degree, and additional dance classes. Her husband and his sister also teach.

Veronica teaches fifth grade at Riffe Park and has earned a master's plus 45 hours. She has invested 32 years of service and earned certifications in early childhood, kindergarten through eighth grade, special education kindergarten through grade twelve, and behavior disorders. She specialized in computer training. Veronica is vice-president of the faculty senate, and a member of the Local School Improvement Council (LSIC) and the state's professional education association. Previous classroom experience includes teaching in kindergarten, first, and fifth grade classrooms. Veronica is the only teacher in her family.

\section{Mini-forum the Initial Interview Initial Interview Question \#1: Curriculum "How do you decide what to teach?" \\ Celine and Veronica's curricular decisions.}

We gathered around the library table for a natural segue from social chat to the heart of curriculum and the arts. Both teachers highlighted their commitment to curriculum content and standards. They talked comfortably about specific examples of arts integration, and they shared their recipes for the perfect blend of curriculum content and arts integration.

Celine was first to answer to the question, stating that she enhanced her fourth grade curriculum through arts integration, especially for those students with challenges in understanding concepts: 
When it comes to adding the arts in the curriculum, there are some standards I hold fast to. Like my puppets. I know we get a lot out of that project and sometimes when you do something and think, 'Wow!' these kids have shown understanding in this concept. Maybe we can explore that. I know last year with a group of kids who had a lot of challenges, any kind of hands-on interactive or any other way you could get them to understand a concept may just happen to be through music and movement. When you see a group of kids that you have, you get to know what they might respond to or how to try to get them connected to what you are doing.” (Celine II-TC-5.1.09)

Of course you have to go by our state content standards, and I think whenever I find something fun for children, and I can see them take off, then it is also fun for me in teaching. I want more fun to integrate the arts into the curriculum in every area. (Veronica II-TV-5.1.09)

One of the most incredible dynamics of this conversation-interview was the way both teachers exchanged ideas. Each one was a complement to the other. Their thinking and responding took on a natural decorum as they expounded on the interview questions. To the reader: keep this element in mind as a reminder of the power of collaboration among teachers. In Celine's response below, there is a clear point at which the reader can see how carefully threaded their responses are.

When you see those types of things with the kids ... they are not going to run up and say, “When can I turn in my worksheet?” No, they are running up saying, "When are we going to do our puppets? When are we going to do our play? When are we going to do our song?” And Veronica is right; it gets everybody 
motivated and inspired to do more, and they are really into it. You know kids are much more motivated generally to do those kinds of things. So when you see it and you go out on a limb and you do it, then you want to do more because you know you are going to get a lot more from them. (Celine II-TC-5.1.09) And it also goes outside the classroom. They want to share it. They want to share what they have done and what they have learned with others. That makes it nice too, and it builds their self-confidence. It is very good for them in an allaround way.” (Veronica II-TV-5.1.09)

Celine made her point about her decision making from year to year. She cited an example of how each year a different class of students passes through her care. Veronica also mentioned in the previous quote that students share outside the classroom and learn from others. They anticipate the day when it is their turn to have a teacher who teaches using arts integration. These teachers are attaining a stature of respect and a reputation for making learning relevant and fun. Students come to school expecting to have the same arts experience from Celine and Veronica. It is a high standard to uphold, yet a dominant factor that keeps these teachers on the cutting edge of making quality decisions about classroom content. When we did our plays, we use the basal (core reading) program's lessons. I didn't perform it. I helped the kids perform it. They get to drive how they want to do it. Last year's play was different than this year, because we have different kids. But the kids I have this year got to see the play last year. When they hit the door step at the beginning of the school year, they said, "We get to do the play.” They got to make it what they wanted this year, which was way different 
from last year. Then just as Veronica said, "It goes way beyond.” It goes way

beyond because everybody wanted to see the play then. (Celine II-TC-5.1.09) My reflection.

I know this to be true, for in my years as a novice teacher freshly graduated from college, my first teaching assignment was middle school choral and general music director. I had a great love for teaching the content in general music as well as the performance standards and repertoire in choral music class. Students in general music completed a project-based assignment that culminated the content unit on instruments of the orchestra. The six weeks was spent studying characteristics of each instrument in the families of instruments-brass, woodwind, percussion, strings.

For one of the requirements, students were to identify instruments by family, tone quality, and physical characteristics of the instrument. We completed the unit by hosting a final display of instruments in the choral room, transforming the choral rehearsal room into an orchestra-like setting. Thanks to the large glass enclosure of our auditorium balcony classroom, anyone passing by the auditorium could see the display. Teacher colleagues, fellow students, administrators, parents, and even college professors raved about the student work that was accomplished in our general music classes. Student instruments were models that demonstrated understanding of the instrument form and function. The word spread about the school and community, so much that each year the projects became more sophisticated and eagerly anticipated.

Celine summed up the essence of deciding what to teach in the following narrative:

These are the joys of integrating the arts. We could read the play in the classroom and could have just left it at that where everybody can't have a part.

We could have just left it at that. We brought costumes in, and they brought in 
their music and danced a little bit. We have a young man who can play a piano. He brought in his own composition. He knew what kind of piece would go with the play. We have kids in strings class. They wanted to do a piece too. They put pieces together that they had learned all year long, and put that play together themselves. It was amazing! Last year I had support from the music teacher. She came in and helped. This year, these kids were able to do it themselves. So they did!” (II-TC-5.1.09)

Therein lies the teacher-student dynamic. The teacher has the ability to facilitate student learning with her thoughtful decisions about curriculum.

\section{Initial Interview Question \#2: Instruction: “How do you decide how to teach?” Celine and Veronica's instructional decisions and the art of provision.}

This question is both wide open and precise. It leans toward teachers' expounding on methods of delivery, techniques for management, activities, and more. The beauty of the question is in its ambiguity or un-prescribed nature. Teachers have the option of answering without stifling their natural thoughts and impressions on their very important and unique howto-teach decisions.

I think according to each of the groups, that you have to set up your guidelines.

I taught first grade for many years where it was just teacher activities. In fifth grade, now I set up the guidelines and I can adhere to them, which is really rewarding to see that, too. This is the first group of fifth graders that I have not taught as first graders. But to see the difference between them as first graders and then as fifth graders is wonderful. Instead of being teacher directed, I provide them with materials and the guidelines, rubrics, to perform the task. 
They all succeed because they are allowed to choose their favorite area to work at since they all have their own classroom personalities.” (Veronica II-TV5.1.09)

Veronica spoke knowledgably about informal student assessment and its value in student success. She develops rubric criteria in advance and shares with students prior to their efforts in demonstrating content mastery and competence through their class or individual projects. I queried her about student input into developing these rubrics and her response provided information on the application of rubrics that led us to a discussion of incorporating technology into her science lessons. Her use of technology appears to validate my previous question from Antonella's story concerning the use of technology in arts integration and the future implications of such use.

We will be using technology with our science presentations. We have done Power Point presentations in the past that were optional decisions for students. They had to prepare a visual and have a typed biography, then make a presentation or dress up like a scientist for the class presentation.” (Veronica IITV-5.1.09)

I have a question for you, Veronica. Are you working students towards the technology standards? Is that your Tech Steps application? See, she has connected it to science. You really can get in the technology requirements. We are so pressed to get everything in. Doing something like what Celine is doing is differentiation and helps you meet the responsibilities you have for technology at different levels. And they have a real purpose for it, too. This is their life. Not the life I grew up with, but that is what we are facing now. 
Even our art teacher has the kids online where they can create art work on a web site. So, for me, my idea of art is this. But that is not their idea strictly of art, so I think opening all the doors, all the possibilities, allows them to have creativity in the world they are growing up in. That is a prime example of where we are connecting science curriculum with the technology with the arts. You got it all. I have seen what they have done with these projects and it is pretty neat!” (Celine II-TC-5.1.09)

Tech Steps is a teaching-learning software application that helps to assess kindergarten through eighth grade students through a technology literacy framework.

During their collegial conversation, both Celine and Veronica were intertwining their stories into one narrative. Together, each one was seeking understanding of the other's responses and gleaning ideas and interpreting/analyzing the use of arts integration in deciding how to teach their students. I marvel at the natural dynamics between colleagues and their mutual respect for each other's work. I could characterize our initial interview as a collegial conversation similar to a professional development experience. It was easy for me to notice the impact of their work with the university cohort and Dr. S., made possible by the vision of a college professor and foundation grants to support arts integration. I asked both to discuss their professional activities and the impact of what they learned upon their teaching and the students' learning. 


\section{Initial Interview Question \#3 Decision Making: “What professional development do you} seek and how do you use these skills?”

\section{Celine and Veronica's professional development decisions.}

Nothing within a school has more impact upon students in terms of skills development, self-confidence, or classroom behavior than the personal and professional growth of their teachers. When teachers examine, question, reflect on their ideas and develop new practices that lead towards their ideals, students are alive. When teachers stop growing, so do their students (Barth, 1981, p. 145)

For the segue into this next set of interview questions, I thought about how valuable it has been to me to keep refining my professional gifts and talents. Since undergraduate school, I have been on a career quest for increased professional growth and development. Expanding career knowledge is one way for teachers to protect and advance their professional investment. I have come to recognize that we are all at different places on that pathway of professional growth and development. Affiliating with the university representative through the arts integration project in collaboration with a local foundation has allowed me to create and sustain professional development. Through the years, I have experienced a variety of professional development trainings such as the intimacy of a small book-study group of colleagues, an online course, and National Board Certification. These are only a few of the many ways that teachers manage their own growth and development in an already hectic and demanding work schedule. Celine and Veronica are also on their own pathways, sometimes meeting colleagues along the way and other times going it alone.

There aren’t a lot of professional activities that I seek. So I am always looking for something like this course that was offered. I knew this university professor 
and what she touches is golden as far as I am concerned. I jumped on that right away when I had the opportunity. If there is something that interests me, and I think that is going to be really neat to implement in my classroom...those are the kinds of professional activities that I want to do. It is really important to have your administrator in support of the arts. To see the significance of arts integration and offering the opportunity for the classes and for allowing us the license to do it. I think being new in fifth grade, I really didn’t feel comfortable. I needed to look at all that curriculum that I had to give to those kids. Allowing us to have that class with the university ... well, I felt like he was allowing me to expand and do some more of those things that I loved to do in kindergarten. (Veronica II-TV-5.1.09)

Celine shared her experience of professional growth from her student teaching and substitute days through the intermediate fourth, fifth, and sixth grades. But she talked about her personal, more private approach to professional development.

I find that I have always tended to do things like this, but I always did my own thing. I get an idea, make sure it connected with whatever we were doing, and then just did it. I didn’t find too many professional opportunities, but when this course came to us, I was thinking that I will do that. I will do something that appeals to all of us. I think that it is in us that we feel the need to do something. There is something within us that sometimes drives us to certain places. What appeals to me are any kinds of hands-on things because it just links to our nature internally, which is what we like to see kids involved in. (Celine II-TC-5.1.09) 
Celine continued to explain her many years as a first grade teacher and all of the changes in expectations from a socialization approach, to curriculum, and to a more rigorous content-based curriculum. When she moved to an intermediate grade teaching assignment, her realization was that the older elementary students still enjoyed doing some of the same things they did in kindergarten. Celine is spot-on to recognize that teaching her students at both levels required a skill set that was radically different, yet at the same time she could use similar techniques. By recognizing this, Celine has gone to a place where teachers have the opportunity to self-select professional development that is relevant and meaningful to their teaching circumstances.

\section{Initial Interview Question \#4: Reflection: “What does the community say about your arts} integrated teaching?”

Celine and Veronica's instructional decisions: Community.

That is what we all have-humanity. You can connect that way with the kids through the arts sometimes when you can't connect with them any other way. When you see somebody, I can think of a young man last year ... he wasn’t going to do any of that play stuff. I said, 'You don't have to do it.' Well then, once he saw everybody else, he said, 'I think I can do that.' And he did! There is a connection to the arts that pushes students forward beyond their own perceived limitations.” (Celine II-TC-5.1.09) Some of my most moving artist moments, whether listening to a piece of music or watching a drama, become permanent experiences from that moment on. It is powerful. I know 
that there are concerns over the arts in public education due to funding cuts and other priorities set by the business of education. I believe there are forward-thinkers, vanguards, if you will, who will carry on in the absence of public support for the arts. What teachers present to their students is the first step in making a successful connection to the community.

Well, I can say this year, children ask if their parents can come and watch their play. Parents did come and they appreciated and liked seeing that. It wasn't a full-blown invitation, because it was part of our teaching lesson and not necessarily meant to be that. When the children started asking I said 'Yes, these are our performing times for different grade levels in the school.' They came and were all positive. They really appreciated that opportunity to see the kids perform. (Celine II-TC-5.1.09)

Parents always like to see their children perform, so they always turn out for that. I don't know if they think of it as integrating the arts into teaching. It is just what we do. We are having a 'Night at the Arts' this week. There are going to be displays for each student on their desks and poetry readings and performances. I am sure there will be a wonderful turn out for that too, because all children want their parents to watch them perform and show off their arts activities. Celine is pretty good about being involved with their school and their children. I am not sure that they look at it as integrating the arts." (Veronica IITV-5.1.09)

Celine and Veronica's stories described natural use of arts integrated instruction. There was no contrived activity to solicit parent participation. It became the purity of the lesson plan and content that drove their instructional decision. Parent involvement was an unintended 
benefit to the teacher and her students. What is notable here is that the children's enthusiasm for their accomplishments was the vehicle of communication to parents and the community. Think back to your own childhood memories of school holiday songs, plays, poems, and art galleries. It is likely that you can still identify that living and unmistakable connection between your learned content and your performance.

I specifically remember a spring concert by our high school choral ensemble. On the program was a well known selection, "Hallelujah Chorus," from Handel's Oratorio Messiah. At the end of that work the music resounded throughout the auditorium evoking a standing ovation. Even to this day, I recall my alto part. I know the entrances of tenors, sopranos, and basses from having conducted the piece in a public concert. The musical and historical context of my first high school performance of Handel's chorus has not faded from memory, the content of the masterpiece is still as fresh as that high school day, and its power to unite our choral group to the parents and community has a repeated impact year after year.

My reflections:

I imagined that the teacher interviews would be a one-to-one event. My pre-conceived thoughts placed that condition as a more open and honest way for the participants to share their stories. When I scheduled the initial interviews with the two Riffe Park teachers, however, they were interested in meeting together with me. I was new to them and had only met through phone and email interactions. I am amazed with the outcome of meeting together and propose that we actually enhanced our opportunity for gathering rich narrative data. It is difficult for me to pinpoint any particular reason that the initial interview flowed into a collegial format. But if for no other reason than convenience of meeting dates or just being comfortable for the first time having a colleague to share the process, I am glad that we honored another possibility. Setting up the second interview also took on a different character from the first. Each teacher wanted to 
interview one-to-one with me. I was both surprised and comfortable with the spontaneity in which our meetings together evolved.

\section{Veronica’s Comments on Student Artwork}

Veronica provides an elaborate discussion on her students' artwork. She had literally provided me with a portfolio of samples to illustrate her commitment to arts integration. The assignments promoted a variety of arts integration methods including scripts for plays to extend reading textbook units, posters with informational reports for science and health, and lyrics for rap songs on famous people in history. Veronica was clearly a facilitator of student learning. She changed up her methods of teaching and offered students a variety of methods in which to present their knowledge.

I have two CDs that students created. One has an example from the reading textbook. The lesson concept to be taught was biography genre using a story about Evelyn Cisneros, and her climb to fame as a ballerina. I had some really tech-y kids last year and this student completed her think and respond, making connections with the CD about Evelyn. I also use arts integration in health. Students created an asthma commercial. They wrote up the script that included facts and details about the health condition. They set the video in context and had their parents take them to the local ball field. They were running around the bases and video taping an interview about the importance of good health and the facts and challenges of having asthma. At the end they included creative bloopers and rolled the credits for the group participants. Some students created rap songs for health class. They had to take a rap song about not using alcohol. 
There were to be two long-term goals and two short-term goals in this assignment. Some students, of course, have more technology background and it is easier for them. Everyone was involved, not just a small group of students.

I have posters that students created on allergies and arthritis. They were just given some common diseases. Students were assigned a disease to research such as finding all of the symptoms, cures, and conditions. This works really well because health is at the end of the day and student groups become flexible in order to incorporate schedules for band and chorus.

Here is another play that students wrote and performed. It was based upon a reading and creative writing assignment. It was Pinocchio. They would come up with these typed scripts which I absolutely loved. It was not required that they type it, they just knew that is how you did it. They were so motivated to do it. (IF-TV-5.5.09)

\section{PINOCCHIO}

(Included is an excerpt of "Pinocchio.” Adapted script written by Veronica’s students.) One day was just a normal day for Geppetto working in his work shop but all the sudden an unexpected guest pounded at the door.

Antonio: Geppetto, I want some thing a wooden doll not just a normal one. One with detail like ... like a kid.

Geppetto: Ummmm Ahhhh (rubs chin) sounds ok. Antonio: by Thursday!!!!

Geppetto: by Thursday!! But is Tuesday 
Antonio: follow as directed Geppetto (stomps away)

T.w.: Geppetto quickly went to work he had no time to fool around but he felt shameful that he gets ordered around.

Geppetto: it's done finally it's done all that as I need is paint and I'm ready.

T.w.: Geppetto worked hard and steady line by line.

Geppetto: (painting) finished...finally (smiles)

T.w.: Geppetto finally went to bed that day exhausted from working on something that was for the meanest man alive.

Geppetto: (goes to sleep)

Using the four over-arching interview questions of curriculum, instruction, reflection, and community, the matrix for discussing student artwork connects teacher decision-making to student work samples. The following table takes the matrix checklist items and summarizes the categories of teacher instructional decisions that can be seen in student lesson samples. Matrix for student play “Pinocchio”

\begin{tabular}{|l|l|l|l|}
\hline \multicolumn{1}{|c|}{ Curriculum } & \multicolumn{1}{|c|}{ Instruction } & \multicolumn{1}{c|}{ Reflection } & \multicolumn{1}{c|}{ Community } \\
\hline $\begin{array}{l}\text { Reading, Writing, } \\
\text { Social Studies }\end{array}$ & $\begin{array}{l}\text { Writing, Text } \\
\text { Interpretation }\end{array}$ & $\begin{array}{l}\text { Confidence, Esteem } \\
\text { Efficacy, Aspiration }\end{array}$ & $\begin{array}{l}\text { Tolerance, Conflict- } \\
\text { Resolution, Community } \\
\text { Service, Social Problem } \\
\text { Solving }\end{array}$ \\
\hline
\end{tabular}

Veronica's students clearly understand the format of a play script. Their motivation to voluntarily type the script is an indicator of their engagement in presenting their work above the required standard. A sense of understanding tolerance and conflict resolution comes through the script in Geppetto's role as willing to overcome his feeling of "shameful to be ordered around" in order to create Pinocchio for the "meanest man alive.” The assignment was 
one that came from the extending learning activities section of the student textbook. It was part of the making connections to the story in which students were expressing their feelings. Veronica uses her instructional resources with thoughtful consideration for content. In addition, she is able to lead students to relevant arts activities to extend their learning. What we see here are ways that her students produce assignments that are fun, enjoyable and connected to content.

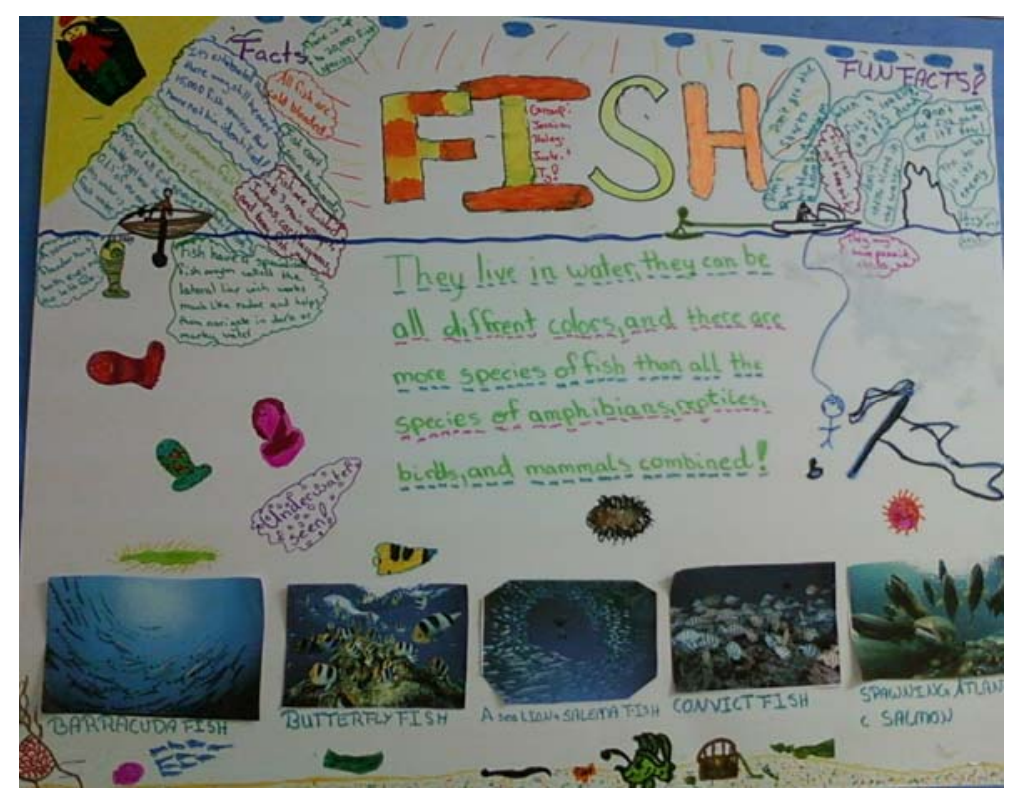

Figure 2. Arts integrated group poster project. Students collaborated in groups to create a poster and gave a presentation to their classmates.

I had the students working in cooperative learning groups for this assignment. It was a science lesson on environment. There was a rubric that I used to give them feedback on their work. Some students made a poster presentation on fish and some on reptiles. The assignment was to research their topic, then gather enough facts to make a visual presentation showing that they had learned content. Each student has a responsibility and has to do their share to contribute 
to the assignment. You can see their fact bubbles in both upper corners of the poster. (II-TV-5-5-09)

Using the over arching interview questions of curriculum, instruction, reflection, and community, the matrix for discussing student artwork connects teacher decision-making to student work samples. The following table takes the matrix checklist items and summarizes the categories of teacher instructional decisions that can be seen in student lesson samples.

Matrix for student science posters—illustrated posters:

\begin{tabular}{|l|l|l|l|}
\hline \multicolumn{1}{|c|}{ Curriculum } & \multicolumn{1}{|c|}{ Instruction } & \multicolumn{1}{c|}{ Reflection } & \multicolumn{1}{c|}{ Community } \\
\hline Reading, Science & $\begin{array}{l}\text { Text Interpretation, } \\
\text { Writing, Graphics }\end{array}$ & Confidence, Efficacy & $\begin{array}{l}\text { Community Service, } \\
\text { Social Problem Solving }\end{array}$ \\
\hline
\end{tabular}

\section{Celine s Comments on Student Artwork}

I do this art integration project every year. And every year it is successful. You can see the puppets lined up across the top of the library shelves in here. It is a special project and one that, at first, students are not sure of. They have to do a book report and create a puppet to represent the story. It helps them in a lot of ways to learn to focus on the details of the story. Once they start learning more and get more involved with their puppet and report, the excitement grows. Parents get involved with their children. They don't have to use anything fancy to put the puppets together, just things they have around the house. But they go to great extremes once they begin to see it coming together. It is so exciting to hear them tell about their progress and to see them give their reports. They make a great display, too. These have been up for quite a while, and we are 
going to have them shown at our school wide arts celebration.” (Celine II-TC5.1.09)

I was in the cafeteria and saw the custodian moving a large cardboard flat. I asked him if I could keep it. We took it to the room and the kids came up with this little play—-this is why we're loved. This is a child's world. I said to them, 'Here’s our cardboard. What are we going to do with it?' I gave it to them and they created a puppet stage. And their plays were phenomenal! Part of the cardboard became a back drop; part became a mural for the cafeteria. It once used to be the stage that we use when we do our puppets. They get behind it so they don't have to feel like they're right in front of everybody. I like things like that because it works, you know. (Celine IF-TC-6.8.09)

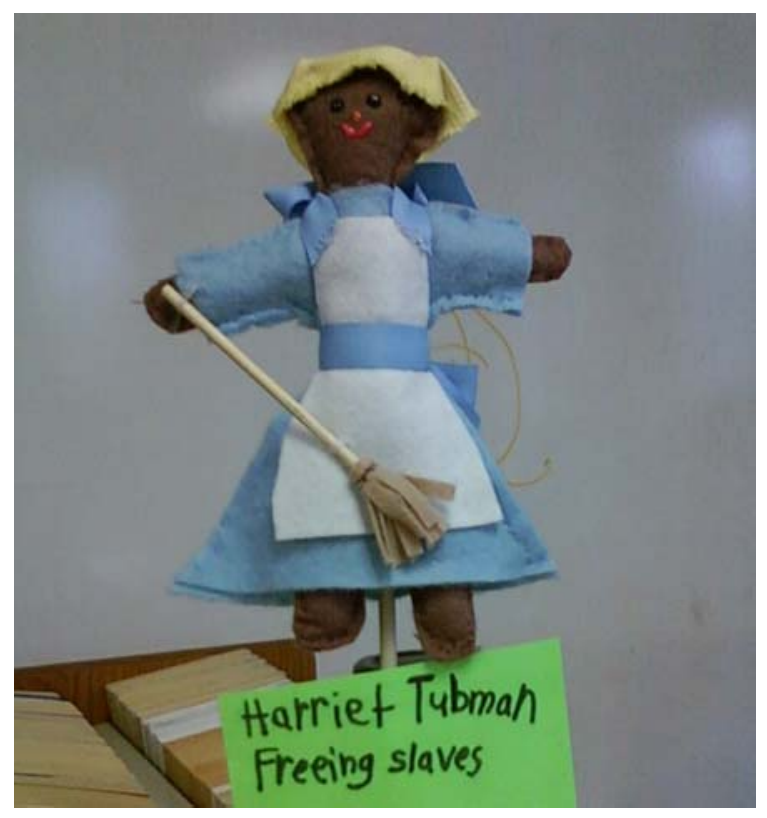

Figure 3. Puppet character from book report. 
Using the four over arching interview questions of curriculum, instruction, reflection, and community, the matrix for discussing student artwork connects teacher decision-making to student work samples. The following table takes the matrix checklist items and summarizes the categories of teacher instructional decisions that can be seen in student lesson samples. Matrix for puppet-Harriet Tubman

\begin{tabular}{|c|l|l|l|}
\hline \multicolumn{1}{|c|}{ Curriculum } & \multicolumn{1}{|c|}{ Instruction } & Reflection & \multicolumn{1}{c|}{ Community } \\
\hline Reading, Social Studies & $\begin{array}{l}\text { Text Interpretation, } \\
\text { Writing }\end{array}$ & Confidence, Esteem & $\begin{array}{l}\text { Tolerance, Social } \\
\text { Problem Solving, } \\
\text { Conflict-Resolution }\end{array}$ \\
\hline
\end{tabular}

Celine’s commitment to her students is grounded in content and backed up with a high standard of expectation for herself and her students. She is committed to giving each year's cohort of students a set of rich arts integrated experiences. Her puppet project reaches layers of content ranging from historical importance to social implications. Engaging the learner in a hands-on project is a sure way to seal the experience students have with content, parent involvement, and an art product such as a puppet.

\section{Follow up Interview Over Arching Question \#1: Demographic Setting and professional} attributes of an arts rich teacher.

\section{Celine's self-characterization of professional educator.}

Celine has some very clearly defined thoughts on her philosophies, ideas, and attitudes towards teaching. She knows her responsibilities to the youth she serves, and these responsibilities are what distinguish her as outstanding in her field. She exemplifies qualities that will resound for years to come as influences upon her students' lives. Hear now, in her own words, how she describes her inner ethic for teaching children: 
Well, I feel that as an educator, I am responsible for the children I take care of all day. I'm a caregiver to them, and I'm a role model to them. But my job is to teach them what the state says I need to teach them. So, I try to orchestrate being a good role model with what has to be done. I always tell the kids, "You know, this is something that as a fourth grader you need to know. So how are we going to go about getting it?” (Celine IF-TC-6.8.09)

\section{Celine's personal experience with the arts.}

Who among all of these children, and we who teach them, has had a charmed life? To sort it all out and be fair to each other and ourselves, there are some very tough questions to answer, questions that require a step back to the days of our youth and to our own educational experiences. Did we have charmed lives full of dance and piano lessons, trips with parents to the theatre, ballet, or opera house? Celine did not hold back as she reached back to her past for understanding and for answers that may help illuminate her teaching decisions.

Characterizing my own personal experiences with the arts ... I have to admit that I missed opportunities as a young person. I was very timid and shy. I love the arts, but I didn’t experience them fully as a young person through adulthood. Being as creative as I think I could have been, and now so given the opportunity to help children find themselves, I like to pull in any experience that I've gained over years of being a teacher, parent, spouse, and community member. For example, my husband is a potter. We have the kiln and clay all around our house in pieces. I have one of his pieces here in my room that has a cracked handle. I thought there was nothing wrong with this piece, but it wasn’t good enough for his high self-standards. (Celine IF-TC-6.8.09) 
What transpired throughout this interview with Celine were exchanges about our families, our love of teaching, our appreciation for the arts, and how our students are impacted by our instructional offerings. This interview accomplished all of the data gathering goals, but went beyond that into a realm of spiritual trust. I was able to share with her my unfulfilled promise to take pottery lessons with my recently-widowed young adult daughter, a conversation I would not have had if the methodology's question design had not sought data on the participants' personal experience with the arts. Having the initial interview with both Riffe Park teachers together sealed us with a full measure of trust and willingness to share more than just arts integration in the classroom—arts integration in our lives. This deeper element of understanding the need to experience the soul of art within us may one day lend its understanding of what commands us to make our teaching decisions.

\section{Celine's professional growth and development.}

When given the opportunity, and it's something I can do, I try to participate, but when the class was offered to us in the form of the faculty meeting, the principal had said, ‘OK, who would be interested?’ Some said, 'Yeah, I think I’d like that,' just because it really spoke to who we were. I'm a messy teacher, I know. That's because I let the kids do things. (Celine IF-TC-6.8.09)

\section{Celine's reflective practice.}

Celine was able to provide multiple examples of student interactions in the classroom. Many were related to arts integration, and many were grounded in general classroom management and curricular content. She described her classroom activities, the long range projects, and her reflective practices. She approached learning from her students' perspective. 
Asking leading questions defines her reflective style. "What are we here for?” and "How can we incorporate our learning with what we want to do?”

See, that's what I like to do. I've given to the kids, and I think that kind of speaks to up here, methods, or reflective practices. I try to incorporate what the kids are inspired to do. These kids just take and idea and go with it. (Celine IFTC-6-8-09)

\section{Celine's classroom teaching context.}

Celine described the students in her 2009 class as the best in her whole teaching career. She has had other outstanding groups that compare to classes in former schools. She spoke about each group with great zeal and promise.

A group of students that I had seven or eight years ago were phenomenal. I'd say, 'Jump!' and they’d say, 'Are we high enough?' instead of, 'How high?’ You know, that's my analogy I use all the time, but this class, I think, slipped ahead of them. It was a phenomenal experience this year. For example, that little girl who was a phenomenal artist helped make our Dr. Seuss Day an event. That morning, I said, 'Kristin, can you make a cat and a hat for us?' And everybody wrote up their favorite book. I left her picture up all year. She received the Awesome Artist Award. Everybody really appreciated her art. And nobody was jealous of it. They really appreciated it; do you know what I mean? (Celine IF-TC-6.8.09)

Celine’s students are her prized possessions, and their artworks are her trophies. The children's puppet stage and their puppets, plays, and drawings are all hard to part with. "I’m kind of like one of those teachers who has a lot of excess in the room, because this is just the 
way I teach. I value their art and that it represents our time spent together.” (IF-TC-6.8.09)

Celine's classroom is spacious with room for desks to be arranged in student work groups. One entire wall is windows and shelves. Computers line one of the side walls, and the teacher desk is located out of the main instructional area. Larger work tables are set up for students to collaborate on big projects, and student work is displayed on bulletin boards and classroom walls.

Follow up Interview Over Arching Question \#2: Arts integration and the influence of job satisfaction, commitment, autonomy, and change Celine’s commitment to arts integration.

Celine prefers a very high level of student-engagement in her classroom. She does not turn students free to pursue a group or individual project without first asking, "What is the purpose?” Even though students are begging her to take on a project, she has a way of making her students justify the end goal and its connection to learning. “That's the style of teaching that I prefer. I like it to be hands on. I know what my job is, but I like to be student-driven. And if it can be through the arts, if it can be through my other love-science ... whatever it is, I just like it to be something that is meaningful to the kids. So I try to bring all of that to the classroom with me. (Celine IF-TC-6.8.09)

\section{Celine's teaching satisfaction.}

This question of describing their level of teaching satisfaction sometimes made me pause before I asked it. It did so, because the teachers I spoke with are zealots for their students. Just listening to their stories was proof enough. Whatever it takes, truly committed teachers will do just that to bring their students to a level of success. I have had conversations with many jaded and disillusioned teachers ranging from novice to retired. Some teachers do 
not experience job satisfaction for a variety of reasons. Perhaps the more enlightening question to probe is, "What is it about your work that brings professional teaching satisfaction?" This research seeks to find whether teacher satisfaction can be qualified into a measure that will help to determine decision making effectiveness. So I framed the question for Celine like this: "Your work with students is like an orchestration. I think of the metaphor of orchestra and conductor and it is similar as what you do as teacher. You're a conductor. I'm going to ask you to describe your level of professional teaching satisfaction.” Here is her response: I love teaching! My husband will sometimes say, 'Why don’t you go get a new profession?' I will not do that! It's not me. It is not what I'm about. I would not have joy. I love this job. My little son will say, 'You really love those kids, don’t you, Mom?' My kids know that. It’s just who I am. I can’t help it. I can’t help who I am, and that's not a bad thing. I love doing this job. I just can’t imagine never doing it. There are stresses, but these little faces bring you back every day — even the ones that have the hardships. They're the moment of joy in my life, too. I know that there is a lot of love in this classroom. (Celine IF-TC-6.8.09)

Celine has fostered a culture and climate of learning excellence. She has set the standard for acceptance and caring for all, and has confidence in her ability to help the students who are transient, the ones who are shy and withdrawn, and those who live a charmed life.

\section{Celine's control over curriculum and instruction.}

For those teachers who feel compelled to keep fidelity with the content and still keep up the commitment to arts integration, there are decisions to be made and challenges with 
schedules and time frames, not to mention covering the requirements of formative and summative assessments.

I just think basically that my teaching style is one that I'll never let go of. I value too much the opportunity for kids to experience at their own hand what they can to whatever they create. And if that's called art—creation through the arts-it's their creativity. I am open to whatever is good for the kids to learn it, to get through. I always preface everything to the kids. I even read the CSOs before taking on a divergent project.

I ask myself and the students, 'How can we incorporate our learning with what we want to do? What are we going to be able to say to support our valuable school time in doing this project?' I headed over to the CSO notebook and handed a copy to the students. 'You highlight anything in there that you think we're going to be able to say that we are doing to help our learning in fourth grade.' And you know ... those girls did it! Talk about differentiation and their instruction. Some kids get the task at hand done now, and there are others that you need to work with more. So, I need to work with one child more. (Celine IF-TC-6.8.09)

Celine demonstrates that the curriculum for her fourth grade standards is imperative. Asking students to read to determine the relevance of their CSOs before committing to a project demonstrates a keen awareness of her commitment to curriculum and instruction. 


\section{Celine on making and sustaining change in teaching.}

The question of sustaining change took on a story unrelated to arts integration. It was, nonetheless, one that Celine used to illustrate how she and the students deal with making and sustaining change.

I don’t know if I mentioned this to you before, but this is not necessarily arts in the curriculum. My kids wrote a letter to the principal about the flower bed outside. It was built, soil dumped over a year ago. It was just left there. The principal wrote back to them in a letter that encouraged them to take it to a different level, including labeling flowers, calculating cost effectiveness, and a plan for the future such as compost. (Celine IF-TC-6.8.09)

This scenario involved students’ insistence in creating a beautification project. The plan was broad in scope and evolved into a joint project with parents. The adults helped with digging, and the local florist provided an assortment of flowers. Celine described the requirements of making and sustaining change in this beautification project and the stretch required to bring it to fruition.

We never got that up and off the ground. There was so much rain that we couldn’t get out there. This was all prior to our state accountability testing. We picked May 10th as the planting date. Students were begging me to get the project done. 'We really have to stay with this project. We'll keep it going. I promise you we will not let it go.' But it was a labor of love. (Celine IF-TC6.8.09)

The project did come to completion. The principal wrote a feature article in the Riffe Park monthly newsletter, acknowledging the fourth graders as project innovators, the Girl 
Scouts who adopted the project, and the local parents and greenhouse for providing plants. Making and sustaining change for Celine was a practical and real event with her students in an authentic learning setting, requiring real-life problem solving strategies. It may have been easier to abandon the project. Students, however, demonstrated that they were invested in making and sustaining change according to their class vision.

Follow up Interview Over Arching Question \#3: Student Learning and how you integrate the arts.

\section{Celine's awareness of student motivation.}

This right here. (Pointing to student work sample) OK. That's graphic art. They knew what program to use. I didn't tell them. They just went over there to the computer. As for integrating arts, that may not be dancing. We are talking about two little boys that are phenomenal in animation on the computer. I mean, this was their venue, right there. And whatever it is that the children can be inspired to learn and be and embrace what they're learning ... I'm game for. I just think it is who I am. In some regard, I think that those children that I had last year were much more open to the arts. They were freer with it, but they struggled a lot with academics. And I think these kids were a little bit more conforming to what you would call a typical standard classroom, and so it took them a while to feel confident. (Celine IF-TC-6.8.09)

\section{Celine's views of student motivation and impact upon lesson design and pacing.}

I framed the question on motivation's impact upon planning and pacing as an important gauge to determine the students' responses to her lesson preparations. Most teachers have experienced student responses that fall suddenly quiet or unexpectedly take flight. This student 
response has potential to put the teacher in a tailspin as to making and adjusting the instructional pacing.

As far as the plan ... a lot of times it is student driven. As long as I say, 'I'm responsible for you to understand this. We need to get to these things. This is what I have to do. I'm employed by the state to do this for you.' As long as we can show that we're getting through it, then I'm OK with it. As far as pacing, I think you just have to pace and design for the kids you have.

Certainly what we did this year is absolutely not what I did last year with the group of kids that are fifth graders this year. Basically, pacing and planning depends on your person. It's a juggling act. You can have a group of kids that come together, or kids that don't. You never know what you're going to get. It's an adventure. I guess teachers are explorers in that way because you are creating what you can with what you have here. And you don't know where you're going! I had a student that joined our class late in October. Simple situations like the timing of when a student comes into the class and their social and academic adjustments can influence the entire classroom dynamic, and that will change our plans and pacing. It's an adventure because you don’t know what they're coming with each day. You know what you have to get through in content matter, and you know as teacher you've got your ideas. But you know what? It many not motivate them. It may not be something that clicks with them. (IF-TC-6.8.09) 


\section{Celine's teaching design for successful and struggling students with special needs.}

Working with the university facilitator had a noticeable impact on Celine's approach to meeting struggling and special needs students. The discussions and exchanges from fellow classmates resounded in her next response:

Last year, I noticed that there were a few kids very intimidated with arts integration activities. I never forced anybody. I got this from our university class, that we must give students other options. Give them other ways. For one child with special challenges, I would back off and say, 'OK, well, we have to learn this. We'll get to it some other way. I'd find out that they would eventually come around. When I said "You have to learn this somehow, some way.” Then I would back away and let them simply think about it for awhile. After thinking about it, the student came forward for help. This is proof that students were very safe with me knowing that I wasn’t going to force them. (Celine IF-TC-6.8.09)

Celine has strong ideas about her students as whole individuals. She wisely questions how the children can be left without the same dignities that teachers would otherwise afford their non-struggling students.

I guess I just don’t really get it when people say that students can’t learn. I know that we're responsible for certain things, but I think sometimes if you stop and just think. This is a little human. This is a person. This is not just a student, which is an entity in and of itself. It's a little human, and she needs us to understand that she needs a little bit more time. Differentiating her 
instruction is just the mode or the method, or the measure of when she will do it.

If I just let her be the person to think it through and control her behavior, she can be in control. I didn't take it away from her. I saw instances of when control was taken away from her. She would shut down. (Celine IF-TC-6.8.09)

\section{Follow up Over Arching Question \#4: Use of the arts beyond the classroom.}

\section{Celine's involvement with parents and colleagues integrating arts.}

In the previous narrative stories, Celine discussed her involvement with the community and parents through the planting and beautification project at school.

So it’s just something meant for me to be in this profession. Getting parents involved with the community made it happen. And, like I said, for one it's a bigger picture of the world. I try to help my students to see that this is a community here. We're part of the school community. We're part of the county, part of the state, of the nation and the world. To help them see that they are part of a bigger place than just the desks in this room. (Celine IF-TC-6.8.09) In previous responses, such as parents working with their students to create puppets, Celine indicated parent involvement in student arts integration. She collaborates with her colleague, Veronica, from fifth grade to assist students in their progress from one grade to another. "One little boy, he was a tough one, but he joined in our group arts activities. I think Veronica probably solved some of that with him this year. I know last year I didn’t force him into participating or back him into a corner.” Celine’s interactions with her colleagues involve helping students gain success in their social and academic performance. The discussion on community involvement in the arts and the opportunities for enhancing arts instruction in the classroom centered upon the beautification project of planting flowers in the parking lot. 


\section{Celine’s Lesson Plan Analysis}

Our discussion of lesson plans focused on the overarching question \#3 on Student learning and the way student motivation impacts lesson planning and curriculum pacing. "I am open to whatever is good for the kids to learn. I always preface everything to the kids, I even read the CSOs. I may not go as far as writing it up.

Perhaps sometimes I've written it up there and said, 'Look how this was written.' But I always say, 'This is important. Let me read to you what it says. Are we going to get there with these CSOs?'” The participant did not share lesson plans for analysis of arts integration.

\section{Follow up Interview with Veronica}

\section{Follow up Interview Over Arching Question \#1: Demographic Setting and professional} attributes of an arts rich teacher

Veronica's self-characterization of professional educator.

This final set of questions provided Veronica a chance to characterize herself as an educator. The demographics questions from Initial Interview \#1 provided information to begin this characterization. This question was a chance for Veronica to paint a portrait of herself that blends the colors from a palate of rich experiences and unique personal attributes. These attributes have the potential to shape a teacher's view and thereby her decisions. Veronica can paint her own professional portrait through her narrative insights into her own professional efficacy.

I think I am concerned, caring, have high expectations. I talked about the rubrics and how I set the standards that kids build their projects to meet. (Veronica IF-TV-5.5.09) 


\section{Veronica's personal experience with the arts.}

Veronica’s rich description of her childhood experiences with arts is indicative of her views on what today's children should be entitled to experience. She provided the following response:

I have always loved the arts. Since I was a child, I was exposed to it. We didn’t have all these things. We had a record player and we had records. The Wizard of $\mathrm{Oz}$ was on once a year, and that was a huge thing to sit down and watch it. That was big time. As a child, we loved The Sound of Music in my family. We didn't have video games and things like that. So we had to create our own things and that is one thing I can say we were very creative as children, because we were told to go outside and play. We had what was surrounding us. We lived next to my grandmother, and grandfather had a construction business and a big pile of sand. We would get that sand and make chop suey and feed the jaxs. Large imagination in the play. We would visit my aunt every Sunday, so we would put on The Sound of Music and there were enough of us that we could all act out this musical. This is how I grew up. I know how much fun that was when we were doing our plays. A lot of that childhood experience has definitely come across as an educator in my classroom. (Veronica IF-TV-5.5.09)

Veronica has many samples of artwork, plays, scripts, and song texts. These arts integration samples are not the usual crafty or drawing types of arts lessons that students are accustomed to. Her decisions to encourage students to try these options gave them arts integration opportunities. Veronica says, "I think that the majority of students are missing out.” (IF-TV-5.5.09) 


\section{Veronica's professional growth and development.}

Veronica spoke candidly about the opportunities for fostering her professional growth and development. Participating in the university cohort course with Dr. S. and integrating the arts into the curriculum was a golden opportunity for Veronica: “Not many things are offered along the way. So that is why when the university professor offered the class to us, a few of us just jumped on it.” (IF-TV-5.5.09)

\section{Veronica's reflective practice.}

A very powerful form of professional development is teacher reflection upon student progress, what is working and what is not working, action research, and even personal commitment to continuous improvement. Some teachers write in journals, others engage in collegial conversations of professional reading materials and publications, or even professional learning communities focused on analyzing student assessment data. Veronica prefers to think back reflectively on her teaching.

\section{Veronica's classroom teaching context.}

With regard to providing a description of the classroom teaching context, Veronica provided the following information for her current fifth grade classroom of 22 students.

Well, my desk is in the back of the room, and my children are arranged in groups.

I do not like rows. Not only do they need to get along with each other, but they also need to do cooperative learning. I think that is really important. Sometimes, I will let them choose who they will sit by, and sometimes I will choose. I like to mix it up. I used to, once a month, change their seats around. I have done that every year. (IF-TV-5.5.09) 
There are the usual challenges that all teachers face, for example, finding a fair way to group the students, allowing them to find their own grouping arrangements, random by picking numbers, and helping students find the working partners whose personalities work well in cooperative groups. Veronica's class numbers 22 students; 16 are boys. This does not seem to impact the arts integration in her room.

One thing that I think is so interesting during inside recess is, I will let them dance. I have a dance music CD, and it is the boys that will dance. I have two girls that will dance, and the boys are the ones who ask me. Day after day that is what they like to do during inside recess. (Veronica IF-TV-5.5.09)

\section{Follow up Interview Over Arching Question \#2: Arts integration and the influence of job satisfaction, commitment, autonomy, and change}

\section{Veronica's commitment to arts integration.}

Teachers believe some attitudes are important to the profession. Every teacher makes choices based upon what they believe about their teaching situation. Veronica stated, "I have a high commitment to the arts, because I enjoy it so much myself. I have also had such tremendous response from the children. So I think I have a high commitment to it. Anytime I can plug it in, I do so. I would say that is a high commitment.” (Veronica IF-TV-5.5.09)

\section{Veronica's teaching satisfaction.}

I have a high level of satisfaction. I don't think anybody who is in this business would still be here if they didn’t enjoy what they are doing. I like summer vacation. (Veronica IF-TV-5.5.09) 
Love for summer vacation is something that hard-working teachers both strive for and use to re-tool their professional development and replenish their energy levels. Many teachers love summer for travel, study, coursework, and professional conferences.

\section{Veronica’s control over curriculum and instruction.}

Is a teacher's autonomy part of what makes her decide the course of her curriculum and instruction? In an educational era when so many reading programs are scripting the instruction in order to target a child at risk, the prescribed curriculum requirements will help a failing child achieve success. How does this impact the way you feel in general about your sense of autonomy?

I am sarcastic when I have to follow scripted lessons. Now, when I am doing the state accountability test, I tell the students beforehand, I have to say this a certain way so it is a little frustrating to do scripted things because I am too spontaneous. It is just so different to be given something like that as opposed to working with the children. (IF-TV-5.5.09)

\section{Follow up Interview Over Arching Question \#3: Student learning and how you integrate the arts}

Veronica's awareness of student motivation.

Capturing the essence of what part student learning plays in her teaching is a question that flows out of Veronica as smooth as silk. Teachers and students have an interactive dynamic that is unique to the classroom.

Well, I will use the examples of these CDs from last year. The girls were so motivated.

This was not only a classroom lesson. It was done outside the classroom, and they arranged for transportation to go to a certain location where they had all of this scripted. They did all the planning. How much more motivation do you need to get involved and 
coordinate all of these things? They were just so motivated, and then when you see the Power Point and the research done, and the pictures they looked up . . . there are just no questions about high motivation and high interest levels. That is just absolutely awesome. This year, with the interest level we have just once again a different level group. But when they do these plays, it will be something a bit different. It is elaborate, but certainly when they do their plays or art work. You can still see who has enjoyed this. Even the shyest classmate will still have a part in that play. Probably you need to know the students and their personalities and when you see them coming out and participate, and then you know that they are involved and motivated. (Veronica IFTV-5.5.09)

\section{Veronica's views of student motivation and impact upon lesson design and pacing.}

Students' reactions to a lesson or their motivational response have the potential to influence lesson plans, curriculum design, and pacing. Veronica believes that "Motivation is the key to almost everything. How motivated are they to do anything? Pace ... well that affects the whole classroom, absolutely. All the way around.” (IF-TV-5.5.09)

\section{Veronica's teaching design for successful and struggling students with special} needs.

Her years of experience and her knowledge of special needs students provide Veronica with an edge up on her design for adjusting to the individual needs of students. She said:

Well, you have to keep trying for the ones who struggle. For the ones that succeed, that is easy. You just keep giving them work, but the ones who struggle ... change things often and make activities successful for them. This 
way, they get motivated too when they are having success. Whatever levels

their success comes on, you have got to change it up. (Veronica IF-TV-5.5.09)

\section{Veronica's teaching accommodations for special needs students.}

Oftentimes there are struggling students who are not identified as special needs students. It is a special teacher who can masterfully identify what a student needs when trying to achieve content mastery.

Last year I had some very challenging situations in that we had behavior problems.

These were not special needs labeled. However, at this age students often exhibit preadolescent behaviors and anger can boil off. Even this year, I have students like that. I can recognize the fact that they just need to express themselves in one way or another, and we need to talk. They need to have somebody they feel comfortable with, or need to be the star of the play. This one student really wanted to play his guitar, told everyone he was going to perform, and never brought back his permission slip from home. I said to him, "With the play being tomorrow and you have no permission slip." The student was emotionally needy, but recognizing that he needed that attention and then allowing for him to play his guitar throughout the day for the classes really helped. It was not going to solve all of the problems, but will feed a need so much along the line. (Veronica IF-TV-5.5.09)

Veronica gave another opportunity to the student whose permission slip may not have been signed for reasons beyond his control. She used the arts integration culture to make a decision on behalf of the student. 


\section{Follow up Over Arching Question \#4: Use of the arts beyond the classroom Veronica's parental involvement as important to teaching.}

Teaching has evolved over time to recognize involvement beyond the classroom. Currently there seems to be a strong push for collaboration with professionals, parents, and communities. There are publications and strategies for gaining teacher input over the external classroom influences and ways that those influences impact arts instruction. Veronica provided wise insight on these influences:

Well, I think when you have parents that have special talent, and they are willing to share. I always take that opportunity to invite them to come in and work with the kids and do a project for the class. So I think that when they speak up, if we know and can ask them to come in, that it is really an important time to take advantage of the people in the community who have these special skills.

(Veronica IF-TV-5.5.09)

\section{Veronica's community involvement and opportunities for arts instruction.}

There are things offered for the children that I know the majority of us were pretty supportive of. For example, trying to get them to go to plays. Students are not exposed to that as much as we would like them to be. We have a perfect opportunity in Madreas to take advantage of that. So we always try to go to a play. We go to the university creative arts center as a special activity for them at Christmas time. Some of the children, especially this year, we have a few girls that are involved in the ice skating and the Madreas theater group. I think it was last year or before, I had a student that was performing so the whole school actually got to go down as a cast member. We found out in just enough time 
that we were able to do that. They try to take them to opportunities that are

presented here in town also to include the children. (Veronica IF-TV-5.5.09) My Reflection

In my work as a planning period resources specialist, I taught music, art, and physical education in a small elementary school. Grades kindergarten through sixth grade and one special education classroom attended this downtown school. Teachers welcomed my presence in their classrooms for more than just the planning time they gained. I stayed in touch with their planned curricula and made every effort to create meaningful art and music lessons linked to their content. Some of the arts integrated activities included creating a life-size painting of Civil War General ... "Stonewall" Jackson. Fifth graders concentrated on Civil War and fourth graders studied West Virginia history. Both grade levels could collaborate on similar content and creating a life size painting of this general united both classrooms and their teachers.

In addition to studying the works of a great military general, the student artists learned about large scale drawing, selecting appropriate brushes, shading and light techniques, and mixing paint pigments. A local merchant featured the student's painting in their display window, including student photos of their stages of progress on the painting. When one newspaper reporter saw the student work in the downtown window he wrote an article featuring this project. This motivated students to provide their very best work because the community was interested and watching for their next learning success.

Veronica's collegial interactions among other team members and school districts.

In Riffe Park, there were three teachers who started out in the university arts integration planning and implementation for the public school system. In addition to discussions in the professional development part of our interview and collaboration with other colleagues at all 
levels in the school system, Veronica discussed what was happening at Riffe Elementary and beyond.

We really don’t have a great deal of collaboration time. If we did have collaborative, we definitely would take advantage of doing so. I think that just in our classroom, and of course, we can share with each other. When we do a play or when fourth grade comes in our classroom to see our work, there is a measure of provision that we lend to the other classrooms. But like collaboration as far as working together with the children in a project, we have not done that yet. (Veronica IF-TV-5.5.09)

All of the effort expended in helping at-risk children see new ways to learn carries forward to middle or high school. You are teaching valuable skills here, so they have become life skills. Veronica can talk fluently about the school-wide American flag with painted hand prints of each student in red, white, and blue on banner fabric. It hangs on the wall of the school vestibule for visitors to marvel over.

That is from our art specialist. She and the music specialist are instrumental in putting the Night of the Arts together as collaboration between them. Personally, I haven’t had any collaboration among my colleagues. I guess we have had past opportunities if we were doing a project in a classroom and needed to ask them for assistance. Most of the time schedules are so backed up with curriculum that they would say, "I will try to squeeze that in, so I hate to ask anyone, and I would just do the job myself or not do it. Just once again, there is so much you have to teach and you have only so much time to teach it. It leaves very little time for that kind of stuff.” (Veronica IF-TV-5.5.09) 
Veronica is an independent thinker and doer. She takes classes in arts integration and comes back to the school house and implements it with mastery. She is not reluctant to call it like it is. Her lessons are grounded in CSOs and the teacher manuals, but she facilitates student learning outside the confines of her textbook.

\section{Veronica's Lesson Plan Analysis}

The lesson plan discussions focused upon the content located in her student and teacher manuals. She uses these resources skillfully and with efficiency. She is teaching reading in her health class. Then she gives students the option to complete activities in the standard series that falls in alignment with state content standards and objectives. The previously discussed health posters and video commercial came from an extension in the chapter review activities. Students can select the activity they most want to complete and demonstrate their knowledge of content.

Veronica provided me with examples from textbook chapters where she has helped students make connections using activities right out of the textbook. She said:

I will get you the book and show you the story from the textbook. It must have been another one of the making connections activities. It asked students to write a letter to the main character, and then express your feelings. I think this is how you have to do it. I don't know of how you could do it any other way. This is the one thing I really liked about this reading series - the way they had the assignment set up, you could also incorporate writing. (Veronica IF-TV-5.5.09) We had a rigorous discussion over lesson planning and using the classroom textbooks as resources for planning and pacing. Veronica was skillful in her use of textbook instruction. 
She had confidence in the content and strategies provided by textbook design. She used the suggestions in her teacher's manual to provide students with sound instruction and choice options from the "making connections” section of her textbook. This research participant did not share lesson plans for analysis of arts integration.

\section{Selena M. Day Primary School}

Selena M. Day Elementary fits the description of a precious jewel box in the heart of its sunny little neighborhood. Approaching the school on a lane of tall shade trees makes for a welcoming approach to this quaint, primary-grades schoolhouse. The neighborhood boasts steepled churches, a bank, independently owned businesses, eateries, and is just minutes away from the sprawling campus of the local university.

Children in pre-kindergarten through third grade attend Selena M. Day primary school where there are two classes per grade level and a teacher-pupil ratio of 1:16. The average class size is 17.5 , and students come to school at a $97 \%$ attendance rate. Teachers have an average of 20 years of experience, and 73\% have achieved a master's degree with additional hours beyond. Resource educators include counselor, music teacher, art teacher, media specialist, physical education teacher, and speech pathologist.

With a 22\% poverty rate, Selena M. Day Primary does not qualify for Title I federal programs assistance. Selena M. Day is an affiliate of the local university collaborative for teacher reform, and its business partner is a local community bank. Accountability testing in this state begins at grade three. Students in pre-kindergarten through second grade receive informal assessment inventories and benchmark assessments in literacy and mathematics. 
Selena M. Day’s website is a base of informational resources for parents and the community. Its school information link provides a glimpse at the school vision, mission, and three instructional themes guiding its goals and strategic planning. A close affiliation with the university collaborative makes the school an indispensable resource for pre-service teachers. Strategic planning was this school's practice for years prior to the state requirements for strategic planning. The school's vision and mission statements reflect strong staff commitment to a quality practice environment for their pre-service teachers with a focus upon students' creative abilities. Affiliation with Dr. S., the university facilitator of arts integration, provides a dual effect. Selena Day is a school environment where the university's pre-service teachers have access to instructional excellence in arts integration, and Selena Day's teachers have access to professional development at the university level. This is a win-win situation for all educators and ultimately for the students.

Vision Statement: The Selena M. Day Primary School community is a place where individual differences are valued, where varying needs are met, and where each person's potential to learn and grow is realized. All members of the Selena M. Day Primary School Community are actively engaged in developing their abilities as life-long learners. We envision that Selena M. Day Primary School will provide an example of the best classroom practice and an effective forum for pre-service teachers.

Mission: Selena M. Day Primary School strives to implement a processoriented, student-centered curriculum. Our mission is to build on students' strengths and creative abilities to facilitate the holistic development of children, enabling them to become life-long learners. The mission of our school supports the state goals, county goals, and the belief statements of the University Professional Development School program.

S. M. Day's learning themes were included on the website. Professional development collaboration with teachers and the university was included in their three goal-like themes. 
Theme 1: To plan, implement and assess a developmentally appropriate curriculum, address individual differences and diversity issues, give emphasis to the integration of the arts in early childhood education, include appropriate and meaningful assessment, and encourage effective use of technology.

S.M. Day has committed in writing to a theme that articulates arts integration for its

students. It has systematically and strategically incorporated its arts initiatives into the heart of its school culture. The next bullet that expounds on Theme \#1 above elaborates on this school's commitment to arts integration.

- S.M. Day primary teachers have been trained to use the 4MAT model (About Learning, Inc.) to design instructional units that meet the needs of a variety of learning styles and balance instruction for the left and right brain. Instruction is further enhanced through the integration of the arts across the curriculum. Teachers help students learn through music, visual arts, movement, and drama. Instructional technology is available in the classrooms and in the technology lab. Teachers and students use technology resources regularly to enhance teaching and learning. The state instructional goals and objectives provide guidelines for the total program.

- S.M. Day is part of the Professional Development Schools (PDS) network at the local university. The Teacher Education Center at S.M. Day Primary was designed in collaboration with the university to provide rich field experiences for pre-service teachers. Kara serves as the PDS site coordinator. Other classroom teachers mentor these pre-service teachers during many hours of field placement.

The strategic planning, professional development collaborations among school staff and university staff are presented throughout stories of each of the five research participants from S.M. Day Primary School.

\section{School Culture}

Walk into Selena M. Day and you enter a children’s art gallery. Immediately inside the school vestibule the art show begins. Two large colorful murals depicting the school and its distinction as an exemplary school arise to greet all who enter. Madreas County High School 
students designed and painted the murals. Hallways are equipped with art mounting strips so that student artwork can be displayed with integrity as trophies of teaching and learning. All student artwork is matted and represents children's media such as crayons, markers, pastel, and chalk. Life-size students made of butcher paper cut outs stand sentry outside health class to announce student mastery of human organs and systems. Displays of illustrated poetry and stories, hanging mobiles, and abstract geometric designs represent arts integrated learning. Students are comfortable painting and drawing as they fill the page with details and command use of color and variety of art themes. And that is only what's happening in the hallways! Classrooms are equally rich in student artwork samples, musical instruments, and arts materials stations. In one kindergarten classroom, students returning from the playground enter into their dimly lit classroom with a CD playing softly to greet their return. So thorough is the importance of arts in this school culture that even the smallest tutoring room was brightly adorned with real student art, matted, and labeled with the student-artist's name.

Of the five teachers participating from Selena M. Day Primary school, one is currently teaching; four are retired. All are or were participants in the university’s professional development collaborative and committed to classroom arts integration for their students. S. M. Day’s teacher interview narratives, student work samples, and lesson plans are presented in the following format: one current teacher narrative, one retired teacher narrative, and three retired teachers narratives in a collegial conversation interview. Student work samples and discussions will be included with each teacher's story. 


\section{Kara}

\section{of Selena M. Day Primary School}

In the uncertain light of single, certain truth, Equal in living, changingness to that light In which I meet you, in which we sit at rest, For a moment in the central of our being, The vivid transparence that you bring is peace.

Wallace Stevens, "Notes Toward a Supreme Fiction"

Listening to a teacher talk about the spiritual work of shaping human minds and spirits is a both a privilege and an exchange of human energy. Kara and I had never met, other than talking on the phone and through email communiqués, so meeting for the first time was an opportunity for two colleagues to expand and grow a new relationship. We both took time to pause in the middle of our full schedules, and in a small sunlit tutoring room we began the retelling of our life’s work. It was a risk-taking chance. I had questions, so I am sure Kara did too. What if we did not understand each other? Would there be judgments about our work with students and colleagues? Would we put one another on the spot with our questions or answers? All of these and more "unspokens" loomed before us prior to meeting. Yet we still agreed to work together, for the sake of our profession, our students, and the possibility that the story told honestly and written with integrity would shatter the unknown, illuminate the transparence, and unfold into a feeling of peace. For what, if anything in our work, at the end of a long day, week, semester, or year is more precious than finding peace with ourselves and the world?

Kara’s 37 years in the teaching profession has led her to a role of teacher-leader among her colleagues at school and at the university. Specialized training in working with pre-service 
teacher education has been her hallmark and is in concert with the school's mission and vision.

She has served on numerous educational committees in the university's professional

collaborative. Currently, her teaching assignment is with kindergarten, although she has taught first grade and has certification in pre-kindergarten through eighth grade. Kara has

demonstrated commitment to furthering her professional development through attaining a master's degree and 45 additional hours. Prior training in the arts includes piano lessons. Kara has a family of her own, and her sister is also an educator - the principal of an elementary school.

\section{Initial Interview Question \#1: Curriculum “How do you decide what to teach?”} Kara's curricular decisions.

Kara has a quiet energy and enthusiasm for her work. Years of experience with small children has graced her with a comfortable ease of expression and tone of voice. She began her story about the curriculum without hesitation and was skillful at extending with details and rationales.

Curriculum is for the most part guided by state and county guidelines.

However, I have been teaching for 37 years, and I pretty much know what is for kindergarten and what isn't. I work with the other kindergarten teacher in our building, and we collaborate and reflect on what we are doing. We have developed a curriculum map with types of things we are going to be teaching throughout the year. It changes throughout the year, and at the end of the year we spend time reflecting on how we are going to change it for next year. (IITK-4.29.09) 
In her story, Kara continued with rich details of thematic instruction that determines her kindergarten curriculum. She could articulate the scope and sequence of these contents with explanations for the timing and conditions for each unit. For example,

We always start out at the beginning of the year with all about me and about the children's families and themselves. We do units on community at the beginning of the year and careers and friendship. (II-TK-4.29.09)

Other themed units include holidays, Appalachian culture, patriotic America, and science for plants, insects, and sea life in the spring. In this portion of the conversation, attention to the content standards was clearly prominent in determining what to teach. But her rationale did not stop at content.

As for instruction, that is pretty much based on the children's needs. We try to teach to each child's individual needs. We might be teaching the same concept, but we might have different expectations of lower than higher. Also, it depends from year to year. Like this year, all of my students either knew their alphabet letters, and most of their sounds, when they came into kindergarten or able to learn as we went along. So it depends on the students. Also, it is on their interest. Like some years you might do a unit like the last two weeks on insects. The kids this year were really a lot more interested than they have been in other years. So we went into it a little more deeply and did a little more of the science content. It depends a lot on the students. (II-TK-4.29.09)

In hearing her rich description about the content of reading and science, I redirected the question to focus on arts integration. Kara provided specific examples to exemplify how she used arts integrated lessons for science, literature, and social studies. 


\section{Initial Interview Question \#2: Instruction: “How do you decide how to teach?” Kara's instructional decisions: The art of provision.}

We try to incorporate the arts in everything we do, such as having a type of music and art every single day. Just last week we were doing the insects unit and the day we were talking about butterflies, children painted butterflies and made little models. We incorporate literature into everything we do. We read books about butterflies and talked about those things. We put on music and the kids pretended to be butterflies and fly around the room. Some children pretend that they are flowers and the butterflies go to the flowers and get the pollen. We try to get those concepts of gathering nectar from plants and how they transfer the pollen. We try not to just tell them, but have them actually doing these things. We do a lot of class books. When we were doing the Appalachian lesson, we read the book about being down in the mountains. After that we had everyone make their own class book, and each child designed a page and wrote the words to go with it. Here we were incorporating the arts with literature. (IITK-4.29.09)

In the teaching profession, professional development greatly influences what we do.

Teachers are constantly trying to find relevant professional development that will work and still yield those meaningful connections to teaching and learning. For teachers who keep their eyes on the professional development prize, they have the wisdom to convert their professional development experiences into their instructional practices.

Of course I seek out things about the arts because I enjoy that, and a big part of our school's mission is incorporating the arts into the curriculum. Over the past 
several years, I have also been trying to attend as many technological

professional development things as I can. When I went to college, we didn't use

computers, and even in my first twenty years of teaching, we didn’t use

computers. I feel like I have a lot of catching up to do. I try to attend

professional development sessions to learn to do more things with the computer

and then take those back to the classroom. (II-TK-4.29.09)

The fortune of having six computers in the classroom and a university pre-service

teacher makes a greater opportunity for students to become more technologically literate. Kara indicates that the university students have technology skills and are a great resource for having students gain proficiency in technology tools for teaching and learning.

Initial Interview Question \#3 Decision Making: “What professional development do you seek and how do you use these skills?”

\section{Kara's professional development decisions.}

Throughout the narrative so far, there have been numerous references to self-selected professional development opportunities at the university—especially in the areas of technology and teacher education. There are responsibilities and advantages that accompany a desire to stay current with changing trends in education, the affiliations with professional development agencies or the university collaborative. Kara's high quality work with pre-service teachers is important to the university and to her fellow colleagues at S.M. Day Primary. She described the responsibilities of preparing to assist her novice university students:

We attended the Association of Teacher Educators in Texas where I was part of the presentation team. I talked about what I do as a teacher education coordinator. I am also the teacher education coordinator here at Selena M. Day 
Primary school. My work with pre-service teachers enables me to have release time throughout the week during the school year. One of our newly graduated master's program teachers works in my classroom as I assist the university preservice students in managing their responsibilities as pre-service educators.

Together, we do all of the planning. (II-TK-4.29.09)

This is an excellent chance for the all of the collaborating teachers to achieve success. Kara's investments of time, collaboration expertise, and other shared knowledge are integral for her successful oversight of the pre-service teachers at S.M. Day.

Initial Interview Question \#4: Reflection: “What does the community say about your arts integrated teaching?”

\section{Kara's instructional decisions: Community.}

In previous sections of the interview conversation, Kara mentioned ways that parents are involved in the March student artwork show. The week-long show is held in conjunction with the school book fair. School stays open one evening so that parents can come back to school to see the art on display as they walk through the hallways.

Kara has a class website that is updated weekly for parents' information, and she sends home a printed copy so they can always be aware of classroom happenings. She sends curricular updates at the start of new unit to share the current goals and objectives to be covered by students. She views this informational service to parents as a rewarding one.

I got an email from a parent saying just how much she loved the insect project that her child brought home. She thought it was a really creative idea and wanted to let me know. That was really nice, and I thanked her saying, "We don’t often hear positive things from parents.” (II-TK-4.29.09) 
There are numerous churches and small businesses in this compact community. Community partners can be an incredible resource to schools, teachers, and students. When I posed the question of community school relationships, Kara replied,

We don't really affiliate with them but we do use St. Mary's church down in the neighboring community. We use their green and pavilion to have our field days and science fairs. The local bank, also a partner in education, is very supportive, and we have taken numerous field trips for career enhancement. Every month a different class focuses their artwork, and on alternating months, students prepare individual and class artwork for display in their work for pre-kindergarten. (IITK-4.29.09)

\section{Kara’s Comments on Student Artwork}

Two very elaborate 4MAT units and a variety of other student work samples were offered for this research study. Units were collaboratively designed and taught by Kara and her pre-service teachers from the university. Her nutrition unit was developed in fall 2001 and featured creating songs, rhymes, puppets, and a pizza game,. The Eric Carle unit from fall semester 2004 was collaboratively developed by Kara and a pre-service teacher. Students experienced arts integration through activities that coupled with Carle's children's books. For example, after reading Carle's book, The Tiny Seed, an arts integrated extension for the literacy lesson included the "build-a-plant” activity. Science content was supported throughout the story; students learned about the parts of a plant: roots, stems, leaves, flower. After illustrating their own plant picture, students cut plant parts into sections and rearranged them in order. Other unit arts integrated activities included creating Styrofoam bowl tortoises after reading Carle's The Foolish Tortoise. Students used rhyming activities, and in science they 
incorporated sinking and floating activities. During morning circle time, students listened to a read aloud for Little Cloud to support listening comprehension. Students learned to move to music when they sang simple songs and chants to support learning body parts and playing "stand in this position" games.

This sample is part of a sea life unit. This is a piece we do when we introduce the unit on the ocean and sea life. We do this on the second day of the unit because we are talking about seaweed ad how it provides oxygen. We discuss the circle of life in the ocean and how fish feed off the seaweed. Small fish first, then medium size fish feed off of those larger fish. We also emphasize the bottom of the ocean and the water and seaweed floating in there. Then they can decorate the fish. We also discuss scales on the fish and their gills. (IFTK-5.11.09)

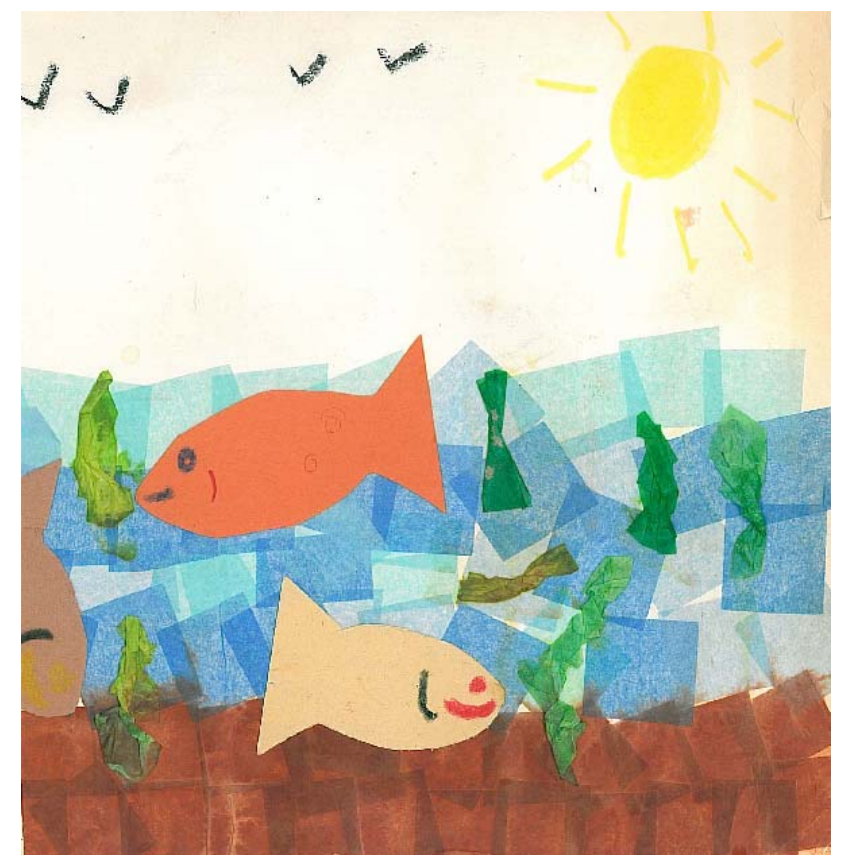

Figure 4. Sea Life Science Lesson. Students learned about circle of life in the ocean then used torn tissue paper in mosaic style. 
Using the four over arching interview questions of curriculum, instruction, reflection, and community, the matrix for discussing student artwork connects teacher decision making to student work samples. The following table takes the matrix checklist items and summarizes the categories of teacher instructional decisions that can be seen in student lesson samples.

Matrix for student tissue paper mosaic Sea Life

\begin{tabular}{|l|l|l|l|}
\hline \multicolumn{1}{|c|}{ Curriculum } & \multicolumn{1}{|c|}{ Instruction } & \multicolumn{1}{c|}{ Reflection } & \multicolumn{1}{c|}{ Community } \\
\hline $\begin{array}{l}\text { Reading, Writing, } \\
\text { Social Studies, Science }\end{array}$ & $\begin{array}{l}\text { Writing, Text } \\
\text { Interpretation }\end{array}$ & $\begin{array}{l}\text { Confidence, Esteem } \\
\text { Efficacy, Aspiration }\end{array}$ & $\begin{array}{l}\text { Community Service, } \\
\text { Social Problem Solving }\end{array}$ \\
& & & \\
\hline
\end{tabular}

Kara’s students can master concepts required through integrating arts and science concepts. They write and illustrate stories and class books. Appropriate kindergarten content is planned and provided through the state content standards (CSOs) and supplemental instructional resources such as informational literature trade books and maps to locate oceans. During class discussions, students increase their knowledge and awareness of environmental issues and ways to protect and appreciate our sea life creatures.

The pizza pie art activity from the nutrition unit helped students understand the nature of this food item by studying its origin and all of the rich food pyramid items that go into making a pizza pie. Students created their real food pizzas identifying the food groups for each item. While pizzas were baking, the pizza pie art activity kept students engaged in creating their own versions of pizza. Materials include: a paper plate pizza shell, red paint for pizza sauce, black pipe cleaners for olives, white yarn for the shredded cheese, green pipe cleaners for green peppers, and red construction paper for pepperoni. 


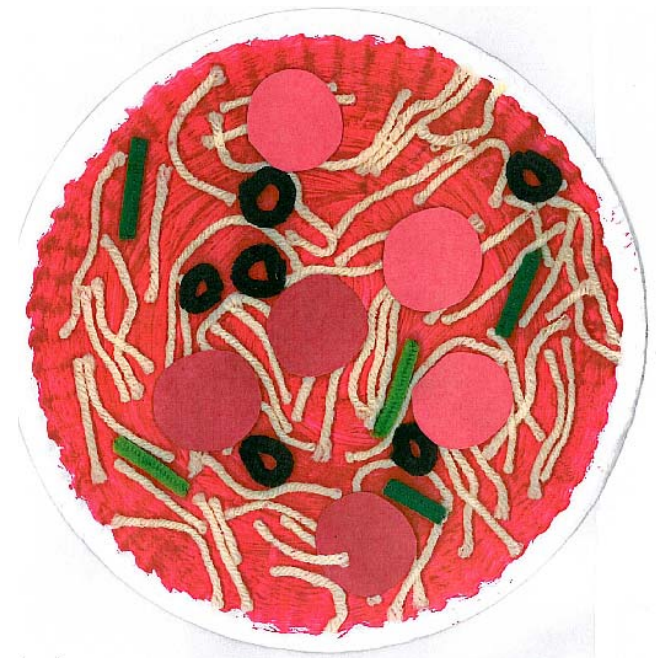

Figure 5. Pizza Pie Health Lesson. Students learned about food groups and created a craft pizza while real pizzas baked in the oven.

Using the four over arching interview questions of curriculum, instruction, reflection, and community, the matrix for discussing student artwork connects teacher decision making to student work samples. The following table takes the matrix checklist items and summarizes the categories of teacher instructional decisions that can be seen in student lesson samples. Matrix for student pizza pie art

\begin{tabular}{|l|l|l|l|}
\hline \multicolumn{1}{|c|}{ Curriculum } & \multicolumn{1}{|c|}{ Instruction } & \multicolumn{1}{c|}{ Reflection } & \multicolumn{1}{c|}{ Community } \\
\hline $\begin{array}{l}\text { Reading, Social Studies, } \\
\text { Health, Science }\end{array}$ & Interpreting text & $\begin{array}{l}\text { Efficacy, Confidence, } \\
\text { Aspiration }\end{array}$ & $\begin{array}{l}\text { Social Problem Solving, } \\
\text { Tolerance }\end{array}$ \\
\hline
\end{tabular}

Kara's students use the concepts learned through integrating arts through health and nutrition concepts. They locate Italy on the map and discuss the ways food groups nourish their bodies. Appropriate kindergarten content is planned and provided through the state content standards (CSOs) and supplemental instructional resources such as informational 
literature trade books and maps. During class discussions, students increase their knowledge and awareness of the food pyramid and health awareness issues.

Follow up Interview Over Arching Question \#1: Demographic Setting and professional attributes of an arts rich teacher. Kara's self-characterization of professional educator.

A long and rich career is a teacher's crowning glory. To hear Kara talk about herself as a professional educator is an inspirational insight into her commitment to teaching. Her life’s work has evolved over her 37 years teaching early childhood children. A rich and rewarding career such as hers positions her to have a perspective of the myriad of changes in education. It is also a testimony of her willingness to bend and grow throughout the decades of continuous school improvement that face educators.

Even though the overall demands have changed, I still feel it is really important to follow the National Association of Young Children guidelines. I feel like you can still teach your goals and objectives through play, through art, through music. So I try to do that. I think that is one of the main things. I would want people to know how I teach. I have been here at S.M. Day for 20 years. I don’t know what else to say, except that I grew up teaching. I love the people that I work with, and I have a really wonderful family here at Selena M. Day Primary School. (IF-TK-5.11.09)

Kara has a sincere demeanor that is modeled for the kindergarten students she has shaped over her 37 years of teaching. As she characterizes her professional self, she reveals that she wants others to know about her teaching decisions. She recognizes the power in 
following standards and her own ability to accomplish these standards through her arts integration lessons. She has identified her own arts experiences from childhood to present.

When I was a child, I took a few years of dance lessons, and I took piano lessons

for several years. I guess I have been more in the arts with my children, as I have been raising my two children, than I have personally for myself. My daughter was a dancer all the way through high school and was involved in piano and clarinet lessons. My son took piano lessons for several years. Both children took art classes over at the university on the children's Saturday and after school sessions. Also, we tried to take our children to many plays and concerts as they were growing up both in our hometown and in the city of Pittsburgh. Even on vacations we tried to go to theater or concerts. I have been involved in the arts that way, personally.” (IF-TK-5.11.09)

\section{Kara's professional growth and development.}

It has been said that the best way to learn a concept is to become actively involved in teaching it to someone. As teachers seek to share their experiences—successes as well as shortcomings - there are professional development exchanges taking place. For those who are dedicated to helping the novice teacher survive the grueling initiation into teaching, there is an authentic measure of reality that helps a student become the best one can be. Kara's position with the university as the teacher education coordinator for her school is the capstone of her professional growth and development experience. She has chosen to serve and grow professionally by being the liaison between pre-service teachers and the university's education department. 
I try to attend professional development sessions in the summer, either the ones offered by the district or by the university. For the last few years, I have been about to do more of those since my children are older. Although when they were smaller, there were often times I would take them to the babysitter so that I could still go to the trainings. It is a marvelous experience, especially as far as being able to reflect on your own teaching. By helping them reflect on their teaching, it helps you reflect on your own teaching. I know when I am observing now, the things I am writing about them, I think, 'Oh I am doing what I wrote down that they were doing, or what I am encouraging them to do.' I think it helps me be a better teacher, not only in the delivery of the instruction, but getting new ideas from them as well. (IF-TK-5.11.09)

\section{Kara's reflective practice.}

That ability to exercise self-reflection is the beginning of a conversation that identifies one's best and least favorite attributes or practices. The work of reflective practice must begin somewhere. For some, it is self-reflection. For others, it is reflection with a partner. Either way, reflective practice is a behavior that, when used, has powerful implications to impact the human spirit.

I think first of all, no matter what you teach throughout the day, you always immediately reflect, 'Was that successful? The next time I teach that, I want to add such-and-such. I might change it in some way.' I am very fortunate that the other kindergarten teacher and I talk just about every morning or afternoon. We try to teach the same units at the same time. We might not be teaching the same lesson the same day, because we do share materials. We are constantly 
reflecting with each other back and forth with the sharing of ideas. Also, I have the graduate student in my classroom four mornings a week for two hours each morning. I have to be discussing and reflecting with her about what she is teaching and how it fits into what I am teaching, and how we are sharing materials and ideas. Again, with our pre-service teachers, evaluating them, working with them, and helping them plan their lessons helps me to be a better teacher. (IF-TK-5.11.09)

\section{Kara’s classroom teaching context.}

Kara's 23 students are fortunate to have a teacher with a "good system.” Her description of the classroom context is reflective of her sense of order and structure for her kindergarteners. The school's mostly average income students receive strong core instruction in their formative early years of school. There are no Title I teachers at S.M. Day, and students identified for special needs services attend school at the larger sister school. Kara characterizes her teaching context in the following statement:

The classroom is very child friendly. I tell my kindergarteners and their parents that there is nothing in kindergarten that can't be fixed. If you make a mistake, we can always fix it. That is why we have tape, glue, and erasers. If something gets spilled, we can wipe it up. Nothing is broken so the classroom is very child friendly. I think it is very attractive. I display a lot of the children’s art work, posters and pictures on the bulletin boards. I keep the room organized, and each child has his or her own mailbox and a cubby to keep their things. Student organization is a folder that goes to and from home. I think you can say, 
although sometimes it looks chaotic, it is organized. It is child friendly, and I

feel it is attractive. (IF-TK-5.11.09)

A teacher's classroom is her sacred domain. It is a place to nurture and be nurtured.

\section{Follow up Interview Over Arching Question \#2: Arts integration and the influence of job satisfaction, commitment, autonomy and change \\ Kara's commitment to arts integration.}

Knowledge of the young learner and an awareness of their need for movement and role playing were two elements coming through in Kara's narrative. She realized that the arts integration gives students a chance to expand their learning and meet the developmental needs of her five year-olds. "I think I am very committed to integrating the arts. We do some type of art activity every single day. We do music every day. We don’t do drama every day, but we try to do it often.” (IF-TK-5.11.09) She explained that the unit development with her colleagues and the university pre-service teachers is something that needs to be incorporated in their lessons.

\section{Kara's teaching satisfaction.}

What constitutes a teacher's measure of satisfaction? Is it made up of a compilation of events or locations or students? Is it made up of the relationships created and sustained with colleagues or a set of content knowledge that becomes a teacher's special interest or joy? Does it consist of her unequivocal knowledge that she has taken a group of children who could not read and transformed them into book lovers? Whatever it is that makes for teaching satisfaction, Kara articulated her heartfelt response with specific examples that trace her levels of satisfaction. 
"Very satisfied. I have been very fortunate in my teaching career that I have been in schools with high level parent involvement. I have only been in four different facilities. My first two years were in a church basement. That was when the kindergarten program was just starting in the county. Then I was in a very small school similar to Selena M. Day. Then I came here. All of those schools had high levels of parent involvement—nice families. I have been fortunate that people that I have worked with over the years have been very professional and got along well. I have been very fortunate to have good teaching aides. On a scale of one to ten, I would say my professional satisfaction is probably a nine. I guess the only thing I am not satisfied with is that every year there are more and more demands placed upon the classroom teacher in terms of assessing the student. There are new things that come out from the state that we have to incorporate into our curriculum. We have to do more things, but they don't give us more time to do those things. With young children, kindergarten and primary-aged children, it is not like you can say we are going to have silent reading now, while the teachers pull one child out to do individual assessments. If I had to say one thing that would be it—-the time factor.” (IF-TK-5.11.09)

\section{Kara's control over curriculum and instruction.}

When asked about her perceptions of control over her curriculum and instruction, Kara provided the following response:

I think as far as what we teach, we don't have a whole lot of control because it is guided by the state CSOs. However, I think how we teach it is one of the things 
I like about teaching. You are kind of your own boss as long as you are sure you are covering CSOs. You can pretty much deliver it however you feel. I feel like trying to deliver it to the whole child through the guidelines. NAYEC is really important so that it is not constantly academic. That you are teaching your goals and objectives through play, through art, through music, through literature. I just feel that is really important because they are only five years old, and they are only going to be in kindergarten one time in their life. You try to make it a successful experience whether they are happy and enjoying school so that they continue in school ... they have good feelings about school. (IF-TK5.11.09)

Kara discussed a survey that was used to help her analyze the kindergarten program and to reflect upon its effectiveness in their school. The focus of the program was upon reading and she requested input from parents on their students' progress in kindergarten. She indicated that it was pleasing to receive so many responses, mostly positive, from the parents. Information on the survey included student enjoyment of reading, quality and readability of the take home books, value of sending books to read at home with parents, student success in kindergarten, and strengths or concerns about kindergarten.

\section{Kara on making and sustaining change in teaching.}

Kara had no hesitation in admitting that professional development influences her to make the changes. "Well, professional development. When you hear things about professional development you want to try. And then if it is successful, you talk to another teacher and she says, 'We have done this in our classroom and it has been really successful.' That makes us 
more willing to try it. And then if it is successful and you feel like it is something better than what you have done in the past ... naturally, are going to keep doing it. Success spurs you on to try or to continue with something.” (IF-TK-5.11.09)

There is always the question of how we as humans respond to a good stimulus; perceived or proven, it is natural to do what seems to work. Educators have access to, rather are inundated with, all of the latest educational developments. "Research-based" is the most recent guide word in purchasing and using intervention materials, curriculum supplements, and core academic programs. We want proof that a program works. Although publishers of these programs assure us that they will work, there may be conditions that control the outcome for students. Some of these conditions include number of instructional minutes per day, following the scripted protocols, tracking student progress, and making prescriptive adjustments for individual students. Kara made an honest statement that success spurs you on to continue with something. The rankling question is, "What about those teachers who perceive their instruction to be successful, when the data says students aren’t demonstrating success? Is there always vigilance in even looking at student achievement data to determine if it is successful? Is it considered to be successful because students seem to be enjoying the instruction?”

\section{Follow up Interview Over Arching Question \#3: Student learning and how you integrate} the arts

\section{Kara's awareness of student motivation.}

Teachers and students have an interactive dynamic unique to classroom instruction. Teachers and students exchange learning throughout their classroom interactions. Students ask questions, and teachers provide answers or facilitate finding the answers. Teachers ask students probing and clarifying questions, and students provide deeper answers that 
demonstrate their levels of content understanding. Teachers show enthusiasm for learning a particular content, and students respond in kind. So, when teachers plan instruction, a variety of decisions come into play. I asked Kara to talk about her own knowledge and awareness of student motivation. How do you recognize this motivation or even offer specific classroom examples? What do you do when your class or a particular student becomes motivated?

I guess just in the excitement that the children show. When you introduce something, like when we were doing our insects, children were really excited about learning more and more about it. They wanted to learn so much that we had a guest speaker come in. They really enjoyed that. So, I guess just the excitement of the children. I guess if they are motivated and want to learn more, then that motivates you as a teacher, to provide them with more. For example, I'm looking on the internet to find some extra things for them to look at. Also, going to the library lets me bring in more things to show them. A lot of times, we will let them bring something from home to contribute to the lesson. (IFTK-5.11.09)

\section{Kara's views of student motivation and impact upon lesson design and pacing.}

When I asked Kara to discuss how student demonstrations of motivation impact her choices when making lesson plans, curriculum themes, units and pacing, she offered the following insight:

Probably somewhat. Naturally, when you are talking about the November time of year and Thanksgiving, children are motivated to learn about that. That motivates children about Native Americans at that time of year. We try to judge when things work as far as the seasons and times of the year. We do insects in 
the spring because they can go outside and actually look for insects. We do plants also in the spring because we can actually plant things and they can take them home. The ocean we do at the end of the year because it is almost summertime, and a lot of kids from this area go to the beach for summer vacation. I think depending on the time of year and what you are teaching, I think that has a lot to do with it. If you were doing the ocean in November, it probably wouldn't be as exciting to the kids as doing it in May since they go there in summer or over spring break. (IF-TK-5.11.09)

\section{Kara's teaching design for successful and struggling students with special needs.}

A teacher's chance to impact any child gives her the ultimate, altruistic reward and sense of purpose. It is mastering the ability to help struggling students succeed and keeping the successful ones achieving beyond their potentials. Kara believes in her own self-efficacy to reach all of the diverse students in her charge. Here is her story with real world examples.

For those who are succeeding, we teach a lot of the same things to all the children, but then I provide enrichment materials for those who are successful. For example, some of the little take-home books that we give to these students would be different than the ones that the lower achieving students would take. Higher level books with challenging content are what we provide.

As for the struggling students or those who have difficulty focusing on tasks, we are very fortunate. As I said before, we have university students in our classroom. When we do station activities every day for the entire morning block, we divide the class into groups of four to six students, so if somebody has difficulty staying on task, we will make sure that person is sitting right next to 
an adult to keep them on task, focused, and help them along with their work. So, mainly giving them individual attention. Also, in working with them a little bit individually while another adult might be reading a story or teaching a whole group, one child could be working individually with an adult. We do a lot of communication with the parents, too, in sending things home with a note for them to review and work on it at home as well. (IF-TK-5.11.09)

\section{Personal Reflection for Successful Students}

For ten years, while my children were small, I stayed active in teaching as a substitute teacher. After that, I worked as a half-time specialist who provided planning period time for teachers. The first part of my story addresses my work with gifted students, and in the second part I share an arts integration story from one of my special education classes. Both stories highlight my efforts to use the arts as a means to assist students to both reach and reach beyond their learning potentials.

My first narrative is about a group of gifted students whose regular teacher was absent on medical leave. I was invited to be the substitute to cover her absence. These bright and motivated students rode a bus to our gifted center. There were 12 students per class, and they came once weekly from across various locations throughout the county. In the brief period I spent as their "gifted teacher," I facilitated their schoolwork through a unit on futurism. Use of internet searching was on the verge of its information explosion. Our three small groups of four learners each were charged with researching all of the possible future issues they could think of. Some of the topics included limited food and energy resources, humans living on space stations, space communication travel, technology and learning, health and wellness. They created models of transport vehicles, designed medical equipment, sketched agricultural advancements, and designed space stations. 
For our culminating activity, the group buried an informational time capsule on the school property. Students were very thoughtful about the contents of this capsule and how to document its whereabouts. Each student chose one item to include, and together they illustrated a location map for future reference-perhaps when they were having a 50th class reunion.

Capsule items included a letter introducing each student and the purpose of the time capsule, pictures of the models they created for the unit, illustrations of their future suggestions for improved medical equipment, transportation vehicles and space stations, a newspaper, and small toys of the time such as "Papa Smurf." The community became interested in this project and asked students to talk to their organizations, and news and television media covered the capsule planting. Our administrator also provided support for the event and permitted digging in the yard as well as keeping the capsule location map in the school safe. When planning for instructing, I found that these gifted students came to class with high hopes for their daily work. They were buzzing with each other on the bus ride to and from school about what their assignments and findings meant to them. Many came to the next class with print outs of websites they had found helpful in their futurism studies. They had taken their learning outside the four walls of classroom instruction. Self-motivation, conversations with parents, creativity, and critical and analytical thinking are all indicators that lesson planning and design are integral to meeting the needs of high achieving students.

Personal Reflection for Struggling Students:

I will include the following narrative to illustrate how the use of arts for struggling students honors their rights to learn. In my half-time teaching assignment, my subjects as a specialist were music, art, and physical education. I taught in a small, downtown school with six classrooms, kindergarten through sixth, and a special education classroom. Teaching through the arts was what my work was all about. Each class period was 45 minutes long, and I scheduled 
the subjects in six-week blocks to match the grading periods. One of the best musical experiences for the special needs students included learning a program of holiday carols in preparation for the December PTA's musical program. I collaborated with the teacher and classroom instructional aide to get students performance ready for this meeting. The standard for our program was five songs, memorized, a capella, with a premium vocal quality. During the preparation, students improved their ability to match pitch as we focused on isolated tones that they were to vocally match.

There was a very special unintended outcome to this music project. I tossed out a risky possibility to the students. Why didn't we take a chance and send our recording and a picture of our class to President Ronald Reagan? It was, after all, holiday season, and if nothing else we could send along some musical enjoyment to our country's President. This was big! Students really stepped up their attention to the musical preparation. With the tape recording and an accompanying photo and letter of greeting, our mailing was off to the president. In January, a package addressed to the students arrived at school. A response letter signed by President Reagan, along with signed pictures, was delivered to our special education students. The reward for their efforts was acknowledged by the country's highest official. Bigger than that, though, this project promoted student self-esteem, a sense of accomplishment, the musical experiences of concert preparation, and learning to train the musical ear. I learned that my struggling students could achieve beyond their potentials, and that it was my responsibility to provide and prepare for this opportunity.

Follow up Over Arching Question \#4: Use of the arts beyond the classroom Kara's involvement with parents and colleagues integrating arts. Increased educational emphasis upon the importance of involving parents in their child's education led us to consider how many strategic planning initiatives have a clear 
direction for community involvement. Madreas County's belief statement is proof positive of the importance the school system has in involvement beyond the classroom: "Meaningful collaborations/partnerships with parents, business, industry, higher education, community at large in order to enhance the educational process.” Here is Kara’s story about her arts beyond the classroom:

Our parents help us with stations, so we have a volunteer come in and help supervise a station. That is very valuable. Not only does a child like their parents to come in on occasion, it allows us to have a station that could be more involved. If you have an adult here and one that has just children there, we can do more arts integration if we have the parent in to help. We also involve parents in read aloud and in special projects. Parents here are really good about helping us with any kinds of special projects. Like if we wanted to do a big painting. Every year at the end of the year, the children bring in a plain white tee shirt and then we decorate it with hand prints and we have parents who help us do that. We do murals. We also have a parent who is arts chairperson of our parent-teacher group. She provides different things throughout the year for our students. We had the senior citizen's musical band play for the students. In the next upcoming week on each of the days, a different grade level is going on a tour of the local community glass factory. We have had the puppeteers in from our university arts department. They presented a puppet play to the students. And these are just three events for this semester alone. (IF-TK-5.11.09) I asked Kara to explain the school's “A is for Arts” event. She highlighted the idea that special arts events are part of the school vision and 
mission and are incorporated throughout grade levels during the year. One example is the school-wide theme of studying Appalachian culture. "Of course we incorporated art into that theme, and last week the whole school took a field trip to our local historical Prickett's Fort. This was a culminating activity. Each grade level did things all throughout the year focusing on the arts and Appalachia. In kindergarten our focus was in February when we studied our America unit, incorporating many of our state Appalachian concepts such as doll making, quilt making, and basket weaving. (IF-TK-5.11.09)

\section{Kara's involvement with colleagues.}

I asked Kara about the inner-collaboration with other schools in the district. The high school students who painted the entry murals at S.M. Day are great arts role models for the primary students. Opportunities for student exchanges, visits by high school arts, music, and drama students are a few of the ways schools could collaborate and keep younger students looking forward to their middle and secondary educations. Kara indicated the following: "Last year we were supposed to have a concert visit from our middle school students, but there was an unexpected cancellation and it was not rescheduled. We try to do some things like that.” (If-TK-5.11.09)

Our conversation together ended with a special drift towards trends in education today. Kara and I both have the advantage of a career characterized by longevity. We have the advantage of professional perspective. We have seen the impact of time and change upon our colleagues, the curriculum, societal influences, and the nature of student learners. She spoke with compassion about her observations of student needs. 
Students still need a place where they can feel secure, and they need an adult they can trust. Sometimes the school is the only place they can get that. They need to feel successful. Ever since my first year of teaching, I have been trying to make sure the children feel happy when they come into the school, and to make it a place where they can be successful. So, I don't think how many goals and objectives you add to the curriculum ... that is still one of the most important things about coming to school. I don't know if it is just the times or where I am now and where I was when I first started teaching. When I first started teaching there were many more children who came to school dirty and hungry than there are now. I don't know if we are more adept now as a society at providing relief to families than we were then. I can remember there were children in the early days of my teaching that came to school quite dirty and hungry, and there was no breakfast provided in those early days when I began teaching. Now, we don't have children that come to school dirty and we have breakfast for them here. (If-TK-5.11.09)

\section{My Reflections}

I can relate to that. Every now and then I think back to earlier times in my career. I reflect upon the lives I may have impacted-both positively and maybe in a not-so-positive manner. In my years as a reading specialist, I saw many culturally deprived, physically abused or emotionally traumatized children. I remember one year when I taught a fifth grade student who was being raised by a grandparent. It was Christmastime and students were shopping in the little gift shop set up by the parent teacher association. The child I will call Steven had no money to make a purchase, as several of them did not. They were, however, allowed to be a part of the browsing to 
buy event, so I took the children to the auditorium stage where the gifts were on display. Steven handed me his jacket to hold while he browsed. A few minutes later, he came back and said I could hold his books for him while he browsed. A third time, he returned to hand me his pencil case. I jovially said, "Gee, Steven, I feel like your mother holding all of your stuff!" He stopped square in his tracks, paused a second before looking me in the eye and said, "I wish you were." I was the one who was stopped in my tracks. His from-the-depths remark poured over me, permanently sealing my views about my purpose for teaching.

This fifth grader needed more than content standards and objectives. He needed more than to be able to read and compute-though he needed these, too. I realized then, and forevermore, that his need for acknowledgement, kindness, and compassion were responsibilities I was to provide for every student in my charge. I knew then, that if for only the short time these children were in my room, if I could help them feel confident around each other, and successful in our work at school, then I had accomplished my goals and objectives whether or not I had taught reading and math! For the brief time students were in a learning environment with me, I would seek to help them achieve peace with themselves and with the world.

\section{Kara’s Lesson Plan Analysis}

Kara provided two unit plans that were collaboratively developed with her pre-service teachers during their internships at Selena M. Day Primary School. The shared responsibility of planning for these units resulted in two notebook-sized collections of daily structured plans. Plans were associated with or linked to the state content standards, incorporated arts throughout the unit, and consisted of a set of table of contents, resources, websites, handouts, recordings, book lists, and an appendix with the unit outline. 
Unit \#1: “Exploring and Learning with Eric Carle” was a kindergarten curriculum unit that Kara and her student teacher designed in the fall of 2004. The opening page of the unit began with a website link to the state CSOs. Even though the unit was grounded in the children's literature of renowned children's author Eric Carle, here are some of the content areas covered: science, health, reading and English language arts, mathematics, and social studies.

To give you a glimpse into the depth of design for this unit and how thoroughly committed to integrating the arts, here are ways the arts are integrated into the curriculum:

- Music (songs, chants, finger plays, instruments)

- Visual Arts ( painting, collages, drawing, coloring, creating)

- Movement (dance, drama, pantomime, acting)

- Literature (books, poems, songs, journal entries)

One lesson plan featured as its instructional foundation one of Carle's children's books, The Foolish Tortoise. This lesson focus was comprehension and rhyming words. Included in this lesson was an arts integrated objective, situated in a learning station, in which students created a tortoise using arts and craft materials. Strategies for instruction included a circle activity to discuss the illustrator's artwork. Children also sang and performed a song, clapping out the rhythmic pattern. Station \#2 supported rhyming and phonics to support their literacy skills. Morning circle was the forum for students to demonstrate their understanding. An evaluation of the lesson was included through the use of station activity work and checklists.

Unit \#2: A Nutrition 4MAT Unit was developed in Fall 2001 by Kara and her university preservice intern. The opening pages of this unit are grounded in kindergarten content standards which set a standard for providing activities that are meaningful and challenging in ways that 
develop higher-order thinking skills. Standards included in this unit are language arts, mathematics, science, social studies, music, art, and health.

Unit Lessons that are comprehensive in design are developed for student learning and include the following topics:

- Pizza Day (pizza pie art)

- Grain Group (sing song, "Five a Day”)

- Fruit Group (role play fruit pyramid)

- Field Trip to Grocery Store (singing songs)

- Vegetable Group (veggie puppets, songs and motion activity)

One lesson that focuses on the vegetable group included both singing and creating veggie puppets. The purpose was to culminate foods on the food pyramid. In this lesson, students were learning about various nutrients that help their bodies grow strong and healthy. Enrichment arts activities were used to help reinforce their conceptual learning about nutrition. Assessment for this lesson included checklists of student responses to vegetables on the food pyramid, participation in songs and finger play motions while singing, and creating the veggie puppet from craft materials.

\section{Carline}

\section{of Selena M. Day Primary School}

From the perspective of the individual teacher, it means that the process of understanding and improving one's own teaching must start from reflection on one's own experience.

Kenneth M. Zeichner (1993, p8.) Connecting Genuine Teacher Development to the Struggle for Social Justice

Drawing upon their experience is a privilege that the wise understand and practice.

Those who persist through the passage of a career gain perspective by years of service earned 
in the profession coupled with stepping away from the work to embrace their well-earned memories. There are also times when people find themselves going full-circle to the doorstep of their starting place.

Carline spent 23 years teaching elementary school children. She earned her bachelor’s degree in elementary education with science and social studies specializations. Her experience in teaching comes from the following grade configurations: first, third, a third-fourth split grade, and fifth grade. Specialized training includes writer’s workshop, state reading conference attendance, and membership on staff development council. Carline did not have prior training in the arts, and the only family history of teaching is her mother who taught 43 years for the school system. As a child, Carline attended Selena M. Day Primary School, did her student teaching there, and taught in the same first grade room where she was a student. It was powerful to hear a retired teacher trace her memories across a lifetime from her childhood first grade classroom to teaching first graders in the same school room. In our conversations together, Carline told her story as naturally as if she were in the height of her career at S.M. Day Primary School.

\section{Initial Interview Question \#1: Curriculum “How do you decide what to teach?” Carline's curricular decisions.}

Teaching standards have gone through numerous revisions. Carline is aware that her learning outcomes are now called something different: content standards. She explains, "What you are going to teach is pretty much dictated by those.” The units she and her student teachers worked on incorporated the learning outcomes, but she talks about certain items that are not specific to every first grade learner’s outcomes. Carline says, “These are really enrichment, and I think with kids that some of those experiences are important because they're exposed to 
things that they might not be exposed to. It might help them to draw on things that they already know and put their knowledge into a different concept.” Carline understands the concept of schema or background knowledge. Her understanding of enrichment experiences distinguishes her understanding of required content or learning outcomes, and the resulting knowledge gained from her decisions to expand learning opportunities for students.

\section{Initial Interview Question \#2: Instruction: “How do you decide how to teach?”}

\section{Carline's instructional decisions: The art of provision.}

A teacher's intuitive ability regarding certain aspects of teaching is yet another attribute of character. Asking Carline this question evoked a response grounded more in intuition than decision making.

I guess it depends on the children, the kinds of children that you have. You know ... I don’t really know. It's just something I do, but I think you have to keep them focused. So if it takes more hands-on activity, then I do the kinds of things where they're not just sitting in their seats. I guess it all depends on your class and the subject matter that you're using. (II-TC-5.1.09)

Everything about wise teaching leads us to the children. There is so much to be gained from listening and paying attention to the children. Their responses are genuine and pure- the essence of knowing what and/or how to teach.

Initial Interview Question \#3 Decision Making: “What professional development do you seek and how do you use these skills?”

\section{Carline's professional development decisions.}

S.M. Day was fortunate to have a strong collegial relationship with the local university. Staff buy-in was strong, and their professional development opportunities opened the door to 
school improvement through long-range strategic planning. The teachers were active in learning the Bernice McCarthy 4MAT instructional design which is an eight-step cycle that capitalizes on students' learning styles and brain dominance processing strengths. 4MAT incorporates motivation, creativity, and knowledge transfer. The four learning styles are: imaginative, analytic, common sense, dynamic. When using the 4MAT approach, teachers incorporate their positive attitudes and new teaching techniques into classroom instruction, helping to increase student motivation and learning. 4MAT is a natural planning format that is well suited to arts integration because it values a variety of learning styles, one of which is imaginative. Selena M. Day Primary teachers decided to commit to the 4MAT professional development and to train through a variety of methods including, but not limited to: conference workshops, consultants, university classes, collaboration, and sharing at the school and district levels. A positive result was the collaboration that resulted in teachers' and pre-service teachers' elaborate integrated arts units. The school district offered sessions, and Carline served on staff development council to prepare workshops.

I don't think they do it in the same way as they have in the past. It used to be a week-long event where you could take the different classes. You had the opportunity to sign up and sometimes professional development programs were specific to a grade level or new textbook training. (II-TC-5.1.09) Teachers who are co-teaching or participating in a team teaching delivery model need planning time together. Principals and site-based leadership teams valued common planning periods or opted to stay after school to design units of study or discuss student work and assessment progress. Carline appreciated her opportunity to plan with the student teachers one 
morning a week to collaborate on instructional content. The collaboration was one way to lighten up the teaching load by sharing ideas and working smarter.

I always felt like the professional development at the beginning of the year-the few days before school starts-you are so bombarded with things. That's not really the time because everyone is anxious to get into the building to get going with setting up for school. I liked it when we did our training the first weak after school was out. People started to relax by then. But then you have all that summer before you can actually implement what you learned. (II-TC-5.1.09)

Timing is a very important consideration in planning professional development.

District planned trainings and teacher workshops are important to instructional staff, and they want to participate. Caroline shares some of the pros and cons that are important factors in deciding whether to participate in the offerings.

Initial Interview Question \#4: Reflection: “What does the community say about your arts integrated teaching?”

\section{Carline's instructional decisions: Community.}

Community is a broad concept for teachers. Community can mean a small collaborative learning group, a classroom, grade level or school, several schools in a geographic area, business and school partnerships, the larger local community, and national and international networks of learning communities. So, in framing this question, I proposed to Carline that she could share her choices to integrate the arts from all of these broad community concepts. Carline related events where third grade parents helped out with activities and the exciting news spread throughout the classrooms. The students would say, “Oh, I can’t wait until I get to be in third grade and can do those things.” Carline believed that informing parents was part of 
her teacher role. She did very proactive things to inform them and to encourage parent participation. "We would tell them what we were going to learn about. If there were items that we needed them to send in, we asked. Every unit has some sort of introduction to the parent.” (II-TC-5.1.09)

\section{Carline's Comments on Student Artwork}

Carline reminisced about the excellent work of three of her colleagues in the small university collaborative. She was the "second wave" of arts integration 4MAT enthusiasts. The first three teachers gained knowledge of this instructional system by attending a conference together. Their professional development opportunity was a result of their affiliation with the university professional development collaborative. The conference highlighted Bernice McCarthy's 4MAT system. These three enthusiasts returned to school armed with a new teaching strategy and knowledge to back it up. Janice, Char, and Kate became paragons for the rest of the staff, and their work with university pre-service teachers permeated the entire culture of Selena M. Day Primary. Carline explained her gratitude and willingness to learn from them, and through her affiliation with her student teachers created many wonderful social studies arts integrated units. At first she shared her reluctance with having her first graders learn using units on China and Egypt—suggestions that her student teachers wanted to develop. But she agreed to collaborate blending her seasoned experience with their novice pluck. She elaborated on her perspective:

I had a student teacher, and I really wasn't sure at the time, because I thought it might be too difficult to make social studies units on China and Egypt. They went back in time to Egyptian days. But if there was something that she was 
really feeling strongly about, we could try it and if in the spring the kids were a little more mature, it could work. You can see what the kids did at the end of the unit. They wrote about what they had learned, and it was incredible. Now, we continued with that unit, and another year when we studied China we used the same kind of ideas. (II-TC-5.1.09)

Carline was reflective and open in telling her story about collaboration with university pre-service teachers. She honored their presence and the content knowledge and enthusiasm they brought to the classroom. Her willingness to be supportive and flexible was beneficial to the learners. And she was not reluctant to shower praise where praise was due.

This is what my student teacher wanted to do. I found myself to be pretty flexible with the girls. I learned a lot from them. It had been a long time since I had been in school. This was something she was really interested in most of her life, so she was really into it. The kids, they were really into it, too. The students learned a lot of things. (II-TC-5.1.09) I asked Carline if she collaborated with each student teacher on creating a unit of study during their placement in public school:

It was one of their requirements for student teaching. If there were vacancies in this building, the interview committee talked with the applicants about arts integrated units of study. This is something that we do here. We asked candidates if they were willing to have student teachers. (II-TC-5.1.09) In their unit plan on Egypt, students took a mock trip in an airplane made of student desks, with their stamped passports. They searched for mummies, wrote little books of Egypt documenting their travels. Students illustrated their artwork for the little books while music 
played in the background. Students designed, wrote, and mailed postcards home. They participated in an archeological dig to uncover relics and wrote in their reflection journals. The student work sample below shows one student's awareness of drawn symbols representing written language. The student was thinking about his learning and was inspired to create symbols of his own as a reflective journal entry.

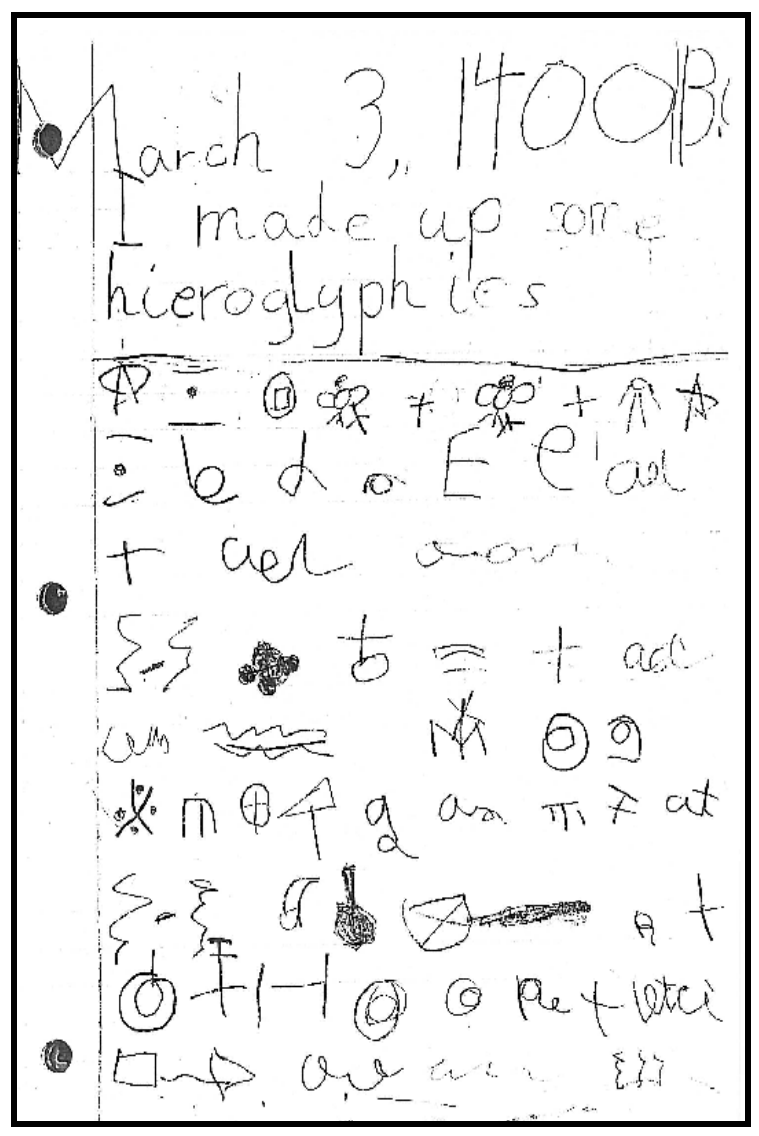

Figure 6. Hieroglyphics Journal Entry. Student created and drew symbols to represent written language.

Using the four over arching interview questions of curriculum, instruction, reflection, and community, the matrix for discussing student artwork connects teacher decision making to student work samples. The following table takes the matrix checklist items and summarizes the categories of teacher instructional decisions that can be seen in student lesson samples. 
Matrix for Student Hieroglyphics

\begin{tabular}{|l|l|l|l|}
\hline \multicolumn{1}{|c|}{ Curriculum } & \multicolumn{1}{|c|}{ Instruction } & \multicolumn{1}{c|}{ Reflection } & \multicolumn{1}{c|}{ Community } \\
\hline $\begin{array}{l}\text { Reading, Writing, } \\
\text { Social Studies, } \\
\text { Mathematics }\end{array}$ & $\begin{array}{l}\text { Writing, Text } \\
\text { Interpretation, Graphics, } \\
\text { Codes }\end{array}$ & & Confidence, Esteem \\
Efficacy, Aspiration & $\begin{array}{l}\text { Community Service, } \\
\text { Social Problem Solving, } \\
\text { Tolerance }\end{array}$ \\
\hline
\end{tabular}

Carline spoke of her own commitment and her school's commitment to integrating the arts. A relationship with the university supported a continuation of arts integration through a school mission and vision that was grounded in arts integration. With the realization that the Egypt unit was so successful for student learning, both novice and expert collaborated once again to create a similar unit on China. Learning through the arts included planning around the Chinese New Year. They created dragon faces and presented a skit. Students in grades kindergarten through third came to a presentation of the lion dance, a very big activity for this unit. For the skit, some children had acting parts, and others played the drums. The unit included an assessment mechanism for knowing when students were excelling.

Co-authoring these thematic units presents its challenges and is described as a learning process. Learning the planning process includes knowing the component parts of lesson plans, researching the appropriate resources, book lists, and supplemental activities, which consumes the teachers' time and attention.

At first, it is really overwhelming because some parts are more difficult to plan a lesson for. You have to get "the catch" part of the lesson that catches the students' attention. Sometimes that is difficult. We have to plan for the literature story and the props and all that supports the instructional unit. So, yes, some are more difficult. It truly is a two-person job. (II-TC-5.1.09) 
Over time, Carline co-created a collection of units with her pre-service teachers. Approximately one per semester is the usual output for the co-authors. Some of their ideas work across the units. For example, the units on China and Egypt, students participated in a simulated aircraft flight by lining up their desks to imitate the inside of an aircraft. They also created passports to record their travels from one location to another.

A second co-authored unit featured science content using a study of the weather. The way this unit started was with a great big bag of weather-related items like sunglasses, a rain jacket, snowflakes, boots, and gloves. The children had to make up a story. One would come up and draw an item from the bag and start the story. Then the next person came up and drew one and continued the story; story that became collaboration. Sometimes they were better than others because some of the kids had more imagination. That is the "catch" or how this unit started. (II-TC-5.1.09)

Carline explained that the lessons in her units may have lasted for two weeks depending on the content or scope of the individual lesson plans within the study. Some units lasted longer depending on the time allotment for the subject. For example, 40 minutes for a science lesson each day may be different from an hour-long math lesson. Carline provided insight into how lessons continue to develop over time and ways that they can be refined or expanded.

This reminds me of a book I had purchased one time when I was at the Smithsonian. It was lessons on famous art geared to children. One of the lessons in that book was on clouds. I incorporated that in this unit, too. It was after the unit was written, but I remember using that to teach the kids. 
In the unit on weather, Carline included a culminating activity in which students met one of the reading/language arts content standards and objectives: using the text and illustrations to predict and confirm. Students closed their eyes and used imagery to visualize different types of weather. For each of the four seasons, students listened to a different type of music ranging from surfing music to rain and thunderstorms. They pictured themselves in similar weather to visualize what they were doing and wearing.

After the visualization activity, students drew what they saw in their mind's eye.

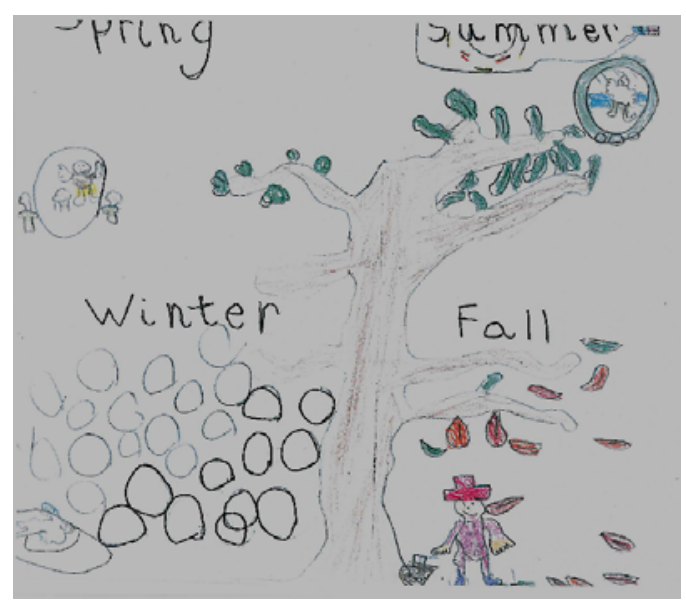

Figure 7. Four seasons weather drawing. Students used visualization to sketch the weather of the seasons while listening to music of thunderstorms and surfing waves.

Using the four over arching interview questions of curriculum, instruction, reflection, and community, the matrix for discussing student artwork connects teacher decision making to student work samples. The following table takes the matrix checklist items and summarizes the categories of teacher instructional decisions that can be seen in student lesson samples. Matrix for student Four Seasons Weather

\begin{tabular}{|l|l|l|l|}
\hline \multicolumn{1}{|c|}{ Curriculum } & \multicolumn{1}{|c|}{ Instruction } & \multicolumn{1}{c|}{ Reflection } & \multicolumn{1}{c|}{ Community } \\
\hline $\begin{array}{l}\text { Reading, Writing, } \\
\text { Science }\end{array}$ & $\begin{array}{l}\text { Writing, Text } \\
\text { Interpretation, Graphics }\end{array}$ & $\begin{array}{l}\text { Confidence, Esteem } \\
\text { Efficacy }\end{array}$ & Community Service \\
\hline
\end{tabular}


Carline's students learned science concepts through integrating the arts in multiple lesson activities throughout the thematic unit. The geography objective included in this student assignment queries how climate/weather affects the way people live, e.g. food, clothing, shelter, and recreation. In the work sample above, a student demonstrates clothing choices and weather-related activities. Science objectives covered include describing changes in nature and weather cycles. By analyzing student drawings, a teacher can gain insight into the depth of student knowledge, their misconceptions, and their thinking skills levels ranging from comprehension to analytical thinking. In this weather unit, students experienced many arts integrated activities. Musical movement guided their imagery. They compared paintings of the four seasons, created drawings of the weather cycle, played charades, and “danced up a storm” in physical education. Students increased their knowledge and awareness of the weather through music, art, dance, and dramatic role play.

\section{Follow up Interview Over Arching Question \#1: Demographic setting and professional} attributes of an arts rich teacher

\section{Carline's self-characterization of professional educator.}

Carline has the benefit of her life's career vision and spoke to her range of growth as her career expanded and developed. She looked both back and forward from her perspective as a retired school teacher, with an understanding of the challenges facing her novice pre-service university students. She described herself as a professional educator and spoke eloquently of how complex an art teaching really is:

I think that I am somebody that really enjoyed teaching. I spent a lot of time in my preparation for what I did in my lesson plans. I tried to integrate the 
kinds of things I thought the children needed, tried to make it interesting, tried to expand on things, tried to bring in parents for their expertise. I just think that it's not just you teaching. I think you have to draw on a lot of other kinds of help that you can get. It's not just one person, it's the family, the other teachers around you, and so forth to help out.(IF-TC-5.11.09)

\section{Carline's personal experience with arts.}

She described her personal experience with the arts and described her mother's strong influence in her experiences.

My mother was a piano player and, of course, we had lessons. I never gained the expertise that she did. We were exposed to music and singing in the choir and other events. I was in the band starting in junior high and high schools. We attended plays and other concerts and things. We watched many musical things on public television. (IF-TC-5.11.09)

\section{Carline's professional growth and development.}

Carline had insight into the professional relationships required to experience the full joys of teaching. Her colleagues were important to her, and she was able to acknowledge them for their contributions to her success and her teaching satisfaction. Carline talked with her own understanding regarding the importance of every educator from her pre-service teacher to the music specialist.

Well, I don't know if this is the place to say it, but I feel like we're coming into another area here ... but this school, this faculty, we're all people who were willing to share ideas and expertise. It wasn’t like you were in competition with 
anyone. It was for the good of the school, the kids, and everybody. (IF-TC-

In schools where there are additional specialists, computer teachers, physical education teachers, art and music teachers, there often arise some turf issues. Who teaches whose subjects? With professional considerations, teachers want both the expertise and collaboration of their specialist colleagues, but they want the autonomy to teach these lessons within the context of their own classroom instruction.

\section{My Reflections}

My role as reading specialist for low achieving poverty students prepared me to work in a large rural elementary school. We had a music specialist who was very proactive with her musical program offerings. She was confident in her ability to collaboratively plan music instruction that extended learning opportunities for my reading students. For example, she researched Appalachian musical culture, and created a unit of study for grades K-5. When the students went to music class, she was committed to doing her share of collaboration.

Carline shared her planning and teaching experiences with specialists in her school.

Not so much the specialist ... for example, when we were working on a unit, there was some area on one part of that field where we were having trouble finding an activity that fit just exactly. We would always call on our lead teachers or whoever else had a little more experience in that. And this faculty was really good to support you in your lessons. Someone would come in on their planning time and lend their expertise or a helping hand. (IF-TC-5.11.09)

\section{Carline's reflective practice.}

Carline considered various aspects of the reflective process in her response. 
She provided insight into her thinking in making those adjustments in a teaching lesson.

I think it is a daily thing. I mean, when you've done an activity and the results of that show whether or not it is working. So you can see what about it didn't work that you want to change. If you want to try the same kind of activity again, what kinds of things do you do? I just know that there were certain periods of the day when some things worked better than others. So you would just have to adjust your schedule to meet the students' needs. (IF-TC-5.11.09)

\section{Carline's classroom teaching context.}

Carline told me about her teaching context when she was developing these units with her pre-service teachers. She spoke about individual students' academic performance and their achievement as a class. She also talked articulately about the individual learning challenges she saw over her years of teaching. Carline reminisced over a child whose life was changed during his time spent in her room. In her response, she provided a glimpse into her reflection process as she characterized an individual student's progress in her classroom. Her teacher beliefs and attitudes were important in shaping her instructional decisions and portray her as a capable decision-maker. She based her decisions on her student needs and her unique teaching situation.

Students we had at this school were pretty average to above average children. You would have a few children that you knew struggled, like one little fellow that came here one year from Try-again Homes. They had removed him from his circumstance and put him into a foster home. And he really did blossom. Later in the year, he was given back to his parents. It just really seemed ... but 
back to the question. I think things are set up in the room to suit the kinds of things you are going to do while you are teaching. (IF-TC-5.11.09)

Though Carline did not describe her pre-retirement classroom set up, their cultural experiences, or her approach to teaching strategies like differentiating instruction, she went to the deeper self, to the life of a student who made great strides in her classroom. This transparent think-aloud raises the important question: "Is a teacher’s classroom teaching context more about the students within the room or the room within the students?”

Follow Up Interview Over Arching Question \#2: Arts Integration and the influence of job satisfaction, commitment, autonomy and change

Carline's commitment to arts integration.

As she traced her teaching career and her arts integration, Carline admitted that her commitment goes back farther than just her most recent arts experiences.

You know, actually, before I came here I probably did some of these types of things. It just wasn't in those terms. I just felt like the kinds of units that we presented with the children, the things that we did ... I think that those were so exciting to them that you really saw a lot of learning. And I think that those are the kinds of lessons that teachers need to use, whether it's found in an entire unit or just a particular lesson. It was like we were drawing in something that is a different way—an unusual way and using the arts to get them to grasp the concept. (IF-TC-5.11.09)

\section{Carline's teaching satisfaction.}

When a retired teacher speaks of teaching satisfaction, is their crown of glory coming from knowing that their work has had a lasting effect on humanity? Carline said that her 
objective was to enjoy her teaching, while having the higher goal of her students mastering content standards balanced by sharing experiences that carried into life.

I was just one of these people that really enjoyed teaching. I knew when it was time to retire. It's the kind of thing that I looked forward to. I enjoy making plans and trying to make the plans interesting as something new. I tried making something that the children would not only enjoy, but learn, gain from. When they learn things, this carries on over the years to be life-long. (IF-TC-5.11.09)

\section{Carline's control over curriculum and instruction.}

Carline answered from wisdom and experience. When she looked back on her classroom planning and decision-making, she admitted that her classrooms experienced the learner outcomes as a necessary focus, but there were also conflicts between what had to be taught and how a teacher decided to expand teaching and learning beyond the prescribed CSOs.

I feel like we were given leeway to expand on some content. It may not be exactly, but you're covering what you need to cover and bringing in the enrichment kinds of things to expand on those outcomes. In the here and now, many days I heard the lament about having to follow the CSOs. Sometimes you don’t have a choice. (IF-TC-5.11.09)

Perspective was Carline’s best teaching tool. She looked over the past six years of working with the learner outcomes. During our conversation, her transparency of think aloud reasoning was mentally working through the possibility that anyone would object to the thematic instructional unit approach to teaching. She expressed the exhaustive documentation of numbering the instructional goals and objectives (IGOs) in the plan book. Even Carline was aware of her colleagues' feelings about having to teach using the IGOs and CSOs. 
Maybe it's the kind of school ... maybe it's the population of the school as to the kinds of things that you have to do. But my plans always had objectives. It got to the point I think after I retired—-that putting those numbers in ... well, I would just rather write what I was going to do instead of trying to look up all that stuff and get all those numbers. No, I always had objectives and assessments. (IF-TC-5.11.09)

\section{Carline on making and sustaining change in teaching.}

Change is not an easy fit for many teachers. I experience times when I do not want to step away from my comfort zone as a teacher. For example, when I taught as college teaching fellow in a local teacher college, I experienced a large change in curriculum design. For me, working with the adult learner to make content challenging and model lessons of an engaging nature was really a stretch. But I did step out to meet that growth head on, and I am glad that I did. I trusted that the discomfort of change would eventually show its pay-off. Ultimately, it did and I am glad for the opportunity to evoke change. Carline had strong opinions on the idea of making and sustaining change and these are expressed below.

Sometimes you don’t have a choice. How your teaching is going really dictates what you need to change and how you need to change it. If you want to continue to work, then you have to stick with the change. I am thinking about some of the reading changes in one year when we bought new textbooks. I didn’t care for it at all. It seemed so repetitious. After you taught it, you could see what the purpose was, especially in the carryover to another subject. (IFTC-5.11.09) 
Carline shared how important it was to have a partner in teaching and planning. Her student teachers were amazing, and when they planned together it was exciting. "I was totally amazed when we got into working on the plans how exciting it was, not only for the kids but for the teachers. We planned different kinds of lessons and activities and dressing the part. It was fun and they learned a lot. But it was fun!” (IF-TC-5.11.09)

\section{Follow up Interview Over Arching Question \#3: Student Learning and How You}

\section{Integrate the Arts}

\section{Carline's awareness of student motivation.}

In the initial interview, Carline talked about student outcomes she never dreamed would have materialized just because they were motivated and excited about their learning. This was evidenced in the lesson where students were time traveling. One little fellow wanted to stay in for recess to finish his writing assignment.

Well, you can really tell by their reactions to what you're doing. They look forward once you start a lesson or unit. Think of the airplane cabin set up in the classroom and our trip to Egypt and China. I guess it is sustained by the kinds of activities that you use with them. I can remember the kids that wanted to know more about the mummies, hieroglyphics, and so forth. You can see from what you read and the plans and things they did. They really did get into it! It's a shame every lesson can’t be that way, but you can’t just make everything exciting. (IF-TC-5.11.09)

Carline was right on the mark with her comments. One of the things to notice is that students are asking more questions. They have a deeper desire to learn more and to expand their knowledge and go deeper into the content. During independent journal writing time, one 
student made up a page of hieroglyphics. Parents provide relevant feedback when they come to school and share what their children are saying about their classroom learning! One parent said, "I don't know what you did in here, but it must be really exciting." Next to the student response, parent excitement for a child’s learning is the ultimate teacher-compliment.

\section{Carline's views of student motivation and impact upon lesson design and pacing.}

When children “gobble up” a teacher’s content lesson offering, in what ways does that increase the teaching-learning exchange? Does the lesson planning change or the curriculum delivery in terms of pacing? Are teachers deliberate in moving quickly or slowing down at certain times of the year, or speeding up at other times? In the university and district teacher classes, some teachers expressed concern that their units were not as extensive as Carline’s.

Some of these units were better, more extensive and done in the second semester. Some teachers in the class were concerned that they didn't have extensive units to share or document. And they don't have to. With this kind of teaching, you couldn’t possibly teach every unit you have in its entirety. You wouldn't get anything else done. So pick and choose from those things. In first grade, we have so many other things going on. Sometimes the community gets involved and it takes more time to cover the lessons. The year that we did three countries, supposedly one unit, it ended up being three units. We went way over the amount of time intended. It worked out. Some days we didn’t get finished and moved to the next day. When you're in control and not worrying about other teachers or the time spent on it, we arranged things in morning and some in the afternoon. You adjust as you go. (IF-TC-5.11.09) 
Carline's teaching design for successful and struggling students with special needs.

Carline recognized the value of shared learning experiences. She guided students in assisting each other and not just trying to make adjustments for the struggling students. Peer learning and teaching along with small group instruction were some of her strategies.

Students who are succeeding are going to try to go out on their own. Here is a real life example. When we were on a unit and they were working on something, they would come to the library to check out a book to learn more. Students who struggle get help from other students. We did lots of things in small groups, so I could get around and help them. Selena M. Day does not have a large special needs or struggling students population. (IF-TC-5.11.09)

\section{Follow up Interview Over Arching Question \#4: Use of the arts beyond the classroom} Carline's involvement with parents and colleagues integrating arts.

Currently, my involvement with the community, business partners, local university collaboration, is an essential element for schools and systems. Carline is able to relate how important parent and community involvement is to her instruction and the students' learning. For example, during bicycle safety week, a parent cyclist brought equipment, safety gear, and the knowledge of how to ride correctly, signal, and stop safely. Another parent, a banker, helped students create a savings and checking account. She credited parents with having great expertise. For example, Carline’s first graders watched a performance of Hansel and Gretel, then extended their arts involvement by illustrating their version in a class book. Carline invited parents to participate in class activities with their students at school.

I do these kinds of activities with my class, and I find that they learn better because they're doing more hands-on kinds of things. I think parents really have 
great expertise, and they're really willing to come in and spend a little bit of time. We went over to the university one year for the pottery class and toured the Creative Arts building. Our fortunate involvement with the university professor was valuable because she steered us in the different directions for the arts. (IF-TC-5.11.09)

\section{Carline's involvement with colleagues.}

Selena M. Day Primary focused its growth and development around the arts instruction. One pass through the main floor will assure any visitor that arts instruction is alive and well at the primary school. Interactions amongst colleagues in S.M. Day and amongst other schools are described below through Carline's narrative.

Everybody here worked together. They would know what your unit was going to be and then offer you books to support. My student teacher and I did the weather unit, and teachers started offering books and anything they had. Our teachers were not possessive or un- sharing. We were careful, though, to not infringe on any part of a unit someone else had done. For example, second grade was doing a unit on quilts. We stayed away from anything they were using as a professional courtesy. Our commitments and our years of teaching experience were similar. S.M. Day has been fortunate with faculty fitting in with each other. (IF-TC-5.11.09)

\section{Carline’s Lesson Plan Analysis}

Carline developed many units and provided two plans that were collaboratively developed with her pre-service teachers during their internships at Selena M. Day Primary 
School. Her enthusiasm and collegial trust in working to develop numerous themed content units provided this research narrative with rich documentation. She respected her student teachers and was pleased when they designed units that challenged the students and her thinking. The complex unit design includes state content standards that are incorporated and integrated all throughout the unit.

Unit \#1: "Egypt: Now and Then" is a unit that integrates the fine arts and supports multi-cultural education. Teachers have brought a positive approach and new techniques to their students. Students respond to the instructional plan and design by demonstrating a greater desire to learn. In the opening pages of this unit, collaborators included the learning wheel graphic organizer that provides a visual summary of learning experiences throughout the unit. Some of these include planning a trip to another country, understanding the purpose of a passport, participating in guided imagery using Egyptian music and video, activities such as book and mask-making, archeological dig, and designing and sending postcards.

Planning web is a full-page graphic organizer that incorporates all of the content areas involved in the Egypt thematic unit. Eleven components make up the content covered, and each objective is highlighted to demonstrate fidelity to course content. To provide a glimpse into the depth, breadth, and scope of content activities, are listed in the bulleted list below.

- Reading - teacher read-alouds for listening and student independent reading

- Social Studies-geography, history, and cultures

- Science-archaeological dig

- Physical Education-chariot race

- Math—measurement and Egyptian numerals

- Music_cultural music

- Art-drawings, masks

- Language-hieroglyphics, Rosetta Stone 
- $\quad$ Speaking-oral reports, discussions

Lesson One features planning for an imaginary trip to Egypt. This lesson focuses on the importance of a passport. Students have a map study and locate their place in the United States. Students discuss the need to fly versus drive. Children use the skill of visualization throughout this lesson as soft music plays as background for the activity. When finished, students illustrate their images and write about what they see in their minds-eye. Assessments include student participation, cooperation, and passport design and development.

Lesson eleven connects previously learned concepts by reintroducing geographical locations. Students locate geographic sites in ancient Egypt. The unit activities assist students with finding their way along a map. They discuss map design and locate and label major rivers. The teacher leads a discussion through the use of effective questioning strategies that probe for deeper understanding beyond the knowledge domain. For example: "Why do you think the land around the Nile River is green?”

Unit \#2: “Weather-A Focus on Change” is a unit supporting first graders in their understanding and knowledge of weather concepts using inquiry-based learning. The opening pages of this unit include a strong statement as well as a connection to the learner objectives. Seeing the standards highlighted adds credibility to this unit plan and supports the activities selected for individual lesson plans. Some of the arts integration objectives associated with the weather unit include the following:

- General Art: art work can evoke emotions

- Dance: improvise movements from feelings

- Theatre: dramatic play using personal experience

- Music: songs and poetry 
The planning web for the weather unit includes eleven components that integrate across the arts in this science unit. The weather and the Egypt unit have a similar structure making the instructional design predictable and familiar. Listed below are some, but not all, of the activities and their associated content header:

- Reading - teacher and student, poetry, listening to trade books

- Social Studies - map reading, weather-related jobs, seasonal holiday weather

- Science-recording weather patterns, charting and classifying weather objects

- Physical Education-dancing and movement

- Math—graphing and charting weather, using thermometer measure

- Music—guided imagery

- Art—comparing paintings of weather, cloud pictures, weather socks, posters, mobiles

- Written Language-labeling drawings and writings stories in journals

- Oral Language - story bag story, daily weather report

One lesson plan called “Guided Imagery” had as its three objectives, visualization; knowledge of the changing weather on humans, and describing visualizations and drawings. The teacher-led lesson opened with listening to music and descriptions of different types of weather. Students created a drawing with four sections of weather images from the four seasons. At the end of the visualization-illustration activity, students shared their illustrations with one another. Assessment strategies included teacher observation of student participation, accuracy and completion of illustrations and checklist of student discussions.

Another lesson plan on seasons connected to the previous lesson on guided imagery. Objectives included listening to read aloud stories, understanding the sun's importance to seasons, and creating a mural of four seasons. In this lesson plan, students participated in open discussions of the seasons and how weather changes all of the time. Students worked collaboratively in groups to create a mural depicting the four seasons. Students learned how to paint murals. Informal teacher assessments included teacher observation, interest and 
participation in discussions, accurately identifying seasons of year, and accuracy in preparing and developing the season mural.

\section{Janice, Kate, and Ida}

\section{of Selena M. Day Primary School}

Teamwork is often like the weather-everyone talks

about it, but often nobody does anything about it. It is seldom achieved by intellectualizing, but is rather the practical application of attitude, common goals, and experience working

together. It is a learned art.

Twyman L. Towery (1995, p. 18)

The Wisdom of Wolves

Where two or three retired teachers are gathered together, you can count on great

stories! The trio of retired teachers from Selena M. Day is an incredible unit. They still meet together monthly for lunch. Service to the community arts remains a habit as they continue to assist the university and schools with professional development trainings and arts-related events. I contacted each of these participants individually, expecting that we would interview at three separate times. From the beginning, the three proposed that we all interview together in a mini-forum. They explained that their work together at S.M. Day was so collaborative that it would be difficult to distinguish the lines among their integrated arts instruction. Besides this, their companionship and joy at being together also insured trust and provided a safety net of “there’s security in numbers.”

The trio spoke with equal voices in a spontaneous, natural manner. Janice would express an idea or describe a scenario, and Kate would add her own perspective. The group is fairly homogeneous — similar in age, gender, race, years of experience, degree levels, certifications, residential location, grade levels taught, professional development experiences, and professional association membership. As a small reflective group, there were no 
discernable roles or distinctions. All are recently retired, yet they speak of their experiences as though they were going to work in the morning. These professionals still care deeply for the teaching profession. They care enough to think out loud and to put their teaching stories out to the public.

Janice took the lead in securing our meeting place by opening her home for both interviews, where we met around the dining room table-a safe and natural setting for this professional collaboration. Even though we all knew one another through our affiliations with the professional university collaborative, I wanted so much to portray my respect for their time, knowledge and expertise, and to be prepared as facilitator for the collegial conversation. I came into the group balancing my interview materials and immediately sensed their sheer delight at being together to share the glory days of their arts integration thematic units.

Janice taught third grade at the primary school. She boasts 44 years of primary grade teaching with an elementary education degree, and her highest degree is Master of Arts with 45 additional hours. Her specialized training is in the administrative area as a trainer for kindergarten through third grades in northeastern states. Janice is a member of the state education association. No one in her family is affiliated with the education profession, and she has no additional arts training.

Kate taught grades kindergarten through second grade during her thirty years in the profession. She has elementary and early childhood certifications, and her highest degree is Master of Arts with 30 additional hours. Kate was in the band, her daughter is a substitute teacher, and Kate's husband is a university professor.

Ida taught 28 years before retiring from the profession. She was certified in grades kindergarten through eighth, and a reading specialist with kindergarten through twelfth grade, 
though she taught mostly third grade. Ida was widely involved with the university professional development association and with the local chapter of her professional teacher's association. She was in the band and dance groups while growing up. Ida was active with the university’s professional development schools through their collaborative.

The retired teacher trio from S. M. Day Primary School was naturally forthcoming with their narratives and was not to be bound by any certain protocol when responding to the interview questions. Therefore, the discussion flowed as a conversation with deeper, more authentic responses thanks to the give and take of conversation-conversation that was at the heart of their life’s work.

On my first phone call to request Janice’s participation in the research, her enthusiasm to share her work was contagious. This was her first year of retirement, and all of her ideas and insights were fresh and ready to burst forth. On that day she shared pertinent thoughts that are introductory remarks and set the stage for the trio’s mini-forum interview. I present these as the introduction to our initial collegial conversation:

All three of us are experienced and confident of what we are doing, and that our work is solid. We were very involved in molding the arts in our school. Each voice knows how to relate to our Content Standards and Objectives (CSOs) and connect to the content. When you make it real, you give kids time . . . time to think. You call on another child to absorb . . . to sit back and look at the art. Time is of the essence. We knew the way to appreciate real art. Students looked at art masterpieces in the halls; they entered an art gallery, seeing art everywhere, 500 pieces. We practiced the rules of the gallery such as respectful viewing, and don't touch, but observe and look. We three were soul mates in 
this project. Teachers need to have a partner. You can’t defend yourself when alone. We showed our colleagues that it was OK not to be an art teacher.

Everyone doesn't need an arts background. But we did need support from our colleagues, even if you didn't have it from your supervisor. (Informal preliminary phone conversations with Janice TJ-3.17.09, 4.9.09)

As soon we sat down to the dining room table to begin our conversation around the interview questions, the teachers began talking about their teaching opportunities. Ida started out singing the praises of the collaborative relationship between the university and the primary school. Janice and Kate chimed in, and the conversation flowed of its own accord. The structure pre-planned through the interview questions did not guide this conversation; rather, the trio's experiences, reflections, and strong ownership of their own stories gave them rights to say what they would. Therefore, the following narratives from Joyce, Ida, and Kate are structured from their emerging themes. From these themes, I connect the four overarching questions to the powerful stories of three retired master teachers.

\section{Initial Interview Question \#1: Curriculum “How do you decide what to teach?” Janice, Kate, and Ida's curricular decisions.}

Consider the dissertation question, "What commands teachers' attention when making decisions?” These teachers were on a quest in their relationship with the university collaborative of professional development schools. Their primary school was fertile ground for growing professional development initiatives. The university provided resources of professor collaboration, plus funds for release time and staff development. New initiatives for schools became realities. 
We had a chance to be part of the beginnings of the collaborative, and we thought that our primary school was a really good, solid foundation, with strong teachers. We thought that it would be a good opportunity to work with the university collaborative. With that, we had to come up with some goals and strategies of how we would work together. We came up with science and math -but we really thought if we couldn't figure out how kids learn, then it wouldn't matter what course we had taught, so we decided we would work with learning styles. So we came up with goals to accomplish that, and one was integrating the arts through the curriculum. (Conversation with Ida II-TI-4.20.09)

Being elementary teachers, there are lots of times you'll say, 'What's your specialization?' Well, our specialization was teaching. We wanted to know how to teach. We wanted to expand our repertoire of strategies so that we could teach science, math, and reading, whatever it is. Our job was to teach, and how many ways can children learn? And how can we expand our own personal strategy repertoire so that we can meet those needs? The arts were one of those ways that we started exploring, and the more we looked at it, the more potential we saw there. Most of us ... not everyone in the school, bought in at the same level as the three of us did. When we started experimenting with it, we were having fun with it. It opened up a lot of more possibilities for us. The children really responded so positively. (Conversation with Kate II-TK-4.20.09) 
I think we tried to make it a real-life experience, and the more we could make it real rather than this fake stuff. We made it as real as possible. Then we got into it, and we really liked it. I think the fact that Janice and I being partners-you know we fed off each other. And Kate had a partner, and they fed off each other. We were all doing the same things, and it was just contagious. So, I really think that helped. If we were doing this by ourselves, it would have been, I think, a lot harder or more discouraging after awhile. (Conversation with Ida II-TI-4.20.09)

All three teachers acknowledged their strong leadership role in the development of goals for integrating the arts at S.M. Day Primary School. Janice characterized the three of them as leaders in the arts integration project. The three women were as tight as a major chord! One would put out a thought, and the other would finish it. Here is a perfect example of their unison way of thinking:

It was the three of us who were really ... we were kind of known as the movers and shakers over there. But the one good thing was, that there was nobody there that was a . . . they may not have been a leader. (Conversation with Janice IITJ-4.20.09)

. . . or bought into the same degree. (Conversation with Ida II-TI-4.20.09)

Same degree! That's a good way to say it. (Conversation with Janice II-TJ4.20.09) 
Some were taking baby steps, and we were taking leaps and jumps.

(Conversation with Kate II-TK-4.20.09)

As for deciding what to teach, the answer took a divergent course from the other research participants' focus on content standards. The three illuminated their approach to peeling back the layers to find broader and deeper concepts like learning strategies, learning styles, and integrating the arts in math, science, social studies and language arts.

\section{Initial Interview Question \#2: Instruction: “How do you decide how to teach?”}

Janice, Kate, and Ida's responses to instructional decisions: The art of provision

\section{theme: Approaches to lesson design.}

Inherent in Janice, Kate, and Ida's responses are the evidences that the real work of arts integration began with this trio of master teachers. Their sense of ownership for getting the movement started in S. M. Day and for sharing their knowledge with fellow colleagues and university pre-service teachers is clearly visible in their responses. Additionally, when they talk about "how to teach" aspects of the second question, their responses focus on the inceptions of integrated arts instruction in their classrooms.

Because we had the background in learning styles, and we studied those intensively, then through the integrations of arts we understood those traditional learners too. So, we weren’t singing and dancing every time you walked into our classrooms. We balanced the arts with a lot of other strategies so the kids who were more traditional learners received the little bit of time to get comfortable with all of this. You know ... the teacher could be dressed up in a costume and having their tap dancing shoes on! One little boy said, “Do they have normal school here?” That was pretty normal for us. 
Kids knew if they were being drawn out of their comfort zone sometime, that maybe later on that day they were going to be OK again. We were taking risks, and we had to make it comfortable for them to take risks and we knew that. (Conversation with Kate II-TK-4.20.09)

Like our university professor said ... we had to be accountable. We really knew we wanted to use an impressionist unit. It took us a couple of years to figure out how we can do this. We can't just do it because we like it. How are we going to be accountable to that? Then we decided we were going to use it to teach critical thinking skills. It seems to never fail that once we get started on a unit, we would always go back and fill in what the objectives were. And we always ended up with so much more than what we started with because then we would start integrating. This kind of teaching took a lot longer ... It took lots of time, which is one reason why everybody didn't want to do it. That's because it was hard work! (Conversation with Janice II-TJ-4.20.09)

The other thing is that we were in charge of our day. It wasn't broken up like a middle or high school day. So, if we wanted to spend all day and occasionally we did. The kids sometimes didn’t even know when you were changing gears and bringing in the social studies part. They’d say, "Yay! We didn’t even have social studies today.” That's what you did all day. (Conversation with Ida II-TI4.20.09) 
I listened to three teachers define how they taught, and each responded by describing her approach to lesson design and how students and colleagues responded to their decisions. Janice talked about their levels of confidence, and how they were looking for a new approach. They did not want their work to become robotic in nature or just something anyone off the street could do by reading scripts in manuals.

Initial Interview Question \#3 Decision Making: “What professional development do you seek and how do you use these skills?”

Janice, Kate, and Ida's professional development decisions. Theme:

\section{Collaboration}

Teachers often take on a new approach or challenge themselves in order to keep up on current strategies and to build their professional repertoires. In speaking and listening to the trio, they all were ingrained in staying up on professional learning. These women were visionaries in maintaining their commitment to professional learning communities. Even to this day, though retired, they still meet monthly and responded enthusiastically when asked to participate in this research. What a blessing for pre-service teachers to have affiliations with teacher-experts such as Janice, Kate, and Ida. The university collaboration was hugely instrumental in their professional growth and development.

Our university professor liaison provided us with numerous in-house professional development sessions. She showed us some other ways to use our techniques in practice. Sometimes, we just needed time, and funds would be available for us to have team collaboration (Conversation with Janice II-TJ4.20.09) 
One of the other things that developed from this university collaborative is that our traveling specialists—music, art, physical education—could extend our teaching units with their expertise and assistance. For example, I wanted to have some games in my unit, but didn't have the time in my schedule. I spoke with the physical education teacher and she taught them games that had to do with my unit. We would work together on content instruction. (Conversation with Kate II-TK-4.20.09)

I think it says a lot for a small school. We all knew what each other was doing. I just remember so much about the first graders punching their tickets and having their desks all lined up like a plane trip with their passports. When I saw the first grade teacher in the hallway, she said "I'm so exhausted. We have been all over the world and I'm so glad to be back in the USA!” It was exhausting work—more than she thought she would be taking on. And it was! (Conversation with Ida II-TI-4.20.09)

The professional development theme of collaboration resounds throughout this conversation. S. M. Day teachers voluntarily meet regularly, and the trio agrees that it was collaboration worth looking forward to. At those meetings, staff were free to be open with one another. The conversations during that time included opportunity for sharing their honest thoughts. If there were disagreements, they were worked out at the table and then dropped in favor of a high collaborative relationship with site-based decision making and teacher empowerment. 
Initial Interview Question \#4: Reflection: “What does the community say about your arts integrated teaching?”

Janice, Kate, and Ida's instructional decisions. Community theme of parent and university relations.

I was privileged to gain insight into these teachers' abilities to involve parents and the community in their teaching. This dimension of their work was alive and vibrant. Their work with students evoked parent interest and support. Their wisdom in planning engaging arts integrated lessons fostered a strong connection between the public school and higher education collaborative. The trio did not leave their community involvement element to chance. They designed parent response questionnaires, surveys, and comment sheets.

I got a parent note thanking me for their child's opportunities and others who think I'm doing a good job. When we did a unit, we would have parent forms so the adult could respond back to us as to how their child did. For example, one response asks if the child discussed the unit at home, or share his portfolio in detail. They filled out the survey either at school and sent back the next day. That gave us some feedback. If they are never sharing at home then something is amiss here-we haven’t done our jobs. (Conversation with Ida II-TI-4.20.09)

Our students are our best P.R. people because they go home and talk about integrating the arts. Actually, I'd include the parents even when the unit was being taught. I also depended on them to come in and help instruct for me because I was not a quilter at that time. I had a community quilt guild come in to class. We had a quilt donation project with the local hospital that even got us 
some publicity. Things just snowballed and people know what you are doing when it is exciting. The format of integrating the arts is just so compatible with each other. At the end of the unit, you know what you will do with your projects. There was always that application part. In traditional education, we never did it. (Conversation with Janice II-TJ-4.20.09)

Our kindergarten teachers often come over at the end of a unit. I remember them coming over to my second graders, and they did a little play for my second graders that had content similar to a unit going on in my room. (Conversation with Kate II-TK-4.20.09)

These examples of parent and community involvement show that the trio from S.M. Day Primary School recognized and valued the importance of relationships outside their immediate classrooms. In their responses, community means parents, businesses, university, and classrooms within the school. Each teacher spoke to the different roles of their community involvement.

As facilitator for this conversation, I really was committed to listening and being comfortable with the group’s confidence in expressing their stories. I was not sure how or even if I would be able to connect the responses to the question frameworks. It was amazing, though, that their themes flowed naturally back to the four over arching questions, with a large amount of appropriate detail. 


\section{Janice, Kate, and Ida’s Comments on Student Artwork}

\section{Janice comments on student artwork.}

Janice worked collaboratively with two of her colleagues on an extensive third grade thematic unit called "Developing Young Writers: Lessons for Informative, Descriptive, Narrative, and Persuasive Writing.” The intent of this third grade unit was to build capacity for writing skills that are assessed in fourth grade. To ground their content and activities and to set the bar for the third graders, the planning team referenced the fourth grade Writing Assessment Technical Assistance Manual. Their goals for this unit were to provide developmentally appropriate activities for all learning styles and to provide a balance for left/right mode activities while integrating the arts. Janice was enthused with all of her arts integrated lessons. But the Bandy Snatcher was one she spoke of most enthusiastically. She introduced Bandy Snatcher lesson with a 1975 song by Joe Wayman called “Bandy Snatcher.” After talking about the lyrics, students drew their impressions of a bandy snatcher while music played softly in the background.

Parents were invited to send odds and ends types of materials such as buttons, pipe cleaners, and yarn, and these items made up the supply store. In a follow-up lesson, the bandy catcher informative writing was further explored when students constructed a bandy snatcher catcher or trap. Students role-played the experience of setting up a supply store and purchasing their materials with play money. Students had time to create their the bandy snatcher catcher and the written instructions using proper sequence of events and time order words such as first, next, and then. Below are samples of the initial sketch drawn to bandy catcher song along with the written directions for making a bandy snatcher catcher. 


\section{Bandy Snatcher Sketch}

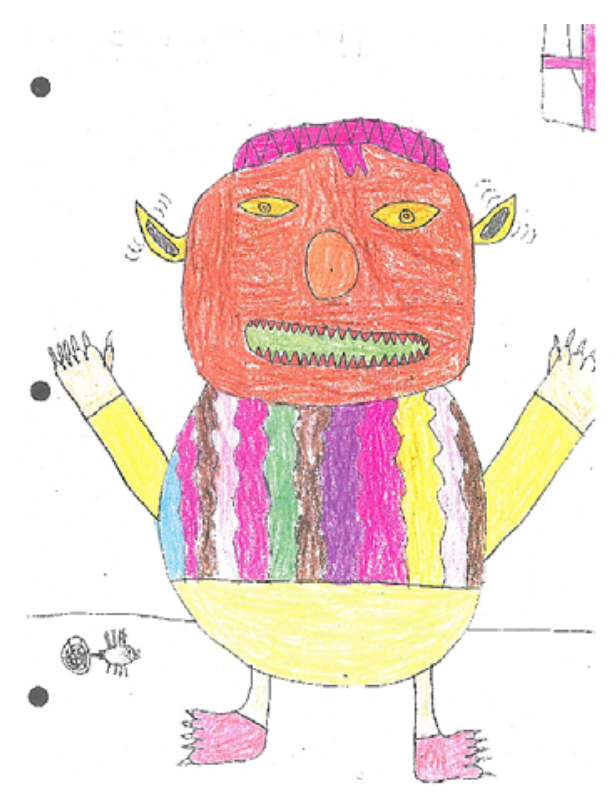

Figure 8. Bandy Snatcher Sketch. Student drew Bandy Snatcher while singing along with songs. In a follow up assignment he wrote instructions to build a Bandy Snatcher catcher.

Student Created Directions to Build a Bandy Snatcher Catcher:

1. First, place in a dark and warm closet. It would be better to set it the trap on the floor. Make sure the closet is at least forty degrees.

2. ... bell and you will know he is in it. He will knock down the fuzzy wire and he will be trapped.

3. Next, when you catch the bandy snatcher you have to watch it night and day. A bandy snatcher never sleeps. Last, whatever you do don't let a cat or dog see the bandy snatcher because dogs and cats think bandy snatchers are toys. By the way, it only eats dry noodles.

Using the four over arching interview questions of curriculum, instruction, reflection, and community, the matrix for discussing student artwork connects teacher decision making to 
student work samples. The following table takes the matrix checklist items and summarizes the categories of teacher instructional decisions that can be seen in student lesson samples. Matrix for Bandy Snatcher illustration and Bandy Catcher written instructions.

\begin{tabular}{|l|l|l|l|}
\hline \multicolumn{1}{|c|}{ Curriculum } & \multicolumn{1}{|c|}{ Instruction } & \multicolumn{1}{|c|}{ Reflection } & \multicolumn{1}{c|}{ Community } \\
\hline Reading & $\begin{array}{l}\text { Writing, Text } \\
\text { Interpretation, } \\
\text { Graphics }\end{array}$ & $\begin{array}{l}\text { Confidence, } \\
\text { Esteem, Efficacy }\end{array}$ & $\begin{array}{l}\text { Community Service, } \\
\text { Social Problem } \\
\text { solving }\end{array}$ \\
\hline
\end{tabular}

Janice spoke about this project with enthusiasm and ownership. Although she is very proud of the student work, she is equally committed to balancing the arts into her purpose for the lesson-informative writing. The students were given liberty to use their critical thinking skills to create the bandy catcher trap—an extension of their drawings, plus a real-world experience of shopping for the products to create their models.

\section{Kate Comments on Student Artwork Samples}

Kate told a passionate story about her integrated arts lessons on quilting and on studying the works of not-so-well-known artist, Romare Bearden. Just being able to take students to the university creative arts center gallery was a privilege for her classes. She explained how she came to select this artist for arts integration.

As we developed these units, we became interested ourselves in the content development. For instance, I have no idea who gave me the name of Romare Bearden. He's not a household name, to any of us. I got his name, and because he was a famous collage artist, that just spoke to the smaller age child. When they got to the third grade, the impressionist kind of thing also spoke to the child. But once I started to do some research about Romare Bearden, then I 
found that his parents were so into music instead of art. I then introduced jazz and blues and all those different music genres. It just fell into place.

(Conversation with Kate II-TK-4.20.09)

Romare Bearden masks were to accompany a print of Romare Bearden's

"Conjur Woman," the collage that he did in 1975. The students were so

interested in the woman with the snake on her arm that they supposed she wore

a mask. We then constructed masks to remember this particular print. At the Art Gallery Open House we had for the parents, friends, and other students, I believe that bulletin board elicited the most attention! I was co-teaching when I was released for the university in order to supervise the pre-service teachers we had.” (IF-TK-5.11.09)

The picture below reflects student examples of masks created in the arts integrated study of artist Romare Bearden.

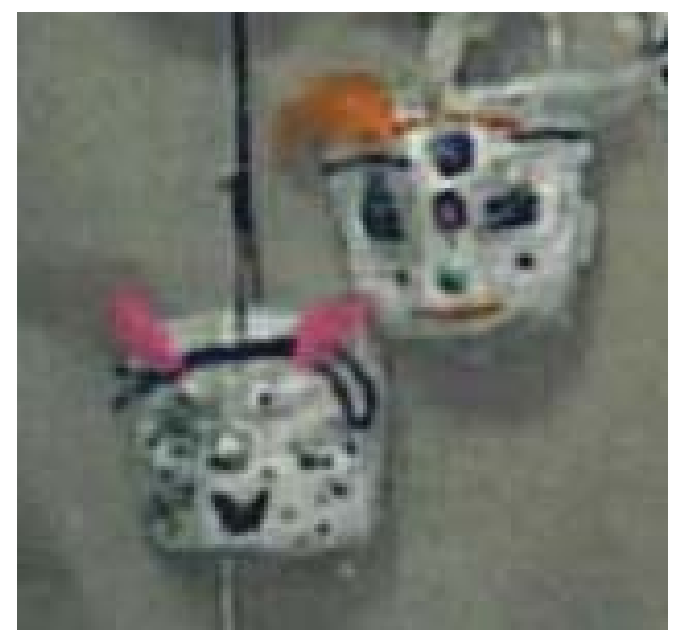

Figure 9. Student Masks. Students created papier mache masks to accompany study of artist, Romare Bearden.

Using the four over arching interview questions of curriculum, instruction, reflection, and community, the matrix for discussing student artwork connects teacher decision making to 
student work samples. The following table takes the matrix checklist items and summarizes the categories of teacher instructional decisions that can be seen in student lesson samples. Matrix for student Masks

\begin{tabular}{|l|l|l|l|}
\hline Curriculum & Instruction & Reflection & Community \\
\hline $\begin{array}{l}\text { Reading, Social } \\
\text { Studies }\end{array}$ & $\begin{array}{l}\text { Text Interpretation, } \\
\text { Graphics, Codes }\end{array}$ & $\begin{array}{l}\text { Confidence, } \\
\text { Esteem Efficacy, } \\
\text { Aspiration }\end{array}$ & $\begin{array}{l}\text { Social Problem } \\
\text { Solving, } \\
\text { Community Service, } \\
\text { Tolerance }\end{array}$ \\
\hline
\end{tabular}

Kate gave examples of how the music, arts, drama, dance had the power to teach holistically. "It just became such a part of us, so no matter what you were doing ... if you noticed that kids were either not getting it or they were falling asleep-you just inject some of this, and it changed your lesson!” (II-TK-4.20.09) Trio member Ida added the following: “As an arts integration teacher, you have to give yourself permission to let the arts integration take on a life of its own. You have to be willing to go where it takes you. Oftentimes educators have trouble with where the materials take you, but you have to be willing to use this instructionally. (II-TI-4.20.09)

\section{Ida Comments on Student Artwork Samples.}

Ida and Janice collaborated on several arts integration units. One especially noteworthy unit was the Impressionist Unit. The following statement is from a letter to parents that describes the intent of instruction for the students.

These third graders experienced a unit that integrates impressionist art, critical thinking skills, and creative and artistic expression. In keeping with the educational goals of Selena M. Day Primary School, the unit design is based on the 4MAT instructional model to meet the needs of all basic learning styles and to provide a balance of left and 
right brain activities. The use of impressionist art and the hands-on activities are designed to meet our goal of integrating the arts into the curriculum. (Conversation with Ida II-TI-4.20.09)

Students were asked to bring an old shirt so that they could experience many of the painting activities planned in the unit. The following student water color sample is indicative of several art assignments in which students had task-card assignments. The famous painting by Guy Rose (1867-1925) titled On the River, c 1908, is oil on canvas from the Rose Family Collection. The painting was influenced by Monet. A picture of Rose's painting was on the front of the task card, and the flip side of the card listed the assignment. For example: Change the picture in two ways. Show what the whole boat looks like. Then put yourself in the boat instead of this lovely lady. What would you be doing in the boat? Try to make the water look like the artist's painting.

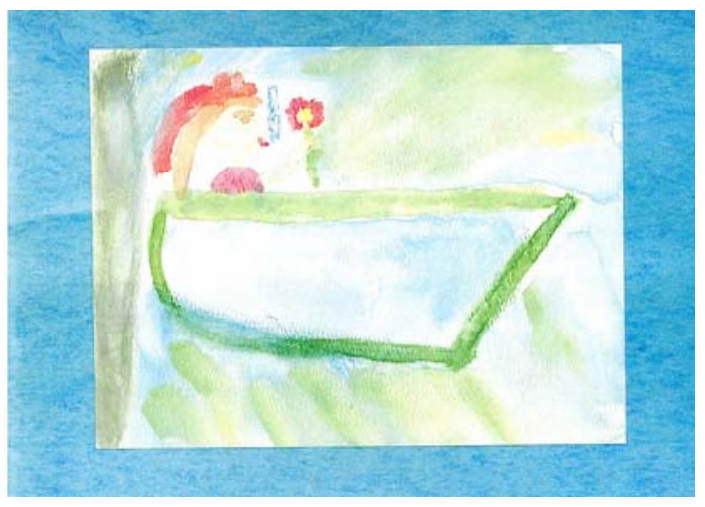

Figure 10. Impressionist water color style. Students studied famous paintings of Impressionist artists then recreated their own water color rendering to reflect a change in perspective.

In this unit, students experienced a gallery-walk. The classroom was arranged so students could walk about observing posters and prints of impressionist art work. Soft music played Debussy or Ravel's work. Students were encouraged to use their eyes and ears for the 
experience; talking would be reserved for later discussions after the gallery walk was

completed. Listed below are some of the student responses following the gallery experience:

- Blurred, none the same, lots of color

- Showed lots of feeling, details, shadows

- Reminds me of dreams, my younger days, someone I loved

- Relaxed feeling, good feeling, saw movement

Students were encouraged to think and reflect on other reactions to the gallery walk. Some of these included: What did you like or dislike? What made the paintings interesting? What did you notice or like or see? The unit objective was to help students develop critical thinking skill through creative expression in artistic responses to impressionist paintings.

Using the four over arching interview questions of curriculum, instruction, reflection, and community, the matrix for discussing student artwork connects teacher decision-making to student work samples. The following table takes the matrix checklist items and summarizes the categories of teacher instructional decisions that can be seen in student lesson samples. Matrix for Impressionist Paintings

\begin{tabular}{|l|l|l|l|}
\hline Curriculum & Instruction & Reflection & Community \\
\hline $\begin{array}{l}\text { Reading, Social } \\
\text { Studies }\end{array}$ & $\begin{array}{l}\text { Text Interpretation, } \\
\text { Writing, Graphics, }\end{array}$ & $\begin{array}{l}\text { Confidence, } \\
\text { Esteem, Efficacy, } \\
\text { Aspiration }\end{array}$ & $\begin{array}{l}\text { Social Problem } \\
\text { Solving, Tolerance }\end{array}$ \\
& & & \\
\hline
\end{tabular}

Collaboration among the third and first graders on this unit made it possible to meet S. M. Day's mission and vision of having an arts integrated classroom and school culture. The intellectual and artistic intent was for students to experience famous artworks by impressionist painters, increase understanding of communication through art, and promote an understanding of Impressionist art form. Throughout this unit, the master-teachers collected documentation 
on student work for research and presentation purposes. Teacher sharing was common amongst this trio, and they frequently attended national conferences with their university professor liaison.

Ida’s logical thinking unit was co-created with her university pre-service colleague. The rationale states that the “... unit is designed to develop, strengthen, and encourage logical thinking skills.” The extensive structure of the themed units portrays multiple goals and expectations. For example: “Teachers bring a positive attitude and new techniques to the classroom. This directly affects the student's ability and desire to learn.” (Logical Thinking 4MAT Unit Designed for Third Graders, fall 2001)

Thinking outside of the box was an important component of Ida's unit. She systematically incorporated creative or divergent thinking into the curriculum through weekly 25 minute creative thinking activities. The student work sample below is an example of one student's divergent thinking. Procedure for the activity is to see how many different items can be created from a simple circle. The teacher is able to catch a glimpse into student thinking about insects, animals, weather and plants.

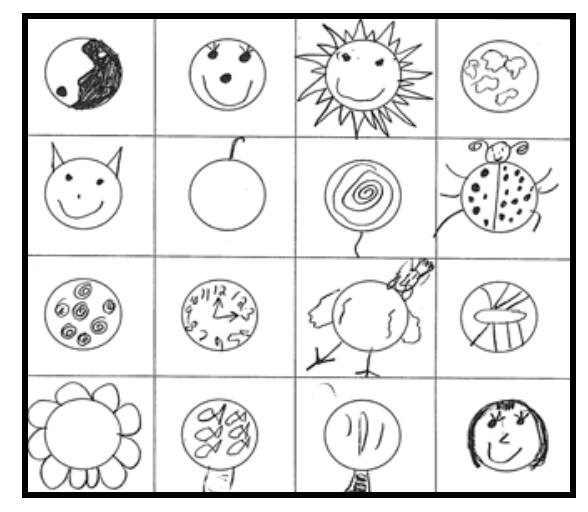

Figure 11. Divergent Thinking Sketching Activity. Students used creativity to draw many different items from a simple circle. 
Using the four over arching interview questions of curriculum, instruction, reflection, and community, the matrix for discussing student artwork connects teacher decision making to student work samples. The following table takes the matrix checklist items and summarizes the categories of teacher instructional decisions that can be seen in student lesson samples. Matrix for student Divergent Thinking Circles

\begin{tabular}{|l|l|l|l|}
\hline \multicolumn{1}{|c|}{ Curriculum } & \multicolumn{1}{|c|}{ Instruction } & \multicolumn{1}{c|}{ Reflection } & \multicolumn{1}{c|}{ Community } \\
\hline $\begin{array}{l}\text { Reading, Math, Social } \\
\text { Studies, Science }\end{array}$ & $\begin{array}{l}\text { Writing, Text } \\
\text { Interpretation, } \\
\text { Graphics, Codes }\end{array}$ & $\begin{array}{l}\text { Confidence, Efficacy, } \\
\text { Aspiration }\end{array}$ & $\begin{array}{l}\text { Community Service, } \\
\text { Social Problem } \\
\text { Solving, Tolerance }\end{array}$ \\
\hline
\end{tabular}

A communiqué to parents explained the unit’s instructional intent, inviting them to work alongside their child with logical thinking and problem solving skills. To extend logical thinking beyond confines of the classroom and into students' homes, Ida developed weekly take-home packets for a Monday-Monday cycle. Parents were encouraged to participate with students as they developed creativity and divergent thinking skills.

Follow up Interview Over Arching Question \#1: Demographic setting and professional attributes of an arts rich teacher.

Janice, Kate, and Ida's Self-characterization of professional educator: Theme: Present in the teaching moment.

Speaking of privilege-it was! It was a privilege just being part of this trio’s conversation, observing their oneness, their ability to expand upon a theme, and to meet professional obligations of marrying content to instruction. The wisdom gained from a lifetime of continuing education and teaching is the dividend for their dedication to staying in teaching 
profession. Each retired teacher spoke from her own knowledge of self and ability to analyze and interpret professional accomplishments.

I was always at the right place at the right time. I was always there. Looking back at what I've done, I'm amazed! But I think I was ... I wouldn't want to be teaching now. I've heard so many teachers say, 'What goes around comes around. Don't worry about it. I'm just going to keep this old lesson plan, because it’s going to come around again eventually. Like clothes, you know. The style’s coming back.' I knew that, but I was always anxious to see the next new thing. I didn’t jump on every bandwagon, but I was aware of it.

(Conversation with Janice IF-TJ-5.11.09)

\section{My Reflections}

I think you are forward thinkers; you are willing to outgrow yourselves. You are always striving to find how to be the best you can be and to stay ahead of the game. Sometimes there are great advantages to that. My son said yesterday, "I put an idea out there for us in my company to work smarter and not harder. But the idea fell flat." He was struggling with the esteem part of risk taking on the job. I said, "You know why? It is because you are ahead of the other thinkers. And they did not get it. They did not process it. Now give yourself two months, and they are going to be coming to you saying, "We have a great idea. It is going to be exactly what you said." That is sometimes the fate of forward thinkers and their visionary ideas. The rest of the world has not caught up with their forward thinking.

Janice has been talking about publishing, and we've all been asked several times to publish. We have refused because it's more about the process of using the art and integrating the arts. (Conversation with Kate IF-TK-5.11.09) 
Because we were experienced teachers, we knew it wasn’t about time . . . we knew that the CSOs were in our lessons somewhere. We didn't have to go and double check, and I know sometimes an administrator will write down every CSO taught at every single minute. I think you are missing the picture when you do that. I think if you look at a bigger picture and then fit them in, you're going to be sure the CSOs are being met. (Conversation with Ida IF-TI-5.11.09)

\section{Personal experience with the arts.}

When considering what makes an arts-rich teacher, we have to step back and be willing to listen to their stories, to observe their students at work, and to ask them more about their work.

That was one thing that we often kept when people would come and observe or look at our program. We are not art teachers. We are not artists. We never considered ourselves artists in any way. But it's just that we have an appreciation for it, and their children enjoyed it—and it added such a different dimension to our teaching by bringing that in. So we were learning with the children, because we really haven't had any training in the arts. (Conversation with Janice IF-TJ-5.11.09)

In high school, I was in the band. I took music lessons, but I wasn’t an artist. When I was in college, I had art appreciation, which I didn't appreciate too much at the time because it was rote memory. I always loved to go to galleries-didn’t appreciate what I was seeing as much as I do now. (Conversation with Kate IF-TK-5.11.09) 


\section{My Reflection}

I had the privilege of a background infused with piano lessons at age five. I can honestly say that I do not ever remember a time when the arts were not accessible to me. My parents were not artistic or musical, but they provided art and music lessons. I was educated in a school system where a traveling music teacher visited bi-weekly, I took art classes in junior high and high school, sang in choir throughout high school, and had dramatic roles in school plays. I had difficulty deciding between art and music for a college major, but decided on music. I taught elementary school as the specialist who provided planning periods for classroom teachers. Classroom teachers' foremost focus is upon the content area subjects-reading, math, social studies, and science-taking core subject content and augmenting by adding arts integration. My planning centered upon how to take the arts and augment with content. For example, I wanted a 5th grade class to have a dramatic arts experience, so I found a book of American history plays. I wanted them to experience dance, and introduced cultural dances, square dance steps, and tinikling sticks. For art methods, I thought it would be important to introduce sculpture, so students created the instruments of the orchestra using papier-mâché.

My strong arts influence presented challenges to my teaching. I distinctly remember thinking about which art, music, or drama concept to teach. I realized both then and now that I was maximizing the arts focus at the expense of introducing core subject content. In retrospect, these were conscious decisions based upon my own affinity for the arts and my confidence and self-efficacy to provide arts instruction to my students.

Professional growth and development.

Teachers who are committed to increasing their expertise have conversations among themselves. I have heard teachers talk about their desire to learn new strategies and improve instruction. The retired trio from S. M. Day Primary School offered strong talk 
about their motivation to collaborate together. They characterized their work together on integrating the arts as "having a good time.”

And we encouraged other people to integrate arts in small ways. Not everybody went off the deep end with it like we did. We just ... we were enjoying it! We were having a good time with it and growing professionally. It was very exciting for me to be doing something new in the teaching profession. We did encourage people. (Conversation with Janice IF-TJ-5.11.09)

So, I have grown professionally and personally in what I'm seeing. I'm sitting here looking at the student's print and seeing different things that I wouldn't have seen fifteen years ago. If there's an area of expertise that you need, it's the teaching, the delivery of instruction. And you must be willing to take a risk and try some things. And we had the willingness to put the time in to try some things — that's where a lot of people aren't willing to give it the time. We just had a good time with it. (Conversation with Kate FI-TK-5.11.09)

We also had a good working relationship, and we were also friends. We didn't mind spending the extra time before and after school working on this. We worked summers on it. But we didn't mind because we enjoyed the company as well. (Conversation with Ida FI-TI-5.11.09)

This group of primary school teachers was committed to learning and growing together. They shared ideas, supported each other in developing themed units, and talked about their 
work together. They were willing to give their time and monetary resources to design arts integrated lessons. And, thanks to each other, they thrived in their professional growth and development.

\section{Reflective practice.}

Both the initial and follow-up interviews with the three retirees could be likened to an exercise in reflection. Janice is newly retired. Her perspectives are still rooted closely to last year being in the classroom. Kate and Ida have up to four years distance from the classroom. Though out of the profession, all talk openly and analytically about their work. Their work with the university and professional development collaborative provided fertile ground for building a reflective practice skill set.

The other thing that our professional development collaborative taught us is that we need to reflect—-to look back, self-evaluate, reflect, and journal. And that was definitely because of the university collaborative influence upon us. We just didn't take time to do that before. On the reflecting business, we also practiced teaching our students to reflect, because then that really informed us about how things were going, too. (Conversation with Janice IF-TJ-5.11.09)

We had to train ourselves to reflect, but we also had our students reflect. We had them keep journals, and we got some of the best comments from kids. I think one of Janice's student reflections became my favorite reflection was this: “I learned more than I wanted to.” But reading what the kids liked and didn’t like was big. (Conversation with Kate IF-TK-5.11.09) 
We were doing action research before it was vogue. We had a session at a national conference. I remember people who were stopping by to look at our student comments. One of the comments that I heard form other educators was, “They asked the kids!” Well, one thing kids know about is school! (Conversation with Ida IF-TI-5.11.09)

Janice, Kate, and Ida were drawn by the university professional development collaborative into the skill of reflection. They grew to appreciate the benefits of knowing if their lessons were working for students. They were encouraged to reflect through their affiliation with the university professional development collaborative. In our conversation, they shared how their own reflective practice involved asking students for feedback to verify what was working, important enough to risk what the students were thinking about their teachers' instruction, and important enough to feature at a national conference.

Follow up Interview Over Arching Question \#2: Arts Integration and the influence of job satisfaction, commitment, autonomy and change

Janice, Kate, and Ida's commitment to arts integration with Theme: Creating Resources.

Talking about the impact of teaching an arts integrated classroom can reveal a teacher's beliefs, attitudes, commitments, satisfaction, and perceived autonomy. Commitments of time, resources, planning, expanding personal content knowledge, or learning teaching strategies are some of the topics teachers share when expressing their commitments. 
It was mostly time. Then we had to get some training. Either we trained ourselves or our university professor did workshops for us. Time was the biggest thing. The money part was ... if we weren't able to spend that money, we probably still would have found a way to do it. (Conversation with Janice IF-TJ-5.11.09)

I think so. Time really covers a lot. Time to do the hands-on kinds of things with books, time to do research, talk with people. Time to reflect, to search out people who knew more than I did about this. (Conversation with Kate IF-TK5.11.09)

And for a lot of people, I think time is the biggest four letter word that everybody worries about. You have to create time. Maybe this was an issue because we were a small school, but I don't believe so. We would create our own time by combining groups or splitting them into smaller groups, trading lunch and playground duties. (Conversation with Ida IF-TI-5.11.09) Teaching satisfaction and control over curriculum and instruction: Theme: exploring teaching satisfaction and teaching success.

The three S. M. Day teachers talked about job satisfaction and autonomy. Their responses blur the distinction between both topics. This raises the possibility to question if teacher satisfaction is a result of having control over the curriculum and instruction. Ownership over how and what you decide to teach is a perception that is unique to an 
individual teacher. Can a teacher’s perceived autonomy be attributed to her teaching satisfaction, as well as her curriculum and instructional methods?

Am I satisfied because I am successful with teaching, or am I successful because I am satisfied with teaching? This question comes to me through my work with this dissertation as I listen to teachers share their levels of satisfaction and their perceptions of autonomy. Finding an answer to this question requires deep understanding and reflection upon our own educational experiences.

S. M. Day's retired trio shared their views about having the power to make decisions. They used terms like empowerment and freedom. They described decisions ranging from using the textbook to strategies like cooperative learning.

I think it's one of the things that kept me in the profession because I was just having a hard time following the manual kind of thing. I wanted to be making decisions for my classroom, so it was empowering. I didn't want somebody else telling me, through a teaching manual, "This is what you will do today." Another thing is because we taught so long, we knew what was in those manuals. (Conversation with Janice IF-TJ-5.11.09)

And that certainly comes with experience. The manuals became my resources. I feel like I was confident in my teaching. I wanted to make decisions for my classroom. (Conversation with Kate IF-TK-5.11.09)

One advantage a seasoned teacher has over a novice teacher is the accrued skill set gained over the life of a career. Even though strategies, materials, and teacher's manuals 
change, teachers who know their curriculum have greater confidence in claiming their rights to autonomy. They have confidence to risk stepping away from teacher manuals and standards, and more practice with combining activities that teach multiple concepts.

\section{Making and Sustaining Change in Teaching.}

In both teaching and supervising, I have seen the discomfort of change, and how it can be hard for many teachers. Change was not hard for the three teachers at S.M. Day Primary School. Perhaps change has a stimulus-response effect in which the excitement of doing something new creates a new energy for an old task.

Change was not hard for the three of us. We relished change. Not just change for change sake, but we welcomed new opportunities. Remember, Ida, you and I were the first ones to even introduce a computer to the primary school. It was a Tandy Radio Shack computer. We never wanted to be left out. Maybe that was a selfish thing. We always wanted to be on the cusp of whatever was going to go on. (Conversation with Kate IF-TK-5.11.09)

A lot of changes were made, depending on the student group that you had that particular year. There's always some tweaking. And those of us who do this say, “I can’t do that. I can't do a thing.” I mean, we had a sketch of what was going to happen on day one. We had to wait until we met our students, because we didn't know how the students were. Those influences that we make on children are life-long, and I think because we make those influences, we feel we 
can sustain whatever change we make. (Conversation with Janice IF-TJ-

Sometimes I had to water down some things. Sometimes I could do the whole lesson. I'll be honest with you: not every lesson plan was done in this book every year. With my student teachers from the university, their needs, interests, and capacities made a difference in working with us. These things determined the success of the unit, also. I know it did because we said the motivation of the teacher had a lot to do with the motivations of the children. (Conversation with Kate IF-TK-5.11.09)

In one instance, we were going to study the Holocaust, and some naysayers cautioned against this concept. And because we were strong enough and we had not just done our research, we really did our research on that one. We really pounded the research before we got into it. So, we were strong enough to say, “Just trust us. We've got this covered.” And we didn’t back down. I think that makes a difference. Everyone was pleased with the instruction. But it takes some trust also ... trust ourselves, and the kids. (Conversation with Janice IFTJ-5.11.09)

The resolve that we got from students, I think, is ultimately what sustained the big change and the shift we were making. We were getting such good results, 
academically, and we were having such a good time. There was no way I was

going back. (Conversation with Kate IF-TK-5.11.09)

Self-selection and determination are two elements in making and sustaining change. Teachers can articulate what moves them to decide upon a change element. Kate wanted to be on the cusp of new initiatives and ideas. Janice strove to bring premier instructional lessons to her students. Regardless of the internal reasons for embracing change, for those brave enough to step out there, change will happen. Change comes from growth, and with growth comes learning a new skill set. With new skills comes the ability to offer greater learning opportunities for the students.

Follow up Interview Over Arching Question \#3: Student Learning and how you integrate the arts.

Janice, Kate, and Ida's awareness of motivation and teaching for struggling and successful learners. Theme: Learning for all children. Motivation and Teaching for struggling and successful learners.

Much of what we have discussed regarding academic performance involves elements of student commitment to learning, their response to well-planned instruction, and their achievement levels. Student motivation is not just for the chosen students who excel without a great deal of effort. This section of four questions became a conversation that flowed freely and unstructured among the three teachers. Within the time spent sharing, they answered each of the question structures, but in their own time and using their own examples to illuminate. 
I am amazed at this good example: The kids who did have a label were always present for the first time. The students with academic challenges, for the first time, were above the pack. The more talented and gifted children wanted it perfect, so they really struggled. All of a sudden, these kids were looking to the others amazed at their accomplishments. So it gave the struggling ones more confidence to try other things. I think those were surprises for me- to know that all of a sudden, these kids have something to be proud of. (Conversation with Kate IF-TK-5.11.09)

Those kids were able to stay on task, and that was another thing people observed in our classrooms. When you walked in, you couldn't tell which child had learning difficulties. (Conversation with Janice IF-TJ-5.11.09)

When the university students came over, I would challenge them to pick a student who was labeled as disruptive. They couldn't find one because everyone was engaged and all that disappears for them. (Conversation with Kate IF-TK-5.11.09)

The artwork was so dramatically different for these students, but wonderful to show that students with conditions like autism could stay focused long enough to do brilliant artwork. (Conversation with Ida IF-TI-5.11.09)

Students started respecting each other. (Conversation with Kate IF-TK-5.11.09) 
Honoring diversity as we always called it. (Conversation with Ida IF-TI5.11.09)

They started looking at parts of their peers’ paintings and honoring the best parts. Providing their assessment and giving feedback. (Conversation with Kate IF-TK-5.11.09)

That's because we modeled it. You think about how many hours we had those kids. We just learn ... we accepted the child. That's the one who came to us and that's the child we accepted. (Conversation with Janice IF-TJ-5.11.09)

Yes, like the student I just let sit for a long time with a mirror and he would draw an outline then make adjustments to his design. And so you make those adjustments for autistic or other behavior challenged students. I think you just have to give them a different kind of time. (Conversation with Ida IF-TI$5.11 .09)$

I had a little boy who wouldn't sing, absolutely wouldn't sing. It was kind of disturbing at first. I spoke to his mother to gain insight and came to provide him with other options. We just learn ... we accepted the child. That's the child who came to us, and that's the child we accepted. It's just accepting the child for who they are and where they are. (Conversation with Kate IF-TK-5.11.09) 
Kate, what you're saying, I think, is neat because in the teacher's room we weren't complaining about our kids. We're telling those stories. The teacher's room is a fun place to be, because nobody was complaining. We were celebrating the successes of each student. (Conversation with Janice IF-TJ5.11.09)

There's one thing I want to say about meeting needs of different learners, because we did have a whole range of abilities in the classroom. With doing this type of teaching, we didn't have to offer different assignments for different kids. Everybody was doing the same thing, but when you looked in the room, you didn't notice how a child was functioning on level. So if a gifted child was doing a writing piece, we encouraged him to go beyond what third graders would do. If a child had deeper challenges, we would kneel at the desk and help them physically move the pencil. But nobody knew. (Conversation with Ida IFTI-5.11.09)

My biggest challenge was a first grader who was blind. Teaching art to her was a bigger struggle for me than it was for her. Finding the color blue, for example...I got scratch and sniff stickers for her crayons. She could smell the orange and know her crayon colors. She grew up and went to the local university and was willing to be a guest speaker for one of my college preservice classes. (Conversation with Kate IF-TK-5.11.09) 
This section of our interview conversation was one of the most naturally flowing conversations among the teachers. Perhaps tossing out the question structure enabled a true discourse unencumbered by my having to facilitate the interview. Although I tried to present the questions, the teachers were clearly more interested in having their opportunity to talk without being bound to a set of questions. They shared rich descriptions of their students who depended upon them for success in school. All participants talked honestly about their challenges to meet student needs. Each one found a way for students to learn through the arts. None shied away from ensuring that all students have an equitable arts-learning opportunity in their classes.

\section{Follow up Interview Over Arching Question \#4: Use of the Arts beyond the Classroom Janice, Kate, and Ida's involvement with parents and colleagues integrating art.}

These teachers were involved with the parents in a multitude of ways from inviting them to classroom gallery displays, arts shows, letters, and communiqués to introduce themed lessons and to request items needed to complete arts integrated lesson activities. They worked with their parents to keep them informed and to use their expertise and resources for classroom instruction. Always valuing the parent and community offerings, students and teachers received benefits of this collaboration.

We had our own art show. We planned all kinds of things such as social skills and how that is different from going to a football game. Our Parent Teacher Association (PTA) was very supportive of our teaching. We could 
write grants to get money for the arts activities. They never questioned us on our needs. (Conversation with Kate IF-TK-5.11.09)

But we also kept them informed. In order to have them be supportive, they needed to know what it was they were supporting. So we tried to send letters at the beginning of our units so the parents would know. Teaching this way was the biggest resource, because the children would go home and speak about school happenings. The kids talked to their parents. A parent rushed to tell me that one day they were going out shopping. It was the day we studied Vivaldi. To this day, the student's mom says he will go and choose classical music or something that he remembers from third grade. Or he will go shopping at the department store and look through all of the art to find something of his interest. She said that is so unusual—so different for him. (Conversation with Janice IFTJ-5.11.09)

And it really spoke to him, because he was not an athlete. He will not get his glory in high school being an athlete. He will get it as a bright child. (Conversation with Ida IF-TI-5.11.09)

Involvement with the community has helped teachers develop breadth and depth in their understanding of arts integration. A strong affiliation with university professors and the professional development collaborative opened up opportunities to attend workshops, symposiums, and conferences. The Madreas area provides rich access to dance, music, artists, 
musicians, and theatre performances. Opportunities to present at national conferences played an important role in their success within classroom arts integration. Although they are retired, the trio still remains involved in working with the school system and with the university to promote their themed arts instruction.

We have taught classes for the university just specifically on how to design a unit. Teachers in the class are experienced ones who would take a summer class with other schools in the collaborative. (Conversation with Ida IF-TI-5.11.09)

Just three weeks ago, I took my quilt unit into the children's literature class. In two hours' time, I showed how my units integrated the arts with teaching reading. Being in a university town certainly helped me a lot. Being able to go to the Creative Arts Center and having the professor as a resource was incredibly valuable. Each year we went to a gallery. The community had influenced me a lot. I don't know that I could teach the Romare Bearden unit as effectively in other areas. I would have had to make adjustments in the absence of the university arts department. (Conversation with Kate IF-TK-5.11.09)

Our university professor has sponsored smaller projects in which we have been able to share our work with teachers hoping to get on board with arts integration for their classrooms. (Conversation with Janice IF-TJ-5.11.09) 
Clearly, the three retired teachers recognize the community's gifts and resources. This is a community that has bountiful intellectual and performance opportunities at the university level as well as public forums to work with parents, community artists, and performers. The trio of teachers stepped up to the challenge of learning new ways of instruction in the autumn of their careers. Even in retirement from public school teaching, they continue their involvement with the school system, growing stronger pre-service teachers and sharing projects that benefit their community. What began as a way to strengthen their teaching has evolved into a way of life-even after their commitment to teaching public school children was fulfilled.

\section{Lesson Plan Analysis}

Janice, Kate, and Ida represent the concept of three-in-one. They are three individuals who have blended their individual talents and brilliance in curriculum and instruction. Yet they are one unit closely bound by their oneness in thought and action. This trio has made some outstanding contributions to the work of teachers—lesson planning, integrating the arts, and student achievement. I would like to suggest that they have achieved a trifecta--perfection in three areas of study in this research. Janice, Kate, and Ida are distinguished teacher-exemplars who have poured their hearts and souls into their work, resulting in a well-spent energy that empowers children. In the lesson plan analysis below, I will feature four units. One unit designed individually by Kate and her university pre-service teacher, and three units collaboratively designed by Joyce, Ida, and their university pre-service teachers. 
Unit \#1

\section{Kate’s Lesson Plan Analysis}

"A Quilt is Worth a Thousand Memories: A Second Grade Unit”

Kate’s quilting unit is still working its magic with teaching and learning because it is a model for exemplary design in planning and instruction. Kate continues to share her experiences with public school teachers and university pre-service teachers. In fact, this 2001 unit was ahead of its time and designed to keep pace with the changing face of instruction. Kate's active involvement with teaching and supervising university pre-service teachers has been an opportunity to reinvent the quilt unit in a current and keeping-pace way. For example, in one of her Power Point presentations, she raises a thoughtful and provoking question: "Is Quilting a 21st Century Skill?”

In the introductory letter to parents, the quilt unit was described as “an excellent theme selection that offers a variety of ways to learn important concepts in all areas of the curriculum, while the students learn more about themselves.” The letter continued to explain that quilting tells a story of a person's history and traditions; it invited parents to help and participate in classroom activities.

The comprehensive unit design opened with a graphic organizer that visually organized the right and left brain activities as well as the scope and sequence of content. Some of these included playing Appalachian background music while students illustrated common elements of quilts on display; students sharing and talking about old swatches of fabric from their past; culminating patchwork picnic; fabric crayons to make a quilt square on a T-shirt; identifying geometric shapes and patterns. 
Planning web features for each of the unit's ten components made up the content that was to be covered. Listed below are the content categories with examples of lessons and integrated arts activities:

- $\quad$ Listening Skills_-Teacher Read-Aloud with quality children’s literature

- $\quad$ Physical Education-4-Square, parachute with quilts

- $\quad$ Social Studies - history of Appalachian culture, guest speakers, oral histories

- $\quad$ Science-natural dyes

- $\quad$ Math—patterns, geometric shapes, symmetry

- $\quad$ Art—quilt blocks, textures in quilts, patterns and quilt colors, class family quilt

- $\quad$ Music-Appalachian music

- Writing - poetry, thank you cards, sequencing stories, mini-books

- $\quad$ Oral Language_-following oral directions, quilt vocabulary words

Lesson Six Plan was a Language Arts/Social Studies/Technology lesson. The objectives for this lesson included understanding the history of quilting as a concept, using the internet to research information on quilting, and completing comprehension activities using a how-to quilting book. The lesson required only common classroom materials such as crayons, markers, and a mini book with quilting theme, computer and internet access, television, and scan converter. Students designed their own "history" quilt square and shared the meanings with their classmates (social studies). The teacher facilitated a discussion on how students used the internet as a resource to gather information on quilting (technology). Using the mini quilting book, children were invited to read aloud and explore answers to confirm their comprehension of the topic (language arts). Teaching and learning strategies included whole group read-aloud, small discussion groups and modeling internet research strategies. Assessment strategies included classroom participation, teacher observation, and comprehension questioning techniques. 
Lesson Nine's plan was an art and math integrated lesson. The objectives included exploring the concept of texture and an understanding of symmetry and pattern. Tactile awareness of real-world textures was a feature for this primary grade lesson. Common materials included tag board squares, glue, and common craft items such as buttons, ribbon, crepe paper, markers, and crayons. Activities included exploring the textures of items in the classroom and describing those textures to their classmates. Using common craft items, students created a quilt design incorporating their understanding of texture, symmetry and geometric patterns. Assessment of student understanding included student participation and discussion, effective use of materials, and appropriately demonstrating patterns and symmetry.

Unit \#2

\section{Ida's Lesson Plan Analysis: Logical Thinking, A 4MAT Unit Designed for Third Graders}

Ida's unit rationale explained her vision for student success. She taught this unit to her third grade students at S. M. Day Primary School and conducted action research as a professional development teaching experience. Results were shared with the university collaborative. Following is a statement of rationale for the Logical Thinking unit:

This unit was designed to develop, strengthen, and encourage logical thinking among third graders and to support the National Council of Teachers of Mathematics (NCTM) teaching standards which emphasize the shift toward “conjecturing, inventing, and problem solving as opposed to “mechanistic answer-finding.” For our purposes, we have defined logical thinking as "drawing conclusions or making decisions based on a body of information.” A varied approach to problem solving has been taken in our efforts to integrate the arts, technology, and family involvement. Creative thinking activities have also been 
included in this unit, because it is our belief that experience with divergent thinking will enhance the logical thinking process. (Logical Thinking 4MAT Unit for Third Graders, TIFall 2001)

Opening sections of this unit provided content credibility by subscribing to two strong standards resources: NCTM Standards for problem solving and communication and state instructional goals and objectives.

Lesson one was a 90-minute introductory lesson called "Logical Journey of the Zoombinis” and proposed to offer students an encounter in logical thinking along with the opportunity to practice logical thinking skills using computer technology software. Materials required included specific technology items such as LCD projector, laptop, and computer software and manual. Lessons included in this unit required teacher preparation to utilize the software program upon which the unit lessons were built. The lesson had a strong parent component. Digital pictures, taken throughout the unit, were emailed to parents and featured in the parent newsletter.

Teaching a lesson of this nature depends on skillful use of the software as it is designed to be used and support for student learning using technology as a tutoring tool. Students are guiding the Zoombinis through their journey’s obstacles. Teacher observation is an important assessment tool to determine student engagement and performance standards.

Lesson three was grounded in creative thinking activities. Materials were simple, everyday items, with the exception of a digital camera. Teacher preparation included establishing class norms, rules, and/or guidelines with the students, and gathering props for the students to use with their creative thinking activities. Procedures included a warm-up circle game in which students pass a "magic" spoon to classmates. When the spoon passes to a new 
person, it becomes something other than a spoon. Students then explained what the imaginary new items were and communicated without words. After this practice with large group pantomime, students engaged in partner pantomime.

The dramatic vocabulary was part of this lesson plan. For example, students were learning how to use props and to improvise and portray using non-verbal communication and dramatic interpretation. Props cannot be used as what they really are; therefore, students must imagine that they were to be used differently. Once completed, students responded to questions in a creative thinking activity. Some of the student responses to the pantomime imagination activity are included below:

“We got to use our imaginations.”

"We ran out of time when we got to the good part!"

"I found it easy to think and act out."

"I was a little nervous to go in front of the class."

"The easy part was when you have to guess what they are doing; the hard part was doing the acting.”

Student response sheets assist teachers and students in determining the most successful elements of the learning experience. Assessment for this lesson is informal in nature and includes teacher observation, student engagement, evidence of creative thinking, and perceived student success as indicated on the creative thinking response sheets. 
Unit \#3

\section{Janice and Ida's Lesson Plan Analysis: Watery World Poetry an Integration of Poetry, Fine Arts and Technology}

This unique unit plan extended outward to include planning efforts of classroom teachers, and university pre-service teacher and professor with design built upon integration of poetry, fine arts, and technology. The ten-lesson unit included a rationale with a strong and purposeful intent: “Fine arts are used to inspire students to write creatively and to nurture an awareness and appreciation of the arts. Technology was used to enhance the writing process, the publication and presentation of student work, and the home/school connection.”

Four learning goals were stated in the introductory pages of the unit:

- Introducing students to poetry forms

- Using writing process for poetry composition

- Integrated arts activities including art, music, movement, and drama

- Technology use to facilitate and enhance writing process

Janice and Ida articulated a carefully crafted unit structure that is clear and explicit, making the plan procedurally grounded for instructors and for students. The unit one summary is as follows:

“Using a water theme throughout this unit, students will write many poems. Activities are varied so that the needs of varied learning styles are met and both the left and right brain are engaged. Each pre-writing will include fine arts experiences. Each piece of poetry will be published in a way that emphasizes the importance of an aesthetically pleasing presentation. Technology is used throughout to facilitate the writing process, to enhance the presentation of student work, and to maintain school-to-home communication.” (Introduction to Watery World Poetry Unit) 
An emphasis upon content standards grounded this unit’s credibility. Janice, Kate, Dr. S, and the pre-service teacher incorporated the Technology Foundation Standards for Students by quoting the International Society for Teaching in Education's (ISTE) and the National Education Technology Standards (NETS). These frameworks for planning technology activities guided students towards achieving successful learning, communication, and life skills. Other standards for the unit design included the state goals and objectives and National Standards for Fine Arts developed by the Consortium of National Arts Education Associations.

Lesson one is the Introduction to Watery World Theme. The three guiding objectives for this lesson are as follows:

- Brainstorming resource/reference charts for the unit

- Introduction to Microsoft Word software

- Introduction to internet movie site

Materials are not the usual common, everyday items available in every classroom. They require appropriate technology knowledge and support. This unit is forward-thinking and raises the bar for quality arts-integration with a technology component. Required for this unit are the following: multi-media computer, word processing program, internet, chart headings stored on storage disk, color printer, and digital camera.

Procedures involve transforming the classroom into a watery world environment by supporting student learning with pictures, posters, books, magazines, and music. Children can visit a website to see videos of sea life. In class discussions, teachers used effective questioning techniques to probe for student learning and to check for depth of knowledge and schema. For example, "How does water move? What does water feel like? How do we use water?” Students engage in the discussion, and the teacher records student responses and projects on a large screen as responses develop. Final charts were posted throughout the 
classroom for all classmates to see throughout the unit study. Lesson one explained and highlighted unit features, including frequent and multiple types of student assessments, both formal and informal. Teachers observed and documented student performance in the writing process, participation in fine arts experiences, and appropriate and responsible use of technology. Lesson one explained the student culminating work portfolio that demonstrated to students, parents, and administrators the unit’s effectiveness.

Unit \#4

Janice and Ida’s Lesson Plan Analysis

Developing Young Writers: Lessons for Informative, Descriptive, Narrative, and Persuasive Writing, a Third Grade Unit to Enhance Writing Skills.

Janice and Ida developed their writing unit in 1998 with the following rationale: This unit was developed for third graders in order to enhance writing skills that will be assessed at the fourth grade level. The Fourth Grade Writing Assessment Technical Assistance Manual, published by the Office of Student Services and Assessment, at the State Department of Education, was used as the resource for planning and designing activities and assessments. The 4MAT instructional model was used to design instruction that not only emphasizes the writing process, but also provides developmentally appropriate activities for all types of learners, provides a balance for left and right mode activities, and integrates the arts. These 4MAT cycles represent the writing process as used to provide third graders with experience in descriptive, narrative, informative, and persuasive writing. (4MAT Unit Rationale Janice and Ida)

Janice and Ida envisioned their students’ future creative writing success. They acted on their vision and came up with a design to make it happen. In the opening pages of this unit, 
collaborators have included the learning wheel graphic organizer that identifies left and right brain activities. The wheel includes stages of informative writing and publishing along with the activities sequence. The unit begins with a prewriting experience in which students listen to the music and lyrics of “The Bandy Snatcher” while drawing their interpretation of a bandy snatcher. Culminating the entire unit is a Young Authors' Conference. Throughout the stages of unit development, students make progress through the writing process, including expanding the prewriting, drafting, revising, editing, and publishing. Consistent with the unit development is a planning web graphic organizer that includes the eleven instructional content components outlined below:

- $\quad$ Social Studies_-informational writing from a period, 1950 in New York City

- Music — sing song “Bandy Snatcher”, orchestrate sounds in drawing a picture, music as background

- Drama-improvisation, role play, guided imagery

- $\quad$ Art-draw bandy snatcher, make bandy snatcher catcher, examine paintings of renowned artist, illustrate stories, use colors to express feelings

- $\quad$ Math-using money, purchasing materials to create bandy catcher

- $\quad$ Technology - using word processing, using overheads, stereo

- Written Language - informative, descriptive, narrative, and persuasive writing along with five step writing process

- $\quad$ Oral Language-discussion, giving directions, improvisations, street voices

- $\quad$ Teacher Read-aloud-books by student authors, visiting author

- Culminating Activity-Young Authors’ Conference

State content standards are integral to the unit and are highlighted to include the most pertinent of responsibilities - to insure and deliver appropriate curricular content. Some of the standards and objectives are as follows:

Reading Language Arts_reading, writing, speaking, listening, viewing, spelling, vocabulary, language, study skills 
Mathematics — number theory and number sense, fractions and decimals, pattern, symmetry

Lesson two featuring Informative Writing is designed for a three-hour block of time.

Objectives include prewriting experiences in the following:

- $\quad$ Constructing a bandy snatcher catcher trap

- $\quad$ Practice planning and purchasing supplies for the trap

- $\quad$ Use problem solving and decision-making skills

Lesson two materials involve basic craft and household items such as glue, straws, paper clips, yarn, and empty boxes. A call for materials assistance note to parents is helpful to gather supplies for students to create their trap. Parents are invited to send materials from home to support this creative construction and to assist the teacher at a mock craft store where items are arranged by category and priced for shopping.

Students are prompted to think analytically to visualize what a bandy snatcher trap would look like. "It is our job to catch the bandy snatcher. What are some things we would have to think about? What is he like? Think about your drawing. If given $\$ 20$ to make a bandy snatcher catcher, what would your trap look like? Some standards are provided to guide students in their thinking. For example, the bandy catcher trap does not need to be mechanically correct, must be 3D not flat, and must fit on cardboard base. Students take turns visiting the mock craft store with their play money and shopping bag. Students who are not shopping will be working on their independent writing packets until it is their turn to shop.

Lesson four is an informative writing lesson to draft instructions for the bandy catcher trap. Writing implements are the only materials necessary. The procedures call for review on elements of clarity: details, order, time order words. Students are charged with writing directions for catching the bandy snatcher. The standard is pre-designed and stated clearly to 
students, both as a guide and as a quality standard. Each set of directions has three steps that use time order words. Steps answer the following questions:

- Where to set the trap

- How to set the trap

- What to do when Bandy Snatcher is caught.

After a rough draft of the directions on how to use their traps, student work is measured against the editing/revising checklist.

\section{Chapter Conclusion}

Eight research participants provided their responses about their decisions to use an arts integrated curriculum in their classroom instruction. We heard their voices and saw their student assignments and lesson plans. Their honesty and open invitation into their very spiritual work of teaching children was nothing short of a gift . . . a gift of their time, and an open invitation to share vulnerabilities such as what happened when a lesson did not work or when a student did not respond. Most of us would really rather not face these realizations about our work. We would prefer to tell only our success stories. Eight research participants, classroom giants, chose to share their daily successes and struggles for the higher cause of informing their profession with honesty and candor. 


\section{Chapter 5}

\section{Results}

The arts live continuously, and they live literally by faith; Their nature and their shapes and their uses survive unchanged in all that matters through times of interruption, diminishment, neglect;

They outlive governments and creeds and societies, even the very civilizations that produced them.

They cannot be destroyed altogether because they represent the substance of faith and the only reality.

They are what we find again when the ruins are cleared away.

Katherine Anne Porter

This dissertation strives to provide insight into teacher decision making. Eight

research participants gave examples of their teaching experiences in four areas study:

curriculum, instruction, community, and reflection. Arts in education continue to prevail

largely due to the efforts of university professors, teachers, administrators, parents, performers, and arts zealots.

My interest in arts integrated teaching moved me to seek answers from teachers who have knowledge to share. I have experienced various roles as teacher, reading specialist, academic coach, administrator, and curriculum supervisor, all of which demanded that I stay current on teaching and learning developments. There is always the stark reality of knowing firsthand about the rewards of good instructional decisions versus the defeats of unsound instructional decisions. I believe that all educators withstand the pressures of that personal accountability to the educational community.

\section{My Reflection}

I have always been intrigued with how teachers decide what to teach and how to teach it. Although my earliest recollections are of formal schooling in kindergarten, I have some poignant memories as an adult learner in college and in teacher professional development courses. I am 
also aware of my children's most significant teacher-learner experiences, along with the tears of their most painful classroom experiences. The hardest reconciliation for me, however, is that of teacher-learner as I grapple with decisions I have made "for the students," but were, perhaps, designed more for my teaching satisfaction, convenience, or routine, than for my students' command of content and life-long learning. These reflections haunt me, but without their sting I would be unable to honestly answer my own questions of what commands my attention when deciding teaching content, planning instruction, interacting with community, and reflecting upon arts integration work.

The eight participants comprise a broad range of expertise that can be seen in the participants' demographic matrix found in Appendix F. Teachers range in years of experience from a low of 14 years to a high of 44 years. Their degrees span from Bachelor of Arts degrees through Master of Arts degrees plus 45 additional hours. All teachers have elementary education certification; two are certified in special education and two are early childhood certified. There is one reading specialists and two teachers with science specializations. Five of the eight teachers state that they have had previous arts training ranging from piano and dance lessons to playing in the high school band. As for their teaching positions, seven of the teachers have experience teaching first grade, five have experience teaching kindergarten, and three teachers have experience teaching fifth grade.

Seeking clarification of teacher decision making in arts integration brought me to the research literature regarding this intriguing topic. I wanted a broad understanding to ground this research analysis. Emerging themes from the literature guided me to investigate decision making from the following perspectives: student learning, teacher autonomy, community involvement, and teacher satisfaction. My intrigue with what the literature offered in these four 
areas should connect to the reflections of research participants and to my own story. I present each research narrative from a teacher's unique perspective on teaching decisions about curriculum, instruction, community, and reflection.

\section{Summary of the Literature Review}

The curriculum component of the literature review focuses upon decision making and a greater knowledge of educational procedures such as standards-based instruction. I struggle with the premise that the standards movement is responsible for promoting a standardized curriculum for teachers and students. My struggle comes from being skilled in teaching a textbook curriculum, using its supplemental resources, and seeing the results of staying steadfast to the curriculum design. Are music, art, drama, dance, and creative writing in peril because of a focus upon teaching and mastering learning standards and objectives? Are we in an either-or situation, or is it conceivable to have the best of both worlds: a strong focus on content that grounds teachers and students on learning essentials alongside a rich arts-infusion? Torres-Guzman and Hunt (2006) suggest that through collaborative groups focused upon creative and effective teaching, teachers can overcome uniformity and conformity of a standards-bearing curriculum.

The instruction component of the literature review suggests that teacher development and support for making change is, in large part, due to understanding when and why teachers make changes and how instructional theory evolves into classroom practice. Dichele (1994) presents research that teacher beliefs impact instructional behaviors and that these beliefs change. My quest for understanding how these behaviors and beliefs change is what I believe will fracture the unknown and shed light upon what commands teachers' attention in decision making. Callison's 1970 research indicates that teachers are influenced by three factors: (1) 
ability to set teaching goals; (2) freedom to teach towards accomplishing these goals; and (3) self-establishing a set of standards for goals attainment. All three of Callison's factors rest upon the integrity of teacher decision making. Eight teachers in this dissertation discuss what they teach, how they teach, and what reflective practices they use to make instructional and curricular decisions.

In earlier research, Elliott's 1956 study asserts that decision-making is deciding upon the job content. How to do a job is ultimately left to the discretion of the person doing it. An employee is expected to make choices that will best accomplish the tasks he was hired to do. Teachers are able to make these decisions when their work is not pre-designed or prescribed. Opportunities for collaboration and risk taking empower teachers to think, research, create, and decide (Elliott, 1956). Are educators conflicted in the struggle between the curricular and instructional aspects of their work? To suggest that curriculum should be standardized and ask teachers to have freedom in instruction seems ambiguous. Therefore, critical to this research is hearing the voices of master teachers. Through actual teacher narratives of successful delivery of required content, the profession stands a chance to bond curriculum to instruction.

The community component of the literature review offers support for arts integration and teacher instructional decision making. This can be evidenced when there are mechanisms for funding through community grants and when involvement and collaboration from local artists are more accessible. The arts, unlike other school subjects, present a public face to learning (Burton, Horowitz, Abeles, 1999). If arts in education are central to student learning, why is it that arts educators struggle so with its implementation? Could it be that general education teachers are not confident in their abilities to integrate arts? Do they feel that it is not their field, and therefore specialists should be responsible for students’ arts learning? Are 
administrators and curriculum designers unable to provide mechanisms for professional development with an arts focus? I am grateful for my educational experiences from teaching through supervising programs. My experiences have connected me to the research participants in this dissertation. As a researcher, I have worked diligently to tap into the power of experiences as the conduit between experiences and actual classroom practice. Listening to and understanding teacher stories have been both rewarding and challenging as I seek to capture insight through their stories.

The reflection component of the literature review portrays a tension-resolution effect from the 1960's to present. Early on, teacher associations and federations took a greater role in legislative activities through unions and associations. Strong advocacy, employee unity, and teacher leadership helped to return decision making power to teachers. Simons’ 1985 study shows teachers becoming classroom researchers and informing their own practice through action research. This study suggests a stronger connection to self-selected professional development and knowledge of research. Since the 1990s, top-down leadership has shifted to a more collaborative role. Along with that privilege came the need to put teacher reflective practices into place.

I have many unresolved questions about reflective practice and believe that any contribution to the research would enlighten the profession about reflection as a self-selected professional practice. Reflection is, by nature, a spiritual activity that requires a willingness that cannot be taught. As a profession, are we holding ourselves to a high expectation of reflective practice? Do we rely upon its most valuable lessons including the process of revision, accountability, methodology, pedagogy, and ethics? Those with wisdom, who value the benefits of reflection, do so without mandate. They model reflective practices such as 
rethinking the success or failure of a lesson or journaling their thoughts and perceptions. Some teachers provide a culture of reflection for their students through journaling, observation logs, and critical thinking tasks. Wiles, Bondi (2000) propose that establishing a culture of teacher confidence and innovation in the classroom can improve teaching. One way to accomplish such a culture is to encourage teachers to try new ideas and techniques in classroom instruction and to reassure teachers that "lessons learned” from an unsuccessful outcome will benefit the entire teaching and learning community.

The question swirling around in my head and a concept that requires a great deal of vulnerability for teachers is the concept of "no-risk failure.” It is true that we learn lessons from our failed attempts. Those lessons can be positive, even though they accompany the risk of failure. And it cannot be a "no-risk failure" if there is no self-reflection. The price to pay can be costly: teachers leaving the profession, students losing command of content, and the arts being portrayed as "fluff." To achieve such a culture, the reflective element is essential.

Teacher collaboration provides a forum for the reflective practice among educators who are seeking clarification of "what is working" in their classrooms. For this reason, in the interview question framework, teachers have numerous opportunities to reflect upon their experiences.

\section{Leading to the Research Questions}

This dissertation exercises the practice of shared experiences and relationships with colleagues. It is an opportunity to connect the life work of educators to life opportunities for students. I am in a special situation as researcher because I have experiences and understandings as learner, teacher, administrator, and community member. Thanks to this unique position, I am able to connect with the research participants as we explore our knowledge and processes of decision making in the arts. Many voices are heard in this project 
and all of our connections to students, parents, business community, university, and school district are critical to the research.

Research of this nature requires attention to process and a flexible posture. I had to accept that the research participants were taking us on a mutual journey of greater understanding of the spiritual aspects of teacher decision making. The substance of curriculum and instruction in classrooms is complex and personal. Throughout the dissertation, I talk about the art of provision. The natural role of teacher is one of giving, not receiving, and providing for a warm environment in which all learners can thrive. A certain vulnerability hovered over this project as teachers shared their planning strategies and brought to the table the evidence of student achievement. Every participant contextualized her unique approach to teaching academic content. The sharing of stories became a spiritual event in that they were willing to reveal the nature of their work as teachers.

The methodology design was based on my preconceived notion of interview questions. It was a starting point. What evolved was a manifestation of teacher brilliance that continued well beyond the confines of the classroom walls and into the teacher heart and spirit. I experienced an opportunity for dynamics that could never have been planned—a serendipity. Teachers functioned differently within the interview conversations. Some waited for the questions to come forth, while others launched into dialogue as soon as we sat down together. I experienced an invitation to a story-telling performance of genius proportion that was both interactive and personal. For the interviews that were between one teacher and me, I sensed energy ranging from tentative to complete openness. In all cases, I felt a welcoming presence and a hope that their stories would be respected, valued, and represented with integrity. This is a true testimony to the warmth and brilliance of a teacher spirit. Two groups requested a 
collegial conversation forum. I experienced an amazing exchange among the teachers: a flurry of memories, celebrations, and real-life exchanges. In each of the three instances, I was a participant in the conversation, though moving from participant to spectator. I believe this was because of the collegial bond among them.

\section{My Reflections}

I came to this study through a variety of experiences and influences. One critical question looms over me, a question that requires thoughtful consideration: "How do my personal experiences relate to all educational stakeholders-students, colleagues, parents, community, and research participants?" Asking myself this important question demands answers that will provide a lens of understanding regarding my role in this research.

I am a curriculum supervisor who collaborates with teachers to improve student performance and to bring about effective instruction. A major part of my work includes designing strategic plans that include professional development workshops for teachers, schools, and the school system. My reflective study from National Board Certification endeavors taught me to think about my role of teacher as a leader, learner, and collaborator. I also have job responsibilities and demands that result in facilitating schools on improvement, a federal requirement that has state department oversight. Additionally, grounding my work and always present in my thinking is my own personal knowledge of instructional decisions and their results.

To trace my experiences over my lifetime requires transporting back to the earliest memory of arts in my life. It would be next to impossible to identify any one experience or significant event as more important than another. This sense of equity of experiences stands out to me because something as simple as attending a concert or play as a five year old could be the profound event that is foundation to all other arts influences. Having a father who acknowledged his daughter's musical ability by providing piano lessons is not just serendipity, but more so an 
act of provision. My piano teacher, who did not teach students until second grade when they could read, agreed to teach me piano lessons not because I could read, but because I could play tunes on the piano by ear. He knew I was ready for the next step of musical reading. My mother enrolled me in art lessons at the public library and purchased pastels, drawing tablets, and charcoal pencils to support my learning. This was a significant arts event providing a life experience because now as an adult I purchase authentic art works. Serving as an accompanist to my high school choir, playing the lead female vocal role in our senior-class play, and playing the organ for a small country church were among my top teen experiences. When I was lead college accompanist for the community musical theatre series, my study major provided me with more than just work and performance experience. I gained a commitment to community service and exposure to professional singers, dancers, and directors. Teaching for a local music company in the piano lab was a pivotal point in deciding my college pathway.

As far back as my formative childhood and adolescent days, the influence of the big-four research themes emerges as I make connections to this research. In retrospect, I can make these connections through the research framework. The four areas emerge clearly in my own teaching and learning narrative: curriculum studies in high school and college, instruction as a piano teacher, reflection on educational pathways, and community involvement with local business and community theatre.

Throughout my professional career path, I see significant influences and experiences that reinforced my views on integrating arts. Composition and conducting undergraduate classes shaped my involvement in community service events, such as festivals, community theatre, and both sacred and secular choral groups. Graduate school master's level courses are foundations of my teaching and performing career. Teaching as a middle school general music and choral director was a successful and satisfying first teaching job. 
My Concluding Remarks

This chain of experiences has become a means to an end, but never a stopping point for me. I have continued to expand and broaden my repertoire of experiences to include certifications in elementary education, leadership and administration, reading specialist, and national board certification. For my purposes, teaching and learning have never languished, and even the doctoral degree represents a full-circle experience leading me from learner to teacher and back. With broader experiences have come broader responsibilities from teaching to administrating programs. With broader responsibilities has come the opportunity for greater community outreach and administration of programs that can support and enrich teachers, students, and the community at large. I have presented the intertwining of my personal reflections as they are grounded in the four-question framework of curriculum, instruction, decision making, and community. In so doing, I have held myself accountable as researcher, educator, and human being on a quest for understanding the intriguing nature of teacher decision making.

I've come to the frightening conclusion that I am the decisive element in the classroom. It's my daily mood that makes the weather. As a teacher, I possess a tremendous power to make a child's life miserable or joyous. I can be a tool of torture or an instrument of inspiration. I can humiliate or humor, hurt or heal. In all situations, it is my response that decides whether a crisis will be escalated or de-escalated and a child humanized or de-humanized.

$\sim \sim$ Hiam Ginott

\section{Summary and Conclusions}

\section{Antonella as an Arts integration Decision Maker}

\section{Deciding what to teach: Curriculum.}

A simple twirl around Antonella's kindergarten classroom proved to the viewer that curriculum was first and foremost in her teacher skill set. She took no pause when revealing 
her teaching decisions regarding curricular content. She knew the content standards so well that she organized the entire year's structural plan based upon the scope and sequence of kindergarten learning standards. Her resources and strategies were the content standards document, her core subject teacher manuals, arts websites, and planning with colleagues. Antonella talked about her organizational scheme of grouping the state standards into folders and then finding their connections to core program instruction. Time spent understanding what the standards documents deem as important kindergarten content could be daunting, but not to Antonella. She went the distance to connect these standards to her teacher manuals. Her content provision was anything but random. She said:

So looking through the CSOs and at the art and music CSOs that are included on the website ... from that, I can tell what to teach, too, and even get some ideas for things to add to my own lessons. (II-TA-4.23.-09)

Antonella knew the personal accountability for providing rich connections to the content suitable for her kindergarten students. Blending content with her unique creativity was indicative of her decision to teach beyond the content standards and the teacher manuals. She did not rely solely on one primary resource for content, but expanded it to broaden student learning.

I understand this perspective. I have a grasp of the importance of content standards documents, because I have sought guidance from this resource. I also know that long-range planning for a year-long class requires a thorough understanding of appropriate grade level content that I do not assume to determine myself. The decision making comes in at the expansion point. Antonella and I both know that the sole source standards document is not sufficient for providing our students with content knowledge acquisition. What commands our 
attention when we make the decision of "what to teach" rests upon our decision to delve more deeply into the content. At this point, there is a thin line between our students as learners and their teacher as learner.

\section{Deciding how to teach: Instruction.}

Antonella's art of provision was a complex one. Many considerations confronted her as she developed student lessons in an almost artistic manner. Antonella seemed to dance with her content and instruction. As she moved about her classroom pointing to the student artwork, she touched it lovingly. Shining through her countenance, I could see her love and appreciation for the students' accomplishments. Participating in the university collaborative was indicative of Antonella’s desire to immerse her class in arts integration. Her decision to participate with Dr. S. indicated her willingness to join with others to expand knowledge and a repertoire of teaching strategies. Her ebullience for teaching children was contagious:

I love my job! I am very satisfied with teaching. I'd like to see the arts integrated into all classrooms from pre-kindergarten to grade twelve. I mean, if that's what we're dealing with . . . we're dealing with the creative arts end of it. It just needs to be everywhere! (II-TA-4.23.-09)

All of these elements factor into her instructional presentation. She had knowledge of each student's needs and motivation. She had confidence and believed in her charge to control the instructional offerings. Antonella wisely identified instruction through the eyes of experience. She controls the balance between what is required and her art of provision:

I feel like I have quite a bit of control over my lesson presentation . . . I do follow the content standards, and I use the phonemic awareness book. I use what I've been 
instructed to use, but I'm able to extend that, and I think my lesson presentation is the whole thing. (II-TA-4.23.-09)

Insight into Antonella's story has potential for all educators who seek to reconcile their internal conflicts with teacher autonomy. She models for us by thinking-out-loud in a clear fidelity to her content standards documents. Then she turns around and presents them in her own decidedly creative way. Her story helped me clarify my deeper struggles to understand the plight of teachers as they struggle through the growth and development prompted by the need to change. A major factor influencing Antonella’s buy-in for arts integration was her connection to Dr. S. and the university professional development collaborative. Through this affiliation, she made connections with others to support her own learning and to realize the potential to impact student learning through thoughtfully planned arts integration lessons.

\section{Decision making and professional development.}

During the initial interview, Antonella discussed her professional development activities from the perspective of how she incorporated her ideas in the teaching. She spent time talking about standards-based instruction and following a skill through to its arts integrated activity. In the first interview, insight into what professional development activities she sought fell second to her description of ways she used what she learned in instructing children. I am pleased that my methodology included two interviews, so that I could re-direct for additional information and a chance to expand on the framework questions. Notice in the two following narrative quotes that Antonella's first response focused upon how she uses what she learned in instruction, and then she elaborated on the specific trainings.

Our book is divided up into themes and it happened to be environment, so I just try and say, what can I do with the environment? It's tough. It's tough to 
decide. We did put the pond in, so we thought, well ... writing. We gave them the day to look at the pond and all that was in it ... The next day we water colored. Then we kept the paintings and said, OK let's write about that. (II-TA4.23.09)

I have done some conferences with Dr. Jean who does a lot of music. I went to a conference out of state which covered a lot of topics on differentiated instruction. Using the arts in that, you are really being able to meet the different levels that these kids have. As for the required 100 professional development hours required for teachers in Reading First school, it will be nice ... not to be dictated ... you have to do it, but I can foresee still ... you're going to look for ways, especially when you get little people. You're confused about what they need. (IF-TA-5.12.09)

In both interviews, Antonella offered specific insight into professional developments where she sought out both arts integration knowledge and core curricular reading knowledge. Her story told of her arduous work of understanding children's needs, the "tough” decisions of how to move from introducing reading and writing content into arts integration through water color. Antonella does not hide behind any false image. She was transparent and willing to share what she struggles most with. Above she talked about the "little people ... you're confused about what they need.” Antonella implied that she draws upon her own bag of tricks to meet struggling learners’ needs.

That's the most difficult one, because you want to feel like you're giving enough to those children that have already done a lesson before. I like to buddy them up with someone ... I've asked them to pantomime to each other. They take turns 
being the leader. Get those kids in here and let them be introduced to all this

learning. (IF-TA-5.12.09)

\section{Decisions around reflection and community involvement.}

When a teacher refuses to reference her students as her number one client, one could infer that she understands the important business of teaching and learning. Antonella regards students as the ones who matter most in the community. She sees her work with students as the conduit to parent and community involvement. Even though she says that people do not know what goes on inside a classroom, she and her students know. They are more than prepared to demonstrate their work in the classroom setting. She invites anyone to "take a walk in my room and let me tell you why we did this. Actually, let me ask the kids to tell you why we did this.” (II-TA-4.23.09) This style of confidence is what Wiles, Bondi (2000) suggest when they propose that establishing a culture of teacher confidence and innovation in the classroom can improve teaching.

Antonella has been recognized by her community through an award sponsored by the local newspaper. Her response to the distinction was to praise another colleague for receiving the same distinction. What the public recognizes as outstanding, Antonella considers part of her everyday work with children. She has command of present and future issues along with solutions on how to accomplish teaching and learning tasks:

I think the realization of this 21st Century Learning is the biggest thing right now. We have got to be able to meet what the community needs are. There is no longer this teach-regurgitate kind of thing anymore. Students must be able to problem solve and work as a team. That's been the biggest thing I noticed as a change. (IF-TA-5.12.09) 
Her insight into building capacity for the work force is evident even at the kindergarten level through collaboration. Businesses clamor for this type of worker because they know that skill in human relations can make or break a company. Antonella is part of this important human resource development. Antonella is diligent to the usual elements of community involvement such as weekly parent newsletters, volunteers, invitations to special learning events, and at-home read together assignments. She attends to all aspects of community involvement from her classroom culture to the greater outreach that lies beyond her sphere of classroom influence.

\section{Decisions in student assignments.}

Instruction in core subjects of reading, science, social studies, and math is key in her classroom. These content areas consume the lion's share of her thought and preparation, her resources and planning. In the analysis of a student work sample, Antonella used the integrated arts approach to deliver her science and social studies focused lesson. She launched from reading informational trade books on the ecosystem and environment into turning her classroom's central learning area into a pond. Using the hodge-podge of items in their creation station, students replicated a pond environment using a diorama. In this carefully orchestrated plan, students experienced reading, writing, and language arts, science and social studies curriculum.

Through Antonella’s skillful instruction, students learned to interpret text and symbols. Arts integration provides students with opportunities to build confidence, esteem, and they aspire to a pursuit of excellence through their art products. Additionally, their community awareness is heightened as they understand the conflicts that exist in protecting the balance of 
our ecosystem, their responsibility to social problem solving, and the opportunity to serve the community as they protect each creature in their diorama model.

\section{Decisions in lesson planning.}

There is no lesson plan analysis for this research participant. In a brief conversation about planning, Antonella explained that she keeps things in a central location by her learning circle. She explained, “I keep things because I can’t get it all in my lesson plans because sometimes there are things that just pop up.” (IF-TA-5.12.09)

No lesson plans were offered for analysis of arts integration. At the state level, guidelines for lesson planning require that teachers plan only to the degree that in their absence, a substitute would be able to conduct instruction.

\section{Conclusion}

So, what commands Antonella’s attention when making decisions to implement an integrated arts curriculum? What is the role of her experiences and histories in the decision to implement arts integration into the classroom? I believe, foremost, that Antonella is committed to providing strong standards-based instruction to her kindergarten students. She turned first to the content standards and used the teacher resource manuals to determine the scope and sequence of her instruction. Largely due to her sense of confidence and belief in her own autonomy, she took the liberty to augment instruction with her own creativity offerings that depart from the textbook to enrich student learning connections.

Antonella’s students are number one. She is committed to arts integration. She loves the arts and music of all kinds. Her instructional decision to turn her classroom into an academic playground is evidence of her instructional commitment to provide fun, engaging, and real-life learning experiences. She spoke reflectively of her own professional development 
choices. The who, what, and where of her trainings fell secondary to how she used her learning to enrich student achievement. When it comes to community reactions to her integrated arts instruction, Antonella stated that relatively few parents have free time to join in the arts activities. Although there are not many volunteers, she does encourage volunteering through weekly newsletters and personal phone calls. It is clear through her narrative that what commands Antonella’s strongest decision making influences are the taught curriculum and her instructional strategies and activities.

\section{Celine as an Arts integration Decision Maker Deciding what to teach: Curriculum.}

When Celine talked about her classroom arts integration projects, she was like a possessive parent talking about her children: my puppets, our play, our song. She put "what to teach” into the context of arts products and activities. Speaking less about standards documents and prescribed instruction or textbooks, Celine’s decisions are more focused around her instructional activities and the arts projects. "What to teach” translates to amazing and joy. Her curriculum is the students' joy and amazement, and she teaches these concepts to her students through her skill with arts integration.

She takes her responsibility to the students’ education in a very serious manner.

My job is to teach them what the state says I need to teach them. So, I try to orchestrate being a good role model with what has to be done. I always tell the kids, "You know, this is something that, as a fourth grader, you need to know.

So how are we going to go about getting it?” (IF-TC-6.8.09)

I relate to Celine’s curriculum decisions because of my awareness of the energy existing among the teacher, her students, and their curriculum. I call it the energy exchange principle 
and have a graphic representation model to illustrate the concept. (See Figure 12). Celine stated that she does hold fast to some standards. She also finds her plays in the core (basal) reading program lessons. So, while she addresses using instructional content standards and the textbook, her story shows us that she largely approaches deciding what to teach from the dynamic teaching and learning events in her classroom.

When we did our plays, we used the basal reading program's lessons. I didn’t perform it. I helped the kids perform it. They get to drive how they want to do it. These are the joys of integrating the arts. We could have read the play in the classroom and just left it at that, where everybody can't have a part. We brought costumes in, and they brought in their music and danced a little bit. (II-TC-

This teacher-learner dynamic is a result of Celine’s ability to understand students and to respect their ownership of the learning process. She demonstrates her ability to blend the nuts and bolts of curriculum with the true spirit of learning.

\section{Deciding how to teach: Instruction.}

Teachers seek clarification from one another. They want to know how another colleague approaches a topic, an assignment, or a new student learning. Through the conversations around student work, teachers are not only seeking to understand how their students learn, but also grasping for greater understanding of how to teach. Celine demonstrated her ability to seek knowledge from a colleague. In her initial interview with Veronica, she demonstrated a strong sense of instructional responsibility to differentiate instruction and to find time to accomplish everything. 
As researcher, watching Celine and her colleague ask one another about their perceptions and instructional approaches was better than opening a birthday present. It was a chance to witness the vulnerability and affirmation of two teachers as they exchanged expertise and sought clarification in a trusting spiritual exchange.

I have a question for you, Veronica. Are you working students towards the technology standards? Is that your TechSteps application? See, she has connected it to science. You really can get in the technology requirements. We are so pressed to get everything in. Doing something like what Veronica is doing is differentiation and helps you meet the responsibilities you have for technology at different levels. (II-TC-5.1.09)

Celine's personal experience with the arts is a connection to the decisions she makes on how to teach her students. Knowing that she missed opportunities as a young person is precisely what helped broaden her commitment to her art of provision for students in her charge.

I have to admit that I missed opportunities as a young person. I love the arts, but I didn't fully experience them as a young person through adulthood. I like to pull any experience that I've gained over years of being a teacher, parent, spouse, and community member. (IF-TC-6.8.09)

This is an antithesis to my own life's experiences with the arts. Do we not we have the same instructional outcome? Her absence of arts experiences and my immersion in the arts were two opposing influences that resulted in a similar commitment to offer students an arts integrated educational experience. We journeyed on two separate pathways that led to the same destination. 
When I began this research, I assumed that those teachers with arts-rich backgrounds would naturally and automatically offer their students arts-rich learning experiences. I have to admit that I based my thinking upon my prior knowledge, confidence with arts integration, training in arts content, and an awareness of the importance of arts in my own life. Not meaning to appear exclusive in my thinking, I just had not thought about how an absence of the arts could create a reciprocal effect: teachers wanting to offer arts in the classroom, because they did not have the chance. Here is what I now believe: I do not think that having an arts background makes a teacher any more committed or capable of integrating the arts than a teacher who has no previous experience with the arts.

\section{Decision making and professional development.}

I am surrounded by the ambiguous nature of professional development. My own experience as a teacher, curriculum supervisor, and administrator puts me in a position of duality. Is a teacher to seek professional development in a collaborative setting, or in a more personal self-selected approach? Is one approach better than the other? Do teachers always need to be in a collaborative setting for their professional growth? How effective is a teacher when she goes it alone to get the skills and training she needs to refine her skills or content knowledge? I tuned into Celine’s story for selfish reasons. I wanted to understand her approach to professional development. Here is a glimpse into her rationale for this very personal aspect of teacher development.

I find that I have always tended to do things like this, but I always did my own thing. I'd get an idea, make sure it connected with whatever we were doing, and then I just did it. I didn’t find too many professional opportunities, but when this course came to us, I was thinking that I will do that. I think that it is in us 
that we feel the need to do something. There is something within us that sometimes drives us to certain places. (II-TC-5.1.09)

I have gained understanding that each teacher must take time to make a thoughtful decision, to look closely at her own needs for development, and to decide for herself how to strengthen her skills. It is not to say that some teachers may be able to sustain professional growth activities only through their work with others. Other external forces may dictate a teacher's commitment to working in tandem or solo. We must seek understanding of the spiritual nature of professional development. There are strong implications for those of us responsible for teacher development programs to see beyond what we design and into the many factors that bombard teachers. What may appear to be resistance to participating in professional development offerings may merely be the individual's inability to balance work, home, and community responsibilities, or perhaps their own personal learning style.

\section{Decisions around reflection and community involvement.}

In talking about reflection and community involvement, Celine brings us to the core of her teacher heart once again. There is profound knowledge of her true purpose in teaching, which is more than delivering content to her students. She wants arts integration to become a lasting life experience. Celine's teaching is art integrated with life.

This is what we all have ... humanity. You can connect that way with the kids through the arts sometimes, when you can't connect with them any other way. There is a connection to the arts that pushes students forward beyond their own perceived limitations. (II-TC-5.1.09) 


\section{Decisions in student assignments.}

Celine is committed to the arts integration from a project based approach to learning. Her assignments are gauged at a high level of student involvement. She subjects the projects to a standard of purpose, expecting that the ends justify the means and that class time spent has a direct connection to learning. Her keen level of teaching satisfaction is a driving force in selecting learning experiences. When posed with the possibility of seeking a new profession, she was adamant that she embodies teaching: "I will not do that! It is not me. It is not what I'm about. I would not have joy. I love this job! My kids know that. It's just who I am. I can't help who I am, and that's not a bad thing.” (IF-TC-6.8.09) She is willing to face the stresses of her work for the students' sake. Her perceptions of professional control over the curriculum are clear. Based on what is good for them to learn and their needs for ownership of the creativity, she revealed how she decides the worth of arts integrated assignments:

I always preface everything to the kids. I even read the CSOs before taking on a divergent project. I ask myself and the students how we can incorporate our learning with what we want to do. What are we going to be able to say to support our valuable school time in doing this project? (IF-TC-6.8.09)

\section{Decisions in lesson planning.}

Awareness of student motivation upon her lesson design and pacing once again focused on student-driven learning. Her goal for students was inspiration to learn, and she was committed to helping students who struggle with academics.

As far as the plan ... a lot of times, it is student driven. As long as we can show that we're getting through it (the curriculum), then I'm OK with it. As far as pacing, I think you just have to pace and design for the kids you have. 
Basically, pacing and planning depends on your person. It's a juggling act. (IFTC-6.8.09)

Celine's contribution to this research is in her wise understanding that there is nothing formulaic about teaching. Yet, to understand the nature of successful teaching, we desire specifics that can be replicated. If something is working well, do we want to know what it is? Is there anything wrong with modeling and adopting professional behaviors? Should we deserve a chance to do the same successful things? It is the human condition to watch others and model their successes. This dissertation research sought to bring to light any awareness of teacher decision making related to arts integration—and to pass the torch on to others. Celine has her control on lesson design:

You never know what you're going to get. It's an adventure. I guess teachers are explorers because you are creating what you can with what you have. And you don’t know where you're going! (IF-TC-6.8.09)

\section{Conclusion}

Celine is unequivocally certain that she is where she should be. Her work is of an altruistic nature, unselfish and self-chosen. "So it's just something meant for me to be in this profession. And, like I said, it's a bigger picture of the world. I try to help my students see that they are part of a bigger place than just the desks in this room.” (IF-TC-6.8.09) Decisions for integrating the arts in her classroom are based upon her life experiences and upon her commitment to developing the students as whole, complete human beings. Celine spoke from her commitment to human interests and values. She also realizes, in Hiam Ginot's words, that she is the "decisive element in the classroom with the power to make a child's life miserable or 
joyous.” Celine's story is an incredible revelation of her life experiences. She told us that her attention to instructional decisions is grounded in student joy and amazement for learning. Veronica as an Arts Integration Decision Maker

\section{Deciding what to teach: Curriculum.}

Veronica's immediate response to curricular decisions went directly to the state content standards. She spoke of her desire to create fun learning experiences and to help students build self-confidence to share with others. Her childhood love of the arts connected her to students in her classroom who are missing out on the fun of large imagination and play acting. She was aware of student motivation and captured that quality to create an interactive dynamic that is unique to her classroom. When it comes to determining content for students with special needs, Veronica turned to her expertise and training in special education, behavior disorders. She characterized herself as "concerned, caring, and having high expectations." She sets standards and uses rubrics to guide students in acquisition of content.

\section{Deciding how to teach: Instruction.}

Veronica has the advantage of scope and sequence. Her years spent teaching first grade required teacher-developed activities designed for students. Now that she is a fifth grade teacher, she sets firm academic guidelines and facilitates students towards achieving their tasks. Such a shift in instructional strategy puts Veronica in a position to create experiences of an unprescribed nature.

In making decisions on how to teach, you will see that Veronica's responses provided for an opportunity to use technology. Her use of presentation software such as Power Point inspired her students to turn in assignments using technology. Even Celine queried her 
colleague about technology standards and using TechSteps applications in science class.

Veronica used her resources and instructional tools to get to the heart of curriculum content.

Veronica was not a bit reluctant to share her views on teacher autonomy over

curriculum and instruction. She had little patience for being told how to teach her lessons: "I am sarcastic when I have to follow scripted lessons ... it is a little frustrating to do scripted things, because I am too spontaneous.” (IF-TV-5.5.09) She teaches her students the way she wants to be allowed to teach—with the freedom to choose. "Instead of being teacher-directed, I provide students with materials and the guidelines or rubrics to perform the task. They all succeed because they were allowed to choose their favorite area to work at since they all have their own classroom personalities.” (II-TV-5.1.09)

\section{Decision making and professional development.}

Veronica was judicious in how she spent her time pursuing professional development. She said she would not participate unless it was a topic of interest to her, and it had value in the classroom setting. Affiliation with a credible professional developer was important to Veronica. The university arts integration project and Dr. S. were decidedly worthy of her attention and time. "I knew this university professor, and what she touches is golden. As far as I'm concerned, I jumped on that right away when I had the opportunity." (II-TV-5.1.09) She also reflected upon her new fifth grade teaching assignment knowing that additional skills in strategy and content would be helpful. She said her administrator gave her the license to seek new professional development opportunities.

To see the significance of arts integration and offering the opportunity for the classes and for allowing us the license to do it. I think being new in fifth grade, 
I really didn't feel comfortable. I needed to look at all that curriculum that I had

to give to those kids. (II-TV-5.1.09)

I admired the strategic way in which Veronica approached her professional development. She knew herself and her immediate needs. My own experiences with professional development have left me with mixed feelings about the way I have spent my professional learning time, personal energy, and fiscal resources all in the name of gaining teaching expertise. Here is my reality: I have often jumped on the bandwagon of the latest trend in professional development, only to ride it down the "Lane to the End of Nowhere." Sure, the presenters were engaging, the content worthwhile, and sometimes even the venue a fantastic trip. But this does not mean that I had meaningful and lasting professional development where I attained skills that transferred to my classroom to help achieve learning excellence. How many others in this profession could benefit from Veronica's decision in choosing only relevant professional development?

\section{Decisions around reflection and community involvement.}

The expectation for arts integration in Veronica's school permeated the staff, students, and the community. Veronica understood the basic premise of student performance: "Parents always like to see their children perform, so they always turn out for that.” (II-TV-5.1.09) She created opportunities for parents to become involved with their children both at home and at school. Student motivation leads to community and parent involvement. In more than one instance, when children are learning in the classroom, they go home talking about their school day learning. Parents actually took students to a location for filming a health assignment. Veronica was wise to the special talents of her parent clients, taking advantage of their willingness to volunteer with class projects. 
I think when parents speak up, if we know and can ask them to come in, that it is really an important time to take advantage of the people in the community who have these special skills. (IF-TV-5.5.09)

When it came to providing arts opportunities, Veronica knew how to tap into the community arts offerings. For example, the class attended plays at the university, and some of her students participated in local theatre groups.

As for involvement within her school community, Veronica talked about collaboration and the obstacles to developing community learning. Of course, there were sharing ideas and exchange performances among the grade levels. The Night of the Arts was collaboration among all students and teachers at the school. Overcoming the time constraints at work could be an impediment to building community at school.

We really don't have a great deal of collaboration time. If we did have collaborative time, we definitely would take advantage of doing so. Most of the time schedules are so backed up with curriculum ... just once again, there is so much you have to teach, and you only have so much time to teach it. It leaves very little time for that kind of stuff. (IF-TV-5.5.09)

\section{Decisions in student assignments.}

Veronica was consistent with her use of technology learning opportunities for students. She focuses on technology learning standards to encourage students to use presentation software, cameras and video recording, word processing, and more. Her students created CDs reporting their biography research findings from a textbook lesson on Evelyn Cisneros, ballerina. Some students created an asthma commercial, replete with script, bloopers, and on- 
location filming. These real-life learning projects are connected to the fifth grade learning standards and include opportunity for parent involvement.

Veronica stayed faithful to her curriculum content by striking a good balance between using textbooks and the learning extensions. Her students wrote plays, created posters, sang songs, and danced. She provided technology experiences in all content areas: science, reading, writing, social studies, and math.

\section{Decisions in lesson planning.}

In our conversations about lesson planning, Veronica turned to her teacher manuals and the student textbook. Her decision to use these teacher resources was a conscious one. She praised the manner in which her reading series is designed. Following the strategies and learning connections set forth in the textbook provided ideas and choices for her students to follow.

I have worked with teachers who avoid the use of textbook instruction, and with those who cannot pull away from its spell. Using textbook resources is a safe and efficient approach to curriculum and instruction. I believe that there are teachers who need to stay firmly grounded in the systematic provision of a teacher's manual. Without textbook-driven instruction, some teachers would be in danger of incomplete or inaccurate content delivery. Other teachers have the gift of using the textbook as a teaching resource—one of many in their repertoire of instructional tools. Veronica is an exemplar in the effective use of textbook as resource.

\section{Conclusion}

Veronica is full of experience, instructional skill and content knowledge, and she holds a high standard for student performance. Veronica is resolute. She treats her students as 
professionals, expecting them to put their arts integration products—evidence of their learning — out for all to see. This standard is nothing short of what she expects of herself when in the classroom. This is a teacher who produced a portfolio of student assignments and talked excitedly about each sample. She exuded confidence in her work with students and took on a sincere responsibility for her classroom teaching decisions. Throughout all of her narrative responses, Veronica discussed content. She approached instruction first and foremost from mastering content knowledge. Arts integration augments her curriculum, and there is no evidence that one subject takes precedence over another. She did not favor instructional offerings that satisfy her own teaching preferences. Health and social studies were as important as math and reading. When she decided to integrate the arts into her instructional design, she built upon the foundation of her curriculum content.

\section{Kara as an Arts Integration Decision Maker}

\section{Deciding what to teach: Curriculum.}

Kara had the benefit of a full career teaching kindergarten to substantiate her curricular decisions. She was united to her grade level content. Her collegial relationships with Dr. S at the university and with the preservice teachers have kept Kara on the cutting edge of teaching curriculum standards to small children. Decisions about what to teach are made with her colleagues at the beginning of the year using a curriculum map and pacing guides. Her decisions were neither random nor fixed, but based upon the changing needs of her students and with careful reflection guiding any changes for improvement.

Kara enumerated the entire year's thematic units starting with school and community, progressing through holiday, patriotic, and ending with summer sea and ocean life. Kara also 
credited curricular decisions with what her students need. "We try to teach to each child's individual needs. It depends on the students. Also it is on their interest.” (II-TK-4.29.09) Kara talked most fluently about curriculum content in her decisions on what to teach. She referenced the documents in the National Association of Young Children guidelines. She is no stranger to accountability, and her comments invite others to see her devotion to goaloriented instruction.

I feel like you can still teach your goals and objectives through play, through art, through music. So I try to do that. I think that is one of the main things. I would want people to know how I teach. (IF-TK-5.11.09)

Kara has connections to the arts from her childhood experiences with piano and dance lessons. In her own home, she provided rich arts experiences for her children. She was committed to integrating the arts every single day in classroom activities like singing, drawing, movement, and role play.

\section{Deciding how to teach: Instruction.}

Structure and flexibility coexisted in Kara's classroom. She understood child development and helped the children develop structure and flexibility in their learning. Individual mailboxes and cubbies housed student work folders and belongings. She said that, "although sometimes it looks chaotic, it is organized.” (IF-TK-5.11.09)

Kara understood and accepted the guidance provided from state instructional standards, recognizing that there is not a great deal of control over these curricular issues. Teaching children at the kindergarten level is a once in a lifetime experience for them. Kara articulated that their foundational educational experience should yield an enjoyable school experience. "I think how we teach it [curriculum] is one of the things I like about teaching. You are kind of 
your own boss as long as you are sure you are covering CSOs. You can pretty much deliver it however you feel.” (IF-TK-5.1.09)

I think a lot about how teachers make decisions based on their perceptions. Kara gave her interpretation on autonomy. She said that you are kind of your own boss. But she does not stop at that thought, because she knows that she is part of a larger system of expectations and accountabilities. Her check-and-balance lies in the fact that teachers must cover their CSOs. I wonder if her 37 years in teaching have clarified teaching's liberties and boundaries.

Fortunately, or unfortunately, the autonomy associated with teaching can be a good thing, or not. For teachers who use scripted instructional design, devoid of creativity and cookie-cutter in content delivery, there is no control over curriculum and instruction. I have taught using a scripted approach to teaching reading. I was not my own boss, nor could I deliver the content however I felt. But I observed the procedures and scripted practices, and to my pleasant surprise, I actually had students thrive and become fluent readers. So, what can we infer about being willing to forego teaching autonomy in favor of following the script? And what do we say to teachers who are not willing to let go of their teaching preferences and trust an instructional delivery design renowned for its high success rate when followed precisely and with fidelity?

\section{Decision making and professional development.}

What an influence the university collaborative has been for Kara's professional development. Dr. S. is respected for her contributions to teachers, students, and the entire educational community. She seeks ways to immerse teachers in the arts. Kara is like a vessel for professional development knowledge. She is the teacher education coordinator liaison between her school and the university. Her work with the preservice teachers is an opportunity 
to learn from and with these novices. She related to her observation experiences as a quasimirror effect.

I know when I am observing now, the things I am writing about them, I think, Oh I am doing what I wrote down that they were doing ... I think it helps me be a better teacher. (IF-TK-5.11.09)

Kara saw making change as an opportunity to exercise what she learned through her professional development experiences. Her gift was in sharing her teaching brilliance with her colleagues and modeling for the preservice teachers. She explained in her narrative story that success inspires repeating. After talking with other teachers who experienced success, we want to repeat the outcome. "Success spurs you on to try or continue with something." (IF-TK-

\subsubsection{9)}

\section{Decisions around reflection and community involvement.}

Kara was one teacher who acknowledged the importance of her parent community. She kept open, two-way communication from home to school and back. She used technology effectively to inform parents and to update classroom happenings. There were places in the classroom where parent volunteers could assist with read aloud, special projects, and murals. Kara's class benefited from using facilities in the town for field trips, field days, and academic fairs. They took tours of local businesses and saw puppet plays at the university. In return, her classes prepared artwork displays and correspondences to local nursing homes.

In addition to parent and business community involvement, Kara cited inter-district collaboration with high school student exchanges and music and drama performances for her students. 
My connections to experiences with community involvement allow me to characterize them as magical. I have collaborated with parents and the business community to provide extended day learning programs for after-school tutoring. A project-based learning class received invitations from businesses to tour their facilities. Parents requested permission to attend our after-school programs because of their interest in the topics we studied. Educational connection to community is a powerful resource at teachers' fingertips.

\section{Decisions in student assignments.}

Sharing with colleagues and exchanging ideas and materials are a few of the ways Kara decided what student assignments would be offered. She took a reflective stance asking thoughtful questions about how her students were progressing and asked herself if the assignments were successful. Her graduate student also offered input into what assignments will work best for the current content. Collegial planning and unit development were part of the work that Kara facilitated with her preservice teachers.

An element of excitement piqued Kara's attention when she talked about motivated students and their learning. Her students wanted to learn more and more about the unit on insects. This prompted her to visit the library for more resources and an internet search to find extra things to look at. "I provide enrichment materials for students who are exceeding learning expectations —-higher level books with challenging content.” (IF-TK-5.ll.09) Kara has developed multiple units based on Bernice McCarthy's 4MAT approach. One of the units was a nutrition unit with food games and puppets, while another science unit had strong literature connections. Students participated in writing about and illustrating plant parts. 


\section{Decisions in lesson planning.}

Two complex and articulate unit plans were among the many developed by Kara and her preservice student teachers. Kara had a perfect forum for exclusive lesson plan design through her access to university resources of expertise in content knowledge, pedagogy, and the most current literature on early childhood. This aspect of her university collaboration promoted broad curricular content and arts integrated activities over themed instructional units of ten or more lesson plans. Every lesson had multiple exposures to music, visual arts, movement, and literature. By design, these themed units had a powerful influence in deciding to integrate the arts. Units of this magnitude are a product of professional development relationships among classroom and preservice teachers and university professors.

\section{Conclusion}

Kara came to the research with her entire career spent teaching early childhood students. In her own words, "I have been teaching for 37 years, and I pretty much know what is for kindergarten and what isn't.” She was the consummate role model for teaching her student teachers how to teach her students. Her teacher-leader role was as a liaison between the school and university and kept in line with the school's mission to be part of the Professional Development Schools network at the local university. Kara was the PDS site coordinator who supported preservice teachers and mentors during the many hours of field placement. Other professional development activities included participation on university collaborative committees, and obtaining a master's degree plus 45 additional hours.

Commanding her attention to integrate the arts are experiences and connections to the professional growth and developments that have permeated Kara's career. Excellence in professionalism is her hallmark. As she made her decisions for integrating the arts, ever 
present in her narrative were the experiences she shared with the university, with her preservice teachers, colleagues, and with Dr. S. Arts integration for her students showed up on classroom walls, in student artwork and in their singing and movement activities. Lesson plans demonstrated her decisions to integrate arts in her classroom instruction.

\section{Carline as an Arts Integration Decision Maker}

\section{Deciding what to teach: Curriculum.}

I found myself absorbing Carline’s steady manner. She used precise language to express her teaching. Her competence was evident in her presentation of the five thematic unit binders, teaching trophies that she displayed before us on the table. Carline admitted to having no angst over not being one of the teachers to attend Bernice McCarthy's 4MAT training workshop. She did, however, speak delightfully about connecting with her three colleagues (also research participants) to learn the thematic planning and instructional strategies. She credited the conviction and dedication of her preservice teachers for the thematic designs, and she explained to me how she supported them in their ambitious pursuit of rigorous content offerings in science, social studies, and health. She admitted the difference in her own teacher preparation and that of today's student teachers: “These younger teachers are presented with newer things, and they have so much more experience when they come into the classroom. My student teaching was in the morning, and we went back to the university and had our pedagogy classes in the afternoon.” (FI-TC-5.11.09)

Throughout our conversations together, Carline provided abundant detail about her decisions to incorporate arts into her classroom instruction. She augmented her stories with lesson plans, student artwork, photos, parent communiqués, and more. The most poignant moment was right before saying goodbye. In the hallway, Carline paused, closed her eyes as 
though going far back, and said, "It feels interesting. This school means so much to me. I was a teacher in the same room where I sat as a first grader. Also, I did my student teaching there. I remember where things were in that room, like the sink on the wall. I knew it was my room as soon as I walked in.” (IF-TC-5.11.09)

This part of Carline's story gave me pause to think about childhood connections and teaching decisions. I thought about my favorite elementary classroom: fourth grade, cloak room, piano on the side wall, our record player, and painting table. Many items evoke pleasant memories in music, dance, and art. I have to admit that there may be a subconscious part of me that wants to recreate, perhaps re-live, my own childhood learning experiences, and in so doing, my decisions stem from past personal influences.

Even though she has been away from teaching for several years, Carline spoke the language of teaching. She has stayed involved as a substitute teacher and knows that learning standards have been revised numerous times. "What you are going to teach is pretty much dictated by those.” (II-TC-5-1-09) Carline did not stop at talking about standards; she understood that enrichment completes the circle of learning.

\section{Deciding how to teach: Instruction.}

Carline's natural gift of interpersonal and intrapersonal awareness was refreshing. In my conversations with her, she had wise insight into what students need. She decided first for students and next for content. Spending time on lesson plans was preparation for skillful instruction. Expanding learning was one of Carline's themes. She discussed having the freedom to expand on content through her enrichment lessons. Although training her student teachers required trust, she valued the enrichment accompanying their novice work. One statement summarizes all of the above: "I spent a lot of time in my preparation for what I did 
in my lesson plans. I tried to integrate the kinds of things children needed; tried to make it interesting; tried to expand on things; tried to bring in parents for their expertise.” (IF-TC$5.11 .09)$

Teachers are possessive about their classrooms and students. With the accountability requirements weighing down on teachers, it takes trust to open up to a novice teacher-intern. Carline was willing to be flexible with her student teachers. She said, "I learned a lot from them. It had been a long time since I had been in school.” (II-TC-5.1.09) To build a collaborative relationship, both professionals need to value what the other has to offer. Carline gave what she had to her university students, and in turn, she took what she could learn.

To meet the needs of all students, Carline provided valuable insight into her bank of strategies for struggling learners. Small group instruction, using resource centers and libraries, peer teaching, and knowledge of pacing the instruction are among her best teaching tools.

\section{Decision making and professional development.}

S. M. Day Primary School is known for its professional development relationships both within and without the schoolhouse. The university collaborative and Dr. S. can take credit for growing a culture of relationships. Carline credits Dr. S. with putting the teachers on the right path for integrating the arts in classrooms. Thanks to this brilliant university professor who was willing to help public school classroom teachers develop their arts integration, S.M. Day became a school where teachers learn, share, converse, celebrate, and welcome.

University students practice-teach at S. M. Day Primary and come away with confidence, teaching tools, friendship, experience, and pride. Carline described her professional growth and development as “specific” when she explained her grade level 
textbook training. At times, she preferred participating in professional development right after school closed because it was possible to relax after a big year of teaching. She knew that working with the university teachers was part of their professional development. The unit development was the core of their work collaboration. Carline was honest with the products. "Some of the units were better, more extensive." (IF-TC-5.11.09) She admired her colleagues for going away to get training in thematic development and returning to share with the others. The collegial sharing was a gift that she took to build equally stellar units with her preservice teachers.

\section{Decisions around reflection and community involvement.}

Carline held parents in highest regard. She held herself to a high standard to inform and invite parent involvement. Her units had a conscious attempt to involve parents. "Every unit has some sort of introduction to parents.” (II-TC-5.1.09) Parents were valued for their contributions of items sent in and for assistance with activities. She acknowledged the power of parents to spread good news, so that children in third grade would inspire moving-up students to await these exciting projects.

Collaboration with the university arts integration project opened up the arts world to her students and provided performance offerings and enrichment programs that otherwise may have gone undiscovered. Her involvement with plays at the Creative Arts Center, local theatre productions, and parents who could help with illustrating class books may not have happened without Dr. S’s vision for bringing arts integration to the community and the children.

I became aware of Carline’s ability to expand, extend, and enrich her instructional offerings. She did not stop at one idea, but she was thinking of a way to expand it. For example, Carline offered opportunities for parent participation in the arts integration unit 
activities. When not integrating the arts, she took the parent involvement strategies and found ways to solicit parent involvement in other subjects. For example, parent bankers helped children create savings and checking accounts, and parent bicycle-enthusiasts came to school for bicycle safety week to show children safety gear and signals.

Collegial involvement both at the school level and with the preservice teachers was a priority for Carline. When building the units and delivering the instruction, the school teachers upheld a standard of professionalism. Two professional courtesies emerged: respect for each other's intellectual property and offering to help colleagues create their units. "My student teacher and I did the weather unit, and teachers started offering books and anything they had.” (IF-TC-5.11.09)

I have inquiries that provoke my thinking on teacher cultures as related to decision making. Carline described teachers at Selena M. Day Primary as ones who shared their ideas, supplies, and gave credit for high quality lesson plan development. Did their arts integration project bring this culture about? Can learning through arts take credit for establishing a culture of sharing? Conversely, there are teachers who promote themselves at the expense of others by copying ideas, taking credit for initiatives of others, or other unprofessional practices.

This dissertation seeks to understand what commands a teacher's attention when making decisions for arts integration. The professional development offered through university and public school collaborative relationships is one factor that is associated with the decision making. For all eight teachers, participation in arts integration classes provided knowledge, experience, sharing, practice, skill development, and more. Whether teaching in tandem or alone, all participants took the training and ran. All showed proof of their decisions to integrate arts in stories, student assignments, and lesson plans. 
Knowing that painful aspect of a non-collaborative culture where non-sharing, ideastealing, and professional jealousies occur, I cannot help thinking about what commands the attention to decision making in the arts or any other instructional area. In collegial conversations with the dissertation participants, I saw varying degrees of collaboration ranging from consummate collaboration to independence. I looked at my own feelings and approaches to collaboration. Admittedly, it hurts my teacher conscience to think that I am protective of my teaching designs, intellectual property, strategy developments, unit designs, and other curriculum and instruction. I am, nonetheless, protective. I do not like to think of myself as noncollaborative, but there are times when I want to work alone. Carline capitalized on the resources of her teacher friends. Hearing Carline's stories about working together with her colleagues redirected me to an awareness of her ability to extend and enrich collaboration. This reflection pointed up my preference to work independently, and I wonder about my collaboration skills.

\section{Decisions in student assignments.}

Carline realized that her relationship with the university and her preservice teachers had requirements. Novice teachers had to develop and teach a unit. Topics included themes such as Egypt, China, and the weather, which are themes that Carline may not have chosen herself. She was flexible with her student teacher who came to S.M. Day with a passion to teach a unit on Egypt. "This was something she was really interested in most of her life.” (II-TC-5.1.09) Throughout the unit assignments, students experienced many real-world experiences like plane trips and an archaeological dig for relic-finding. Student learning pay-offs were substantial. In their journal reflections, they developed critical thinking, creativity through music and movement, and demonstrated thinking about learning. Students explored cultures of other 
countries in their units on Egypt and China and were able to accomplish more as the year went on due to their maturity.

In the weather unit, one assignment with a reading language arts focus encouraged students to use text and illustrations. The decision to integrate science and language arts and to illustrate the seasons supported discussions on how climate/weather affects living conditions. Another requirement for preservice teachers was to share the results of teaching the unit. In formal presentations to the faculty, student teachers shared challenges and accomplishments for their unit designs.

Carline noticed that through effective instruction and the engaging nature of the thematic units, students were demonstrating higher interest and motivation. Their questions were deeper, and writing about learning was more complex.

\section{Decisions in lesson planning.}

Carline and her student teachers developed units each semester. We previewed five in our conversations together, and I analyzed two of them for this research. The plans were extensively designed and replete with content standards documents, learning wheel graphics, and hands-on activities. Units were of high quality academic structure blended with engaging arts activities that support cross-curricular content. Wisdom prevailed with respect to the lesson delivery and fidelity. Carline explained: “With this kind of teaching, you couldn’t possibly teach every unit you have in its entirety. You wouldn’t get anything else done. So, pick and choose from those things.” (IF-TC-5.11.09)

Her views on flexibility and change are what make Carline so real and down-to-earth. Her approach to “adjust-as-you-go” is not going to be everyone’s approach. Nor should it be. She gave teachers back a certain element of control when she said, "When you're in control 
and not worrying about other teachers or the time spent on it . . . you adjust as you go.” (IFTC-5.11.09) Pacing was important to Carline because she put the students as priority, and content became secondary.

Lesson plans began with stated goals and objectives and ended with appropriate assessments to determine student achievement. In our conversations, Carline was not overly eager to discuss assessment and accountability, although she was articulate on the plan's strategies and goals development. She was, however, well versed on appropriate assessment structures for the unit designs.

I vacillate like a pendulum over my views on lesson plans. The supervisor in me says good planning evokes good teaching; good teaching promotes assurances for learning. The teachers in this research project who had thematic lesson plans based on the McCarthy 4MAT certainly planned extensively. Five of eight participants provided their units for lesson plan analysis. All eight teachers spoke articulately about their planning decisions, and the proof of their instructional decisions was documented in the student assignment samples and their discussion narratives on the student work. All teachers had exemplary student artwork samples that illuminated their decisions to integrate the arts.

\section{Conclusion}

Carline spent her professional educational career in teaching. She ended her teaching where she began learning, right at Selena M. Day Primary School. Throughout the conversations for this research, she spoke fondly of her students: the child whose life was changed during the time spent in her classroom; the struggling child who really did blossom; seeing the motivation on faces of students who wanted more knowledge about mummies and 
hieroglyphics. This dedicated, retired teacher brought insight and perspective into research on teacher decision making for integrating the arts.

Carline’s decisions were student-centered. Content was important, but secondary to the children she taught. Carline’s thoughtful responses about her students led the reader straight to her heart. In one of her descriptions of student feedback on a lesson activity, she described how students felt about the lesson using smiley face, straight-line face, and frown face: “It was just kind of interesting with different kids, how they felt. It has to do with what kind of learners they are and what kind of activities they like.” (II-TC-5.1.09) Taking the time to survey how students cared about the assignment helped her to draw conclusions on what kind of learners she was teaching. Her students came first and content after that.

\section{Janice as an Arts Integration Decision Maker Deciding what to teach: Curriculum.}

The trio of retired teachers from Selena M. Day Primary wanted to interview together. Their reasons were based upon their collegial relationships during the years at the primary school. The teachers, who still get together socially every month, agreed that their interview together would give each of them an opportunity to show their dynamic in action. That is, after all, how they taught together.

Janice clearly knew her teaching purpose and stated it in terms of core content for reading, science, and math. Although most teachers would state their teaching specializations in terms of a subject, Janice staunchly declared that her specialization was teaching. She was on a quest to have fun with the curriculum and to present it to the students in a manner that would result in their learning enjoyment. Janice explained that teaching required a repertoire of strategies. She and her colleagues bought into arts integration as a chance to experiment with a 
new possibility for all teaching and learning. This was a potential that the children responded to with great enthusiasm. Janice characterized her work and that of her two colleagues in the following quote:

All three of us are experienced and confident of what we are doing, and that our work is solid. Each voice knows how to relate to our Content Standards and Objectives and to connect to the content. (II-TJ-4.20.09)

Art content captured Janice’s attention. She approached her classroom instruction from the purest subject matter that art had to offer. Students got to experience art as connoisseurs. Gallery walks, student art exhibits, dramatic plays, and musical performances were the foundation of her teaching. All events she provided drew students back the subject content.

Also commanding Janice's attention of what to teach was a document designed to assess fourth grade writing, the Writing Assessment Technical Assistance Manual. It is not a surprise that what to teach would be included in the extensive third grade thematic unit that developed young writers. Janice knew what the fourth graders would be tested on, and she designed her writing unit to lead the students to a foundational understanding of standards set forth in the next grade. Developmentally appropriate activities comprised the unit lessons, and both left and right brain arts enhanced their arts integration classroom instruction.

Doing the research to prepare a quality lesson plan had command over Janice’s attention on what to teach. She spoke of "pounding the research" prior to deciding on a Holocaust study. Although the naysayers prognosticated reasons to abort the unit, Janice stood confident and firm knowing that research would uphold her curriculum content decisions. 


\section{Deciding how to teach: Instruction.}

Dr. S.'s influence emerges yet again in Janice's response. The project's success is largely due to the design that Dr. S. brings to her public school participants. Relationships among teachers at public schools and higher education spell "success." An expectation of accountability is ever-present throughout the collaborative process. The accountability element keeps the arts integration approach credible in that arts activities are grounded in the content and not simply disconnected, frivolous activities. Janice admitted that the elements of challenge and process took years to master. "We can't just do it because we like it. How are we going to be accountable to that?” (II-TJ-4.20.09)

Janice upheld the caveat that integrating the arts dispelled fears of teachers who had no prior life experience with the arts. She put herself out as an example that her sincere appreciation for the arts is the first criteria for successful arts integration. It was acceptable to actively learn about the arts alongside the students. We have an appreciation for it [the arts]. So we were learning with the children, because we really haven't had any training in the arts." (IF-TJ-5.11.09)

As for how to teach, Janice talked openly about her perceptions on the power to make decisions on her classroom and on personal teaching satisfaction. Her resource teacher's manual was merely that, a resource. A lifetime career in teaching resulted in knowing what was in the manual. She felt so strong and confident in her knowledge of curriculum's scope and sequence that stepping away from the teacher manual's constraints felt empowering.

\section{Decision making and professional development.}

It is impossible to provide enough accolades to the work of Dr. S for her contribution of service to arts integration and public school teachers. Each research participant had her own set 
of appreciations for the professor's guiding spirit and pure love of the arts. Janice enumerates the ways Dr. S. led them to arts integrated instruction. School-based professional development was a gift that Dr. S. provided the teachers. She led teachers and students to the complex task of arts integration so thoroughly that even music, art, and physical education specialists collaborated to complement classroom arts integration.

Janice positioned herself to take advantage of professional development opportunities. She was not an island-unto-herself in studying arts integration. The energy spent learning about arts was exciting, and Janice admitted wanting to share it with other teachers to help them feel confidence to try. "We were having a good time with it and growing professionally. It was very exciting for me to be doing something new in the teaching profession. We did encourage people.” (IF-TJ-5.11.09)

Professional development was meant to be shared with others. We grow our skills and build upon our strategies, but it is in sharing them that we become one in purpose with our colleagues.

\section{Decisions around reflection and community involvement.}

Through her affiliation with the professional development collaborative, Janice credits the university with her ability to reflect. In some instances, the collaborative either sponsored events or provided release time for teachers to experience opportunity for reflection. Janice presented her work with arts integration at conferences where participants marveled at student responses to instruction. Janice remarked, “One of the comments that I heard from other educators was, 'They asked the kids!'” She is a teacher who sought to grow beyond her own professional development. 
Janice collaborated with her preservice teachers to develop intellectual themed units that required stepping out into the community. She was keenly aware of the support that parents can provide and how their involvement could enhance the unit participation. Students were also part of her community involvement and promotion of the arts. Janice admitted her own shortcomings when it came to developing and teaching her writing unit: “Actually, I'd include the parents even when the unit was being taught. I also depended on them to come in and help instruct for me.” (II-TJ-4.20.09) She offered surveys to parents to see how they thought or understood arts integration in their child's education. One survey asked parents if their children discussed the unit at home. Keeping parents informed through letters and student-parent chats where children talked about school arts activities helped parents support teachers in the classroom. "Teaching this way was the biggest resource, because the children would go home and speak about school happenings. The kids talked to their parents.” (IF-TJ-

\subsubsection{9)}

\section{Decisions in student assignments.}

The art product of one instructional unit may be born of a completely different arts activity. For example, Janice introduced one of her thematic writing skills unit activities with a song. The resulting art assignment, however, was a pastel sketch (Bandy Snatcher) in which music was used to visualize ideas. Janice designed her students’ lessons to evoke depth and higher level thinking. She worked to create a balance between the content of each lesson and the arts with which she integrated critical thinking skills and real-world experiences.

When she talked about learning difficulties, Janice appeared committed to providing equitable services for students with disabilities. She understood change and the difficulty of keeping arts instruction alive for all learners. Her instructional activities were so engaging that 
an observer would be unable to single out those struggling learners. Janice explained her acceptance of all students who came to her classroom, and the teacher's commitment to assist struggling students in their learning: "We just learn ... we accepted the child. That's the one who came to us, and that's the child we accepted.” (IF-TJ-5.11.09)

\section{Decisions in lesson planning.}

Janice’s themed unit called “Watery World Poetry, an Integration of Poetry, Fine Arts, and Technology” included planning with teachers, university professors, and preservice teachers. Her unit included essential components such as table of contents, graphic web organizers, clearly stated learning goals, assessments, and more. She varied the learning activities to included both right and left brain thinking strategies. Janice enhanced her unit with technology-rich activities grounded in national standards, and arts-rich activities grounded in national standards for fine arts. Content standards were integral to the unit and covered core subjects of reading, language arts, and mathematics.

\section{Conclusion}

A phrase like intellectual depth might describe what captures Janice’s attention when making arts integrated decisions for classroom instruction. Just as all teachers do, she wanted to offer students the best of offerings that include enjoyment, engagement, and creativity. She made these offerings available to the class. Janice did not stop at standard fare, though. She expanded instruction that answered bigger and more thoughtful questions. Consider her writing unit. Janice put on music and children learned a song called "Bandy Snatcher.” Then they wrote about and illustrated a Bandy Snatcher, a charming art lesson with colored pencils and pastels. Janice did not stop with the art. She brought the lesson full circle to a set of written instructions to build the Bandy Snatcher Catcher. 
Janice was interested in reading about and researching new elements for student learning. In her quest to provide high quality instruction, she became a learner alongside her students. In justifying the content for her class, she did extensive research on the Holocaust. Professional growth was her hallmark. Professional development was the vehicle taking Janice on the learning path. She extended herself in the university collaborative where a multitude of opportunities for growth and development exist. After learning all she could about a new strategy, Janice put engaging lessons in place for classroom students and shared new knowledge with her teacher friends. Professional development or teacher learning commanded Janice’s attention when making decisions to implement the arts in her classroom.

\section{Kate as an Arts Integration Decision Maker Deciding what to teach: Curriculum.}

Kate described her work with the integrated arts trio of colleagues as "taking leaps and jumps.” (II-TK-4.20.09) University support through the professional development collaborative and Dr. S. was integral to Kate’s work with students. Release time and staff development helped her school achieve lasting and realistic teaching. Working with quilts, masks, and artwork of Romare Bearden was only a small part of Kate’s involvement with the arts integration project. She became a valuable model for her colleagues at S. M. Day Primary School by attending conferences and bringing back knowledge of the McCarthy 4MAT system. The small neighborhood school strategic plan was written to promote student learning through music, visual arts, movement, and drama. Kate moved smoothly between school and the university, gathering all of the resources that both had to offer, bringing together two institutions that needed one another. 


\section{Deciding how to teach: Instruction.}

Kate's brilliance in understanding student learning was evident in her response to this question. She took the opportunity to learn about learning styles and arts integration, and then blended both into a magical approach to teaching her students. Normal for her students was a classroom production that taught students about arts and their subject matter. Kate was able to dress in simple costume to teach her students about a literary character or a historical figure. Kate held herself to a high teaching standard of one that had to be fun from two perspectives: the teaching and the learning. She summed it up perfectly when she said, "We were taking risks, and we had to make it comfortable for them to take risks, and we knew that.” (II-TK4.20.09)

Kate became aware of her desire to learn more about the content as she developed her units. Researching more about the instructional themes was important to her as teacher and learner. Giving of herself contributed to her teaching magic. When students seemed not to get concepts or fall into the doldrums of learning, Kate injected them with moments of magic; a tap dance, a song, or a poem, for a lesson turn-around. Experience taught her that her teaching manuals could be part of her teaching, but that her ability to make good instructional decisions was paramount to what her students could learn in the classroom.

\section{Decision making and professional development.}

Kate was a vessel where knowledge and expertise were stored and available for others' professional development. By building up her teaching relationships, everyone around her grew in knowledge, skill, expertise, and enthusiasm for teaching children. For example, taking what she learned from the university collaboration, Kate worked with the school specialists (music, art, physical education) to expand the unit offerings across the teaching staff. 
Collaboration with a physical education teacher on cultural games helped the unit to expand her classroom into the hands of another specialist. Art and music teachers added to the thematic content by teaching students concepts included in the thematic unit. Kate drew upon the resources of others' expertise and doubled the instructional time by sharing instruction with her colleagues.

Reflection was important to Kate because she wanted to model for her preservice teachers and for her students. Looking at the success of a lesson was critical to refining the art of teaching. Strategies for reflection such as journal writing and conversations with colleagues were two ways Kate stayed grounded in her work. She knew that change was hard for all of education from policy makers to classroom teachers, but she viewed herself as a change agent. New growth and professional development were in her repertoire, and she stayed abreast of opportunities to change. "Remember, Ida, you and I were the first ones to even introduce a computer to the primary school. We never wanted to be left out.” (IF-TK-5.11.09) She went on to reflect about the self-interest in always wanting to be on the cusp of change. I imagine that a willingness to learn new technologies and teaching strategies entitled her to the benefits of conference training and technology resources that come along with learning and promoting that change. Kate stepped up for these opportunities and then brought them back to all who were willing to learn from her.

\section{Decisions around reflection and community involvement.}

Community involvement for Kate started with teachers and students within her sphere of influence at the primary school. She opened up her second grade classroom to welcome kindergarten learners. Sharing dramatic productions made it possible to strengthen and grow both classroom communities by building audiences and performers. Kate brought arts 
consumption to a new level. Her students had the chance to experience the visual arts, music, dramatic plays, and dance. Kate connected to her prior experiences with arts when she went to art galleries. Although she did not appreciate them at the time, now she says she sees much more from the art. Her decision to take her students to galleries connected her to the love of her own gallery experiences. She wanted students to be good consumers of arts; therefore, her work included teaching social participation in arts-related events like observation practices in an art gallery. The school PTA supported Kate’s arts integration activities with funding support such as planning art shows for the school community.

Kate admitted to using all of the resources she could find, such as the university professors, parents, and business partners. Each year students visited galleries, and the arts department professors helped develop her Romare Bearden unit. She said, “I don’t know that I could teach the Romare Bearden unit as effectively in other areas. I would have had to make adjustments in the absence of the university arts department.” (IF-TK-5.11.09)

\section{Decisions in student assignments.}

Kate developed two special units, quilting and Romare Bearden, that impacted her students, colleagues, and preservice teachers. She was able to use the quilting unit to make connections to the Appalachian culture of her region. Artist Romare Bearden spoke to her through his work with collage and his parents' connections to music through jazz and blues. She credited serendipity for the charm of this unit, saying that it just fell into place. The maskmaking activity gained the greatest notoriety of all unit activities at the art gallery open house for parents and community. Through the integration of the Bearden unit, students experienced reading, social studies, and community service. 
As for unique student needs and student assignments, one year Kate had a blind first grader. Providing for this child tapped Kate's abilities to modify and accommodate the learning. Her goal was to provide assignments and activities that would lead her students to value one another's diversity. "Students started respecting each other. They started looking at parts of their peers' paintings and honoring the best parts.” (IF-TI-5.11.09) Valuing a culture of respect and tolerance came from Kate's decisions to provide equity for all students regardless of their unique learning needs.

\section{Decisions in lesson planning.}

The extensive units that Kate created at S. M. Day Primary continue to benefit experienced and preservice teachers, partly due to Kate's continued post-retirement involvement at the university. She shared her units with teachers throughout the state and especially in Madreas County. With her experience came an ability to analyze what creates a successful teaching unit. In her talks about motivation, Kate mentioned that "teacher motivation has a lot to do with student motivation.” (IF-TK-5.11.09) Her honest discussion of lesson planning gave great insight into teacher decision making. "Sometimes I had to water down some things. I'll be honest with you, not every lesson plan was done in this book every year.” (IF-TK-5.11.09) The extensive unit design was structured to allow for multiple daily lesson plan experiences and activities. Working with the preservice students whose unique needs and capabilities often determined how the unit unfolded, she learned to function within a culture of revision and change. "Change was not hard for the three of us. We relished change.” (IF-TI-5.11.09) 


\section{Conclusion}

There was an abundance of offerings for preservice teachers at Selena M. Day Primary. Dr. S. and the university’s investment of time and sharing were resources well spent on teachers in the public school system. Growing quality novice teachers and placing them in a highly engaging practice teaching environment was beneficial to both the university and to their students who become quality new recruits for the work force. From the public school perspective, the university’s collaboration in enriching professional development opportunities was a fine trade-off for the investment of supervising preservice teachers. Kate was the common element in this relationship. Her participation in the arts integration movement helped others see that a lasting change in school culture was possible. For all the effort of attending trainings on arts integration and 4MAT instructional design, coupled with her work at the university, Kate's impact on school curriculum and the arts has continued in full measure, long past her direct presence there.

\section{Ida as an Arts Integration Decision Maker}

\section{Deciding What to Teach: Curriculum}

When she began to integrate the arts, Ida knew that her primary school was a place that recruited and retained strong teachers. She knew that the public school contribution was a quality one and that the chance to combine resources with university professors would produce strong goals and strategies. Through conversation, shared decision making, and consensus, university and public school collaborators first discussed content areas of science and math, but determined that understanding student learning styles would benefit all teachers and students more fully. They felt that the way to best reach students in all subject areas was to teach them through integrated arts activities in core content areas. 
Ida explained that deciding to have students learn about real-life experiences was her course of action. Once she began teaching to that standard of real experiences, she said, "We made it as real as possible. Then we got into it, and we really liked it.” (II-TI-4.20.09) Ida's statement took me once again to that concept of energy exchange between teachers and their students. I seek to understand the exchange between teacher and student, teacher and subject, or teacher and both.

Perhaps the confidence gained from a full 28-year teaching career is what I heard when Ida spoke of her content standards knowledge. She had certain views regarding written documentation of every CSO taught, and reminded us that we should hold on to the big picture when planning instruction. Hear her thoughts on CSOs: "Because we were experienced teachers, we knew it wasn't about time. We knew that the CSOs were in our lessons somewhere.” (IF-TC-5.11.09)

\section{Deciding how to teach: Instruction.}

Ida was able to make broad school connections among the teachers in her small school. She stayed tuned in to her school's successful teaching experiences and wove them into her own narrative stories. "We all knew what the other one was doing." (II-TI-4.20.09) Celebration over student and teacher accomplishments was the norm at S. M. Day Primary. Ida described first graders taking a plane trip with their desks tightly lined up as in an airplane cabin, all of them waving construction paper passports. Activities with high levels of student engagement gave teachers a sense of accomplishment. Their level of teaching satisfaction responded to the student excitement for learning, and that is a condition worth celebrating.

The practical nature of scheduling wisely was one topic where Ida mentioned how she taught. For example, talking about having to create time led her to explain an instructional skill 
of grouping students. Simply combining groups of students or moving them to smaller groups can save time. Ida also took charge of her instructional day. Sometimes an entire day was spent teaching one of the unit activities, or students would not realize that a lesson changed from reading to social studies. She went beyond scheduling and grouping to meet struggling and successful learners' needs. Teaching with arts integration opened up a "whole range of abilities in the classroom.” All students worked on similar items. Ida did not offer different assignments to those who were challenged or gifted. Those who needed additional help received attention, while those who exceeded the assignment could work beyond the grade level expectations. Adjustments for gifted and at-risk students were made based on levels of guidance and direction needed to meet student needs. Ida said:

So, if a gifted child was doing a writing piece, we encouraged him to go beyond what third graders would do. If a child had deeper challenges, we would kneel at the desk and help them physically move a pencil. (IF-TI-5.11.09)

Ida showed us what commanded her attention on how to teach by describing her approach to insuring equitable arts experiences in her classroom. Although the students' needs and abilities were different, all students participated in the same arts integrated activities. Based upon their needs, the level of instructional support and content expectation, Ida adjusted to help students meet or exceed their learning goals.

\section{Decision making and professional development.}

Ida explained that she did not mind putting in the time to get her professional development through classes and collaborations. Developing the units required hours of personal time researching content and designing instructional activities. The extensive thematic units filled large binders and included table of contents, graphic organizers, rationale, 
a minimum of two weeks' lesson planning, resource pages, activity templates, connections to state content standards, and bibliographies. Ida spent summers working on the units. Her training in 4MAT produced five units that she shared during our interview. Ida collaborated with both preservice teachers and her teaching partner, Janice. Of this time investment, Ida said: “But we didn’t mind because we enjoyed the company as well.” (IF-TI-5.11.09) Ida’s decisions to pursue professional development and collaboration on thematic units found connections in rewarding time together.

Action research put the trio from S. M. Day Primary school into a new professional development experience. Ida stayed involved with the university professional development collaborative. Her attendance at national conferences supported her professional growth and development and gave her confidence to build capacity among her colleagues to integrate the arts in their classrooms. She found confidence with professional development experiences and sought to transfer a similar confidence to her students. Ida gained both skill and confidence in unit design and was able to teach university classes that are specific to designing units.

Professional development was synonymous with Dr. S., a professor with brilliance of vision for building capacity and for managing resources, both human and intellectual. She knew the importance of establishing relationships and quality teaching environments in public schools. Providing opportunities for school teachers to attend conferences, collaborate with university professors, hear the experts at workshops, and facilitate time for collegial conversations were investments worth pursuing. Building capacity for teachers to integrate the arts brought curriculum and instruction to a new level of excitement for students and teachers. Accomplishments of this caliber paved the way for training novice teachers in a fertile environment. 


\section{Decisions around reflection and community involvement.}

Parent communication was a conscious planning element within each of the units. Letters to parents, survey questions, invitations, and requests to send materials for student project assignments were among the ways that Ida shared the students' learning experiences. The communication was also two-way between Ida and the parents. Unit plans included two forms asking for feedback and ways that their children talked about the unit activities. She wanted to know if the students were telling their parents about learning in her classroom, or if they were sharing their portfolio samples at home. Ida said the following about communiqués from parents: "If they [children] are never sharing at home, then something is amiss here. We haven't done our jobs.” (II-TI-4.20.09) This form of self-imposed accountability is a powerful indicator of a teacher who values relevant feedback from her clients: the parents and students.

Even in her retirement, Ida works in the community to advance quilting as an art form. In the conversations with her colleague, Kate, Ida said she had never quilted before. She told us earlier that in a small school like S. M. Day Primary, teachers get a chance to see each other's units. Kate's quilting unit raised the level of awareness for many teachers, students, and the community. Ida is carrying out her retirement dreams assisting in a locally owned quilting shop where she is integrating the arts into her life.

\section{Decisions in student assignments.}

Ida takes great pleasure talking about her unit creations, and joy is the motivation that drives the collaboration between Janice and her. When they co-drafted the parent letter describing their Impressionist art unit, Ida and Janice included a connection to the school strategic planning goals of integrating arts into the curriculum. Her impressionist unit was designed to encourage critical thinking skills while relating to the artwork of that period. For 
example, Ida found picture prints of famous Impressionist artists' works and mounted them on task cards. On the front of the card, Ida included the art print, painter's name, dates, and time period. To encourage the critical thinking and reasoning, a task was printed on the back asking the student to re-draw the print from a different perspective. A task card, for example, might say, "Look closely at the entire vase of flowers. Select one flower from the arrangement and water color just that one flower.”

For one student with learning challenges, Ida gave a mirror and let the student draw just an outline, then make adjustments to the design. She says, "I think you just have to give them a different kind of time.” (IF-TK-5.11.09) What commanded Ida's attention when integrating the arts was the success of each student. Whatever it took to help every child attain success is precisely what Ida would do for the child.

\section{Decisions in lesson planning.}

“Logical Thinking, a 4MAT Unit Designed for Third Graders” was Ida’s contribution to action research, a professional development experience. Her rationale for the unit goal of logical thinking was based upon National Council of Teachers of Mathematics (NCTM). Ida's goal was to support students in inventing and problem solving rather than in finding the answer by other less-than-logical ways. Technology integration became a mechanism for parent communication when digital pictures of unit activities were sent home to children's parents. Ida incorporated technology, imagery, dramatic vocabulary, and creative thinking into her unit design and classroom instruction.

Another element that commanded Ida's attention for arts integration was the joy of collaborating with Janice in the unit design. Their Watery World Poetry, Fine Arts, and Technology Unit was an extensive collaboration to create a ten-lesson plan design that would 
inspire student creative writing and nurture awareness and appreciation of the arts. Janice and Ida had an incredible commitment to integrate the arts in their own classrooms. Their commitment to each other was also astounding; they committed both time and money.

\section{Conclusion}

Ida's emphasis upon instruction and lesson plan design were the salient points in her teaching narrative. She spoke eloquently about how to teach her units and made references to the unit plans. For more than one reason, important to her work was the small, quaint, Selena M. Day Primary School. For Ida, it was important to know what her colleagues were teaching and how their students were responding. Ida's response to community involvement was a scenario explaining the importance of children discussing the unit activities at home. The commitment to arts integration questions revealed Ida's thoughts on instruction as she described adjusting schedules to create more time and combining students in smaller groups. What commanded Ida's attention when deciding to integrate arts instruction was her opportunity to instruct using the unit plan?

\section{My Reflection}

Ida's revelation raises the question of whether planning instruction is a driving force for teacher decision making. I have an analogy from my own musical experiences that may connect to Ida's attention to the unit design and lesson plan experiences. A teacher's work does not begin in the classroom; it begins at the desk or other place where ideas are born and written down. Then she researches content information, plans the instruction and pacing, gathers the materials, and comes to teach students. In my own musical performances on the pipe organ, I go through a similar process to prepare for a recital. 
I start with a study of the organ masterpieces to decide what I will perform for the audience. I purchase the music, study the composer, and listen to other artists play the work. Then I practice, practice, practice the music. Only after all elements of the process are refined and complete do I think about giving the performance. In summary, what commands my attention is the preparation plan. Without implementing the plan, I would never get to the performance. Ida's attention to the unit and lesson plans is analogous to the same preparation for teaching performance that I experience for the organ recital. We both know how enjoyable it is to prepare for the "performance." It is time consuming and demanding, requiring focus, attention, and diligence to the task. But we control the preparation, its pace, the amount of time spent, and the sources we turn to for our strength and knowledge.

\section{Implications for Future Arts Integration in Classrooms}

Under the four question framework of curriculum, instruction, reflection on professional development, and community involvement, the eight research participants and I told our stories. We related our experiences through real world scenarios, interactions, activities, plans, and sample assignments. Each narrative tells its own story of a teacher blessed with a career of joy, pleasure in serving children, and teaching satisfaction. All eight and I provided our insight to decision making based on connections to our past teaching and learning experiences, both in and out of the classroom and as related to our unique arts involvement.

Artwork connections to teacher decision making were shown within the student artwork figures. A graphic summary of the artwork figures and their connections to curriculum, instruction, reflection, and community can be found in Appendix G. The student work sample checklist (Appendix D) based upon Burnaford, Brown, Doherty, and McLaughlin’s “Arts Integration Frameworks, Research \& Practice (2007), made it possible to find connections 
among student artwork and the overarching themes of curriculum, instruction, reflection, and community. Media types used in the student samples included diorama, visual art, drama, mosaic torn paper, puppetry, drawing and sketching, water color, and papier mache. All arts integrated assignments shown in the figures reflected reading, language arts, and writing. Math and health showed fewer arts integrated assignments. Teachers provided assignments that encouraged student research and the use of graphics and codes. Social studies arts integrated assignments reflected opportunities for students to exhibit self confidence and to build self esteem. The arts integrated assignments contained a community element when students demonstrated an understanding of conflict resolution and tolerance throughout their artworks.

The overarching questions for the interview conversations focus upon curriculum, instruction, professional development, and community. While reading the eight teacher narratives, several salient points began to emerge. I would like to address these points in a question format because future implications for research may have answers lying within the big four question framework. Following each question, I compile some of the most empowering teacher statements and attempt to make connections to the current research on curriculum, instruction, professional development, and community involvement. See Appendix H for a graphic representation of implications with supporting narratives for future research.

\section{Implications for curriculum.}

Standards-based instruction is one way to insure instructional accountability of content. To what degree should the standards command a teacher's attention when deciding to integrate arts instruction?

In Teacher Power-Revisited, Donald Myers asserts that teachers lack power over their classroom decisions. He contends that other factors and entities make instructional decisions, 
stripping teachers of their rights to autonomy to govern their own affairs (Myers, 2007). Factors influencing this decline in authority and autonomy may be impacted by studies and legislations such as A Nation at Risk (National Commission on Excellence in Education 1983) and U.S. Department of Education Public Law 107-110, known as No Child Left Behind (NCLB). Implications for curriculum research may be pertinent to the teachers' perceptions that their decisions control what they teach. Meyers boldly asserts that "teachers have less control over what goes on in their classrooms, and that content is mandated from above and instruction is affected because this content is often too uniform for all students” (Myers, 2007).

Participants in this research expressed their thoughts, equally boldly, regarding what commands their attention when deciding what to teach. Here are a variety of approaches to making curricular decisions.

I do follow the content standards. I use what I've been instructed to use, but I'm able to extend that, and I think my lesson presentation is the whole thing. You take those CSOs that you have to cover, and then a plan is devised from there. (IF-TA-5.12.09)

I think as far as what we teach, we don't have a whole lot of control because it is guided by the state CSOs. However, I think how we teach it is one of the things I like about teaching. (IF-TKD-5.11.09) 
Curriculum is for the most part guided by state and county guidelines.

However, I have been teaching for 37 years, and I pretty much know what is for kindergarten and what isn't. (II-TKD.29.09)

Reading First, I think, has also been a big part of deciding what I have to teach because a lot of phonics awareness now has been placed upon it. No regrets, because I think it has been wonderful, but those are the things that have made me decide ... that's how I decide what to teach. (II-TA-4.23.09)

Because we were experienced teachers, we knew it wasn’t about time ... we knew that the CSOs were in our lessons somewhere. I think if you look at a bigger picture and then fit it in, you're going to be sure the CSOs are being met. (IF-TC-5.11.09)

Myers echoes two research articles from the Chapter 2 literature review: Wayland's 1964 article, Structural Features of American Education as Basic Factors in Innovation, and Brickell's State Organization for Educational Change: a Case Study and a Proposal. All three writers concurred that much of the decision making associated with teaching was determined by others within the educational system. Meyers discusses national policy and brief (Nation at Risk, and No Child Left Behind) as impacting teachers’ curriculum decisions. Brickell believes that teachers are a functional piece of the bureaucratic system—and replaceable. Wayland suggests that teachers' work involves continuous decision making about student instruction. 
These teachers admitted that their classroom content is prescribed. They said that they teach the content. Even though content is determined for them, each one made a statement about how they cope with the already derived content requirements for their grade levels. Teachers also pointed out that their self-efficacy of content knowledge which they gained over their long and successful teaching careers, was instrumental in deciding what to teach from the curriculum standards.

\section{Implications for instruction.}

Instruction is nearly synonymous with teacher and is a major force upon teacher autonomy. Instruction has far reaching implications on student learning, classroom culture, and teacher morale. What elements of instruction best serve to command a teacher's attention when deciding to integrate arts instruction?

Robert Marzano’s The Art and Science of Teaching, A Comprehensive Framework for Effective Instruction, explores Benjamin Bloom's research and theory on the development of teaching units to organize instructional content. Marzano contends that effective teaching is part art and part science. He recognizes that all teaching and learning is unique to the manner in which a teacher delivers instruction, and how the student responds to that instruction (Marzano, 2007).

During the interviews, teachers shared their personal views about lesson planning and offered insight into their planning procedures and/or samples of their lesson plans. For the purposes of this research, looking at teacher lesson plans focused the lens upon the nuances of teacher decision making. Teachers planned instruction, gathered resources, and set up lessons, which became the work that is never really completely done. Teachers stated they were not finished once a lesson was delivered. Decisions were revisited when a lesson was successful in 
hopes of achieving close to perfection the next time. When there was a stark realization that a lesson was not working, teaching required the heart-wrenching work of delving deeper to admit and refine what did not work. Consider these insights that participants have shared:

I try and put my centers where they work, like the reading center where it's quieter away from the busy middle center. And I change every year. Sit down and rearrange. (IF-TA-5.12.09)

Even though the overall demands have changed, I still feel it is really important to follow the National Association of Young Children guidelines. I feel like you can still teach your goals and objectives through play, through art, through music. So I try to do that. (IF-TKD-5.11.09)

I think first of all, no matter what you teach throughout the day, you always immediately reflect, 'Was that successful?' The next time I teach that, I want to add such-and-such. I might change it in some way. (IF-TKD-5.11.09)

The manuals became my resources. I felt like I was confident in my teaching. I wanted to make decisions for my classroom. (IF-TKM-5.11.09)

This is their life. Not the life I grew up with, but that is what we are facing now. So, for me, my idea of art is this. But that is not their idea strictly of art, so I think opening all the doors, all the possibilities, allows them to have creativity in the world they are growing up in. That is a prime example of where we are 
connecting science curriculum with the technology, with the arts. You got it all.

(II-TCP-5.1.09)

\section{Implications for reflection and professional development.}

Teacher growth and development are paramount to high quality teaching. What aspects of professional development should command teachers' attention when deciding to integrate arts instruction?

In his introduction to The Collaborative Teacher, Richard DuFour sums up research on collaborative cultures: "Researchers consistently report that the collaborative cultures created by these educators have helped students achieve at higher levels, fostered a powerful sense of professional efficacy among teachers, and made the teaching experience more rewarding and fulfilling”(DuFour, 2008).

The following graphic flow chart represents implications for teacher preparation programs as colleges and universities prepare preservice teachers to gain command of content knowledge. Command of content clears the path so that teachers can learn the instructional design process. Teachers who are self aware understand their professional development needs, thus enriching the collaboration between preservice and cooperating teachers. 


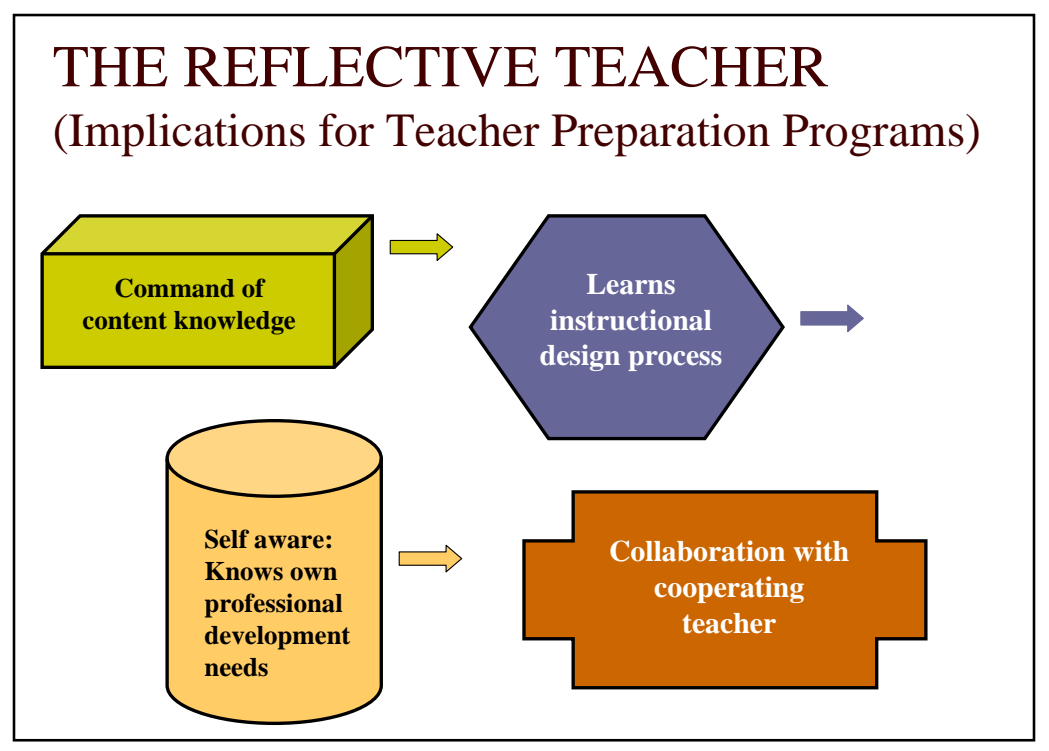

Figure 12. The Reflective Teacher flow chart presents the stages of development flowing from preservice teacher gaining command of content to cooperating teacher relationships where instructional strategies are explored and developed.

Throughout their careers, teachers are on a quest for command of content knowledge.

Teacher preparation programs at the college or university level are designed to support teachers in this quest, so that they can move quickly adequate preparation for learning the instructional design process.

The reflective teacher knows her professional development needs. The collaborative teacher is willing to find a way to join with others to accomplish those needs. The personal nature of professional development is complex. Curriculum-focused administrators are faced with the knowledge of what their schools do well and what changes must be made. Building the bridge between the knowledge of professional development needs and implementing the change is that process teachers either embrace or reject. Each participant in this research offers an important perspective and a glimpse into her unique spirit of professionalism. 
Over the past several years, I have also been trying to attend as many technological professional development things as I can. I feel like I have a lot of catching up to do. (II-TKD-4.29.09)

One of the other things that developed from this university collaborative is that our traveling specialists—music, art, and physical education—could extend our teaching units with their expertise and assistance. We would work together on content instruction. (II-TKM-4.20.09)

Not many things are offered along the way, so that is why when the university professor offered the class to us, a few of us just jumped on it. (IF-TV-5.5.09)

We were doing action research before it was vogue. (IF-TI-5.11.09)

I did the Teacher Leadership Institute for the first year cohort, and we received professional development on what we need to be doing as educators, and what we are not doing. I am also working with a representative from the university on integrated arts curriculum. (IF-TA-5.12.09)

Our university professor, Dr. S., provided us with numerous in-house professional development sessions. She showed us some other ways to use our techniques in practice. (II-TJ-4.20.09) 


\section{My Reflection}

I have come to believe that professional development is an extremely personal and spiritual experience for teachers. In my own pursuit of the most rigorous professional development of achieving National Board Certification, I was in a year-long progression of change. I struggled with the intellectual rigor of understanding my content area specialization. It was not easy for me to open up to the risk that I might not pass the portfolio submission or the full day of written exams. My sacrifices of time and energy were a double edged sword in the cost of time and resources required as I prepared for the learning process and the benefits that my students and I gained during the year of preparation and attainment. I realized later that the very things that consumed my resources led me to the zenith of my professional game. I opened my spirit up to the possibility of growing beyond my own potential.

\section{Implications for community and future policy.}

The nature of arts lends itself to community involvement. In what ways can the community be a factor when teachers decide to integrate arts instruction?

Teachers know and understand that the arts are meant to be shared with the community through exhibits and performances. Schools involved in this study know the importance of asking for and taking the assistance they need. They also know that the culminating performances, displays, and exhibits are to be celebrated by the children, their teachers, and their communities.

Chapter Six of Stevenson and Deasy's Third Space: When Learning Matters is titled "Building Community.” In this chapter, Thomas Sergiovanni’s work Building Community in Schools offers valuable viewpoints regarding school as community. He says, "Democratic communities help students to be as well as to become. They help students meet their needs 
today as well as becoming tomorrow’s caring and active citizens” (Sergiovanni, 1994). The eight research participants are brilliant articulators of the many connections that exist among their classrooms and the community. Some of the connections are stated below and include school as an internal community of collaborators; school connections to the intellectual and artistic community; schools within the system connected to each other; and schools and parents connected through the students.

Being in a university town certainly helped me a lot. Being able to go to the Creative Arts Center and having the professor as a resource was incredibly valuable. The community influenced me a lot. (IF-TKM-5.11.09)

I welcome parents to join us if they have free time. When they can come, I put them at a station, and even though I don't get a lot of volunteers, I do encourage it. (IF-TA-5.12.09)

Not only does a child like their parents to come in on occasion, it allows us to have a station that could be more involved. We can do more arts integration if we have the parent in to help. (IF-TKD-5.11.09)

I got an email from a parent saying just how much she loved the insect project that her child brought home. She thought it was a really creative idea and wanted to let me know. (IF-TA-5.12.09) 
I think the realization of the 21st Century Learning is the biggest thing right now. We have got to be able to meet what the community needs are. (IF-TA5.12.09)

That is what we all have, humanity. You can connect that way with the kids through the arts sometimes when you can't connect with them any other way. There is a connection to the arts that pushes students forward beyond their own perceived limitations. (II-TCP-5.1.09)

Our PTA was very supportive of our teaching. We could write grants to get money for the arts activities. They never questioned us on our needs. (IF-TKM5.11.09)

We are having a Night at the Arts this week. There are going to be displays for each student ... and performances. I am sure there will be a wonderful turn out for that too, because all children want their parents to watch them perform and show off their arts activities. (II-TV-5.1.09)

Teachers knew how important it was to interact with the community. They came from a variety of perspectives on the best ways to reach out beyond their classrooms. Some viewed involvement with community as a way to gain knowledge or make expert connections to improve instruction for students. Others sought assistance in both human and monetary resources. Still, many capitalized on connections with students' parents so that learning at 
home and learning at school were equally supported. For whatever reasons teachers sought involvement, the important lesson for this research is that teachers made instructional decisions with the community in mind. Audiences for student performances, volunteers, visiting classroom experts, funding for activities are only a few of the vast influences that teachers consider when deciding to integrate the arts into their instruction. What our research participants say is that they do interact with the community, and as a result, good things are happening with the arts integration unit activities.

Eight participants have told their stories and provided examples of lesson plans and student work. I had the high honor of hearing their stories and seeing proof of their work with learners. My responsibility to maintain the integrity of their research contribution is a monumental one in which I see and hear through my own lens what they are trying to convey to the research community. Teachers gave of themselves to participate in this dissertation research. They opened to us their hearts and minds through sharing their own decisions to integrate arts instruction. Beautiful scenarios emerged through their conversations about student learning, collegial planning, and even their outreach into the community. See Appendix I for teacher narratives in a graphic representation that support the question frameworks.

\section{Implications for Future Research}

\section{Implications for the Dynamic of Teaching and Learning} Teacher-learner exchange principle framework.

A teacher is a learner during preparation of lesson plans, research, finding resources, and mastery of content, strategy, pacing, etc. There is a juxtaposition of sorts: the teacher and 
the learner. Plans are the pivotal point when a teacher leaves the learner role and readies herself to deliver the work in the learner-to-teacher dynamic. Hidden in the plans is the catalyst for the teaching-learning exchange. Some teachers say, "I can throw away the plans and come in each day with a new lesson, you know ... just wing it.” “I don’t have to make lesson plans. I have what I am going to teach in my head.” “The state department of education can’t require me to put specific things in my plans.” Is this a certain confidence in ability, or perhaps avoidance behaviors to the necessary requirements of thoughtful planning? Master teachers are learners who have a plan.

\section{My Reflection}

In 1990, I was teaching in an elementary school as a reading specialist. Our school was a professional development school with the university collaborative. I was selected to participate in an after-school project-based learning (PBL) program. The project started with at-risk students. Our assignment was to explore the ethnography of oil and gas in our small rural community. I immediately looked in social studies books and began talking to business people from the local oil and gas industry. The four other school teachers participating in the project were from other school districts, and their topics included coal and timber. We were charged with using technology teaching and learning that involved video recording oral histories of the community people I studied. Beginning with monthly time frames, I turned to the social studies content and expanded to science content. From the content, I scheduled visits from resource field experts, communicated with parents, etc. This preparation required enormous reserves of energy and time beyond my 40-minute daily planning period.

I worked nights and on weekends to set up the program and curriculum. I was learner, researcher, planner, organizer, and implementer. I came to the table with content, events, 
challenging curricular assignments. My role was to teach, facilitate, and organize. At an almost indistinguishable moment, the learner took a stand on content. I owned it ... invested in it ... then generated a new level of learning, involvement, and commitment that spread out past the four walls of a traditional classroom. Classroom was the world around us. Traditional classroom walls were abolished, gone. Students were inspired, committed, energized, motivated, and participatory. Bonded with each other and the teacher, students became a community of learners becoming leaders. Parents asked for permission to join in our after school program events, where industry experts taught us from their bank of knowledge and skill. We visited the university archives to study old news articles and photographs, storage stations, built model oil derricks displayed in the school yard, and recorded oral histories of oil and gas museum curator.

We are the leaders turned learners. An implication for future research is to understand the energy exchange that each teacher uniquely related in her narrative. A reciprocal dynamic, which I call the "teacher-learner exchange principle," is so powerful that it is almost tangible. A teacher spends energy preparing and learning. Then she comes to the table with curriculum content as the foundation. Students receive the energy through well-designed lesson preparations. That energy converts to an enthusiasm for new learning in which students and teacher face challenges and responsibilities. This energy returns to the teacher and replenishes her waning stores of energy. The exchange does not stop here, though. It fills the spiritual bank to go to greater heights, do more, be more, give more, and become more. The cycle goes on. Energy spreads out to parents, community, and business, with a powerful potential to change a life.

The following graphic illustrates the teacher-learner exchange (TLE) principle. 


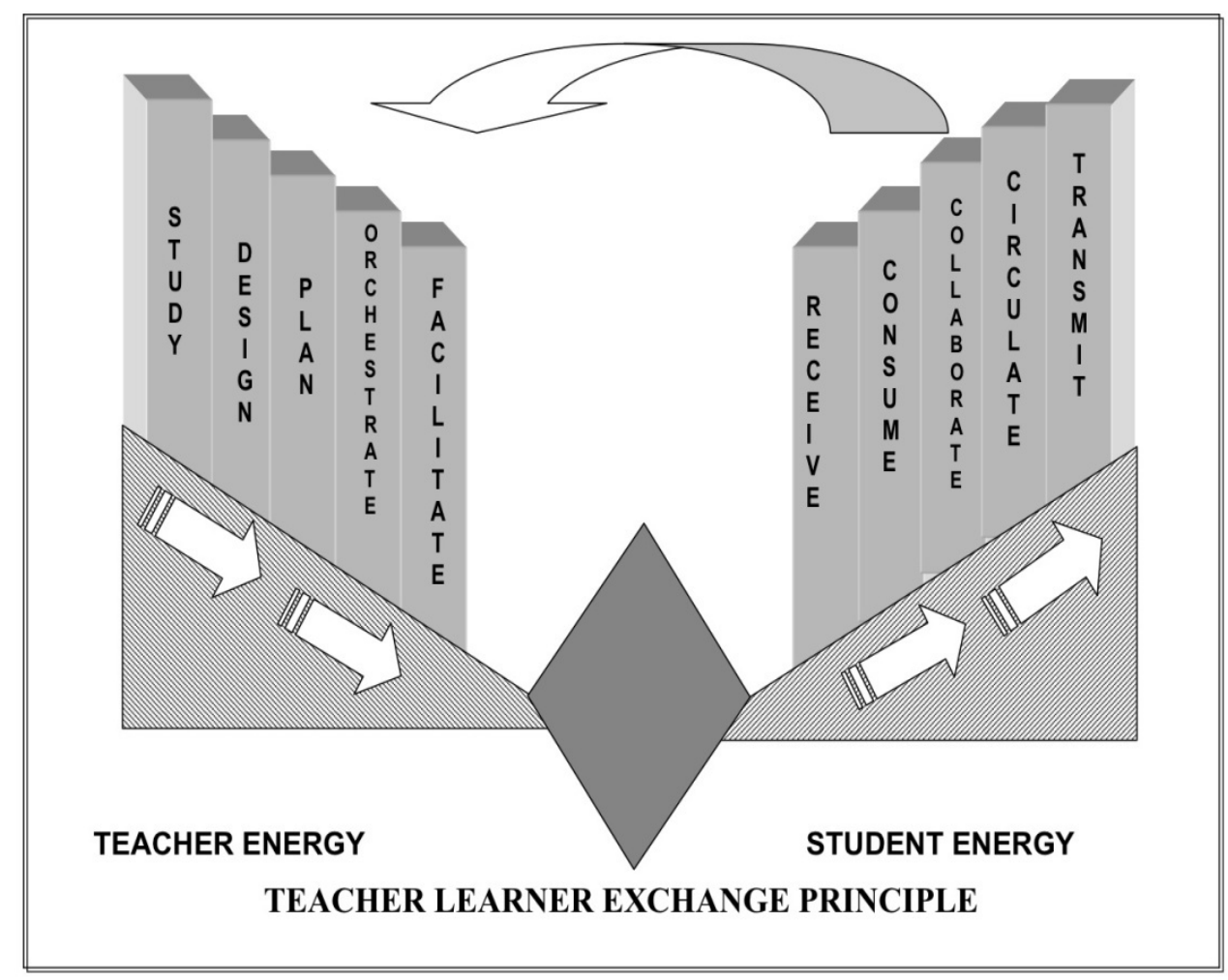

Figure 13. Teacher-Learner Exchange Principle framework shows the energy exchange that transpires when teachers act as learners to study, design, and plan lessons for their students.

The following quotes support the TLE principle. Hear the participants' voices once again as their scenarios illuminate the energy exchange:

Antonella's study of her state's heritage that is rich in clogging: “It's fun for us. It’s fun for the teacher aide and me, and it’s fun for the kids.” (II-TA-4.23.09)

Ida’s Logical Thinking Unit: “Teachers bring a positive attitude and new techniques to the classroom. This directly affects the student’s ability and desire to learn.” (Logical Thinking 4MAT Unit Designed for Third Graders, Fall 2001)

Celine’s annual book report and puppet project: “Once they start learning more and get more involved with their puppet and report, the excitement grows. Parents get involved with their children. They go to great extremes once they begin to see it coming together. It is so 
exciting to hear them tell about their progress and to see them give their reports.” (II-TC5.1.09)

Veronica’s Health Lesson and Power Point: "I will use the examples of CDs from last year. The girls were so motivated. This was not only a classroom lesson ... and then when you see the Power Point and the research done, there are just no questions about high motivation and high interest levels. That is just absolutely awesome.” (IF-TV-5.5.09)

Kara on her Kindergarten Insect Unit: "When you introduce something, like when we were doing our insects ... the children were really excited about learning more and more about it. They wanted to learn so much that we had a guest speaker come in. I guess if they are motivated and want to learn more, then that motivates you as a teacher to provide them with more. For example, I'm looking on the internet to find some extra things for them to look at. Also, going to the library lets me bring in more things to show them.” (IF-TKD-5.11.09) Carline on her Egypt Unit: "This is what my student teacher wanted to do. I learned a lot from them. The kids, they were really into it, too. The students learned a lot of things.” (IITC-5.1.09)

Janice’s Impressionist Unit: "But it’s just that we have an appreciation for it and their children enjoyed it! This added such a different dimension to our teaching by bringing that in. So we were learning with the children, because we really haven't had any training in the arts.” (II-TJ4.20.09)

Kate’s Unit on Artist Romare Bearden: “As we developed these units, we became interested ourselves in the content development. When they [students] got to the third grade, the Impressionist kind of thing also spoke to the child. I then introduced jazz and blues and all those different music genres. It just fell into place.” (IF-TKM-5.11.09) 
My Appalachian Social Studies Unit for National Board Certification: "The work of teaching required me to consider how to introduce and pace the scope and sequence of the unit information. It took personal time to find ways to connect the community and instructional resources into the lesson plans."

\section{Technology as art.}

Mention of technology use in the arts came up in each of the teacher narratives. This causes me to ask the question that may not be one that musicians, artists, dancers, actors, playwrights, would welcome. In the purest sense of the arts, there may be no place for technology. Consider computer generated graphic arts design for a moment. Is it going to be a stretch to say that visual arts could be computer generated? And what do we tell our students about using synthesizers in place of live musical performers? Do we dare explore the impact of technology in the arts? Could that be leading the students down a path where we may not have live performers or real artworks? The reason to research this question stems from the frequent references by teachers that technology instruction is so prevalent. Learners today are immersed in technology options for learning. So when a teacher says her students take a camera out to film a play and produce a commercial on DVD, should we be considering the potential for technology as a possibility for arts integration?

\section{Over arching, four question framework.}

Finding answers to what commands teachers' attention when making decisions to integrate the arts was the impetus of this research. The structure of the four over arching themes of curriculum, instruction, reflection, and community provided a question framework for the participants' narrative stories. As researcher, I began the dissertation with the hopes of finding an answer. I thought that one item would prevail as the key factor in decision making. 
What I found were numerous answers. Throughout the interviews, I realized that just as each teacher's style of instructional delivery was unique, so, too, were their unique reasons for deciding what to teach, how to teach, reflecting on what professional development to seek, and how the community reacts to their arts integrated instruction. Although the big four overarching framework was a model for this hermeneutic research study, implications for future research may find ways to use the framework to unveil additional layers of understanding about teacher decision making.

\section{Values and ethics emerging through arts integrated teaching.}

In an essay found in the Critical Links compendium entitled The Arts and the Transfer of Learning, by James Catterall, the author credits Psychologist Howard Gardner’s 1983 multiple intelligences research as potential force for learning and motivation. In my personal narrative on reaching struggling students, I relate an authentic arts integrated lesson for special needs students. The students and I prepared a tape of Christmas songs to send to President Ronald Reagan. Students really caught on to this project. Their motivation was tangible and could be seen in extended attention to tasks including focused commitment to project completion, and knowledge of our country's executive branch. These students, though struggling to overcome their academic challenges, had the right to a well-prepared and implemented instructional lesson. Because of my position and my expertise and training in curricular content and instructional strategies, I had the moral responsibility to provide for my learners. Music provided the opportunity to reach students in a manner that appealed to their learning capabilities and in a way that promoted self-esteem, self-confidence, and tenacity to complete a task. Daniel Goleman, expert on emotional intelligence, explores the potentials of emotional intelligence, empathy, and social skill. His books, Social Intelligence, Emotional 
Intelligence, and Working with Emotional Intelligence are known throughout the world. Through the arts, teachers have the power to influence a child's social and emotional development. This is a responsibility that can not be taken lightly. We have students who come to us with no parents, no food, and no hope, and ethically, we are not permitted to send them away wanting.

In an attempt to delve more strategically into the moral and ethical values facing educators in arts integrated instruction, it helps to know what processes and skills will best assist us in our work. Knowledge of emotional intelligence is a key component for teachers who hope to use their compassion for students as a complement to instructional strategies. Additionally, a strong awareness of content that appeals to students' and offers motivation would be part of the process. This area of research aligns with the spiritual development of teaching and learning; it is aligned with shared learning experiences, and it is fertile ground, thus, it is wide open for study and research. The entire educational system stands to benefit from such research, and all children will have their rights to learn in and through the arts. 


\section{References}

Alken, M. L. (1970). The occupational role of the public school teacher: an analysis of teachers' expectations of professional autonomy. (Doctoral Dissertation). Retrieved from Dissertation Abstracts International. (Accession No. AAG7100472)

Ashton, P. (1988). Detrimental effects of mandated models of discipline on the practice of reflective teaching. (ERIC Document Reproduction Service No. ED 307 267.)

Barth, R. (1981). The principal as staff developer. Journal of Education, 163(2), 144-162.

Becker, H. S. (1953). The teacher in the authority system of the public school. Journal of Educational Sociology, 27, 129-141.

Becker, H. S. (1962). The nature of a profession. In N. B. Henry (Ed.), Education for the Professions: The Sixty-first Yearbook of the National Society for the Study of Education, Part II (pp. 27-46). Chicago: University of Chicago Press.

Becker, H. S. (1967). Whose side are we on? Social Problems, 14, 239-248.

Becker, H. S. (1985). Outsiders: Studies in the Sociology of Deviance. New York: Free Press.

Becker, H., \& Geer, B. (1970). Qualitative Methodology. Chicago: Markham.

Bochner, A.P. (2001). “Narrative’s Virtues.” Qualitative Inquiry 7 (2): 131-57.

Brewer, J., \& Hunter, A. (1989). Multimethod research: A synthesis of styles. Newbury Park, CA: Sage.

Brickell, H. M. (1964). State organization for educational change: A case study and a proposal. In M. B. Miles (Ed.), Innovation in Education (pp. 493-531). New York: Bureau of Publications. Teachers College, Columbia University. 
Buffum, A., Mattos, M., \& Weber, C. (2009). Pyramid Response to Intervention. Bloomington, IN: Solution Tree Press.

Burnaford, G., Brown, S., Doherty, J., \& McLaughlin, H. J. (2007). Arts integration: Frameworks, research \& practice. A Literature Review. Retrieved from http://www.aep-arts.org/files/publications/arts_integration_book_final.pdf

Burton, J., Horowitz, R., \& Abeles, H. (1999). LearningiIn and through the arts: Curriculum implications. Center for Arts Education Research, Teachers College, Columbia University. Retrieved from http://artsedge.kennedycenter.org/champions/pdfs/Learning.pdf

Callahan, R. E. (1962). Education and the cult of efficiency. Chicago, IL: University of Chicago Press.

Callison, W. L. (1970). Teacher perceptions of autonomy and authoritarian teacher attitudes in rural schools. (Doctoral Dissertation). Retrieved from Dissertation Abstracts International. (Accession No. AAG67112869)

Caterall, J. S., \& Brizendine, E. (1985). Proposition 13: Effects on High School Curricula 1978-1983. American Journal of Education 93. 93:3, 327. DOI: 10.1086/443804.

Catterall, J. S., \& Waldorf, L. (1990). Chicago arts partnerships in education: Summary evaluation. In E. B. Fiske (Ed.). Champions of Change: The Impact of the Arts on Learning. (pp. 47-62). Washington, DC: The Arts Education Partnership.

Catterall, J. S., \& Waldorf, L. (1990). Chicago arts partnerships in education: Summary evaluation. Imagination Project at UCLA Graduate School of Education \& Information Studies. Los Angeles, CA. Retrieved from http://www.gseis.ucla.edu/faculty/files/catterall/catterall.chicagoarts.pdf 
Corwin, R. G. (1965a). Militant professionalism, initiative, and compliance in public education. Sociology of Education, 38(4), 310-331.

Corwin, R. G. (1965b). Professional persons in public organizations. Educational Administration Quarterly, (1), 1-22.

Dana, N. F., \& Yendol-Hoppey, D. (2008). Facilitating the professional development of others: The role of action research and professional learning communities. In C. Collins, B. Ory, J. Reese, \& T. Thoelcke (Eds.), The reflective educator's guide to professional development: Coaching inquiry-oriented learning communities (pp. 1-20). Thousand Oaks, CA: Corwin Press.

Deasy, R. J. (2002). Critical Links: Learning in the arts and student academic and social development. Washington, DC: Arts Education Partnership. Retrieved from http://www.aep-arts.org/resources/toolkits/criticallinks/criticallinks.pdf

Denzin, N. K. (1978b). The research act: A theoretical introduction to sociological methods. 2nd ed. New York: McGraw-Hill.

Dichele, A. M. (1994). Teachers’ perceptions of reading comprehension instruction: A crosscase analysis (Instructional decision-making). (Doctoral Dissertation). Retrieved from Dissertation Abstracts International. (Accession No. AAG9503460)

DuFour, R., Eaker, R., \& DuFour, R. (2005). On common ground: The power of professional learning communities. Bloomington, IN: Solution Tree (Formerly National Education Service).

Edgar, D. E. (1969). Professional socialization and teacher autonomy. (Doctoral Dissertation). Retrieved from Dissertation Abstracts International (Accession No. AAG6917413) 
Eisner, E. W. (Ed.) (1962). The development and use of a typology of creative behavior in the visual arts. (Doctoral dissertation) University of Chicago.

Eisner, E. W. (1964). Creativity in art has many faces. Chicago Schools Journal, 45(4), 311318.

Eisner, E. W. (Ed.). (1976). The arts, human development, and education. Berkeley, CA: McCutchan.

Eisner, E. W. (1985). Educational objectives: Help or hindrance. The art of educational evaluation: A personal view (pp. 29-38). London: Falmer Press. (Original work published 1967.)

Eisner, E. W. (1994a). Cognition and curriculum reconsidered (2nd Ed.). New York: Teachers College Press.

Eisner, E. W. (1994b). The educational imagination (2rd Ed.). New York: Macmillan.

Eisner, E. W. (1995). Standards for American schools: Help or hindrance? Phi Delta Kapan, 76(10), 758-764.

Elbaz, F. (1981). The teacher’s “practical knowledge”: Report of a case study. Curriculum Inquiry, 11(1), 43-71.

Elliot, Jaques. (1956). Measurement of responsibility. London, England: Tavistock Publications, Ltd.

Ervay, S. B. (1971). The relationship between personally perceived autonomy and the professional activity of secondary school teachers. (Doctoral Dissertation). Retrieved from Dissertation Abstracts International. (Accession No. AAG7125363)

Etzioni, A. (1961). A comparative analysis of complex organizations. New York, NY: Free Press. 
Etzioni, A. (Ed.). (1969). The semi-professions and their organizations: Teachers, nurses, social workers. New York: Free Press.

Fiske, E. (Ed.). (1999). Champions of Change: The Impact of the Arts on Learning. Washington, DC: The Arts Education Partnership and the President's Committee on the Arts and the Humanities. Retrieved from http://artsedge.kennedycenter.org/champions/pdfs/ChampsReport.pdf

Gaventa, H. R. (1974). Teacher autonomy and collegial climate in selected self-contained and open space elementary schools: Implications for job satisfaction. (Doctoral Dissertation). Retrieved from Dissertation Abstracts International. (Accession No. AAG7506283)

Gill, N. G. (2007, July 18). Goodbye, Mr. \& Mrs. Chips. Education Week, p 35.

Ginot, H. (1976). Teacher and child. New York: Avon Press.

Greene, M. (1986). In Search of a Critical Pedagogy. Harvard Educational Review, 56(4), 427-41.

Hari-Augstein, S., \& Thomas, L. (1991). Learning conversations (p. 3). London: Routledge. Jaques, E. (1956). Measurement of Responsibility. London: Tavistock Publications, Ltd, Katz, F. (1964). The school as a complex organization. Harvard Educational Review, 34.

Kennedy, M. (1994). The Oxford dictionary of music. Oxford, NY: Oxford University Press. Lawrence-Lightfoot, S. (1999). Attention. In Respect (p. 196). Reading, MA: Perseus Books. Lieberman, M. (1956). Education as a Profession. Englewood Cliffs, NJ: Prentice Hall. Lincoln, Y. S., \& Guba, E. G. (1985). Naturalistic Inquiry. Newbury Park, CA: Sage. Lofland, J. (1971). Analyzing Social Settings. Belmont, CA: Wadsworth.

Marzano, R. J. (2007). The art and science of teaching. Alexandria VA: Association for Supervision and Curriculum Development. 
McMillan, M. B. (1999). The troubling consequences of the ABCs: Intended effects of the ABCs. Retrieved from Common Sense Foundation website: http://www.commonsense.org/abcs/intended_effects.html.

Miller, G. (1997). Contextualizing texts: Studying organizational texts. In G. Miller \& R. Dingwall (Eds.), Context and Method in Qualitative Research, (pp. 77-91). Thousand Oaks, CA: Sage.

Myers, D. A. (2007). Teacher Power-Revisited. The Clearing House, 80(5), 239-242.

National Board for Professional Teaching Standards (2008, June 11). New Report Affirms National Board Certification’s Positive Impact on Student Achievement and Learning. Retrieved from http://www.nbpts.org/about_us/news_media/press_releases?ID=422

National Commission on Excellence in Education. (1983). A nation at risk. Retrieved from http://www.ed.gov/pubs/NatAtRisk/risk.html

National Education Association (1967). The American public school teacher, 1965-66. Washington, D.C.: Research Division, National Education Association.

Patton, M. Q. (2002). Qualitative Research \& Evaluation Methods. $3^{\text {rd }}$ Ed., Thousand Oaks, CA: Sage Publications, Inc.

Porter, K. (1940). Flowering Judas and other stories. 1st Ed., The Modern Library.

Richardson, V. (1990). Significant and worthwhile change in teaching practice. Educational Researcher, 19(7), 10-18.

Richardson, V., et al. (1991). The relationship between teachers' beliefs and practices in reading comprehension instruction. American Educational Research Journal, 28(3), $559-586$. 
Richarson-Koehler, V. (1987). What happens to research on the way to practice? Theory into Practice, 26, 38-43.

Rollins, D.J. (2003). Impact of North Carolina accountability program: Teacher beliefs and perceptions. (Doctoral Dissertation). AAI3109327)

Samuels, J. J. (1966). Bureaucratization of school districts and teacher autonomy. (Doctoral Dissertation). Retrieved from Dissertation Abstracts International. (Accession No. AAG6700451)

Sarber, M. L. (1977). Teacher perception of professional autonomy under varying conditions of negotiations in Arizona, California, and Nevada. (Doctoral Dissertation). Retrieved from Dissertation Abstracts International. (Accession No. AAG7720620)

Sergiovanni, T. (1994). Building community. Building community in schools (pp. 91-118). San Francisco, CA: Jossey-Bass.

Simmons, J. M. (1985, March). Exploring the relationship between research and practice: The impact of assuming the role of action-researcher in one's own classroom. Paper presented at the Annual Meeting of the American Educational Research Association, Chicago, IL.

Sparks-Langer, G. M. \& Colton, A. (1991). Synthesis of research on teachers’ reflective thinking. Educational Leadership, 48(6), 37-44.

Stevens, W. (1942). Notes toward a supreme fiction. In Collected poems by Wallace Stevens. Copyright by Wallace Stevens. Alfred A. Knopf, Inc.

Stevenson, L. M., \& Deasy, R.J. (2005). Third space: When learning matters. Washington, DC: Arts Education Partnership. 
Torres-Guzmán, M. E., Hunt, V., Torres, I.M., Madrigal, R., Flecha, I., Lukas, S., Jaar, A. (2006). Teacher study groups: In search of teaching freedom. The New Educator, 2:207-226. DOI: 10.1080/15476880600820177.

Uhrmacher, B., Matthews, J. (2005). Intricate Palette. Upper Saddle River, NJ: Pearson.

Wayland, S. R. (1962). The teacher as decision-maker. In A. H. Passow (Ed.). Curriculum Crossroads (pp. 40-52). New York: Bureau of Publications, Teachers College, Columbia University.

Wayland, S. R. (1964). Structural features of American education as basic factors in innovation. In M. B. Miles (Ed.), Innovation in Education (pp. 587-613). New York: Bureau of Publications, Teachers College, Columbia University.

Wellington, B. (1991). The promise of reflective practice. Educational Leadership, 48(6), 4-5.

Wilensky, H. J. (1964). The professionalization of everyone? American Journal of Sociology, 70(9), 137-157.

Wiles, J., Bondi, J. (2000). Supervision: a guide to practice. 5th ed. Upper Saddle River, NJ: Prentiss-Hall, Inc.

Willis, S. (1999). The accountability question. ASCD [On-line], 41(7). Retrieved November 27, 2008 from http://www.ascd.org/readingroom/edupdate/1999/1nov.html.

Worthy, J. C. (1950). Organizational structure and employee morale. American Sociological Review, 15(4), 176, 169-179.

Wright, B. D., \& Tuska, S. A. (1968). From dream to life in the psychology of becoming a teacher. School Review. 
York-Barr, J., Sommers, W. A., Ghere, G. S., \& Montie, J. (2001). Essential questions. In R. Livsey, P. Cappello, D. Santoyo, \& K. Journey (Eds.), Reflective practice to improve schools (pp. 22-42, 43-58). Thousand Oaks, CA: Corwin Press, Inc.

Yudkin, J. (1989). Music in Medieval Europe. Boston University. Englewood Cliffs, NJ: Prentice Hall.

Zakaras, L. \& Lowell, J. F. (2008). Cultivating Demand for the Arts: Arts Leanring, Arts Engagement, and State Arts Policy. (Report Commissioned by Wallace Foundation, RAND Corporation). Retrieved from http://www.rand.org/pubs/monographs/2008/RAND_MG640.pdf

Zeichner, K. M. (1993). Connecting genuine teacher development to the struggle for social justice. Journal of Education for Teaching, 19(1), 8, 5-20. 


\section{Appendix A}

\section{Historical Overview of Literature Review}

\begin{tabular}{|c|c|c|c|}
\hline $\begin{array}{l}\text { Time } \\
\text { Period }\end{array}$ & Experts/Researchers & Conditions & Findings \& Salient Points \\
\hline B.C. & Yudkin & $\begin{array}{l}\text { Ancient Cultures, } \\
\text { Establishing arts curricula, } \\
\text { create new learning } \\
\text { institutions, intellectual } \\
\text { market places, }\end{array}$ & $\begin{array}{l}\text { Liberal arts curricula became integrated } \\
\text { into trivium and quadrivium; intellectual } \\
\text { centers in Paris, London; University } \\
\text { masters/students form splinter groups and } \\
\text { establish learning community with self- } \\
\text { governance and intellectual independence }\end{array}$ \\
\hline $\begin{array}{l}\text { Time } \\
\text { Period }\end{array}$ & Experts/Researchers & Conditions & Findings \& Salient Points \\
\hline $\begin{array}{l}\text { Early to } \\
\text { Mid } \\
\text { 1900s }\end{array}$ & $\begin{array}{l}\text { Raymond Callahan } \\
\text { William Callison } \\
\text { Howard Becker }\end{array}$ & $\begin{array}{l}\text { Business/Industrial Values, } \\
\text { efficient management, } \\
\text { autonomy, teacher attitudes, } \\
\text { public school authority } \\
\text { systems and bureaucracy }\end{array}$ & $\begin{array}{l}\text { Teachers recognize administrator's } \\
\text { supervisory role doing as told, status of } \\
\text { teacher as a professional, and barriers to } \\
\text { teacher independent judgment, }\end{array}$ \\
\hline $\begin{array}{l}\text { Time } \\
\text { Period }\end{array}$ & Experts/Researchers & Conditions & Findings \& Salient Points \\
\hline $\begin{array}{l}\text { Mid to } \\
\text { Late } \\
\text { 1900s }\end{array}$ & $\begin{array}{l}\text { Myron Liberman } \\
\text { Sloan Wayland } \\
\text { Henry Brickell } \\
\text { James Worthy } \\
\text { Elliot Eisner }\end{array}$ & $\begin{array}{l}\text { Teacher autonomy, } \\
\text { Bureaucratic system, } \\
\text { Teaching as a Profession, } \\
\text { Supervision/Evaluation, } \\
\text { Instructional Objectives, } \\
\text { Issues of conformity and } \\
\text { standardization }\end{array}$ & $\begin{array}{l}\text { Shared leadership, teacher associations and } \\
\text { federations, budget cuts impacted arts } \\
\text { programs, supportive administrative } \\
\text { leadership promotes teacher empowerment, } \\
\text { commitment to profession, stronger } \\
\text { teacher-pupil relationships, analyzing } \\
\text { creative boundaries, emphasis upon } \\
\text { measurable instructional objectives, teacher } \\
\text { reflection and action researcher }\end{array}$ \\
\hline $\begin{array}{l}\text { Time } \\
\text { Period }\end{array}$ & Experts/Researchers & Conditions & Findings \& Salient Points \\
\hline $\begin{array}{l}\text { Late } \\
\text { 1900s to } \\
\text { Current }\end{array}$ & $\begin{array}{l}\text { Elliot Eisner } \\
\text { James Caterall } \\
\text { Urmacher \& Matthews } \\
\text { Stevenson \& Deasy } \\
\text { DuFour \& Eaker }\end{array}$ & $\begin{array}{l}\text { Arts Associations, } \\
\text { Presidential Arts \& } \\
\text { Humanities Endowments, } \\
\text { Partnerships } \\
\text { Professional Collaborations } \\
\text { with community, Standards } \\
\text { Based Instruction, } \\
\text { Instructional Accountability, } \\
\text { Research data bases, } \\
\text { informational clearinghouses }\end{array}$ & $\begin{array}{l}\text { Community and stakeholder } \\
\text { involvement in arts education, teacher } \\
\text { accountability for adequate student } \\
\text { academic progress, teacher } \\
\text { empowerment, teacher collaboration and } \\
\text { professional learning communities } \\
\text { (PLCs), teaching to standards, } \\
\text { curriculum mapping, and standardized } \\
\text { testing, emphasis upon core subject } \\
\text { instruction, interventions for at-risk } \\
\text { students }\end{array}$ \\
\hline
\end{tabular}




\title{
Appendix B
}

\author{
Initial Interview Questions for Teachers \\ for \\ Decision Making and an Arts Integrated Curriculum
}

\section{Question \#1: Curriculum}

How do you decide what to teach?

\section{Question \#2: Instruction}

How do you decide how to teach?

\section{Question \#3: Reflection}

What professional level activities do you seek?

Describe how you incorporate ideas from professional development.

\section{Question \#4: Community}

What does the community say about your arts integrated teaching? 


\section{Appendix C}

\section{Follow up interview questions for teachers}

\section{Over arching question \#1: Demographic setting}

What professional attributes characterize an arts rich teacher?

“The portrait of teacher is blended from the palate of rich experience and unique personal attributes. These attributes have the potential to shape a teacher's views and thereby her decisions. This final set of questions will give you the opportunity to paint your own professional portrait through insight into your own professional palate.”

1. Describe yourself as a professional educator.

2. Characterize your own personal experience with the arts.

3. How do you foster your professional growth and development?

4. Describe your methods of reflective practice as a professional educator.

5. Provide a description of your classroom teaching context.

\section{Over arching question \#2: Integrate the arts}

What impacts do your beliefs and attitudes regarding commitment, satisfaction, autonomy, and change, have upon your implementation of an integrated arts curriculum?

“Teachers' beliefs and attitudes are important to the profession. They define the knowledge and experience that portray the teacher as a capable decision-maker. Every teacher makes choices based upon what they believe about their teaching situation. From your view, how do the following beliefs contribute to your decision to integrate arts into your teaching?”

6. How do you characterize your commitment to integrating the arts in your teaching?

7. Describe your level of professional teaching satisfaction.

8. What control do you have over your curriculum and instruction? 
9. Describe what influences you to make and sustain changes in your teaching.

\section{Over arching question \#3: Student learning}

Describe how you integrate the arts?

"Teachers and students have an interactive dynamic that is unique to the classroom during instruction. When teachers plan instruction, a variety of decisions come into play. The following question addresses your ideas about what part student learning plays in your teaching."

10. Tell how are you aware of student motivation, and what do you do with it? Can you provide an example?

11. Describe some ways that student motivation impacts your choices in lesson planning, curriculum design, and pacing?

12. Describe what teaching adjustments you make for students who succeed? For students who struggle?

13. How does your teaching accommodate students with special needs?

\section{Over arching question \#4: Teacher use of arts}

How do you use the arts beyond your classroom community to affect your decisions to integrate arts into the curriculum?

"Teaching has evolved over time to recognize the importance of involvement beyond the classroom. Currently, there seems to be a strong emphasis upon collaboration with professional, parent, and community. With this in mind, I'm seeking your valuable input regarding influences from outside the classroom and how these influences impact your arts instruction.”

14. When and how is parental involvement most important to your teaching? 
15. Describe community involvement in the arts and opportunities for enhancing arts instruction in your classroom.

16. Discuss interactions amongst your colleagues in regard to integrated arts instruction. Include interactions within your own school and amongst schools in your district. 


\section{Appendix D}

Student work sample checklist*

\begin{tabular}{|c|l|l|l|l|l|}
\hline CONTENT & Student \#1 & \multicolumn{1}{|l|}{ Student \#2 } & \multicolumn{1}{|l|}{ Student \#3 } & \multicolumn{1}{|l|}{ Student \#4 } \\
\hline CURRICULUM & & & & \\
\hline Reading & & & & \\
\hline Mathematics & & & & \\
\hline Social Studies & & & & \\
\hline Science & & & & \\
\hline REFLECTION & & & & \\
\hline Confidence & & & & \\
\hline Esteem & & & & \\
\hline Efficacy & & & & \\
\hline Aspiration & & & & \\
\hline COMMUNITY & & & & \\
\hline Tolerance & & & & \\
\hline Conflict resolution & & & & \\
\hline Community service & & & & \\
\hline Social problem \\
solving
\end{tabular}

*Selected elements from the April 2007 literature review “Arts Integration Frameworks, Research \& Practice by Burnaford, Brown, Doherty and McLaughlin 


\title{
Appendix E
}

\author{
Integrated Arts Course Syllabus \\ C\&I 414 \& EDUC 414: Promoting Creative Expression in \\ Early Childhood and Elementary Classrooms \\ Syllabus: Spring, 2009, Class Sessions: \\ Tuesdays: 1:00-3:50, Room 603, Dr. S. \\ Wednesdays: 1:00-3:50, Room 603, Dr. H. \\ Thursdays: 1:00-3:50, Room 511, Mrs. S. \\ Professors: Dr. S. \\ Dr. H. \\ Mrs. B. S. \\ Office Hours: By appointment \\ Welcome to a semester of creativity!
}

MIX: This course will be accompanied by the use of the web link MIX and Ecampus. Each student is responsible for checking the MIX and Ecampus websites and MIX email accounts each week during participation in this course.

Social Justice Statement: University is committed to social justice. I concur with that commitment and expect to maintain a positive learning environment based upon open communication, mutual respect, and non-discrimination. Our University does not discriminate on the basis of race, sex, age, disability, veteran status, religion, sexual orientation, color, or national origin. Any suggestions as to how to further such a positive and open environment in this class will be appreciated and given serious consideration. If you are a person with a disability and anticipate needing any type of accommodation in order to participate in this class, please advise me and make appropriate arrangements with Disability Services (2936700).

TB Clinic Requirement: Because this course requires a two-hour per week field assignment, each student must show proof of a negative TB (PPD) test. These test results are good for two years of field placements. If yours is not current, you are responsible for securing a negative test result prior to beginning your field experience. This course cannot be completed without the field component. You are responsible for bringing in your negative test results to begin your field placement.

To assist you in this requirement, a TB(PPD) clinic will be available on the following dates and times, both sessions are required [if you don't attend both the administration of the test on Tuesday and the reading of the test on Thursday, your results are not viable]:

Tuesday, January 20, anytime between 4:00 - 6:00p.m. Test Administration Thursday, January 22, anytime between 4:00-6:00p.m., Test Reading 


\section{Student Health Center, \$20.00 [cash or check only]}

\section{Description:}

This course includes an examination of creative experiences for children in elementary school, preschool-grade 6. Topics include the use of the creative arts in learning activities, curriculum development, and instructional strategies. Course experiences include teaching with, through and about the arts. A field experience of two hours per week is required.

\section{Course Objectives:}

The questions to be explored during this course include:

A. What are the roles of the arts in Pre-K-6 education?

B. How can the arts be integrated into the teaching of a variety of content areas?

C. How can the arts be used for aesthetic education?

D. How can the arts be used to develop creativity?

E. How can the arts support the diverse learning styles and multiple intelligences of students?

F. How can the arts be used to assess students' understandings and creative ideas?

G. How can creative instructional activities involve the children's families and school communities?

H. How can the arts be used to explore multicultural and global understandings?

As a result of successfully completing this course, students will be able to:

-Articulate the differences between divergent and convergent learning activities.

-Identify the characteristics of creativity.

-Describe recent research in the areas of creative thinking and children in preschool - grade 6.

-Articulate the process of facilitating the development of creativity in children from preschool to grade 6 classrooms.

-Design instructional plans that encourage creativity.

-Articulate the differences between process-oriented creative arts activities as compared to product-oriented arts activities.

-Design, teach and evaluate a process-oriented creative arts lesson that is developmentally appropriate for children at one grade level between preschool and grade 6 .

-Identify teaching methods that integrate the arts with a variety of content areas.

-Describe the manner in which the arts can be used to support a variety of learning styles and multiple intelligences of students in preschool to grade 6 classrooms.

-Design and implement a process for monitoring and assessing progress and achievement in the creative arts.

-Identify and analyze current literature on the use of the creative arts in preschool to grade 6 curricula.

-Articulate the ways in which the creative arts can meet the learning needs of diverse students in classroom settings from preschool-grade 6 .

-Plan creative instructional and assessment methods for diverse learners. 
-Design adaptations for instructional methods across a range of students' special needs.

\section{Topical Outline of Course Content: \\ [Attention all students, all sections: Visit MIX/Ecampus each week at least 1 day prior to class.]}

Jan. 13,14,15:

Jan. 20,21,22:

Jan. 27,28,29:

Feb. 3,4,5:

Feb. 10,11,12:

Feb. 17,18,19:

Feb. 24,25,26:
Introductions, Orientation to Course, Review Syllabus.

Students, who are not already scheduled for a field experience, must stay after class to complete the field experience application.

Creative brainstorming experience

To Have Read by This Date: Cornett, 1, 2

Teaching In, About, Through, and With the Arts

The Nature of the Creative Spirit

Convergent \& Divergent Thinking

Multiple Intelligences

The Arts as Ways of Knowing

To Have Read by This Date: Cornett, 1, 2

\section{Bring Draft of Lesson Plan 1}

Observation as Inquiry

Aesthetics/Developmental Concerns

Planning Creative Activities: Lesson Planning in the Arts.

To Have Read by This Date: Cornett, 6, 7

Art and the Young Child: Developmental Aspects

The Visual Arts as Ways of Knowing

Art and the Young Child: Developmental Aspects

To Have Read by This Date: Cornett, 6, 7

The Visual Arts as Ways of Knowing The Visual Arts as Methods of Assessment

Creative Expressions With the Visual Arts

-Portfolio 1 Due

To Have Read by This Date: Cornett, 12,13

Music and the Child: Developing Skills and Abilities

Creative Expression With Music

Music and Mathematics

To Have Read by This Date: Cornett, 12,13

Music as a Way of Knowing

Music as a Method of Assessment 
Mar. 3,4,5:

Mar. 10,11,12:

Mar. 17,18,19:

March 24,25,26:

Mar. 31, Apr. 1,2:

Apr. 7,8,9:

Apr. 14,15,16: in class.]

Apr. 21,22,23:

Expression

Teachers

Apr. 28,29,30:
Change Location-To Have Read by This Date: Cornett, 10, 11 Creative Movement: Developmental Concerns Creative Expression Through Dance

-Portfolio 2 Due

Change Location-To Have Read by This Date: Cornett, 10, 11 Dance as a Way of Knowing Dance as a Method of Assessment

Spring Recess

To Have Read by This Date: Cornett, 8, 9

Developmental Concerns With Drama in the Classroom Creative Expression With Drama; Creative Pantomime GLOBE Curriculum Reader's Theater

To Have Read by This Date: Cornett, 8,9

Drama as a Way of Knowing Drama as a Method of Assessment

\section{-Portfolio 3 Due}

To Have Read by This Date: Cornett, 3, Appendices A, B, C Creative Expression in the Content Areas Creative Methods of Assessment Professional and Personal Development in Creativity

Bring Puppet to Class [This will not be handed in but used

To Have Read by This Date: Cornett, 4,5

Puppetry and Children:

Construction and Application:

To Have Read by This Date: Cornett, Appendices D, E, F, G -Showcase of Creativity: Presentations of Creative Personal Projects Due [Products \& Performances]

-Final Reflections Due

The Future of Arts in Education and Teaching for Creative

Creative Expression \& the Professional Development of

Internet Class Assignment on Ecampus Virtual Class Day 


\section{$\underline{\text { May } 1}$}

\section{Do not come to class, complete webquest on Ecampus by}

\section{Description of the Learning Experiences:}

A. Description of Teaching and Learning Strategies to be included:

This course includes a variety of teaching/learning strategies: lecture, group discussion, student presentations, creative explorations in a variety of content areas, small group activities, performance activities in creative drama and puppetry and problem-solving activities.

This course includes experiences with the following creative arts: art, music, movement, drama, and puppetry. Students will create activities and/or products while exploring basic arts concepts in each area. Students will also attend and critique a creative arts performance and/or display approved by the instructor.

B. Detailed Description of Clinical Experiences or Other Special Features

This class is scheduled to take place the same semester as the EDUC 411 field practicum. Therefore, C\&I 414 \& EDUC 414 students will design, teach, and evaluate creative instructional plans for the classes in which they are placed. C\&I 414 \& EDUC 414 students will also develop plans for the integration of the arts in their placement. Field placements can be made for students that currently are not assigned to a school.

\section{Text:}

Cornett, C. (2007). Creating Meaning Through Literature and the Arts, $3^{\text {rd }}$ Edition. Columbus, OH: Merrill/Prentice-Hall.

\section{Recommended Readings:}

Campbell, B. (2008). Handbook of Differentiated Instruction Using the Multiple Intelligences. Boston, MA: Pearson Education, Inc.

Dodge, D. L. (1988). The Creative Curriculum for Early Childhood. Mt. Ramier, MD: Gryphon House.

Fraser, D. L. (1991). Playdancing. Pennington, NJ: Princeton Book Company.

Gardner, H. (1990). Art Education and Human Development. Los Angeles:

Getty Center for Education in the Arts.

Goldberg. M. (1997). Arts and Learning: An Integrated Approach to Teaching and Learning in Multicultural and Multilingual Settings. New York: Longman.

Greene, M. (1995). Releasing the Imagination. San Francisco, CA: Jossey-Bass.

Haines, J. C. \& Gerber, L. (1984). Leading Young Children to Music. Ohio: Merrill.

Hoffman, S. and Lamme, L. L. (1989). Learning from the Inside Out: The Expressive Arts. Wheaton, MD: Association for Childhood Education International.

Isenberg, J. \& Jalongo, M. (2006). Creative Thinking \& Arts-Based Learning. $4^{\text {th }}$ Ed. Upper Saddle River, NJ: Pearson/Merrill, Prentice Hall.

Jensen, E. (2001). Arts With the Brain in Mind. Alexandria, VA: Association for Supervision and Curriculum Development. 
Lasky, L. and Mukerji, R. (1980). Art: Basic for Young Children. Washington, DC: National Association for the Education of Young Children.

Mayesky, M. (2008). Creative Activities for Young Children, $9^{\text {th }}$ Ed. Boston, MA: Delmar Cengage Learning, Inc.

McCaslin, N. (1996). Creative Drama in the Classroom and Beyond. New York: Longman.

McKee, J. S. (1986). Play: Working Partner of Growth. Wheaton, MD: Association for Childhood Education International.

Rich, B. (2005). Partnering Arts Education: A Working Model From

ArtsConnection. New York, NY: The Dana Foundation.

Stewig, J. \& Buege, C. (1994). Dramatizing Literature in Whole Language

Classrooms. New York, NY: Teachers College Press.

Sullivan, M. (1982). Feeling Strong, Feeling Free: Movement Exploration for Young Children. Washington, D.C.: National Association for the Education of Young Children.

Tegano, D., Moran, J. and Sawyers, J. (1991). Creativity in Early Childhood Classrooms. Washington, DC: National Education Association.

Wachowiak, F. \& Clements, R. (1996). Emphasis Art: A Qualitative Art Program for Elementary and Middle Schools. New York: Longman.

\section{Required Assignments:}

General Requirements: Each class member is required to teach a total of four (4) lessons in an early childhood or elementary school classroom. Each lesson plan will include an integration of the visual arts, dance, drama, music and/or puppetry. These lessons can be taught in any order over the semester. Over the course of the semester, four of the five creative arts areas must be incorporated in at least one lesson plan. The lessons submitted for this class cannot be lessons submitted for a grade in another methods course, these will not receive credit in this course. Please use only a flat, plain pocket folder as your portfolio. Do not submit lessons in plastic protector sheets or three ring notebooks. Student data may be attached in a larger envelope if necessary.

Performance/Exhibit Response \& Critique: Attendance and critique of a creative arts performance [Due one week after the approved performance.]: The student will attend a performance or exhibit of one area of the creative arts. The student will also critique this performance or exhibit. Performance or exhibits are to be chosen from the College of Creative Arts Calendar of events, unless otherwise approved by your professor. If your performance is chosen outside of the Creative Arts Center calendar, and is not pre-approved by your professor, it may not count for completion of this assignment. In a 3-4 page reflection, describe the elements of the creative arts that appealed to you and why. Also describe the elements that didn't appeal to you and why. Include your ticket stub and program. Use the arts elements and terms described and used in the Cornett text for the appropriate art form. Provide an overall summary and evaluation of the event by relating what you learned through your participation as an audience member. Be explicit in your discussion of the details of the performance. Discuss the majority of the performances experienced. Refer to the handout for this assignment for further instructions. For help in choosing a performance, consult with 
the College of Creative Arts calendar found at the college website: This assignment is due within one week of attendance.

Showcase of Creativity: Presentations (during class) of Creative Personal Projects and Performances.

Weekly Class Participation: The student is expected to have all readings completed as scheduled and to contribute to class discussions by using knowledge and experiences in the field and readings. Due to the experiential nature of the course instructional methods, your significant participation in class sessions contributes to the richness of the learning experience for all.

\section{-Due in Portfolio I in Class, 2/10-12:}

Creative Personal Growth Plan and Sharing: Describe in about one half of one page, your choice of a personal creative growth plan. You may choose any arts area in which to develop your skills. You may create a project that can be used in your teaching or in your personal life. Describe:

1. What do you hope to learn?

2. How will you go about developing this skill; identify your resource person and materials resources [lessons, personal tutor, internet, instruction books, classes, family member, etc.]?

3. What product or performance will you ultimately create?

4. How you will share this with the class at the end of the semester?

Chapter Responses for Text: Cornett, Chapters: 1, 2, 6, 7. For each chapter, answer the following two questions in a one page response:

a. Describe aspects of teaching for creative expression that you learned from this chapter.

b. Describe what pedagogical elements you will apply to your teaching from this chapter. Cite specific pages and examples as appropriate [i.e. Cornett, p. 12].

Lesson 1: Plan, teach, and evaluate a lesson from any content area that integrates visual arts, dance, drama, music and/or puppetry. This lesson must also provide opportunities for creative expression for the students. Create a lesson from any content area integrating one of the arts areas to promote creative expression. Evaluate this lesson after teaching. Attach records of children's work and your assessment of their work to the completed lesson plan. Lessons receiving credit in other methods courses may not be turned in for credit in this course.

\section{Due in Portfolio II in Class, 3/3-5:}

Lesson 2: Plan, teach, and evaluate a lesson from any content area that integrates visual arts, dance, drama, music and/or puppetry. This lesson must also provide opportunities for creative expression for the students. Create a lesson from any content area integrating one of the arts areas to promote creative expression. Evaluate this lesson after teaching. Attach records of 
children's work and your assessment of their work to the completed lesson plan. $\underline{\text { Lessons }}$ receiving credit in other methods courses may not be turned in for credit in this course.

Lesson 3: Plan, teach, and evaluate a lesson from any content area that integrates visual arts, dance, drama, music and/or puppetry. This lesson must also provide opportunities for creative expression for the students. Create a lesson from any content area integrating one of the arts areas to promote creative expression. Evaluate this lesson after teaching. Attach records of children's work and your assessment of their work to the completed lesson plan. Lessons receiving credit in other methods courses may not be turned in for credit in this course.

Chapter Reflections for Text: Cornett, Chapters: 12, 13, 10, 11. For each chapter, answer the following two questions in a one page response:

a. Describe aspects of teaching for creative expression that you learned from this chapter.

b. Describe what pedagogical elements you will apply to your teaching from this chapter. Cite specific pages and examples as appropriate [i.e. Cornett, p. 12].

\section{-Due in Portfolio III in Class, 3/31-4/2:}

Lesson 4: Plan, teach, and evaluate a lesson from any content area that integrates visual arts, dance, drama, music and/or puppetry. This lesson must also provide opportunities for creative expression for the students. Create a lesson from any content area integrating one of the arts areas to promote creative expression. Evaluate this lesson after teaching. Attach records of children's work and your assessment of their work to the completed lesson plan. Lessons receiving credit in other methods courses may not be turned in for credit in this course.

Chapter Reflections for Text: Cornett, Chapters: 3, 4, 5, 8, 9. For each chapter, answer the following two questions in a one page response:

a. Describe aspects of teaching for creative expression that you learned from this chapter.

b. Describe what pedagogical elements you will apply to your teaching from this chapter. Cite specific pages and examples as appropriate [i.e. Cornett, p. 12].

\section{Due in Class, 4/21-23:}

Creative Personal Project Narrative: The final creative project is due to be shared in class, with all unsuccessful attempts as well, during classes. In your final portfolio, please submit a one to two [1-2] page paper describing:

1. How did you achieve your goals?

2. What did you learn during this process?

3. How will you use what you have learned in your teaching?

Final Reflections: Reflect on the following questions and word-process your responses in a three to four [3-4] page final reflection paper:

1. Describe 3 major elements from this course that were useful for you in developing your teaching repertoire. 
2. Describe how you have changed as a teacher, as a result of this course, in your teaching for your students' creative expression.

3. Describe how you plan to incorporate what you have learned during this course into your future teaching.

Field Evaluation and Time Sheet [if applicable]: Enclose your host teacher's final evaluation of your work in the classroom. If you have registered for the field experience separate from the course, include your signed time sheet of field visits.

\section{Evaluation/Assessment Procedures and Grading Criteria:}

This course is designed to incorporate the active participation of each student. You are considered to be a professional in your role in the field and in the course. Therefore, it is important for you to attend and contribute to each class session and each field visit. You must notify your host teacher and your professor if you are unable to attend a field visit or a class session. Field time can be made up but class session group learning experiences cannot be made up. Therefore, unexcused absences will lower your final grade. Final grades of A, B, C, D or F will be determined as a result of the average of the grades for each requirement of the course. All assignments are equally weighted. The lesson plans and field placement rubrics will be used to determine grades for each lesson plan and the overall field work. Each assignment will be assessed for content, creativity, construction (if applicable) and application of concepts and research. [See attached evaluation rubrics.] Additionally, the field grade from your host teacher will be entered into your average for the semester.

The grading scale is as follows: $A=90-100 \%, B=80-89 \%, C=70-79 \%, D=60-69 \%$, $F=$ below $60 \%$. 


\section{C\&I 414 \& EDUC 414: Promoting Creative Expression in Early Childhood \& Elementary Classrooms: Lesson Plan Rubric Evaluation Guide}

Lesson Plan Evaluation Rubric University

College of Human Resources \& Education

C\&I 414 \& EDUC 414: Promoting Creative Expression in Early Childhood \& Elementary Classrooms

Student:

Lesson Topic:

Grade Level:

In this C\&I 414 \& EDUC 414 lesson plan, this student has provided evidence of the following qualities:
4
3
2
1

0

\begin{tabular}{|c|c|c|c|c|c|}
\hline $\begin{array}{l}\text { 1.Prior } \\
\text { Approval, } \\
\text { Professional } \\
\text { Appearance } \\
\text { of Plan } \\
\text { Organization } \\
\text { of Plan }\end{array}$ & $\begin{array}{l}\text { Word-processed, } \\
\text { fully organized, } \\
\text { signed \& approved } \\
\text { by host teacher } \\
\text { prior to teaching, } \\
\text { logical order of } \\
\text { procedures, key } \\
\text { points apparent. }\end{array}$ & $\begin{array}{l}\text { Word-processed, } \\
\text { most details } \\
\text { explained, signed } \\
\text { by host teacher, } \\
\text { easy to understand. }\end{array}$ & $\begin{array}{l}\text { Word-processed, } \\
\text { basic information for } \\
\text { each part of lesson, } \\
\text { no prior approval } \\
\text { signature, somewhat } \\
\text { organized. }\end{array}$ & $\begin{array}{l}\text { Word-processed, partial } \\
\text { elements for most } \\
\text { lesson sections, } \\
\text { minimal organization. }\end{array}$ & $\begin{array}{l}\text { Yet to be } \\
\text { developed. }\end{array}$ \\
\hline $\begin{array}{l}\text { 2.Content } \\
\text { Focus }\end{array}$ & $\begin{array}{l}\text { Well-developed, } \\
\text { meaningful } \\
\text { organization, } \\
\text { CSOs identified } \\
\text { for arts \& content } \\
\text { area, content } \\
\text { represented } \\
\text { includes primary } \\
\text { focus for } \\
\text { age/grade, well } \\
\text { developed } \\
\text { resources and } \\
\text { content materials. }\end{array}$ & $\begin{array}{l}\text { Well-developed, } \\
\text { meaningful content } \\
\text { organization, } \\
\text { CSOs identified } \\
\text { for arts \& content } \\
\text { area, content } \\
\text { represented } \\
\text { includes primary } \\
\text { focus for } \\
\text { age/grade. }\end{array}$ & $\begin{array}{l}\text { Content is organized, } \\
\text { CSOs identified for } \\
\text { arts \& content area, } \\
\text { content appropriate } \\
\text { for age/grade. }\end{array}$ & $\begin{array}{l}\text { Content identified for } \\
\text { age/grade. }\end{array}$ & $\begin{array}{l}\text { Yet to be } \\
\text { developed. }\end{array}$ \\
\hline $\begin{array}{l}\text { 3. Diversity, } \\
\text { Special } \\
\text { Needs, } \\
\text { Technology, } \\
\text { Development } \\
\text { al } \\
\text { Consideratio } \\
\text { ns. }\end{array}$ & $\begin{array}{l}\text { Lesson includes } \\
\text { complete } \\
\text { reflections and } \\
\text { detailed consid- } \\
\text { erations of these } \\
\text { areas in context of } \\
\text { lesson objectives } \\
\text { and child develop- } \\
\text { ment knowledge. } \\
\text { Provisions for } \\
\text { teaching } \\
\text { differentiation are } \\
\text { fully described. }\end{array}$ & $\begin{array}{l}\text { Lesson includes } \\
\text { some reflections } \\
\text { and considerations } \\
\text { of these areas in } \\
\text { context of lesson } \\
\text { objectives and } \\
\text { child development } \\
\text { knowledge. } \\
\text { Provisions for } \\
\text { teaching } \\
\text { differentiation are } \\
\text { described. }\end{array}$ & $\begin{array}{l}\text { Lesson includes a } \\
\text { consideration of these } \\
\text { areas in context of } \\
\text { lesson objectives \& } \\
\text { child development } \\
\text { knowledge. } \\
\text { Provisions for } \\
\text { teaching } \\
\text { differentiation are } \\
\text { mentioned. }\end{array}$ & $\begin{array}{l}\text { Lesson includes } \\
\text { consideration of these } \\
\text { areas in context of } \\
\text { lesson objectives \& } \\
\text { child development } \\
\text { knowledge. }\end{array}$ & $\begin{array}{l}\text { Yet to be } \\
\text { developed. }\end{array}$ \\
\hline 4. Objectives & $\begin{array}{l}\text { These are well- } \\
\text { described and } \\
\text { written in clear, } \\
\text { concise, organized, } \\
\text { observable, } \\
\text { developmentally } \\
\text { appropriate, \& }\end{array}$ & $\begin{array}{l}\text { These are } \\
\text { described and } \\
\text { written in clear, } \\
\text { organized, } \\
\text { observable, } \\
\text { developmentally } \\
\text { appropriate, \& }\end{array}$ & $\begin{array}{l}\text { These are provided } \\
\text { and written in } \\
\text { understandable \& } \\
\text { developmentally } \\
\text { appropriate terms. }\end{array}$ & $\begin{array}{l}\text { These are provided in } \\
\text { basic form. }\end{array}$ & $\begin{array}{l}\text { Yet to be } \\
\text { developed. }\end{array}$ \\
\hline
\end{tabular}




\begin{tabular}{|c|c|c|c|c|c|}
\hline & $\begin{array}{l}\text { easily assessable } \\
\text { terms. }\end{array}$ & assessable terms. & & & \\
\hline $\begin{array}{l}5 . \\
\text { Procedures }\end{array}$ & $\begin{array}{l}\text { These are well } \\
\text { described in clear, } \\
\text { organized, and } \\
\text { detailed terms. } \\
\text { Procedures match } \\
\text { objectives \& are } \\
\text { listed in order } \\
\text { according to } \\
\text { objectives with } \\
\text { replicatable detail. }\end{array}$ & $\begin{array}{l}\text { These are } \\
\text { described in clear, } \\
\text { organized, terms. } \\
\text { Procedures match } \\
\text { objectives \& are } \\
\text { listed in order } \\
\text { according to } \\
\text { objectives with } \\
\text { detail. }\end{array}$ & $\begin{array}{l}\text { These are described } \\
\text { in clear, } \\
\text { chronological, and } \\
\text { organized terms. }\end{array}$ & $\begin{array}{l}\text { These are described in } \\
\text { order. }\end{array}$ & $\begin{array}{l}\text { Yet to be } \\
\text { developed. }\end{array}$ \\
\hline 6. Creativity & $\begin{array}{l}\text { Lesson activities } \\
\text { provide many } \\
\text { effective } \\
\text { opportunities for } \\
\text { authentic and } \\
\text { innovative student } \\
\text { engagement in } \\
\text { creative processes. }\end{array}$ & $\begin{array}{l}\text { Lesson activities } \\
\text { provide some } \\
\text { opportunities for } \\
\text { authentic student } \\
\text { engagement in } \\
\text { creative processes. }\end{array}$ & $\begin{array}{l}\text { Lesson activities } \\
\text { provide one } \\
\text { opportunity for } \\
\text { student engagement } \\
\text { in creative processes. }\end{array}$ & $\begin{array}{l}\text { Lesson activities } \\
\text { provide limited student } \\
\text { engagement in creative } \\
\text { processes. }\end{array}$ & $\begin{array}{l}\text { Yet to be } \\
\text { developed. }\end{array}$ \\
\hline $\begin{array}{l}\text { 7. Provides } \\
\text { plan for } \\
\text { assessment } \\
\text { of students. }\end{array}$ & $\begin{array}{l}\text { Plans for } \\
\text { assessment are } \\
\text { well described; } \\
\text { procedures for } \\
\text { collecting student } \\
\text { data are clear, } \\
\text { detailed, and } \\
\text { developmentally } \\
\text { appropriate for } \\
\text { each objective } \\
\text { listed. }\end{array}$ & $\begin{array}{l}\text { Plans for } \\
\text { assessment are } \\
\text { well described; } \\
\text { procedures for } \\
\text { collecting student } \\
\text { data are clear and } \\
\text { developmentally } \\
\text { appropriate for all } \\
\text { objectives listed. }\end{array}$ & $\begin{array}{l}\text { Plans for assessment } \\
\text { are described; } \\
\text { procedures for } \\
\text { collecting student } \\
\text { data are appropriate } \\
\text { for some objectives. }\end{array}$ & $\begin{array}{l}\text { Plans for some } \\
\text { assessment are provided } \\
\text { in basic form. }\end{array}$ & $\begin{array}{l}\text { Yet to be } \\
\text { developed. }\end{array}$ \\
\hline $\begin{array}{l}8 . \\
\text { Effectively } \\
\text { assesses } \\
\text { student } \\
\text { performance } \\
\text { in creative } \\
\text { expression \& } \\
\text { content. }\end{array}$ & $\begin{array}{l}\text { Evidence is } \\
\text { provided in clear, } \\
\text { organized, detailed } \\
\text { terms, for each } \\
\text { child for each } \\
\text { objective. }\end{array}$ & $\begin{array}{l}\text { Evidence is } \\
\text { provided in clear } \\
\text { terms, for each } \\
\text { child for each } \\
\text { objective. }\end{array}$ & $\begin{array}{l}\text { Evidence is provided } \\
\text { for each child for } \\
\text { some objectives. }\end{array}$ & $\begin{array}{l}\text { Evidence is provided } \\
\text { for some children for } \\
\text { some objectives. }\end{array}$ & $\begin{array}{l}\text { Yet to be } \\
\text { developed. }\end{array}$ \\
\hline $\begin{array}{l}\text { 9. Provides } \\
\text { summaries } \\
\text { of student } \\
\text { data. }\end{array}$ & $\begin{array}{l}\text { Data are } \\
\text { summarized to } \\
\text { include data from } \\
\text { each student for } \\
\text { each objective . } \\
\text { Fully developed } \\
\text { reflective \& } \\
\text { evaluative } \\
\text { statements on } \\
\text { whole class } \\
\text { progress are } \\
\text { provided. }\end{array}$ & $\begin{array}{l}\text { Data are } \\
\text { summarized to } \\
\text { include data from } \\
\text { each student for } \\
\text { each objective. } \\
\text { Some reflective \& } \\
\text { evaluative } \\
\text { statements on } \\
\text { whole class } \\
\text { progress are } \\
\text { provided. }\end{array}$ & $\begin{array}{l}\text { Some data are } \\
\text { summarized so } \\
\text { reflective \& } \\
\text { evaluative statements } \\
\text { on whole class } \\
\text { progress are } \\
\text { provided. }\end{array}$ & $\begin{array}{l}\text { Some partial class data } \\
\text { are provided. }\end{array}$ & $\begin{array}{l}\text { Yet to be } \\
\text { developed. }\end{array}$ \\
\hline $\begin{array}{l}10 . \\
\text { Effectively } \\
\text { completes } \\
\text { self- } \\
\text { reflection. }\end{array}$ & $\begin{array}{l}\text { Narrative provides } \\
\text { detailed answers } \\
\text { for all self- } \\
\text { reflection } \\
\text { questions in and } \\
\text { includes references } \\
\text { to lesson activities } \\
\text { and student } \\
\text { assessment data. }\end{array}$ & $\begin{array}{l}\text { Narrative provided } \\
\text { answers for self- } \\
\text { reflection } \\
\text { questions and } \\
\text { includes references } \\
\text { to lesson activities } \\
\text { and student } \\
\text { assessment data. }\end{array}$ & $\begin{array}{l}\text { Narrative provided } \\
\text { short answers for all } \\
\text { self-reflection } \\
\text { questions. }\end{array}$ & $\begin{array}{l}\text { Some self-reflection } \\
\text { questions are addressed. }\end{array}$ & $\begin{array}{l}\text { Yet to be } \\
\text { developed. }\end{array}$ \\
\hline
\end{tabular}


Key:

4=Outstanding, 3=Well Developed, 2=Satisfactory, 1=Still Developing, 0=Not in Evidence

Grading Scale:

$\mathrm{A}=90-100 \%, \mathrm{~B}=80-89 \%, \mathrm{C}=70-79 \%, \mathrm{D}=60-69 \%, \mathrm{~F}=$ below $60 \%$;

Performance assessment on this lesson plan and evaluation:

Grade:___ Additional Comments

\section{C\&I 414 \& EDUC 414: Promoting Creative Expression in Early Childhood and Elementary Classrooms \\ Performance/Exhibit Response \& Critique Guidelines}

For this assignment, you are required to attend a creative arts performance or exhibit. A calendar of events from the Creative Arts Center is provided at http://calendar.edu/ccarts/ for you to use as a list of appropriate choices for this assignment. If you prefer to choose an exhibit or a performance not listed on this calendar please check with your professor for approval of the selection prior to purchasing tickets.

While attending the chosen event, you may want to take program notes to record your impressions of each piece or selection. In your critique, describe the selection that impressed you and the reasons for your reactions. Also, include a description of the selections that you found difficult to enjoy or understand and why. Your critique needs to include a discussion of a majority of the performance selections with explicit detail of each arts element experienced. Be sure to note composers, musical titles, style elements, etc., [For instance, "The dancers were wearing basic tunics with different hues of the green spectrum to reflect the nature of the musical selection, the violin concerto, Spring by Vivaldi.”]

Please turn in a program and ticket stub from the event with your critique.

You may want to consider the following concepts in your critiques:

\section{Musical Performances:}

\begin{tabular}{llll}
\hline Rhythm & Melody & Tone & Color \\
Technique & Unity of Performing Group & Preparation \\
Organization & Musical Selections [Programming & Timing \\
Audience Appeal & Skill & Aesthetic Appeal & Program Balance
\end{tabular}




\section{Art Exhibit:}

\begin{tabular}{llll}
\hline Skill & Line & Texture Color & Preparation \\
Organization & Aesthetic Appeal & Audience Appeal & Technique \\
Display & Lighting & Message from Artist & Arrangement of \\
& & & Pieces
\end{tabular}

\section{Dance Performance:}

\begin{tabular}{llll}
\hline Preparation & Organization & Technique & Skill \\
Lighting & Unity of Performers & Audience Appeal & Aesthetic Appeal \\
Costumes & Musical Selection & Programming & Visual Presentation
\end{tabular}

\section{Play/Opera/Musical:}

\begin{tabular}{|c|c|c|c|}
\hline Preparation & Organization & Costumes & Lighting \\
\hline Dramatic Interpreta & & Unity of Performers & Skills \\
\hline Projection [Voice] & Make-Up & Characterization & Aesthetic Appeal \\
\hline Visual Presentation & Sound System & & \\
\hline
\end{tabular}

\section{Puppetry Production:}

\begin{tabular}{|c|c|c|c|}
\hline Preparation & Organization & Costumes & Lighting \\
\hline Dramatic Interpreta & & Unity of Performers & Skills \\
\hline Projection [Voice] & Make-Up & Characterization & Aesthetic Appeal \\
\hline Visual Presentation & Sound System & Puppet Design & Puppet Construction \\
\hline
\end{tabular}

\section{LESSON PLAN FORMAT: C\&I/EDUC 414}

University Teacher Education

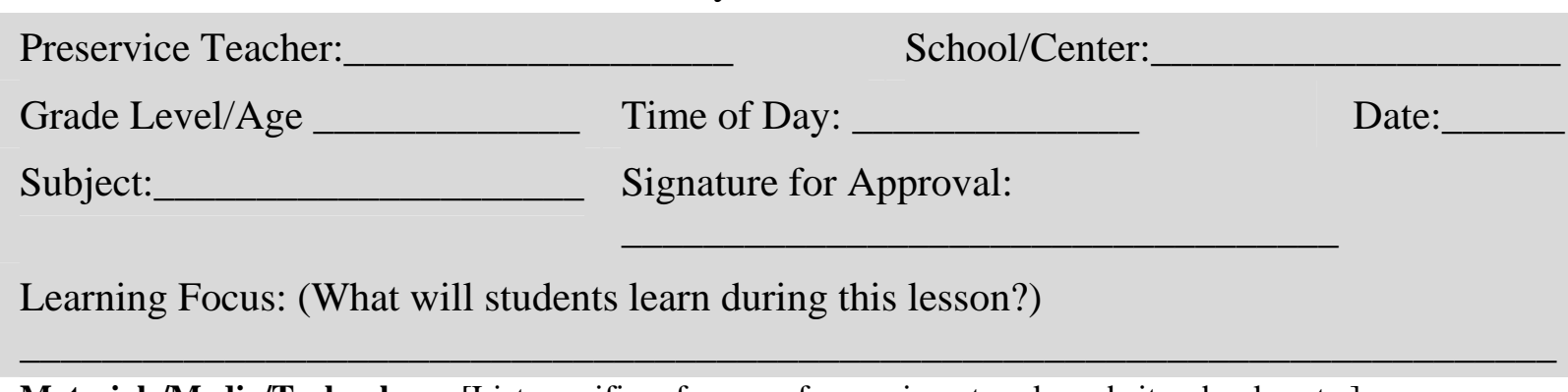

Materials/Media/Technology: [List specific references for music, artwork, websites, books, etc.]

Learner Differences: [Describe learning differences - including special needs and diversity present in this class and how you plan to differentiate your instruction and assessment for these students.]

State Standards \& Objectives: [List by number and in narrative.]

Arts Preparation: [What will you need to prepare, rearrange, organize, set up, and/or divide into containers ahead of the arts processes used in this lesson?] 


\begin{tabular}{|l|l|}
\hline $\begin{array}{l}\text { Objectives: [Specifically, what will students be } \\
\text { able to do? Make these concise, observable and } \\
\text { assessable.] }\end{array}$ & $\begin{array}{l}\text { Assessment: [Assessments must match } \\
\text { objectives. Describe how you will collect } \\
\text { student data to assess each objective. Attach } \\
\text { student data for each child for each } \\
\text { objective.] }\end{array}$ \\
The students will: & The teacher will: \\
\hline 1. & 1. \\
\hline 2. & 2. \\
\hline 3. & 3. \\
\hline
\end{tabular}

Procedures: [Describe completely, list in order in clear, concise statements.

Introduction [How will you, the teacher, get students interested in the lesson?]

1.

2 .

Instruction/Activities [What will you do? What will students do? Include your teaching strategies and transitions.]

3.

4.

5.

Closure [How will you bring closure to the lesson?] 6.

7.

Self-reflection questions: [Complete after you teach this lesson.]

1. Based on your reflection on the attached student assessment data, what do you think the students learned during your lesson, and how do you know? [Refer to attach summaries of student data.]

2. What went well during this lesson, and how do you know?

3. What would you do differently the next time you teach this lesson and why?

4. Summarize what you learned about teaching from this experience.

\section{Host Teacher Feedback Form}

University

College of Human Resources \& Education

C\&I 414 \& EDUC 414: Promoting Creative Expression in

Early Childhood \& Elementary Classrooms

Final Field Evaluation

Student: Placement/Grade: 
In the C\&I 414 \& EDUC 414 field experience; this student has demonstrated these characteristics in my classroom:

\begin{tabular}{|l|l|l|l|l|l|}
\hline $\begin{array}{l}\text { 1. Demonstrates dependable } \\
\text { attendance, arrives on time. }\end{array}$ & & & & & \\
\hline 2. Acts professionally. & & & & & \\
\hline $\begin{array}{l}\text { 4. Demonstrates thorough } \\
\text { planning and organization. }\end{array}$ & & & & & \\
\hline $\begin{array}{l}\text { 4. Plans lessons around meaningful } \\
\text { \& appropriate content. }\end{array}$ & & & & & \\
\hline $\begin{array}{l}\text { 5. Interacts positively with students. } \\
\text { 6. Encourages creative expression } \\
\text { with students' ideas. }\end{array}$ & & & & & \\
\hline 7. Effectively teaches lessons. & & & & & \\
\hline $\begin{array}{l}\text { 8. Effectively teaches lessons which } \\
\text { promote creative expression. }\end{array}$ & & & & & \\
\hline $\begin{array}{l}\text { 9. Effectively assesses student } \\
\text { performance in creative expression. }\end{array}$ & & & & & \\
\hline 10. Overall Effectiveness in Field & & & & & \\
\hline
\end{tabular}

Key: 4=Outstanding, 3=Well Developed, 2=Satisfactory, 1=Still Developing, 0=Not in Evidence Outstanding Very Good Satisfactory Still Developing Incomplete

Additional Comments:

Host Teacher Signature: Date: 
C\&I 414 \& EDUC 414: Promoting Creative Expression in

Early Childhood \& Elementary Classrooms

Field Experience Time Sheet

Student Name:

Placement:

\begin{tabular}{|l|l|l|l|}
\hline \multicolumn{1}{|c|}{ Date } & Time In & Time Out & Teacher Signature \\
\hline 1. & & & \\
\hline 2. & & & \\
\hline 3. & & & \\
\hline 4. & & & \\
\hline 5. & & & \\
\hline 6. & & & \\
\hline 7. & & & \\
\hline 8. & & & \\
\hline 9. & & & \\
\hline 10. & & & \\
\hline 11. & & & \\
\hline 12. & & & \\
\hline 13. & & & \\
\hline 14. & & & \\
\hline
\end{tabular}

Total Hours: 


\section{Appendix F}

\section{Participants’ Demographic Matrix}

\begin{tabular}{|c|c|c|c|c|c|c|c|c|}
\hline TEACHER & $\overline{\mathrm{SCHOOL}}$ & $\begin{array}{c}\text { EX- } \\
\text { PERIENCE }\end{array}$ & DEGREE & $\overline{\text { GRADE }}$ & CERTIFICATE & $\begin{array}{c}\text { SPECIAL } \\
\text { TRAINING }\end{array}$ & $\begin{array}{c}\text { PROFESSIONAL } \\
\text { SERVICE } \\
\text { COMMITTEE }\end{array}$ & $\begin{array}{l}\text { PRIOR } \\
\text { ARTS } \\
\end{array}$ \\
\hline Antonella & $\begin{array}{l}\text { Bickle } \\
\text { Creek }\end{array}$ & 14 & MA & $\begin{array}{l}\text { PK, K, } \\
1,2\end{array}$ & $\begin{array}{c}\text { Elem, ECE, } \\
\text { N-K }\end{array}$ & $\begin{array}{l}\text { Reading } \\
\text { First, } \\
\text { Teacher } \\
\text { Leader }\end{array}$ & None Listed & $\begin{array}{l}\text { Dance, } \\
\text { flute in } \\
\text { HS }\end{array}$ \\
\hline Celine & $\begin{array}{l}\text { Riffe } \\
\text { Park }\end{array}$ & 22 & MA & $4,5,6$ & $\begin{array}{l}\text { Elem, SPED, } \\
\text { Science }\end{array}$ & NA & $\begin{array}{c}\text { Sch Improv } \\
\text { Council }\end{array}$ & Dance, \\
\hline Veronica & $\begin{array}{l}\text { Riffe } \\
\text { Park }\end{array}$ & 32 & $\mathrm{MA}+45$ & $\mathrm{~K}, 1,5$ & $\begin{array}{l}\text { ECE, K-8, } \\
\text { SPED, BD }\end{array}$ & Computer & $\begin{array}{c}\text { Faculty Senate, } \\
\text { School Imp } \\
\text { Council }\end{array}$ & None \\
\hline Kara & $\begin{array}{l}\text { Selena } \\
\text { M. Day }\end{array}$ & 37 & $\mathrm{MA}+45$ & $\mathrm{~K}, 1$ & PK-8 & $\begin{array}{l}\text { Teacher } \\
\text { Ed Prog }\end{array}$ & $\begin{array}{l}\text { Foundation } \\
\text { Committee }\end{array}$ & $\begin{array}{c}\text { Piano } \\
\text { Lessons }\end{array}$ \\
\hline Carline & $\begin{array}{l}\text { Selena } \\
\text { M. Day }\end{array}$ & 23 & BA+ & $\begin{array}{c}1,3,5 \\
3 / 4\end{array}$ & $\begin{array}{l}\text { Elem, Sci, } \\
\text { S.St. }\end{array}$ & Writing & $\begin{array}{c}\text { Staff Dev. } \\
\text { Council }\end{array}$ & NA \\
\hline Janice & $\begin{array}{l}\text { Selena } \\
\text { M. Day }\end{array}$ & 44 & $\mathrm{MA}+45$ & $\mathrm{~K}, 1,3$ & Elem & $\begin{array}{c}\text { K-3 } \\
\text { Trainer, } \\
\text { 4MAT }\end{array}$ & $\begin{array}{l}\text { Foundation } \\
\text { Committee }\end{array}$ & None \\
\hline Kate & $\begin{array}{l}\text { Selena } \\
\text { M. Day }\end{array}$ & 30 & $\mathrm{MA}+30$ & $\begin{array}{c}\mathrm{N}, \mathrm{K}, 1, \\
2\end{array}$ & Elem, ECE & $\begin{array}{l}\text { Curric, } \\
\text { 4MAT }\end{array}$ & $\begin{array}{c}\text { Pre Service } \\
\text { Teachers, Gov. } \\
\text { committee }\end{array}$ & $\begin{array}{c}\text { Band in } \\
\text { H.S. }\end{array}$ \\
\hline Ida & $\begin{array}{l}\text { Selena } \\
\text { M. Day }\end{array}$ & 28 & MA & 1,3 & $\begin{array}{l}\text { Elem K-8, } \\
\text { Rdng K-12 }\end{array}$ & $\begin{array}{c}\text { Foxfire, } \\
\text { 4Mat }\end{array}$ & $\begin{array}{l}\text { Foundation } \\
\text { Committee }\end{array}$ & $\begin{array}{c}\text { Dance, } \\
\text { Band }\end{array}$ \\
\hline
\end{tabular}

\section{Demographic Summary}

- Years of experience: low 14 years; high 44 years

- Degree: BA+ through MA+45

- Certifications: all have elementary education; 2 special education; 1 reading specialist; 2 early childhood; 2 science specializations

- Specialized Training: 7 teachers list specialized trainings including computer, Reading First, reading/writing, Foxfire, 4MAT, Teacher Education, Teacher Leader

- Service on committees: 7 teachers list service on professional committees including school improvement council, faculty senate, foundation, staff development council, preservice teacher committee

- Prior Arts Training: 5 teachers have training, 2 teachers have no prior training, 1 teacher gives no answer; training includes piano and dance lessons, band in high school

- Grades taught: 7 teachers taught first grade, 5 teachers taught kindergarten, 3 teachers taught fifth grade

- Education: 7 teachers were educated at the local university 


\section{Appendix G}

\section{Summary of Artwork Connections to Teacher Decision Making*}

\begin{tabular}{|c|c|c|c|c|c|}
\hline Figure & Description & Curriculum & Instruction & Reflection & Community \\
\hline 1 & Diorama & RLA/ SCI & $\begin{array}{c}\text { Interpreting } \\
\text { Text }\end{array}$ & $\begin{array}{l}\text { Aspiration, } \\
\text { Confidence, } \\
\text { esteem, }\end{array}$ & $\begin{array}{l}\text { Community } \\
\text { service, } \\
\text { conflict } \\
\text { resolution, } \\
\text { social } \\
\text { problem } \\
\text { solving }\end{array}$ \\
\hline 2 & Group Poster & RLA/Sci & $\begin{array}{l}\text { Interpreting } \\
\text { Text, Writing } \\
\text { research, } \\
\text { Graphics }\end{array}$ & $\begin{array}{l}\text { Confidence, } \\
\text { Efficacy }\end{array}$ & $\begin{array}{l}\text { Community } \\
\text { service, } \\
\text { social } \\
\text { problem } \\
\text { solving }\end{array}$ \\
\hline 3 & Puppet & RLA/SS & $\begin{array}{l}\text { Interpreting } \\
\text { Text, Writing }\end{array}$ & $\begin{array}{l}\text { Confidence, } \\
\text { Esteem }\end{array}$ & $\begin{array}{l}\text { Tolerance, } \\
\text { social } \\
\text { problem } \\
\text { solving, } \\
\text { conflict- } \\
\text { resolution }\end{array}$ \\
\hline 4 & $\begin{array}{c}\text { Sea Life Torn Paper } \\
\text { Art }\end{array}$ & $\begin{array}{l}\text { RLA, Writing, } \\
\text { SS, SCI }\end{array}$ & $\begin{array}{l}\text { Writing, } \\
\text { interpreting } \\
\text { text }\end{array}$ & $\begin{array}{l}\text { Confidence, } \\
\text { esteem } \\
\text { efficacy, } \\
\text { aspiration }\end{array}$ & $\begin{array}{l}\text { Community } \\
\text { service, } \\
\text { social } \\
\text { problem } \\
\text { solving }\end{array}$ \\
\hline 5 & Healthy Pizza Pie & $\begin{array}{l}\text { RLA, SS, } \\
\text { Health, SCI }\end{array}$ & $\begin{array}{c}\text { Interpreting } \\
\text { text }\end{array}$ & $\begin{array}{l}\text { Efficacy, } \\
\text { confidence, } \\
\text { aspiration }\end{array}$ & $\begin{array}{l}\text { Social } \\
\text { problem } \\
\text { solving, } \\
\text { tolerance }\end{array}$ \\
\hline 6 & $\begin{array}{c}\text { Hieroglyphics Journal } \\
\text { Entry }\end{array}$ & $\begin{array}{l}\text { RLA, Writing, } \\
\text { SS, MA }\end{array}$ & $\begin{array}{l}\text { Writing, } \\
\text { interpreting } \\
\text { text, graphics, } \\
\text { codes }\end{array}$ & $\begin{array}{l}\text { Confidence, } \\
\text { esteem, } \\
\text { efficacy, } \\
\text { aspiration }\end{array}$ & $\begin{array}{l}\text { Community } \\
\text { service, } \\
\text { social } \\
\text { problem } \\
\text { solving, } \\
\text { tolerance } \\
\end{array}$ \\
\hline 7 & $\begin{array}{c}\text { Four Seasons Weather } \\
\text { Drawing }\end{array}$ & $\begin{array}{l}\text { RLA, Writing, } \\
\text { SCI }\end{array}$ & $\begin{array}{c}\text { Writing, } \\
\text { interpreting } \\
\text { text }\end{array}$ & $\begin{array}{l}\text { Confidence, } \\
\text { esteem, } \\
\text { efficacy }\end{array}$ & $\begin{array}{l}\text { Community } \\
\text { service }\end{array}$ \\
\hline 8 & $\begin{array}{l}\text { Bandy Snatcher } \\
\text { Sketch }\end{array}$ & RLA & $\begin{array}{l}\text { Writing, } \\
\text { interpreting } \\
\text { text, graphics }\end{array}$ & $\begin{array}{l}\text { Confidence, } \\
\text { esteem, } \\
\text { efficacy }\end{array}$ & $\begin{array}{l}\text { Community } \\
\text { service, } \\
\text { social } \\
\text { problem } \\
\text { solving }\end{array}$ \\
\hline
\end{tabular}




\begin{tabular}{|c|c|c|c|l|l|}
\hline Figure & Description & Curriculum & Instruction & Reflection & Community \\
\hline 9 & Student Masks & RLA, SS & $\begin{array}{c}\text { Interpreting } \\
\text { text, graphics, } \\
\text { codes }\end{array}$ & $\begin{array}{l}\text { Social } \\
\text { problem } \\
\text { solving, } \\
\text { community } \\
\text { service, } \\
\text { tolerance }\end{array}$ \\
\hline \multirow{2}{*}{10} & $\begin{array}{c}\text { Impressionist Water } \\
\text { Color Style }\end{array}$ & RLA, SS & $\begin{array}{c}\text { Interpreting } \\
\text { text, writing, } \\
\text { graphics }\end{array}$ & $\begin{array}{l}\text { Confidence, } \\
\text { esteem, } \\
\text { efficacy, } \\
\text { aspiration }\end{array}$ & $\begin{array}{l}\text { Social } \\
\text { problem } \\
\text { solving, } \\
\text { tolerance }\end{array}$ \\
\hline & $\begin{array}{c}\text { Divergent Thinking } \\
\text { Sketching Activity }\end{array}$ & RLA, MA, SS, & $\begin{array}{c}\text { Writing, text } \\
\text { interpretation, } \\
\text { graphics, codes }\end{array}$ & $\begin{array}{l}\text { Confidence, } \\
\text { efficacy, } \\
\text { aspiration }\end{array}$ & $\begin{array}{l}\text { Community } \\
\text { service, } \\
\text { Social } \\
\text { problem } \\
\text { solving, } \\
\text { tolerance }\end{array}$ \\
\hline
\end{tabular}

*Selected elements from the April 2007 literature review “Arts Integration Frameworks, Research \& Practice by Burnaford, Brown, Doherty and McLaughlin

\begin{tabular}{|l|l|}
\hline \multicolumn{1}{|c|}{ CURRICULUM: } & \multicolumn{1}{c|}{ INSTRUCTION: } \\
ALL READING LANGUAGE ARTS & ALL INTERPRETING TEXT \\
8 SOCIAL STUDIES & (READING) \\
6 SCIENCE & 6 WRITING/RESEARCH \\
4 WRITING & 6 GRAPHICS \\
2 MATH & 3 CODES \\
1 HEALTH & \multicolumn{1}{|c|}{ COMMUNITY: } \\
8 REFLECTION: & ALL SOCIAL PROBLEM SOLVING \\
12 CONFIDENCE & 9 COMMUNITY SERVICE \\
10 EFFICACY & 3 CONFLICT RESOLUTION \\
9 ESTEEM & 2 TOLERANCE \\
\hline
\end{tabular}




\section{Appendix $\mathrm{H}$}

\section{Summary of Implications with Supporting Narratives}

\begin{tabular}{|c|c|l|}
\hline TOPIC & IMPLICATION & SUPPORTING NARRATIVE AND QUOTES \\
\hline CURRICULUM & $\begin{array}{c}\text { TEACHERS ARE OK } \\
\text { WITH USING } \\
\text { STANDARDS }\end{array}$ & $\begin{array}{l}\text { lontrary to what critics say (Myers) teachers say that } \\
\text { content is what they teach and plan for their classroom } \\
\text { instruction. Standards provide support for teachers. } \\
\text { Standards are not negative. Standards are a way of } \\
\text { organizing pedagogy. }\end{array}$ \\
\hline INSTRUCTION & $\begin{array}{c}\text { THE PLACE WHERE } \\
\text { TEACHER HAS } \\
\text { AUTONOMY }\end{array}$ & $\begin{array}{l}\text { Instructional planning and delivery are necessary } \\
\text { reflective activities. Teachers are happy designing and } \\
\text { delivering engaging lessons to their students. Teachers } \\
\text { view instruction as a way to met individual student }\end{array}$ \\
needs and to become involved with the community.
\end{tabular}




\section{Summary of Implications with Supporting Narratives (Continued)}

\begin{tabular}{|c|c|c|}
\hline TOPIC & IMPLICATION & SUPPORTING NARRATIVE AND QUOTES \\
\hline $\begin{array}{c}\text { PROFESSIONAL } \\
\text { DEVELOPMENT } \\
\text { PROVIDERS }\end{array}$ & $\begin{array}{l}\text { OBLIGATION TO HEAR } \\
\text { TEACHER NEEDS }\end{array}$ & $\begin{array}{l}\text { It is OK to roll out large district workshops, but first } \\
\text { importance is connecting teachers and learners’ needs. } \\
\text { Provide teachers with opportunities for classroom } \\
\text { embedded professional development. Providers need to } \\
\text { value collaborative time for professional development. }\end{array}$ \\
\hline $\begin{array}{l}\text { POLICY } \\
\text { MAKERS }\end{array}$ & $\begin{array}{c}\text { CONTINUE } \\
\text { STANDARDS WITH } \\
\text { INTEGRITY }\end{array}$ & $\begin{array}{l}\text { Provide standards that focus on arts integration. Uphold } \\
\text { decisions to provide training in teacher preparation } \\
\text { programs to support new teachers' acquisition of arts } \\
\text { integrated teaching strategies. Provide collaborative } \\
\text { planning opportunities so that new teachers realize that art } \\
\text { is a means to conveying content. }\end{array}$ \\
\hline $\begin{array}{l}\text { IMPLICATIONS } \\
\text { FOR } \\
\text { RESEARCHER }\end{array}$ & $\begin{array}{l}\text { FROM TEACHER TO } \\
\text { PROFESSIONAL } \\
\text { DEVELOPER, } \\
\text { TEACHER LEARNER } \\
\text { FRAMEWORK }\end{array}$ & $\begin{array}{l}\text { As planner for district professional development, I need to } \\
\text { build a bridge between what teachers need to know and } \\
\text { the changes that teachers will accept and sustain. Support } \\
\text { classroom teachers with time, human and fiscal resources, } \\
\text { and connections to community in order to implement arts } \\
\text { integration. }\end{array}$ \\
\hline $\begin{array}{c}\text { INTEGRATION } \\
\text { OF ART }\end{array}$ & $\begin{array}{l}\text { INSTRUCTIONAL } \\
\text { MANDATES }\end{array}$ & $\begin{array}{l}\text { Teachers believe that arts integration is backed up by their } \\
\text { standards. Teachers feel constrained by the demands of } \\
\text { teaching core instruction in reading and math, but view } \\
\text { arts integration as a solution. Teachers who have received } \\
\text { staff development in arts integration realize they do not } \\
\text { have to be artists to provide arts instruction. }\end{array}$ \\
\hline
\end{tabular}




\section{Appendix I}

\section{Summary Sample of Data Findings by Question Framework}

\section{QUESTION ON CURRICULUM: HOW DO YOU DECIDE WHAT TO TEACH?}

CONCLUSION FINDINGS: Teachers are comfortable using the content standards documents and as guides for deciding what to teach:

\section{TEACHER EVIDENCE:}

... from that (the standards), I can tell what to teach, too, and even get ideas for things to add to my lessons (Antonella)

... My job is to teach them what the state says I need to teach them. (Celine)

... I feel like you can still teach your goals and objectives through play, art, and through music. (Kara)

... What you are going to teach is pretty much dictated by those (the standards) (Carline)

... Each voice knows how to relate our Content Standards and Objectives and to connect to the content (Janice)

... We knew that the CSOs were in our lessons somewhere. (Ida)

\section{QUESTION ON INSTRUCTION: HOW DO YOU DECIDE HOW TO TEACH?}

CONCLUSION FINDINGS: Teachers exercise their autonomy, their pedagogical knowledge, and knowledge of their students to determine their unique instructional delivery, planning, and teaching strategies.

\section{TEACHER EVIDENCE:}

... I want it to be fun ... I want them to be able to do some problem-solving . . I look at the overall theme of the week and go from there (Antonella)

... I think according to each of the groups, that you have to set up your guidelines. (Veronica)

... As for instruction, that is pretty much based on the children's needs . . . Also, it depends from year to year ... Also, it is on their interest . . . It depends a lot on the students. (Kara) ... I guess it depends on the kinds of children you have ... So if it takes more hands-on activity, then I do the kinds of things where they're not just sitting in their seats. (Carline) ... Because we had the background of learning styles, and we studies those intensively, then through the integrations of arts we understood those traditional learners, too. (Kate)

... It seems to never fail that once we get started on a unit, we would always go back and fill In what the objectives were. (Janice)

... The other thing is that we were in charge of our day. So, if we wanted to spend all day (on a lesson) and occasionally we did. (Ida) 


\section{Summary Sample of Data Findings by Question Framework (Continued)}

QUESTION ON DECISION MAKING: PROFESSIONAL DEVELOPMENT

CONCLUSION FINDINGS: Teachers make conscious choices on what they want and need for professional development.

TEACHER EVIDENCE:

... I have done some conferences with Dr. Jean who does a lot of music. Using the arts in that, you are really being able to meet the different levels that these kids have. (Antonella)

... If there is something that interests me, and I think that is going to be really neat to implement in my classroom ... those are the kinds of professional activities that I want to do. (Veronica)

... I didn't find too many professional opportunities but when this course came to us, I was thinking that I will do that. (Celine)

... We attended the Association of Teacher Educators in Texas where I was part of the presentation team. I talked about what I do as a teacher education coordinator. (Kara) ... Sometimes, we just needed time, and funds would be available for us to have team collaboration. (Janice)

... We were doing action research before it was vogue. We had a session at a national conference. (Ida)

... I wanted to have some games in my unit ... I I spoke with the physical education teacher... we would work together on content instruction. (Kate)

\section{QUESTION ON REFLECTION: COMMUNITY ARTS INTEGRATION}

CONCLUSION FINDINGS: Teachers realize that integrating the arts provides opportunities for community involvement, and community involvement provides opportunities for integrating the arts.

\section{TEACHER EVIDENCE:}

... I think the realization of this 21st Century learning is the biggest thing right now. We have got to be able to meet what the community needs are. I am also working with a representative from the university on integrated arts curriculum. (Antonella)

... Once they start learning more and get more involved with their puppet and report, the excitement grows. Parents get involved with their children. (Celine)

... We are having a 'Night at the Arts' this week. I am sure there will be a wonderful turn out

... all children want their parents to watch them perform and show off their arts activities.

(Veronica)

... We also have a parent who is arts chairperson of our parent-teacher group. We had the senior citizen's musical band play for the students. We have had the puppeteers in from our university arts department. (Kara)

... We would tell them what we were gong to learn about. If there were items that we needed them to send in, we asked. (Carline)

... I had a community quilt guild come in to a class. We had a quilt donation project with the local hospital that even got us some publicity. (Kate)

... We have taught classes for the university just specifically on how to design a unit. (Ida) 